A COMPARISON OF BOTTOM-UP METHODS FOR ESTIMATING INSTITUTIONAL BUILDING ENERGY USE TO INFORM RESOURCE AND EMISSION REDUCTION STRATEGIES

by

Christopher Xavier Mendieta

B.Sc. in Civil Engineering, ITESM, 2013

\author{
A thesis \\ presented to Ryerson University \\ in partial fulfillment of the \\ requirements for the degree of \\ Master of Applied Science \\ In the Program of \\ Building Science
}

Toronto, Ontario, Canada, 2018

(C) Christopher Xavier Mendieta, 2018 


\section{AUTHOR'S DECLARATION FOR ELECTRONIC SUBMISSION OF A THESIS}

I hereby declare that I am the sole author of this thesis. This is a true copy of the thesis, including any required final revisions, as accepted by my examiners.

I authorize Ryerson University to lend this thesis to other institutions or individuals for the purpose of scholarly research.

I further authorize Ryerson University to reproduce this thesis by photocopying or by other means, in total or in part, at the request of other institutions or individuals for the purpose of scholarly research.

I understand that my thesis may be made electronically available to the public. 


\title{
A COMPARISON OF BOTTOM-UP METHODS FOR ESTIMATING INSTITUIONAL BUILDING ENERGY USE TO INFORM RESOURCE AND EMISSION REDUCTION STRATEGIES
}

Master of Applied Science 2018, Christopher Xavier Mendieta

Building Science Program, Department of Architectural Science, Ryerson University

\begin{abstract}
Bottom-up engineering models are an emerging approach for evaluating energy efficiency solutions at district or regional scales. More flexible than statistical models, bottom-up models allow planners to quantitatively evaluate energy efficiency and supply options, leading to more effective policies and energy demand solutions that better reflect our changing climate. This thesis compares two bottom-up methods for exploring resource and emission reduction strategies in the institutional sector: the Wireframe method and the Reference method. These methods are compared by predicting the annual consumption of post-secondary student residences in Southern Ontario and measuring the error of each, compared with the 2013 mandatory energy report data from the Ministry of Energy of Ontario. Both methods produced aggregate energy error ranges of $5 \%$ to $12 \%$ in a detailed analysis, suggesting that they are both effective for large-scale energy reduction studies.
\end{abstract}




\section{ACKNOWLEDGMENTS}

There are many people I would like to thank who helped me complete this work - without their help I would have never have achieved my goals in this program.

I wish to thank my Thesis supervisor, Jenn McArthur for her insight, patience and editing skills in helping me structure and write this thesis. I would also like to thank Dr. Russell Richman and Dr. Mark Gorgolewski for reading this thesis and providing valuable feedback.

I am grateful for those who provided technical support and that have helped with the consumption simulation. My friend and colleague Danku Sobieraj who always provided professional and high-quality work, which pushed me to do the same.

I would like to express gratitude to my peers, Christopher, Tamoril, and Brandon who became friends during my time at Ryerson. Spending time with these people, who were undertaking similar endeavors, helped balance the loneliness that can accompany research.

I would like to thank my girlfriend Christabelle who listened and discussed ideas about this thesis in many occasions. Thank you for the unceasing encouragement and support.

Finally, I would like to thank Fernanda, Diane, Xavier, Teresa, Mary, Frank, and Anna who have shown nothing but support for my decision to move to Canada and continue my studies. 


\section{TABLE OF CONTENTS}

1 INTRODUCTION 1

$1.1 \quad$ Research Objective and Questions 3

2 LITERATURE REVIEW

2.1 Mandatory Energy Reporting as a Data Source 6

$\begin{array}{lll}2.2 & \text { Energy Benchmarking in Post-Secondary Buildings } & 7\end{array}$

2.3 Classification of Existing Building Stocks 9

2.4 Development and Characterization of Reference Energy Models 10

$3 \quad$ METHODOLOGY $\quad 17$

3.1 Data Collection and Validation 19

3.2 Building Stock Classification 20

3.3 Building Stock Characterization $\quad 21$

3.4 Building Stock Consumption Prediction 23

3.4.1 Reference Method Consumption Prediction $\quad 25$

$\begin{array}{lll}\text { 3.4.2 Wireframe Method Consumption Prediction } & 27\end{array}$

3.5 Model Tuning $\quad 29$

3.6 Institutional Residence Building Stock Validation and Error Analysis 30

4 DATA COLLECTION AND VALIDATION

4.1 Data Validation for Colleges and Universities 32

4.2 Data Validation for College and University Building Operations 36

4.2.1 Building Operation Data Cleaning 36

4.2.2 Administrative Office Buildings - College Sample $\quad 37$

4.2.3 Administrative Office Buildings - University Sample 39

4.2.4 Administrative Office Buildings - College and University Sample 41

4.2.5 College and University Benchmarking by Building Operation 42 
5.1 Cleaning of Data Sets 45

$\begin{array}{lll}5.2 & \text { Building Stock Characterization } & 47\end{array}$

5.3 Student Residence Characterization Values 48

5.3.1 Form inputs: pre-1980 Lowrise residence models 48

5.3.2 Fabric inputs: pre-1980 Lowrise residence models 49

5.3.3 Program inputs: Space activity for pre-1980 Lowrise residence models 50

5.3.4 Program input: Occupant densities for pre-1980 Lowrise residence models 51

5.3.5 Program input: Ventilation rates for pre-1980 Lowrise residence models 51

5.3.6 Program input: Lighting loads for pre-1980 Lowrise residence model 52

5.3.7 Program input: Plug and process loads for pre-1980 Lowrise residence model 52

5.3.8 Program input: Water system rates for pre-1980 Lowrise residence model 53

5.3.9 Equipment input: HVAC system characteristics for pre-1980 Lowrise residence model 53

5.4 Additional Template Development 54

5.4.1 Post-1980 Lowrise $\quad 55$

5.4.2 Post-1980 Midrise $\quad 56$

$\begin{array}{lll}\text { 5.4.3 } & \text { Pre-1980 Highrise } & 60\end{array}$

6 STUDENT RESIDENCE MODEL TUNING

6.1.1 Pre-1980 Lowrise residence model adjustment $\quad 65$

6.1.2 Post-1980 Lowrise residence model adjustment $\quad 67$

6.1.3 Post-1980 Midrise residence model adjustment $\quad 69$

6.1.4 Pre-1980 Highrise residence model adjustment 71

$\begin{array}{lll}7 & \text { ENERGY SIMULATION RESULTS } & \mathbf{7 3}\end{array}$

$\begin{array}{lll}7.1 & \text { Comparison of Reference and Wireframe Predictions } & 73\end{array}$

$\begin{array}{lll}\text { 7.1.1 Pre-1980 Lowrise } & 74\end{array}$

$\begin{array}{lll}7.1 .2 & \text { Post-1980 Lowrise } & 77\end{array}$

$\begin{array}{llr}\text { 7.1.3 Post-1980 Midrise } & 80\end{array}$

$\begin{array}{lll}\text { 7.1.4 Pre-1980 Highrise } & 83\end{array}$

$\begin{array}{lll}7.2 & \text { End-Use Energy by Building } & 86\end{array}$

$\begin{array}{lll}7.3 & \text { Error Analysis } & 88\end{array}$

$\begin{array}{llr}\text { 7.3.1 } & \text { Pre-1980 Lowrise } & 88\end{array}$

$\begin{array}{llr}\text { 7.3.2 } & \text { Post-1980 Lowrise } & 89\end{array}$ 
7.3.3 Post-1980 Midrise

7.3.4 Pre-1980 Highrise

7.3.5 Random Sampling

8 DISCUSSION $\quad 93$

$\begin{array}{lll}8.1 & \text { Error Discussion } & 97\end{array}$

8.2 Future Research 98

8.3 Research Implications 98

9 CONCLUSIONS $\quad 99$

10 REFERENCES 100

APPENDIX A: POST-SECONDARY ENERGY BENCHMARKS BY BUILDING TYPE 107

APPENDIX B: REFERENCE BUILDING MODEL COMPARISON AND SOURCES 119

APPENDIX C: REFERENCE BUILDING MODEL CHARACTERIZATION TEMPLATES 155

APPENDIX D: RANDOM SAMPLING IN RSTUDIO

184 


\section{LIST OF TABLES}

Table 1. Description of size categories used to classify Southern Ontario student residences... 21 Table 2. Description of vintage categories used to classify Southern Ontario student residences

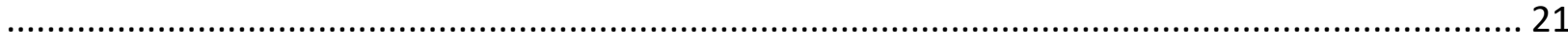

Table 3. Building categories used to review commercial reference energy models ................... 22

Table 4. Buildings reported under the same location for college residences............................ 37

Table 5. Buildings with multiple operations after relevant data has been joined to form a

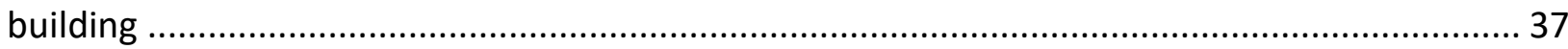

Table 6. Initial sample of Administrative Office buildings considered for benchmarking study . 38 Table 7. Administrative Office buildings results before outlier removal ................................ 38

Table 8. Administrative Office buildings after outliers have been removed ............................. 38

Table 9. Initial sample of University Administrative Office buildings considered for

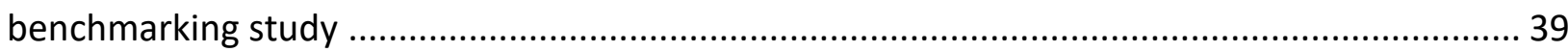

Table 10. University Administrative Office buildings results before outlier removal................ 39

Table 11. University Administrative Office buildings after outliers have been removed ........... 40 Table 12. Initial sample of university and college Administrative Office buildings considered for benchmarking study

Table 13. College and university Administrative Office buildings results before outliers are removed

Table 14. College and university Administrative Office buildings after outliers have been removed

Table 15. Samples derived from the classification process with average descriptors. Note that the post-1980 Lowrise category has the largest standard deviation as one of its buildings was identified as an outlier but not removed.

Table 16. Pre1980 Lowrise Form characterization inputs.

Table 17. Pre-1980 Lowrise Residence Fabric characterization inputs for both, the Reference and Wireframe models 50

Table 18. Space activity breakdown for Lowrise residence reference models .......................... 50

Table 19. Occupancy density for pre-1980 Lowrise residence models................................... 51

Table 20. Ventilation rates for pre-1980 Lowrise residence models ...................................... 51

Table 21. Lighting rates for pre-1980 Lowrise residence models ......................................... 52

Table 22. Plug and process loads for pre-1980 Lowrise residence models .............................. 52

Table 23. Water system rates for pre-1980 Lowrise residence models..................................... 53

Table 24. Post-1980 Midrise residence fabric inputs ........................................................... 55

Table 25. Lighting rates for pre-1980 Lowrise residence models ............................................. 56

Table 26. Building Form comparison between DOE models and Midrise student residence values

Table 27. Programmatic breakdown of the Small Hotel and Mid-rise Apartment commercial

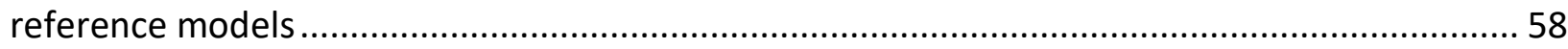

Table 28. Pitman Hall space activity breakdown ............................................................... 58 
Table 29. Space activity breakdown for Midrise Residence reference models ........................ 59

Table 30. Occupancy density for post-1980 Midrise residence models ................................... 59

Table 31. Building form comparison between DOE models and Highrise student residence values

Table 32. Space activity breakdown for Highrise residence reference models ........................ 62

Table 33. Occupancy density for post-1980 Midrise residence models .................................. 62

Table 34. Percentage error ranges for pre-1980 Lowrise buildings ....................................... 76

Table 35. Percentage error ranges for post-1980 Lowrise buildings ....................................... 79

Table 36. Percentage error ranges for post-1980 Midrise buildings ......................................... 82

Table 37. Percentage Error ranges for pre-1980 Highrise buildings....................................... 85

Table 38. Percentage error and RMSE of pre-1980 Lowrise buildings................................... 88

Table 39. Percentage Error and RMSE of post-1980 Lowrise buildings. ................................... 89

Table 40. Percentage error and RMSE of post-1980 Midrise buildings .................................... 90

Table 41. Percentage error and RMSE of pre-1980 Highrise buildings ................................... 91

\section{LIST OF FIGURES}

Figure 1. This image shows how the Reference method predicts aggregate consumption. A simplified energy model is developed to represent a typology of buildings. After simulation, the area normalized consumption of the model is multiplied by measured areas of buildings with same typology to predict the aggregate energy consumption

Figure 2. For the Wireframe method, each building in the sample is modeled using its real geometry and orientation. The individual consumption is added to represent the aggregate load of the sample.

Figure 3. Flowchart summary of the development and evaluation of the Wireframe and Reference models.

Figure 4. Building variables used to classify post-secondary buildings in this study (image from

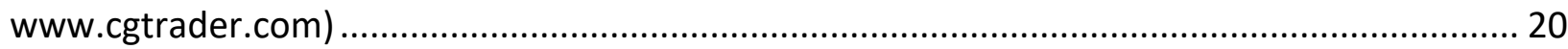

Figure 5. Zoning example using the perimeter/core method ................................................ 23

Figure 6. Process used to create 3D building geometry....................................................... 24

Figure 7. Approach used to develop the energy demand of student residence reference models

Figure 8. Steps to predict consumption using the Reference method: 1) Collection of average building characteristics from a dataset of buildings, 2) Development of Reference model geometry (two orientations), 3) Allocation of weather file and characterization template, 4) Reference model simulation using Energy Plus, and 5) Area normalized consumption predicted from both models are averaged out and multiplied by the total conditioned floor area of the set

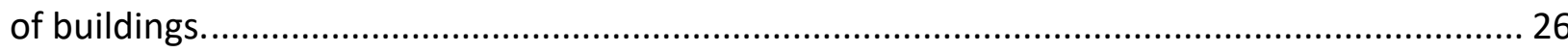

Figure 9 Steps to predict consumption using the Wireframe method: 1) Collection of average building characteristics from a dataset of buildings, 2) Development of Wireframe model geometry, 3) Allocation of weather file and characterization template, 4) Simulation using 
Energy Plus, and 5) Individual building consumption are aggregated to represent the total consumption of the dataset of buildings.

Figure 10. This image describes the process of predicting the end-use consumption of a Reference model: (1) A Rhinoceros 3D model is created using geometrical characteristics of the building stock, (2) Characterization templates and weather data are applied to the 3D model using UMI, (3) The Reference model is simulated using Energy Plus, and (4) The end-use consumption of the model is then determined predicted.

Figure 11. Climate Zone 5 (NECB 2011) and cities were MER institutional data was collected .. 31

Figure 12. EUI of selected college and university institutions......

Figure 13. Mean and median EUI derived from the MER college/university category compared to the $212 \mathrm{ekWh} / \mathrm{m}^{2}$ (Energy Star) and the $264 \mathrm{ekWh} / \mathrm{m}^{2}$ (SCIEU) displayed in Canadian benchmarking studies

Figure 14. Mean and median EUI derived from the college sample compared to the 212 $\mathrm{ekWh} / \mathrm{m}^{2}$ (Energy Star) and the $264 \mathrm{ekWh} / \mathrm{m}^{2}$ (SCIEU) displayed in Canadian benchmarking studies

Figure 15. Mean and median EUI derived from the MER university sample compared to the 212 $\mathrm{ekWh} / \mathrm{m}^{2}$ (Energy Star) and the $264 \mathrm{ekWh} / \mathrm{m}^{2}$ (SCIEU) displayed in Canadian benchmarking studies 35

Figure 16. College Administrative Office buildings considered to develop the sample's EUI ..... 39 Figure 17. University Administrative Office buildings considered in the developed benchmark 40 Figure 18 College and university Administrative Office buildings considered in the developed benchmark 42

Figure 19. Developed Energy Benchmarks for College and University building operations........ 42 Figure 20. Developed MER Benchmarks of Administrative, Residence, and Recreational facilities are compared to SCIEU Energy Star Portfolio Manager Laboratory benchmark is compared to MER laboratories.

Figure 21. Student residence segmentation using building size and vintage as variables. The number of buildings in the master dataset within each category are indicated in parentheses. 44 Figure 22. Quarryview residence (left) was removed due to its typology difference and resultant low EUI compared with the remaining post-1980 Lowrise dataset.... 45 Figure 23. Building geometry and shading devices from of U.S. DOE models (from left to right): Midrise Apartment, Small Hotel, Large Hotel and Highrise Apartment ................................... 47

Figure 24. Pre1980 Lowrise Residence buildings showing typical flat roof condition ............... 49 Figure 25. Post-1980 Midrise buildings compared to post-1980 Large Hotel (top) and 2004 Highrise DOE models

Figure 26. Pre-1980 Highrise buildings compared to pre-1980 Large Hotel (top) and 2004 Highrise DOE models

Figure 27. Visual representation of student Reference method models created with Rhinoceros and UMI... 64

Figure 28. End-use comparison of reviewed DOE models and developed residence models. Cooling, lighting, and equipment EUIs predicted with the baseline template are all between the 
EUI reported for the hotel and the apartment models, therefore, only the water systems enduse was adjusted.

Figure 29. The predicted EUI of the adjusted pre-1980 Lowrise model is $17 \%$ lower than the EUI benchmark of the pre-1980 Lowrise dataset quantified at $397 \mathrm{ekWh} / \mathrm{m}^{2}$ 66

Figure 30. Differences between pre-1980 Lowrise adjusted model and the pre-1980 Midrise Apartment model are seen in heating, equipment and lighting uses 66

Figure 31. End-use comparison of reviewed DOE models and developed student residence models. Baseline heating EUI is larger than the heating EUI of both DOE models while water system EUIs is lower than both DOE models.

Figure 32. The predicted EUI of the adjusted post- 1980 Lowrise model is $7 \%$ lower than the EUI benchmark of the post-1980 Lowrise Category quantified at $339 \mathrm{ekWh} / \mathrm{m}^{2}$. 68

Figure 33. Adjusted post-1980 Lowrise and post-1980 Midrise Apartment end-use breakdown68 Figure 34. Comparison of the end-use EUIs predicted with reviewed DOE and developed residence models. 69

Figure 35. The predicted EUI of the adjusted post-1980 Midrise model is $9 \%$ lower than the EUI benchmark of the post-1980 Midrise Category quantified at $312 \mathrm{ekWh} / \mathrm{m}^{2}$. 70

Figure 36. Adjusted post-1980 Midrise breakdown is most like the 2004 Highrise model. ........ 70 Figure 37. Comparison of the end-use EUls predicted with reviewed DOE and developed residence models.

Figure 38.- The predicted EUI of the adjusted pre-1980 Highrise model is $9 \%$ lower than the EUI benchmark of the pre-1980 Highrise Category quantified at $388 \mathrm{ekWh} / \mathrm{m}^{2}$ 72

Figure 39. The adjusted pre-1980 Highrise predicted energy breakdown is most like the 2004 Highrise model.

Figure 40. Building images and corresponding Wireframe method models for the pre-1980

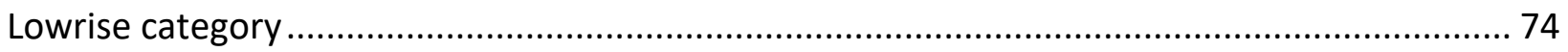

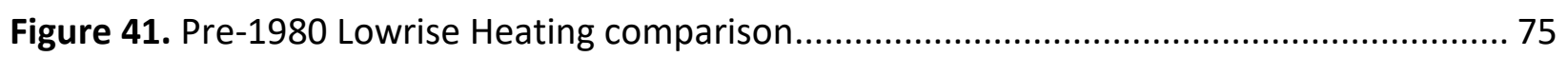

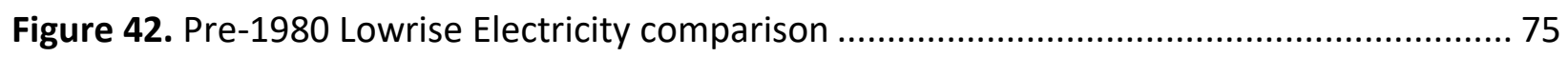

Figure 43. Pre-1980 Lowrise Total Energy comparison ............................................................... 75

Figure 44. Pre-1980 Lowrise Area comparison. The simulated area for the Reference model does not change as the displayed area is the one used to predict the Reference EUI which is then scaled by multiplying by the measured area of the buildings. ........................................... 75

Figure 45. Building images and corresponding Wireframe method models for the post-1980

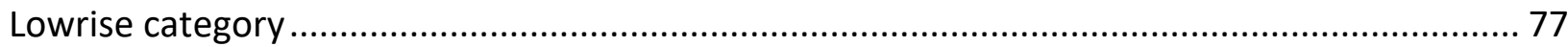

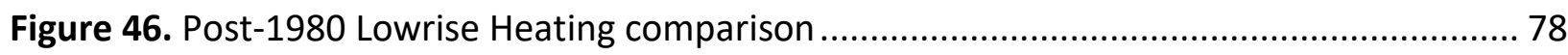

Figure 47. Post-1980 Lowrise Electricity comparison............................................................... 78

Figure 48. Post-1980 Lowrise Total Energy comparison ....................................................... 78

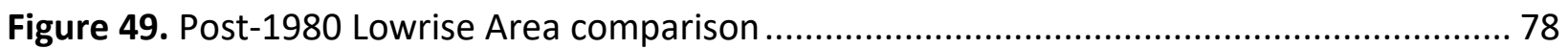

Figure 50. Building images and corresponding Wireframe method models for the post-1980

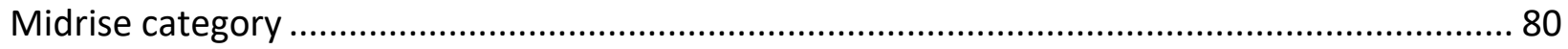

Figure 51. Post-1980 Midrise Heating comparison ................................................................ 81

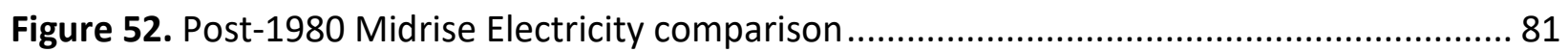




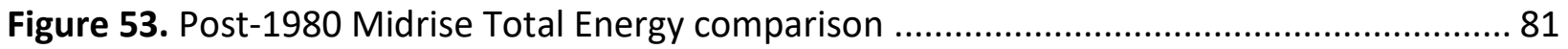

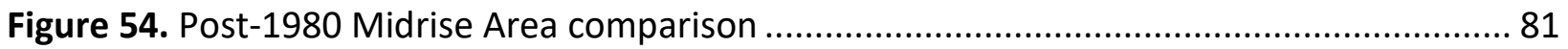

Figure 55. Building images and corresponding Wireframe method models for the pre-1980

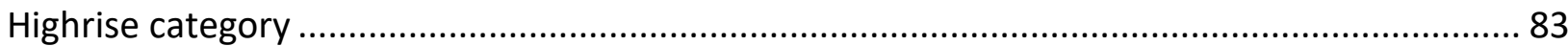

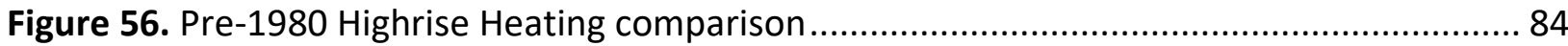

Figure 57. Pre-1980 Highrise Electricity comparison ......................................................... 84

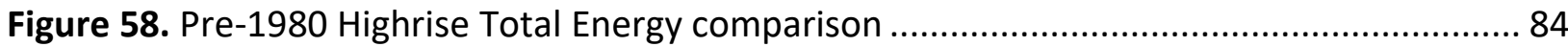

Figure 59. Pre-1980 Highrise Area comparison ................................................................. 84

Figure 60. Pre-1980 Lowrise predicted energy end-use by building.................................... 86

Figure 61. Post-1980 Lowrise predicted energy end-use by building .................................... 86

Figure 62. Post-1980 Midrise predicted energy end-use by building .................................. 87

Figure 63. Pre-1980 Highrise predicted energy end-use by building ................................... 87

Figure 64. Average total energy error rate against sample size............................................. 92

Figure 65. Heating Percentage Error produced by each category using Wireframe and Reference

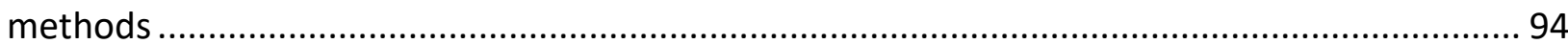

Figure 66. The Pond residence was modelled as two independent buildings rather than one. . 95

Figure 67. Stack effect pressure variability in buildings of different heights [73] .................... 96 


\section{LIST OF ABBREVIATIONS}

ACEEE American Centre for an Energy Efficient Economy

ASHRAE American Society of Heating, Refrigeration, and Air-Conditioning Engineers

BEM Building Energy Models

CES Commercial Energy Survey

DOE Department of Energy

EIA Energy Information Administration

EUI Energy Use Intensity

GHG Greenhouse gas

HVAC Heating, ventilation, and air-conditioning

IEA International Energy Agency

LBL Lawrence Berkeley Laboratory

LBNL Lawrence Berkeley National Laboratory

MER Mandatory Energy Reports

MOE Ministry of Energy

NREL National Research Energy Laboratory

PNL Pacific Northwest Laboratory

PNNL Pacific Northwest National Laboratory

SCIEU Survey of Commercial and Institutional Energy Use

TABULA Typology Approach for Building Stock Energy Assessment

UBEM Urban Building Energy Models 


\section{Introduction}

The issue of energy efficiency has never been more pertinent. With climate change threatening every part of our planet and the urban population expected to surpass six billion by 2045 [1], we are in growing need of innovative solutions that will carry us into a sustainable future. Many countries across the globe have started by setting ambitious carbon reduction targets. The Government of Canada has committed to reducing its carbon emissions by $17 \%$ below 2005 levels by the year 2020. This target presents challenge as projected emissions are currently $17 \%$ above 2005 levels [2]. Because buildings are the largest energy consuming sector in the world and account for over $30 \%$ of total final energy consumed [3]; achieving energy and emissions reductions in the building sector is critical to meet short and long-term carbon reduction targets, therefore progressive designs and action plans are needed to create responsible urban spaces. Governments will look to designers and planners to provide them with solutions that reduce energy consumption and lower emissions caused by the built environment. In Canada, the commercial and institutional building sector accounts for $12 \%$ of energy consumption and $11 \%$ of $\mathrm{CO}_{2}$ emissions [4]. More than $80 \%$ of Canadian buildings are over 15 years old and have been built to meet much lower energy efficiency requirements when compared to new construction [5], making them relatively inefficient. While the introduction of new efficient buildings helps to reduce environmental impact, the demolition and reconstruction of existing buildings is non-ideal due to their embodied energy. Therefore, energy conservation in existing buildings is critical to achieving Canada's 2020 and future goals of $\mathrm{CO}_{2}$ emissions reduction. The challenge is to determine scenarios that will benefit most from retrofit actions as well as policies and incentives that will produce greater strides to more eco-friendly cities

In addition to Federal and Provincial Government targets, a cross-sector public-private collaborative from Toronto has committed to reduce $50 \%$ of the district's emissions by 2030 [6]. As buildings represent a substantial portion of these emissions, progressive cities like Toronto aiming to meet ambitious targets need tools that help designers and policy makers plan both more strategically and efficiently. The reduction of carbon emissions caused by the operation of buildings can be achieved in many ways including: benchmarking building consumption, retrofitting existing buildings, evolution of energy codes, and/or by decarbonizing energy sources. Benchmarking building consumption serves as an assessment of a building's performance; a 
fundamental starting point to achieving energy reductions from the building sector and allows buildings to be compared against others of a similar vintage and operation. Studies show that buildings that benchmark their consumption tend to reduce their energy cost by $7 \%$ in a period of three years [7]. Using energy from sources with low emission processes, such as nuclear, hydro, or renewables, is key to achieving projected carbon reductions. Although Ontario has a low-carbon grid, it still uses natural gas and this source of energy does not seem to be phasing out any time soon. According to the International Energy Agency a combination of energy reduction, use of renewable energy, and decarbonizing power sources will be the main drivers for decreasing global carbon emissions caused by the building sector [3].

For Canada and cities like Toronto to achieve significant reductions in carbon emissions, researchers, planners, and developers must understand in detail the conditions of their buildings and the effects of implementing different policies and incentives. This type of analysis can be realized via top-down or bottom-up building stock energy models [8]. Top-down models utilize measured sector energy and appropriate variables to attribute energy consumption to characteristics of the stock. Top-down models consider the sector as an energy sink. They can determine the effect on energy consumption due to changes within the sector, however they cannot distinguish energy consumption from individual end-uses. The lack of detail regarding individual end-uses limits the capability of top-down models to identify areas of improvement for energy efficiency. Bottom-up building stock energy models are more detailed and can identify the contribution of each end-use towards an aggregated energy consumption. A common bottom-up approach for evaluating consumption at large scales involves classifying a building stock into reference models and characterizing them based on details of the existing stock. Bottom-up models require information from a building stock to predict consumption. This information includes building materials, equipment efficiencies, occupancy schedules, and internal loads. While this data can be obtained for a small group of buildings through audits, such collection becomes impractical for large scale studies. For this reason, bottom-up models utilize reference models to represent buildings at district or regional scales. After reference models are defined, a simulation is used to predict energy consumption and results are typically validated by comparing them to aggregate measured consumption. Although previous work has demonstrated the usefulness of reference models to explore energy and carbon emission strategies [9], there is no agreement on how such models should be defined [10]. 
This thesis compares two bottom-up methods, referred to as the Wireframe Method and the Reference Method, for exploring resource and emission reduction strategies in the institutional sector. Both methods consider average characteristics of a building sample as inputs but differ in their treatment of geometry. The Reference Method simulates the consumption of a single representative building, normalizes the result based on the area of the building, and multiplies the normalized consumption by the total conditioned area of the buildings intended to be studied to predict an aggregate consumption. The Wireframe Method uses geometric and orientation characteristics from all sample buildings to predict individual consumption which is then aggregated to represent the overall energy consumption of a sample.

The Reference Method is based on the approach used by the U.S. Department of Energy (DOE) to assess regional consumption studies [11], while the Wireframe Method is based on the approach used by MIT Sustainable Design Lab to predict the aggregate consumption of the city of Boston [12]. Both the U.S. DOE and MIT research labs used building audits, surveys and engineering judgement for the development of reference models. In this thesis, it was not possible to replicate this degree of background research; instead, pre-existing reference models were adapted to create a preliminary university residence model to test the relative performance of these methods. Several publicly available data sources were used to adjust this preliminary model, but it should be noted that significant additional research would be required to create a generalizable reference model for this typology.

\subsection{Research Objective and Questions}

The objective of this research is to compare the Wireframe and Reference Methods to understand the degree to which the consideration of individual building form affects the energy prediction accuracy. This will be explored through the following research questions:

1. How do the energy predictions between the two methods compare to one another and to the measured consumption?

2. How does the aggregate consumption prediction error change when different sample sizes are considered?

3. To what extent is there benefit to modeling the individual building geometry in a largescale model? 
The hypothesis of this research is that the Wireframe method will provide better prediction accuracies and lower error rates for building categories with lower thermal performance and higher geometrical complexity. These results are expected as buildings with high performance envelopes and compact form retain indoor conditions better, thus decreasing the impact that shape and orientation can have on conditioning consumption. The analysis of predicted consumption and their errors will help inform which method is better according to the characteristics of a building stock. 


\section{Literature Review}

Building Energy Models (BEMs) are recognized as an effective tool to optimize building energy consumption. BEMs can be used to quantify energy profiles, test different HVAC systems, evaluate the effect of building shape, measure the impact of proposed lighting strategies, or allow planners to quantitatively evaluate energy efficiency and supply options which lead to more effective policies and energy demand solutions. One of the challenges that these models encounter is that they require detailed building characteristics for their development. In many cases energy consumption measurements are necessary to validate the models. This type of data can take considerable effort to obtain and makes the development of energy models an expensive investment. One approach to characterizing BEMs utilizes average building descriptors. These are typically based on data collected from existing standards, surveys, case studies, and/or building audits. The quality of the inputs is strongly influenced by the number of case studies, surveys, or audits used in their development and by the number of buildings to be represented. The closer the sample size is to the number of buildings represented, the fewer problems of selection and representation are encountered [13].

BEMs characterized by average building descriptors will be referred to as "reference models" throughout this thesis. These have been used to measure improvements in energy codes [14], assess regional cool storage potential [15], measure cogeneration potential in the commercial building sector [15], and more recently to predict district energy demands using geospatial datasets [12]. The first step to developing reference models for large scale studies involves the classification of a building stock into samples using descriptive building variables such as operation, construction period, and form. The developer must then determine the number of reference models that will adequately represent the building stock. Reference models are then characterized using average building descriptors, for example materials and glazing ratio, collected from the classified samples. Additional inputs such as internal loads and occupancy can be derived from building audits, surveys, existing literature, and engineering judgment. Once reference models have been characterized, simulations are performed to predict their end-use consumption. Results from the models are then extrapolated to represent all buildings part of the classified samples. Simulation outputs should be validated by comparison with measured consumption data to ensure they accurately represent the consumption of the sample. Each of the steps regarding the development 
process of a reference energy model varies according to a model's purpose and availability of data. The approach explained above has been used by the U.S. DOE and other U.S national labs and is the foundation of one of the methods that this thesis will evaluate. A more detailed explanation of previous efforts for reference model development to predict aggregate consumption will be discussed in this review.

The following sub-sections summarize the academic literature to date related to energy disclosure and benchmarking in post-secondary buildings, classification of existing buildings and reference model development. Mandatory Energy Reporting as a Data Source (Section 2.1) reviews Ontario's existing energy disclosure regulation. Energy Benchmarking in Post-Secondary Buildings (Section 2.2) discusses existing benchmarking studies and their limitations. The studies presented in Section 2.2 will later be compared to Ontario Mandatory Energy Report consumption data. Classification of Existing Building Stocks (Section 2.3) reviews approaches and variables used by other researchers to classify building stocks. The studies presented in Section 2.3 will inform the approach and classification variables that will be used to segment Ontario postsecondary buildings. Development and Characterization of Reference Energy Models (Section 2.4) will present a chronological review of previous reference model development methods including their purpose and limitations. These methods will be reviewed to identify sources for characterization data, how simulation outputs were validated and differences among their development.

\subsection{Mandatory Energy Reporting as a Data Source}

In 2009, Ontario's Ministry of Energy (MOE) implemented Regulation 397/11 [16] under the Green Energy Act. This regulation requires municipal, post-secondary, and healthcare buildings to annually report their energy consumption, carbon emissions, building operations, and some characteristics that influence a building's energy consumption. The resultant mandatory energy reporting (MER) data can be used to collect building descriptors such as building operation, location and consumption. At present, the MOE does not validate reported data from the public sector. To use this data to develop reference models for large-scale studies requires that its reliability be verified through comparison to national benchmarks. Those buildings that compare 
well to national average are assumed to be valid and can be used to develop institutional reference models.

Further, although extremely helpful in the development of reference models, MER data does not contain key information necessary to inform bottom-up model predictions, such as building vintage. The building's vintage informs assumptions about construction methods and materials (affecting the thermal resistance and air-tightness of the building envelope) and the age and type of appliances (contributing to electricity consumption and internal heat gains). Additional Building descriptors needed for reference model development such as construction period, number of floors, glazing ratio, and building height must be obtained from other sources, which include Geographical Information Systems (GIS), online documents, campus maps, and visual judgment. Operation descriptors such as occupancy schedules, equipment efficiencies, internal loads, and other can be derived from DOE commercial reference models as these can have similar operations to those seen in the institutional sector and are based on national surveys or audits. While this approach to develop reference energy models is not ideal (as it is not based on institutional building audits or surveys), it is an effective way to address data limitations. Building form is also widely understood to significantly affect performance, with some energy codes prescribing higher Rvalues for less compact buildings as a result [17].

\subsection{Energy Benchmarking in Post-Secondary Buildings}

The term building energy benchmark began to be used in the 1990's as a comparative of a building's energy performance to the performance of other buildings with similar characteristics [18]. Benchmarking a building's performance is not prioritized in the real estate market due to lack of information about building energy use, however benchmarking a building has shown to produce not only environmental benefits but improvements in the overall performance of buildings [19]. In the San Francisco Existing Commercial Buildings Performance Report [20] the authors found a relationship between energy efficiency and energy benchmarking. In their report, commercial buildings that complied with the city's benchmark regulation were able to reduce their energy use by $7.9 \%$ and $17 \%$ of their GHG emissions over three years. In addition, a survey [21] conducted by the American Centre for an Energy Efficient Economy (ACEEE) found that $62 \%$ of utility 
customers in California that benchmarked their buildings changed their energy consumption habits upon realizing how their building compared to others.

Benchmarking data is a key component in energy consumption reductions at greater scales. Although North American national laboratories have developed datasets that include building use, size, climate and energy use, there is a lack of granular data to compare post-secondary building consumption. Since 2000, the Office of Energy Efficiency in Canada has published several energy benchmark surveys. The Consumption of Energy Survey (CES) was the first survey to include all provinces, focusing only on Canada's universities, colleges, and hospitals. In the years following, CES expanded to cover nearly all segments of the commercial and institutional sector. In more recent Canadian surveys, such as Survey of Commercial and Institutional Energy Use - 2009 [22], post-secondary buildings are included in the "other" category. This shift makes comparing consumption benchmarks for institutional building operations a challenging task as all postsecondary operations are now part of the same "other" category alongside entertainment, shopping centres and leisure buildings. Although this limits the possibility of obtaining granular consumption benchmarks to compare post-secondary buildings, there are several commercial building benchmarks with operations comparable to those found in post-secondary institutions, including office and lodging operations. Like [22], Energy Star Portfolio Manager serves as an energy benchmarking tool. More than 40 percent of U.S. commercial building space is already benchmarked in Portfolio Manager and has been recently adopted by the Canadian Government as the platform for the Nation's energy benchmarking program [23]. In 2016, Energy Star Portfolio Manager released a technical reference report that presents median energy use intensity (EUI) by building operation for many Canadian commercial and institutional buildings [24]. Although this reference report includes a nationwide "university/college" benchmark, it does not have the granularity required to evaluate post-secondary buildings consumption by operation, as all university and college buildings are included in the same category. The Energy Star reference report only contains national consumption averages, which are too general when aiming to compare buildings in a specific climate. Nonetheless, the report does have commercial building benchmarks with operations comparable to those found in post-secondary institutions, such as recreational, lodging/residential, laboratories and administrative office operations. 
The ideal benchmark survey to validate MER data is one that reports post-secondary consumption by building operation and is representative of a specific climate. A benchmarking study [25] done for the University of Massachusetts Amherst does this. In total, 100 university buildings $\left(833,919 \mathrm{~m}^{2}\right)$ were considered to develop the university benchmarks. Although the study groups post-secondary buildings by their operation (i.e. administrative, residential, laboratories), the developed benchmarks are based only on buildings part of one university. While [22, 24] considered buildings from multiple institutions and climates, they do not allow for a granular comparison as neither has developed benchmarks specific for post-secondary operations. The benchmarks developed in [25] have the operation granularity but are limited as only one university was considered in their development.

To validate Ontario MER data, commercial building operation benchmarks from [22, 24] will be used as they are based on nationwide studies and consider commercial buildings with similar operations to the ones seen in the institutional sector. However, [22] will be the main source of comparison as this study presents consumption benchmarks for buildings within Ontario.

\subsection{Classification of Existing Building Stocks}

To develop large-scale bottom-up models, an existing stock must first be classified into sets based on building typologies and represented with reference models using descriptive building variables that have the largest impact on their energy consumption. The modeller must determine the appropriate number of reference models required to accurately represent the building stock that will be analyzed. Defined reference buildings must be capable of representing the majority of the existing building stock, be compatible with available data, and suit the intended purpose and scope of the study. While using more detailed classifications based on descriptive building variables (i.e. form, vintage, height) improves the accuracy of the classification, this approach decreases sample sizes within each set and increases the level of effort and model complexity due to the increased number of reference models required. Determining the right set of reference models is therefore a critical challenge in large-scale model development. This section provides an overview of previous classification studies to determine how this challenge has been addressed.

In recent decades, several approaches to define building typologies have been used in European countries to represent their residential stock. The Typology Approach for Building Stock 
Energy Assessment (TABULA) examined these different approaches and derived a concerted method to develop residential building typologies for European countries [26]. The TABULA project has been used to classify existing residential buildings in over fifteen countries including Italy, Sweden, Norway, Spain, and Great Britain. TABULA classifies buildings according to their location, age, and geometry (shape/volume); this has proven to be successful at determining typical energy consumption values for existing buildings even in different climates.

Dall'O et al. [27] developed a methodology based on cartographic documentation, thematic maps, and geometric data to classify the energy performance of residential buildings on an urban scale. Their method allows the development of quick pre-energy certifications of buildings in a desired region by defining sample buildings (based on construction period and surface to volume ratio) and performing energy audits on them. The authors' methodology was tested on a residential building stock in Carugate, Italy, therefore operation type and location climate were also considered in the classification process.

Panayiotoua et al. [28] evaluated different building characteristics and their impact on the energy consumption using the residential building stock of Cyprus. 500 residential buildings were classified according to their climate zone, type, age, and size. Additional parameters, such as time of occupancy use, occupant salary, and heating systems were also used to assess their contribution to building energy use.

Benejam et al. [29] represented the Spanish building stock with 120 reference buildings corresponding to six building categories. The reference buildings used were classified by collecting data on overall characteristics of the Spanish building stock. The same variables: operation type, climate, and construction period were used to segment the existing building stock.

The above methods for classifying building stock have informed the approach used in this thesis to classify Ontario post-secondary buildings: building location, operation, vintage, and size will therefore be used to segment Ontario's post-secondary building stock into categories.

\subsection{Development and Characterization of Reference Energy Models}

In 1983, the Pacific Northwest Laboratory (PNL) published a group of reference models to represent commercial buildings in the U.S [14]. This set was intended to issue a baseline for 
energy conservation standards and their improvement to advance the design of new commercial and residential buildings. The study covered office, retail, elementary, apartment, hotel, warehouse, restaurant and hospital buildings in five climates. The models were characterized based on ASHRAE/IES Standard 90A-1980 recommendations, physical building characteristics collected from selected sample buildings considered typical for the desired operation, and schedules defined by Building Energy Performance Standards. A simulation of the developed reference models was performed using DOE energy simulation program however the simulated energy use was not validated to measured data. In following years, reference models were developed considering a larger variety of existing buildings through small and large-scale surveys.

In 1986, the Synergic Resource Corporation developed a set of simple regional reference energy models to analyze Florida's building energy use in a cool storage assessment study, which included eleven building types and eight energy end-uses [15]. The end-use estimates were based on data from 1200 Florida buildings, energy standard recommendations, and engineering studies. The reference models developed represented offices, retail spaces, schools, higher education, hospitals, hotels, restaurants, and other Florida service buildings and were calibrated against total aggregate annual energy use data.

In 1987, XEnergy Incorporated developed a set of six reference buildings to represent office, lodging, healthcare, retail, supermarket, and school buildings in New York State. The models were used to study energy end-uses and conservation potential in existing buildings (referenced in [11]). Developed models were based on data collected from surveys performed on 184 buildings in New York. The models were simulated in DOE and resulted in seven end-uses.

In 1988, an algorithm to disaggregate commercial whole building hourly electrical loads into end-uses was presented by Lawrence Berkeley Laboratory (LBL) [30]. The End-use Disaggregation Algorithm (EDA) was developed from the analysis of electric-load data taken at 15-minute intervals from selected Southern California buildings, audits, weather data, and simulation results. The primary component used in the EDA is the regression of measured hourly loads as a function of outdoor dry bulb temperature. A regression was performed at a measured temperature to calculate the nominal load of the building. This regressed building load was then divided into two categories, temperature-dependent loads (building conditioning) and temperature- 
independent loads (lighting, miscellaneous, etc.). A base temperature (based on the temperatureindependent loads) and data gathered from audits were then used to characterize simulation models. The energy models were simulated, and end-use fractions were obtained. End-uses were developed with these fractions and adjusted so that they would sum to the actual measured loads. The conditioning end-use is the only variable composed of both temperature-dependent and temperature-independent elements. Note that this algorithm only applied to buildings in cooling mode.

In 1988, Persily [31] used commercial and institutional air tightness data from 139 buildings to assess the impact that building operation, wall construction, number of stories, and construction period have on envelope leakage. The buildings in his report included office towers, schools, retail stores, and other typologies across several locations in the United States, Canada, Sweden and the United Kingdom. The mean ages of these buildings ranged from 20 to 30 years and they varied in height and construction assemblies. Due to the small sample size, no conclusions could be drawn regarding the effect that the selected building variables had on air tightness, however results suggested that frame walls and Low-rise buildings tended to have higher infiltration rates. The results from the paper were presented as airflow rates at a pressure difference of $75 \mathrm{~Pa}$, normalized by the surface area of the building envelope. Results from this study are now used to characterize the airtightness of some DOE reference energy models.

In 1989, LBL established a methodology to develop DOE reference models for Southern California. Nine reference building models were created to represent offices, retail stores, supermarkets, restaurants, schools, health clinics, and refrigerated and non-refrigerated warehouses [32]. Developed reference models were based on ASHRAE standards, 337 on-site surveys, mail surveys, and one year of hourly whole-building load data from 794 billing accounts. The on-site surveys were performed on Southern California buildings to collect characteristics such as number of floors, area, shading, windows, vintage, location, occupancy hours, and building operation. These variables were used to characterize the DOE models and hourly measured datasets were used to calibrate and validate the results. The inability to capture the diversity of starting and stopping times found in commercial stocks is noted as a limitation of this study.

In 1991, LBL and the Gas Research Institute (GRI) developed 481 reference models including hospitals, school/college, prisons, hotels, restaurants, offices, supermarkets, apartments, 
and retail stores [11]. These models were created as a market assessment tool that would analyze the potential of cogeneration in commercial buildings. The models represent 13 major U.S. cities and were characterized based on size of buildings, operation type, location, vintage, and equipment. Three vintages were defined: stock vintage (pre-1981), current vintage (1981-1988) and average vintage (all vintages). Characterization information was derived from extensive analysis of data from the Energy Administration Agency, sector-specific data for hospitals and schools, and 20 engineering studies from across the nation. Output files of the DOE simulation included hourly heating, cooling, electricity, and total loads. Hourly energy profiles were simulated using DOE, however only annual energy use intensities were calibrated against statistical data due to the scarcity of measured hourly load shapes. This study is the basis of existing U.S. DOE commercial reference models.

In 1994, LBL introduced an innovative approach to estimate end-use load shapes and energy use intensities [33]. The novelty of this research was the calibration of estimated end-use load shapes with measured whole-building load-shape data using the EDA described in [30]. The initial end-use estimates were developed using on-site surveys of about 800 buildings and mail surveys of over 6000 accounts. HVAC end-uses and (heating, cooling, and ventilation) resulted from simulations of the models, and non-HVAC end-uses were estimated from engineering analysis of data on reported schedules and installed capacities. Whole-building electricity load shapes were developed from two main sources: 1) Load research data (to develop reference wholebuilding load shape) and 2) Commercial sector EUIs by building type (to determine the magnitude of the load). The EDA methodology was then used to finalize the reconciliation process. However, the advantages of developing complex load shapes were unclear.

In 1999, Huang and Franconi reviewed existing reference models from 17 engineering studies to develop a set of reference energy models to evaluate the contributions of different building components to buildings heating and cooling loads [34]. Building descriptions were separated into three categories: 1) Physical building characteristics, 2) HVAC system characteristics and 3) Building internal conditions and operational patterns. The authors highlight the limitation of model reconciliation in existing reference models, listing the following reasons: 1) scarcity of detailed measured data, 2) large variation of energy use among any collection of buildings, and 3) multiple degrees of freedom in the calibration. This paper defines 36 reference 
models which include two vintages and two (north and south) climatic regions within the United States. Most internal conditions and operating schedules were taken from the LBL/GRI work [11]. Physical building characteristics, and end-use intensities were updated based on the 1989 CBECS. Simulated annual building energy uses were compared to published governmental estimates and revealed significant differences.

In 2006, NREL published a set of 22 benchmark models created in Energy Plus that could be simulated in nine locations [35]. These reference models were built to be representative of new commercial buildings built to meet minimum requirements of ANSI/ASHRAE/IESNA Standard 90.1-2004. Previous reference models $[11,32,33]$ focused on characterizing energy use in existing buildings, while the NREL models were developed to aid in the development of more efficient design guides. These models are based on data from the 2000 Census [36], 2002 Economic Census [37], 2003 CBECS [38], and 2005 construction cost data [39].

In 2009, Swan and Ugursal [8] presented an up-to-date review of several approaches used for top-down and bottom-up modeling energy use. Two distinct bottom-up approaches are identified to evaluate the energy consumption of specific end-uses: Statistical methods (rely on historical energy data, building descriptors, and regression analysis) and Engineering methods (built on power ratings, use of equipment, systems, occupancy schedules, and building physics). Bottom-up models commonly require information of the built stock including building geometry, appliances, climate, occupancy schedules, and consumption. Statistical models use this and other data (socioeconomic, historical energy consumption, etc.) to regress energy consumption as a function of house characteristics. Statistical methods can separate the effect of occupant behaviour, a variable known to have a significant effect on results from engineering methods [40]. Engineering methods (EM) are the most flexible and capable of testing new technologies that have no historical consumption data, however occupant behaviour has to be defined. Three EM approaches are described in this paper: (1) distributions, (2) archetypes, and (3) sampling. The first utilizes distributions of appliance ownership and use with power ratings to calculate the energy consumption of each end-use. A limitation of this approach is that it does not account for interactions amongst end-uses. The second classifies the housing stock according to vintage, size, type, and more (archetypes). Modeling inputs are taken from descriptors of each house class. Simulated consumption is then scaled up to be representative of the regional or national housing 
stock. The third approach defines its modeling inputs from sample houses. The variety of houses in the stock require large databases of representative dwellings, and this is a limitation of this technique. The most apparent drawback of bottom-up Engineering methods is that occupant behaviour must be assumed by the modeller, and this can significantly alter the energy simulation results. In comparison, the drawback of bottom-up Statistical methods is their inability to model the impact of different energy conservation strategies. The Swan and Ugursal thus suggest "hybrid models", combining engineering methods with statistical models to address these limitations.

In 2015, Cerezo, Sokol, Reinhart and Al-Mumin [41] presented three methods for characterizing reference models - for Urban Energy Simulations. A residential area in Kuwait City was selected toe evaluate the characterization methods. The studied neighborhood had 200 houses with several vintages and 140 measured yearly consumptions. The three methods identified by the authors: 1) Available literature, 2) Local expertise, and 3) Probabilistic occupancy parameters. The first assumes one archetype for all buildings that share the same use. The characterization is done deterministically based only on available literature. The second approach classifies the stock using parameters such as vintage and size. For this study only vintage was used, dividing the stock into four categories. This method uses knowledge of local construction and engineering practices, and documentation of representative sample buildings for each archetype. Window to wall ratios are assessed through photography analysis. Occupancy, plug loads, and lighting power density schedules are based on surveys and average room sizes. The third approach reduces the level of uncertainty due to occupant behavior by using probabilistic estimation that assumes that all unknown parameters have uniform distributions. The main difference with this approach is that probability distributions are assigned to uncertain parameters in the model such as occupancy, lighting, plug loads, and set-point temperatures. The model works by first defining the unknown parameters and their acceptable limits. A parametric analysis is performed for each building in the sample through urban energy simulations. The results from simulations are compared to measured data to quantify the error and test the assumption. This method required 640 simulations for each of the studied residences. 105 out of 140 buildings found one or more combinations of parameters that matched the measured EUI. The results show that the third method achieved a $30 \%$ reduction in error from the standard deviation when compared to the EUI distribution. Therefore, the Probabilistic approach was more accurate at predicting individual building consumption, albeit with a significantly more intense process. 
In 2016, Cerezo, Reinhart and Bemis [12] presented a "bottom-up" approach taken to develop an UBEM that represents the city of Boston. Bottom-up models are typically based on building data processed analytically, statistically, or both. Statistical models link measured building energy use to building descriptors via regression models [42, 43]. Since they are based on measured data, statistical approaches are effective at incorporating occupant behavior, a problem encountered in analytical models [44]. On the other hand, statistical models are unable to simulate the impact of several energy efficiency measures in buildings. A workflow for the generation of urban building energy demand models (UBEM) using existing geospatial datasets was introduced as a solution to statistical model limitations. The novelty of this UBEM archetype approach is the use of GIS shapefiles to characterize building geometry on a case by case basis. GIS and Property Tax Records (PTR) were used to develop Boston's UBEM. GIS shape files define building footprints, volumes, function, and orientation. PTR defined vintage and structure types. The non-geometric properties of the archetypes (reference models), such as thermal properties, glazing ratios, internal loads for equipment, lighting use, HVAC settings and operation schedules were based on data collected through the building segmentation process, existing energy codes, and previous documentation of existing buildings. In total, 19 building operations, five enduses, and four vintages were developed to represent Boston's building stock. One thermal zone per floor and single-use buildings were assumed due to simulation times and data availability. Results from the simulation of developed archetypes were compared against measured building energy uses for that building type from Commercial and Residential Building Energy Consumption Surveys (CBECS). The error of the average EUI compared to the CBECS national average was within an error range of $5 \%$ to $20 \%$.

From this review, two distinct bottom-up methods have been identified. The method where one reference model is developed to represent the consumption of all buildings in a sample, and the method, where all buildings in a sample are modeled considering their real form. Although, both methods use reference models to predict consumption, one is more complex as it considers the real geometry and orientation of all buildings in a sample. Both methods have been selected for review to determine if the additional effort in modeling buildings using their real form results in more accurate predictions. Understanding how the methods compare to one another and their differences when different sample sizes are considered will allow to better understand the benefits and limitations of each. 


\section{Methodology}

As discussed in the Literature Review, there is no single agreed approach to developing reference energy models for building stock analysis [10]. This section presents the quantitative approach that was used to evaluate the two bottom-up approaches, the Reference method and the Wireframe method, for exploring energy efficiency solutions at district or regional scales. Though both the Reference and Wireframe methods consider average characteristics of a building sample alongside U.S. DOE commercial reference model inputs, the Reference method (Figure 1) uses a single model and scales its normalized consumption using area factors to predict the aggregate consumption of a sample, while the Wireframe method (Figure 2) uses geometric and orientation characteristics of all buildings in a sample to predict individual consumption which is then added to represent the aggregate consumption of the sample.
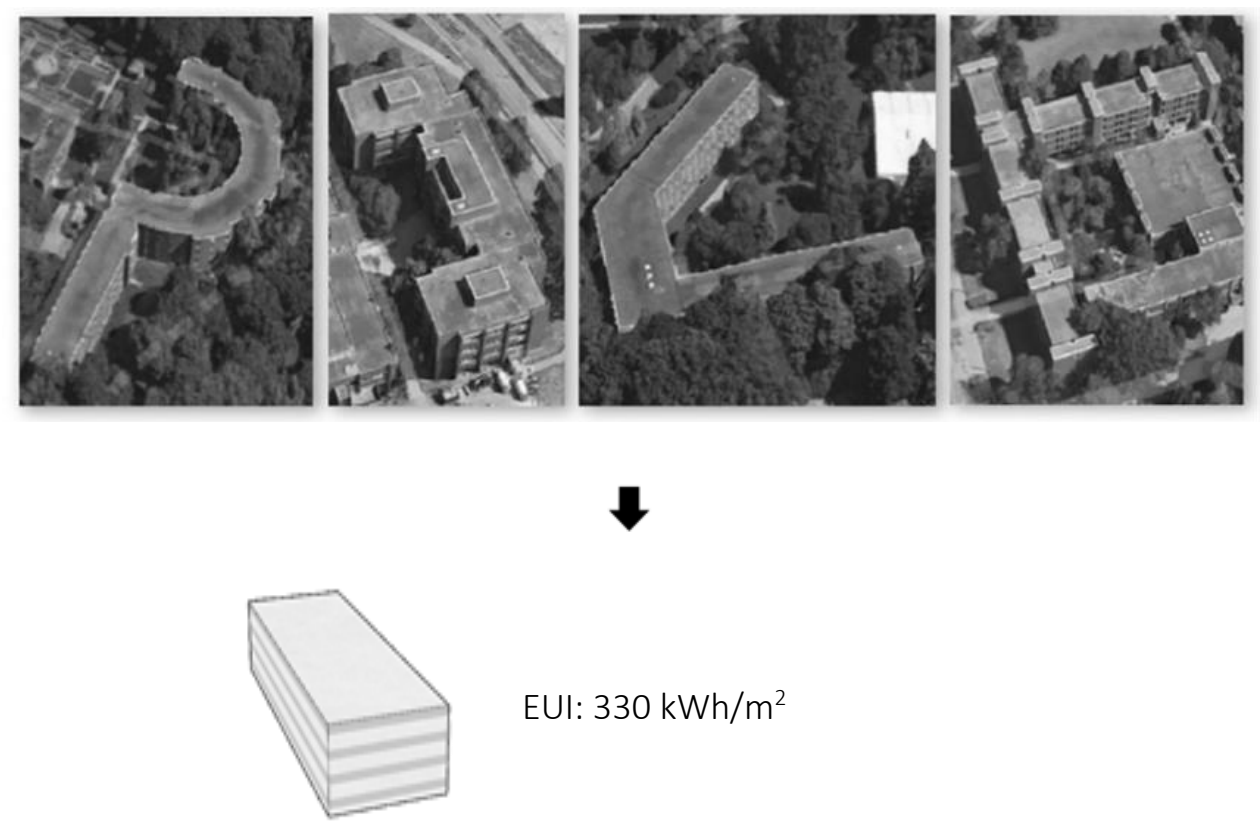

EUI: $330 \mathrm{kWh} / \mathrm{m}^{2}$

Student residence area: $24,211 \mathrm{~m}^{2}$

Est. Student Residence Energy $=330 \mathrm{kWh} / \mathrm{m}^{2} \times 24,211 \mathrm{~m}^{2}$

Est. Student Residence Energy = 7,988 MWh/year

Figure 1. This image shows how the Reference method predicts aggregate consumption. A simplified energy model is developed to represent a typology of buildings. After simulation, the area normalized consumption of the model is multiplied by measured areas of buildings with same typology to predict the aggregate energy consumption 

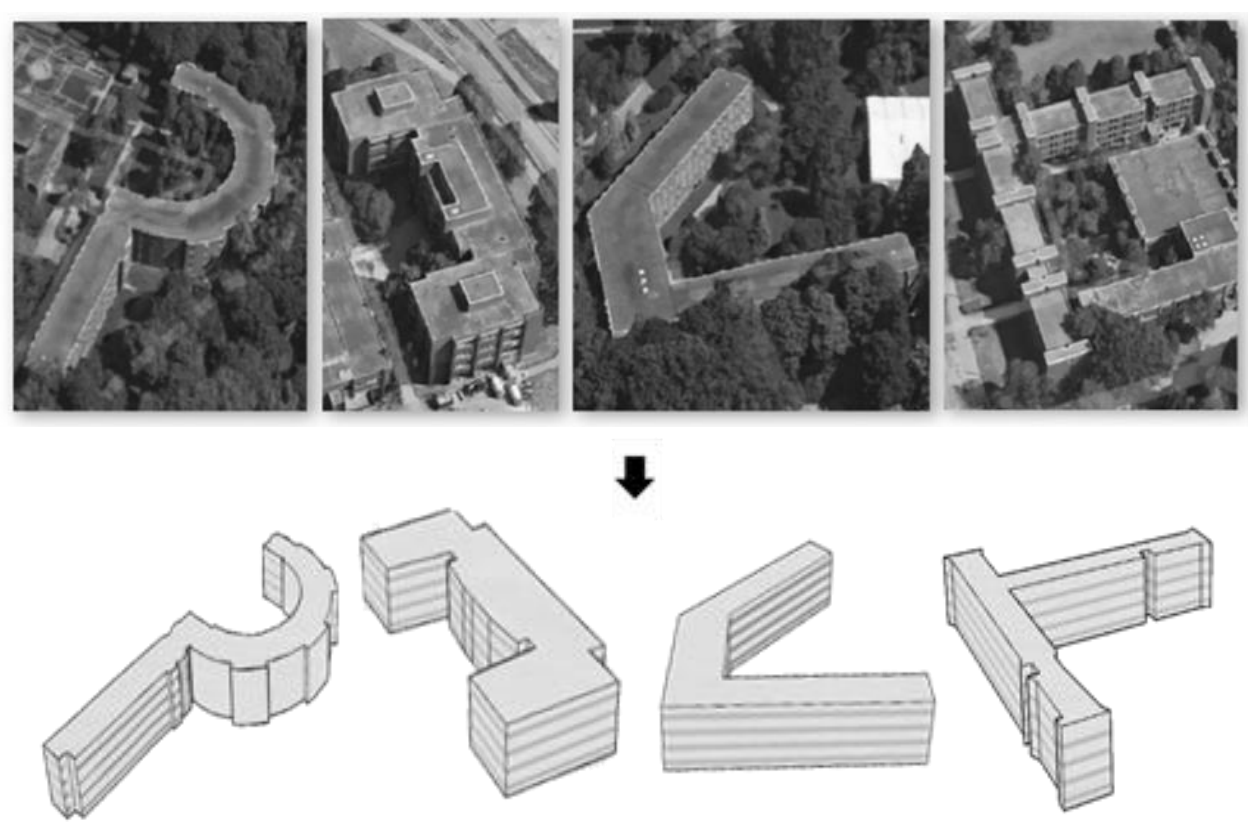

Est. Student Residence Energy =1,973 MWh + 1,986 MWh + 2,155 MWh +1,926 MWh

Est. Student Residence Energy $=8,041 \mathrm{MWh} /$ year

Figure 2. For the Wireframe method, each building in the sample is modeled using its real geometry and orientation. The individual consumption is added to represent the aggregate load of the sample.

Figure 3 presents a flowchart of the approach taken to evaluate the two bottom-up methods using Southern Ontario post-secondary buildings as a case study. A summary of each step follows.

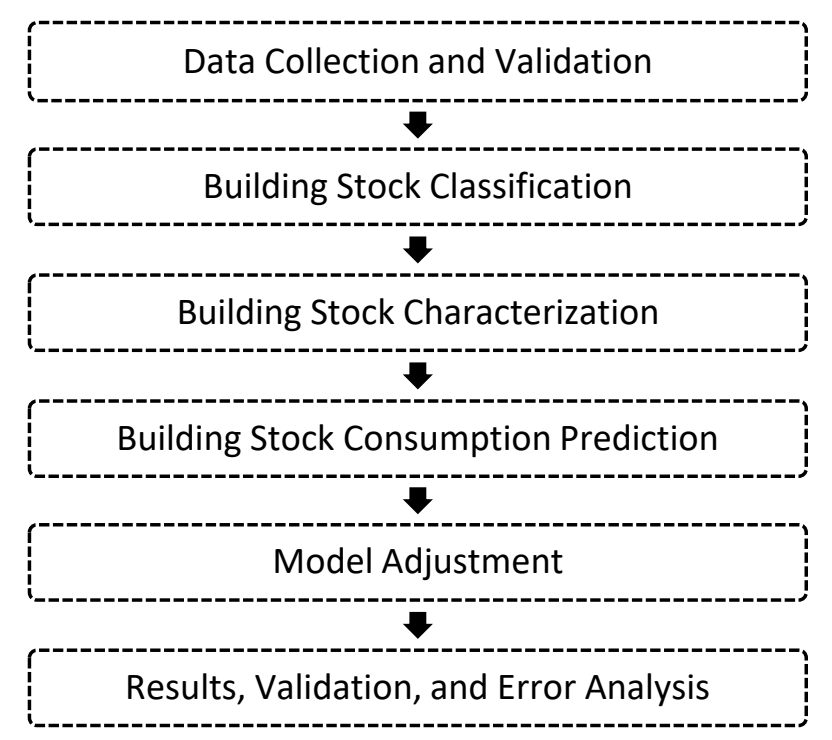

Figure 3. Flowchart summary of the development and evaluation of the Wireframe and Reference models 


\subsection{Data Collection and Validation}

Electricity and fuel consumption for 308 post-secondary institutional buildings in climates representative of Toronto (Climate Zone 5) were collected from Ontario MER data and utilized to develop energy benchmarks. These energy benchmarks were developed to validate the collected institutional consumption data - through comparison with results of other benchmarking studies and to inform consumption differences between university and college buildings. Since erroneous data is found in all data sources, unless proven otherwise, it was important to carefully identify and remove any suspicious entries. Before any detailed analysis was performed, data was checked analytically and visually to remove obvious erroneous data. The identification of outliers was also undertaken; such outliers can exist in datasets due to imprecisions in measurements influenced by instrument sensitivity, human error, or improper judgement of environmental factors that can alter results. The following equations described by Tukey [45] were used to identify energy outliers present in collected building consumption data:

$$
\begin{gathered}
I Q R=Q_{3}-Q_{1} \\
L A V=Q_{1}-1.5 * I Q R \\
U A V=Q_{3}+1.5 * I Q R
\end{gathered}
$$

Where: IQR is the interquartile range, Q1 is the $25^{\text {th }}$ percentile and Q3 is the $75^{\text {th }}$ percentile. Only values that were above the LAV value and below the UAV value of a sample were considered. The LAV and UAV set a range of acceptable values according to Tukey's study.

Over 1 million $\mathrm{m}^{2}$ of college and 2.75 million $\mathrm{m}^{2}$ of university conditioned floor areas were considered in this study. College and university buildings were originally considered in the same category to replicate the "college/university" benchmark displayed in Energy Star Portfolio Manager 2016 data [24]. College and university institutions were also compared separately to determine if their consumptions differed. To further break down college and university consumption loads, post-secondary buildings were then categorized by their use, including the following: 1) Administrative offices and related facilities, 2) Recreational facilities, 3) Laboratories, and 4) Student residences. The results of this section led to the ideal building operation for comparing the bottom-up methods and their consumption prediction capabilities. 


\subsection{Building Stock Classification}

Student residences were identified as a suitable operation to evaluate the bottom-up methods as their EUI were most similar between colleges and universities, while also presenting the lowest errors when compared to Canadian benchmarking studies. Within Southern Ontario, 27 student residence buildings were selected using MER data to predict the consumption of these buildings, a series of reference energy models needed to be developed. Reference model generation consists of two critical steps: classification, or the grouping of buildings with similar properties, and characterization, where a complete set of thermal properties and building systems are defined [46]. To further classify Southern Ontario student residences, their construction period (vintage) and size were considered (Figure 4).

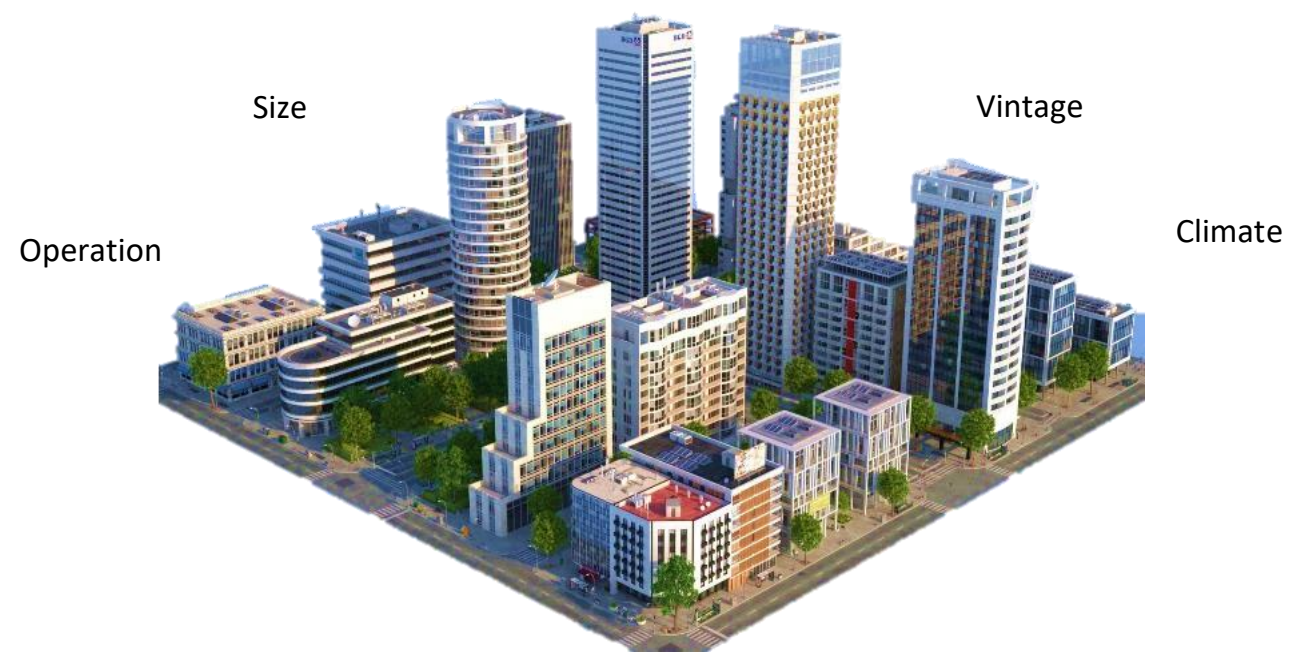

Figure 4. Building variables used to classify post-secondary buildings in this study (image from www.cgtrader.com)

To classify the student residence stock by vintage and size, additional building characteristics had to be collected. These descriptors were obtained from MER data, GIS data, web sources and visual judgment. MER data was used to identify the address, conditioned floor area, and individual consumption of sampled buildings. With reported addresses, GIS data [47, 48, 49, 50], and Daft Logic [51], building height and footprint areas were determined. Campus websites and Toronto Architectural Conservancy data [52] were used to identify the construction period of the residences. Construction periods not available with these sources were defined through visual judgment, as were the number of floors of each building. The three categories used to classify buildings by their size are described in Table 1. 
Table 1. Description of size categories used to classify Southern Ontario student residences

\begin{tabular}{c|l}
\hline \multicolumn{2}{|c}{ Size Category Descriptions } \\
\hline Low-rise & Buildings or houses with 5 floors or less \\
\hline Mid-rise & Buildings with more than 5 floors and less than 10 floors \\
\hline High-rise & Buildings with over 10 floors \\
\hline
\end{tabular}

For consistency with existing DOE reference models for other typologies, three vintage periods were chosen: pre-1980, post-1980 and post-2004. The average age of university buildings in Ontario according to the Council of Ontario Universities (COU) is 42.9 years [53]; although post-2004 buildings were used in the segmentation process, they are considerably less common in the available dataset and were omitted since sample sizes would produce statistically insignificant results. Building vintage characteristics are described in Table 2.

Table 2. Description of vintage categories used to classify Southern Ontario student residences

\begin{tabular}{c|l}
\hline \multicolumn{1}{c}{ Vintage Category Descriptions } \\
\hline Pre-1980 & $\begin{array}{l}\text { Historic masonry buildings } \\
\text { Buildings that contained brick masonry } \\
\text { Buildings with Brutalist architecture (popular in the 60s and 70s) }\end{array}$ \\
\hline Post-1980 & $\begin{array}{l}\text { Default period for buildings that did not meet the other two } \\
\text { building periods }\end{array}$ \\
\hline Post-2004 & $\begin{array}{l}\text { Buildings that showed contemporary construction methods (e.g. } \\
\text { high use of IGUs and spandrels); these were less worn down it was } \\
\text { visually obvious that these had been recently constructed }\end{array}$ \\
\hline
\end{tabular}

When the three size categories were combined with the two used vintage categories, a total of six building classes emerged. Outliers were then identified using equations (1) - (3), and suspicious entries were inspected in greater detail and removed if necessary. Reasoning behind the removal of buildings is explained in Section 0. The median consumption of each category and average building descriptors (building height, number of floors, and conditioned floor area) were then collected from each dataset.

\subsection{Building Stock Characterization}

The characterization of a reference energy model is critical in order to use it to simulate building consumption that accurately represents that commonly seen in buildings of a specific size, operation, and vintage. Once buildings within the dataset were classified by type, the next step was to define a complete set of thermal properties, usage patterns, and building systems for each. All non-geometric building properties required for an energy model can be stored in a characterization 
“template". Characterization templates are beneficial for large scale studies, or when performing multiple simulations on buildings that have similar characteristics as building properties can be quickly assigned to massing models.

To develop characterization templates for classified student residences, their construction assemblies, usage patterns, equipment, and system efficiencies needed to be defined. Such aspects are typically collected through surveys or audits, however, there are currently limited studies available to characterize student residence models in such a way

U.S. DOE reference models were reviewed using four categories described in Table 3. The four categories were selected as these are used in several studies published by the DOE.

Table 3. Building categories used to review commercial reference energy models

\begin{tabular}{c|l}
\hline \multicolumn{2}{c}{ Building Category Descriptions } \\
\hline Form & $\begin{array}{l}\text { Conditioned areas, number of floors, aspect ratio, window to wall ratio, shading } \\
\text { devices, and floor heights. }\end{array}$ \\
\hline Fabric & Air tightness, materials, glazing systems and construction assemblies. \\
\hline Program & $\begin{array}{l}\text { Process loads, ventilation rates, occupancy densities, space activities, domestic hot } \\
\text { water demand and operating schedules. }\end{array}$ \\
\hdashline Equipment & Lighting fixtures, HVAC systems, HVAC efficiencies, and control settings. \\
\hline
\end{tabular}

The floor-to-floor heights, shading devices and aspect ratios of DOE models were reviewed and used to inform geometrical aspects of the student residence models. A floor-to-floor height of 3 meters was set for all student reference models as well as a $30 \%$ window to wall ratio. Although using the same floor heights and glazing ratios can reduce the accuracy of consumption predictions due to actual building to building variance, it was determined that it would be best to set the same values for these inputs across all datasets, as to allow for their comparison, regardless of their vintage and size. Materials and characteristics related to the fabric of the DOE models informed envelope details of student reference models. To inform space activity breakdowns of the student residence reference models, the floor plans and space activities of DOE models and one Ryerson University residence building were explored. Equipment efficiencies, control settings, and lighting power densities of DOE models were also considered.

The complexity of thermal zoning schemes in energy modeling can increase simulation times, which can be significant when simulating consumption for aggregate scale studies [54]. As stated throughout this thesis, the complexity (level of detail) of an energy model generally depends 
on its intended purpose. Including more thermal zones generally improves model accuracy, however, this increases model building time and simulation run time. As student reference models were used to compare two methods for large scale consumption studies, a simplified zoning scheme was employed. Student reference models were auto zoned using the "perimeter/core" method (Figure 5).

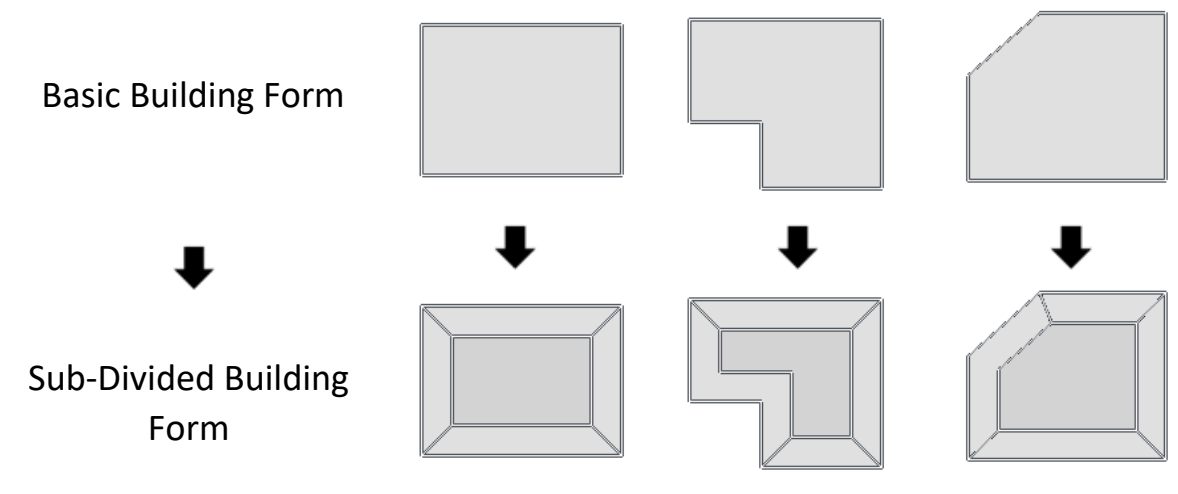

Figure 5. Zoning example using the perimeter/core method

The summary of characterization templates is described in greater detail in Section 5.2, while the comparison of DOE model inputs and their sources are presented in Appendix B.

\subsection{Building Stock Consumption Prediction}

Both approaches predict consumption using EnergyPlus and Urban Modelling Interface (UMI), a Rhinoceros plug-in that serves as an EnergyPlus graphical interface where glazing ratios, floor heights, weather data and other characterization details can be easily applied to an existing geometry. UMI uses the Shoeboxer algorithm to create EnergyPlus text files to then be simulated with the software [55]. The Shoeboxer algorithm consists of closed poly-surfaces, so called boundary representations (BREP). Each BREP consists only of spaces of equivalent activity use, i.e. a building with laboratory space at the bottom and residence space on top would consist of at least two BREPs. For each activity there should be a zone characterization template that contains all non-geometric building assumptions such as construction assemblies, internal gains, occupancy parameters and HVAC settings and controls. To create a BREP, a building model needs to be created. This is done by drawing a $2 \mathrm{D}$ footprint and extruding it to a desired height (Figure 6). When the 3D model is set, the number of floors, glazing ratios, and activities can be assigned. 

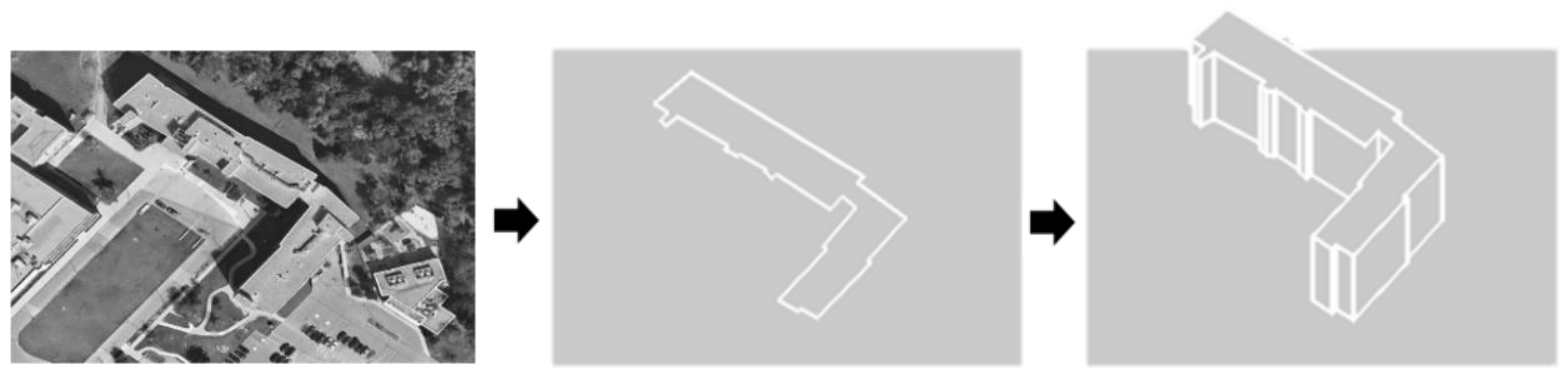

Figure 6. Process used to create 3D building geometry

In addition to building geometry, floor partitions, window-to-wall ratio, construction assemblies, internal gains, conditioning systems, and controls must be defined to run a BEM simulation. These inputs are applied to UMI models using "Unit Properties" and "Zone Templates". Unit properties contain floor-to-floor heights, perimeter offsets, and window-to-wall ratios. Zone templates contain materials, construction assemblies, internal mass properties, glazing properties, schedules, number of occupants, equipment densities, lighting densities, and control strategies. Each 3D model is assigned to a unit property container and a zone template; however, a second Zone Template can be specified in case the 3D model has a core region that is used for a different purpose to the one used in perimeter regions. The algorithm divides a unit into floors by using a user-defined floor-to-floor height, resulting in unit floors. The algorithm divides the area of a unit floor into core and perimeter regions by offsetting floor edges inwards, this perimeteroffset value is also user-defined. The partition between the perimeter and core zone is modelled as opaque surface, however, glazing can be specified to consider radiative exchange between the two zones. Once these geometric aspects are defined, zone properties such as, materials, construction assemblies, power densities, and occupancy profiles can be applied to the zones. Zones are conditioned with an ideal heating and cooling system by UMI. A weather file is then assigned to the shoebox 3D model which is then converted into an input file for EnergyPlus. As student residences compared in this study are in climates representative of Toronto, a Canadian Weather Year for Energy Calculation (CWEC) file for the city of Toronto was used as the weather file for all simulations. CWEC files contain hourly weather observations to represent an artificial one-year period specifically designed for energy calculations. "The National Energy Code of Canada requires the use of a CWEC file representative of a location when the performance path and customized design calculations are chosen as the means of a building energy consumption compliance" [56]. 
Figure 7 shows the approach used to develop the energy demand of student residences using Rhinoceros, UMI, and EnergyPlus. In summary, geometry data was collected and used to develop a 3D Model. Characterization details of the desired typology and weather data were applied to the 3D Model using UMI. UMI then converts the 3D model into an EnergyPlus file and simulated using the software.

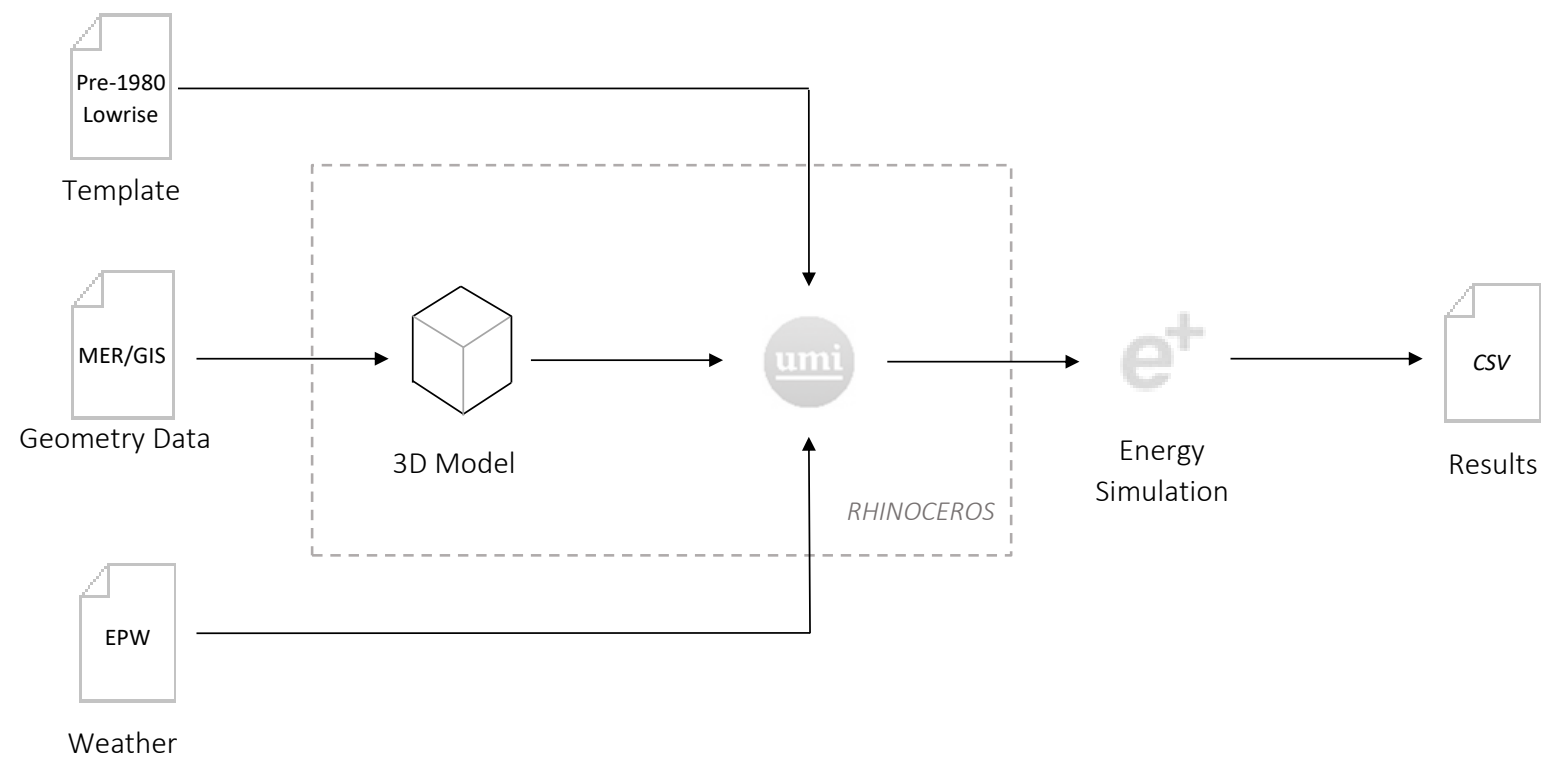

Figure 7. Approach used to develop the energy demand of student residence reference models

\subsubsection{Reference Method Consumption Prediction}

One Reference model was used to predict the consumption of each dataset of buildings as illustrated in Figure 8. Collected average descriptors (i.e. height, area) of each set were used to create a simplified model using Rhinoceros and UMI as the modeling interfaces. The model has a rectangular geometry and an aspect ratio based on the DOE reference model review. The Reference model was simulated facing both east-west and north-south to consider the impact that orientation has on building consumption. The glazing ratio was set to $30 \%$ on all facades and a floor-to-floor height of $3 \mathrm{~m}$ was assumed. Floors of the models were subdivided into five zones, four perimeter zones and one core zone. A $3 \mathrm{~m}$ offset was applied to define the perimeter zone. These values were used in all Reference models to allow the comparison of results across datasets for simplicity reasons, all zones were defined by the same activity template, which was defined to represent multiple activities typically seen in student residences. A Toronto CWEC weather file and a characterization template (created through the review of DOE models) were applied to the 
Reference model to predict its consumption. Results predicted with each orientation were averaged and multiplied by measured conditioned floor areas to determine the aggregate heating, electricity, and total consumption of a dataset.
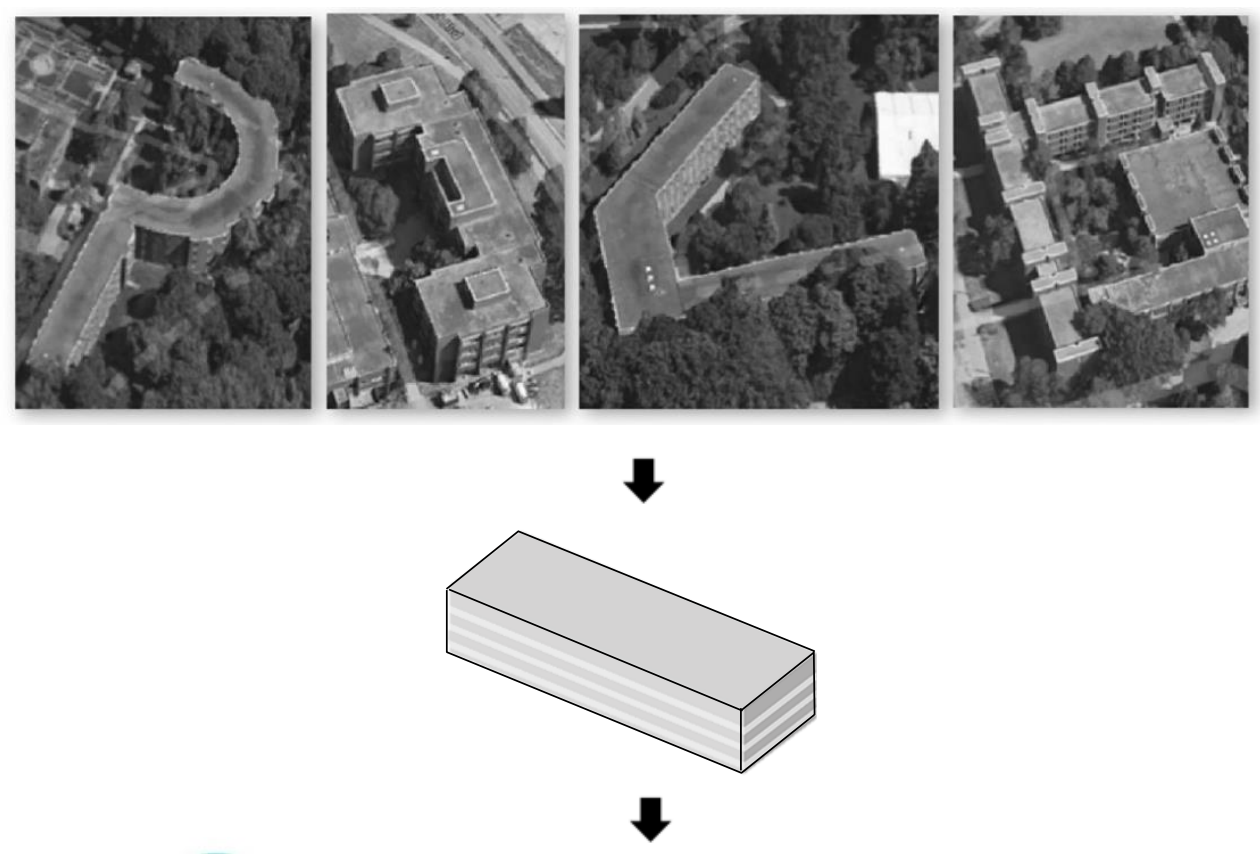

umi Characterization template: Pre-1980 Lowrise

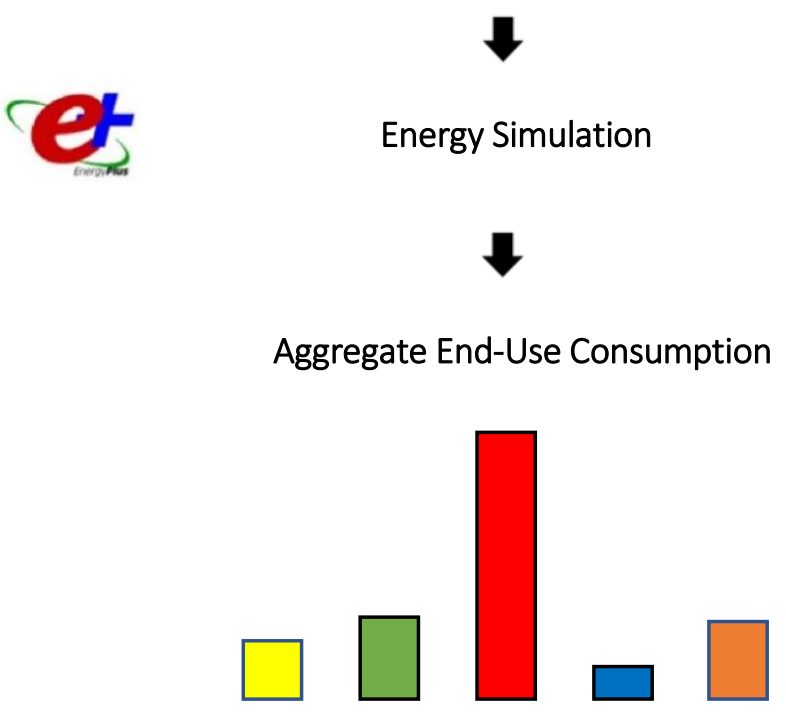

Figure 8. Steps to predict consumption using the Reference method: 1) Collection of average building characteristics from a dataset of buildings, 2) Development of Reference model geometry (two orientations), 3) Allocation of weather file and characterization template, 4) Reference model simulation using Energy Plus, and 5) Area normalized consumption predicted from both models are averaged out and multiplied by the total conditioned floor area of the set of buildings. 


\subsubsection{Wireframe Method Consumption Prediction}

A Wireframe model was built for each building part of a dataset as illustrated in Figure 9. GIS data and Daft Logic were used to obtain building footprints and heights. Footprints were imported to Rhinoceros and extruded to meet a reported height. Once 3D geometries were finalized, UMI was used to apply a glazing ratio of $30 \%$ on all facades and a $3 \mathrm{~m}$ floor-to-floor height. A Toronto CWEC weather file and a characterization template were applied to each of the Wireframe models. Floors of the models were subdivided into five zones, four perimeter zones and one core zone. A $3 \mathrm{~m}$ offset was applied to move the floor edges of the perimeter zone inwards. For simplicity reasons, all zones were defined by the same activity template, which was defined to represent multiple activities typically seen in student residences. Wireframe models were simulated using EnergyPlus to determine their heating, electricity, and total energy. Consumption results are added to determine the aggregate heating, electricity and total consumption of a dataset. 

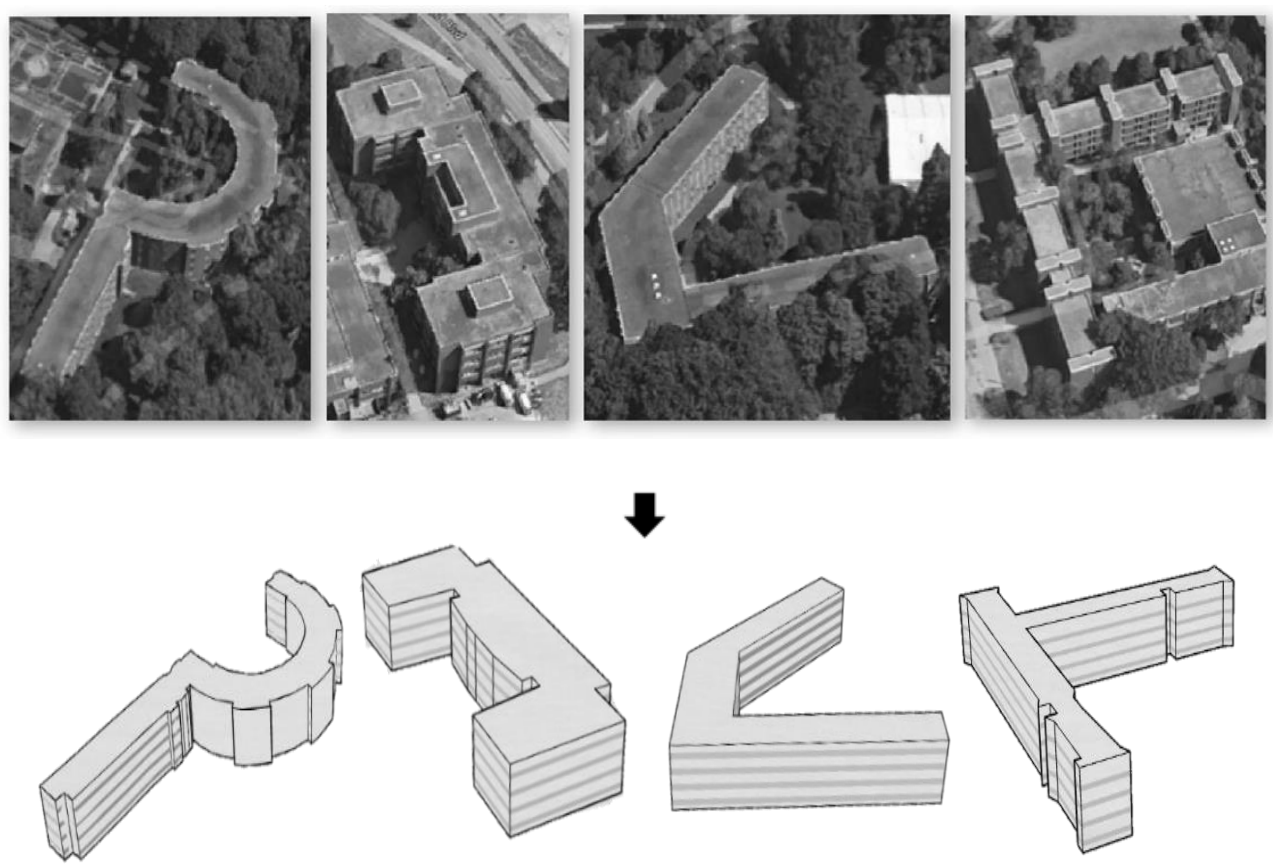

$\checkmark$

umi Characterization template: Pre-1980 Lowrise

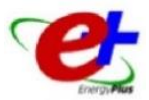

Energy Simulation

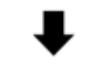

Aggregate End-Use Consumption

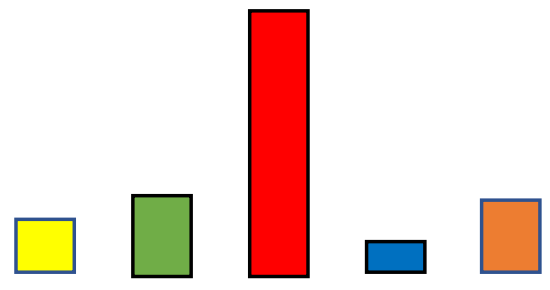

Figure 9 Steps to predict consumption using the Wireframe method: 1) Collection of average building characteristics from a dataset of buildings, 2) Development of Wireframe model geometry, 3) Allocation of weather file and characterization template, 4) Simulation using Energy Plus, and 5) Individual building consumption are aggregated to represent the total consumption of the dataset of buildings. 


\subsection{Model Tuning}

Once characterization details were assigned to a Reference method model, their consumption was predicted using EnergyPlus. Each Reference model predicted five annual enduses: heating, cooling, interior lighting, interior equipment, and water systems (Figure 10). Enduse predictions were later normalized using the conditioned floor area of the Reference model used to produce them.

(1)

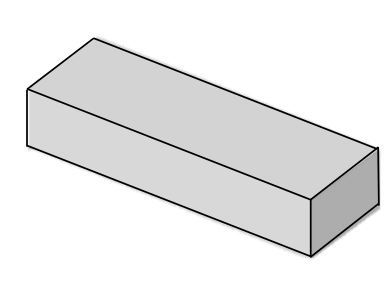

(2)

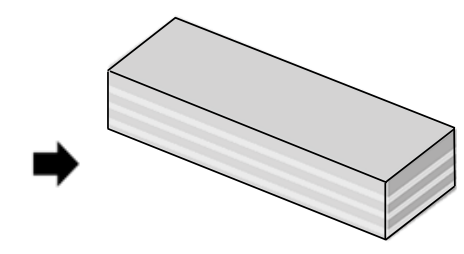

(3)

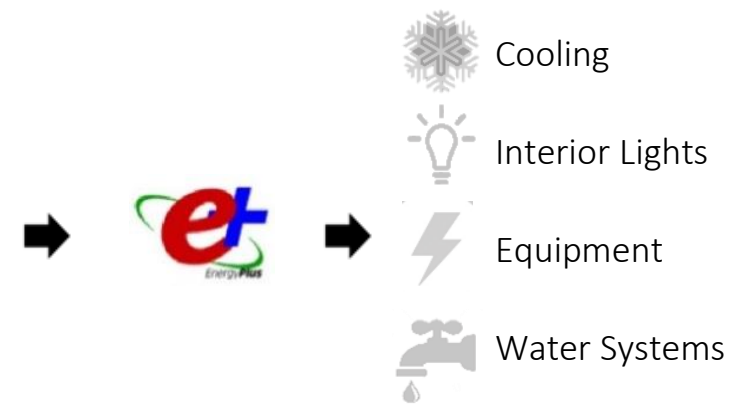

Figure 10. This image describes the process of predicting the end-use consumption of a Reference model: (1) A Rhinoceros 3D model is created using geometrical characteristics of the building stock, (2) Characterization templates and weather data are applied to the 3D model using UMI, (3) The Reference model is simulated using Energy Plus, and (4) The end-use consumption of the model is then determined predicted.

Because two existing DOE models were merged to best match the desired building typology, student residence models were tuned to ensure that the results were consistent with the DOE models (either matching or falling between them) rather than differing significantly from them. If the predicted consumption of a student residence model was significantly off, their characterization template was adjusted, as will be discussed in detail in Section 6. Once characterization templates were adjusted, they were applied using the Wireframe and Reference methods to predict the consumption of student residences. 


\subsection{Institutional Residence Building Stock Validation and Error Analysis}

The predicted aggregate annual heating, electricity and total consumption derived from both methods was compared to their equivalent consumption reported in the MER to validate the results of each method. To test the hypothesis that the Wireframe method would provide better prediction accuracies than the Reference method, an error analysis study was undertaken. Percentage Error (E) represents the capabilities of the methods to predict aggregate load consumption. This equation is very useful to determine the precision of calculations.

$$
(\mathrm{E})=\left(\frac{(\Sigma \text { loadsPredicted }-\Sigma \text { loadsMeasured })}{\sum \text { loadsMeasured }}\right)
$$

Root Mean Square Error (RMSE) represents the sample standard deviation of the discrepancies between predicted and measured values.

$$
\text { RMSE }=\sqrt{\frac{1}{n} \sum_{i=1}^{n}\left(\frac{x_{\text {Predicted }}-x_{\text {Measured }}}{x_{\text {Measured }}}\right)^{2}}
$$

Together, the Percentage Error and RMSE equations allow the model accuracies to be evaluated at both aggregate and individual building scales. In addition to the bottom-up method comparison and accuracy evaluation, a study to determine their capabilities with varying sample sizes was explored. For this study, the final building results were imported into a database and randomly sampled without replacement to generate building subsets of varying sizes $(\mathrm{n}=3,5,7,9,11,13,15,17$ and 19) with replacement between subset generation. The predicted annual total energy of each building was then totaled for each subset and compared with actual totals for the same buildings. The average error rate was then plotted against sample size for each method.

The methodology presented here was used to determine if the inclusion of real geometry and orientation of buildings can have a significant effect on the outcomes of energy prediction for conservation strategy testing at regional scales. 


\section{Data Collection and Validation}

In 2009, Ontario's Ministry of Energy implemented Regulation 397/11 [16] under the Green Energy Act. This regulation requires municipalities, post-secondary, and healthcare operations to annually report their energy consumption, carbon emissions, building operations, and some building characteristics that influence a building's energy consumption. Data collected from these reports is referred to as Mandatory Energy Report (MER) data throughout this thesis. As noted above, MER data collected by the MOE of Ontario was used to determine the energy performance of college and university buildings within climate zones similar to that of Toronto. Figure 11 shows Southern Ontario’s climate zone delimitation as described by the NECB (2011) [57]. The stars displayed on Figure 11 represent cities which contain buildings considered in this study.

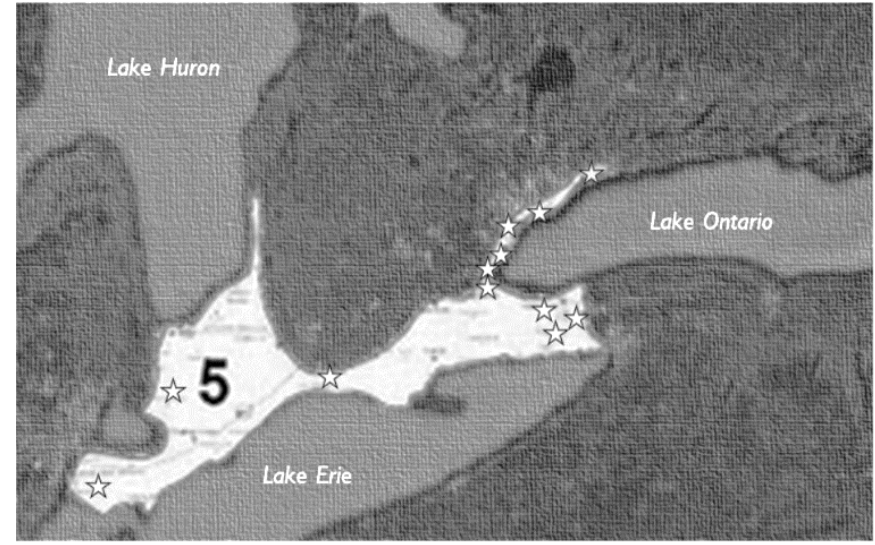
Oshawa
Toronto
Mississauga
Oakville
Burlington
Hamilton
St. Catharine's
Welland
St. Thomas
Sarnia
Chatham

Figure 11. Climate Zone 5 (NECB 2011) and cities were MER institutional data was collected

This climate classification resulted in a sample size of 8 universities and 14 colleges, representing 308 post-secondary buildings. The selection of only those buildings that met this criteria aids in the development of more granular benchmarks. Energy benchmarks developed from MER data were then compared against Canadian benchmarking studies to validate the data from the reports - this was necessary since MER data is not validated by the MOE. Those post-secondary building operations which compare favorably to Canadian benchmarking studies are considered "validated" and their data can be used to develop the reference energy models of Ontario's institutional building stock. Developed benchmarks were also used to inform consumption differences between university and college building operation. The results will help to identify building operations suitable for a comparison of the bottom-up methods. The findings of this investigation are summarized in this section. 


\subsection{Data Validation for Colleges and Universities}

To validate the consumption reported for colleges and universities, their energy use intensity (EUI; measured ekWh/m $\mathrm{m}^{2}$ ) and area $\left(\mathrm{m}^{2}\right)$ were collected. Figure 12 presents college and university EUIs collected from Southern Ontario MER data.

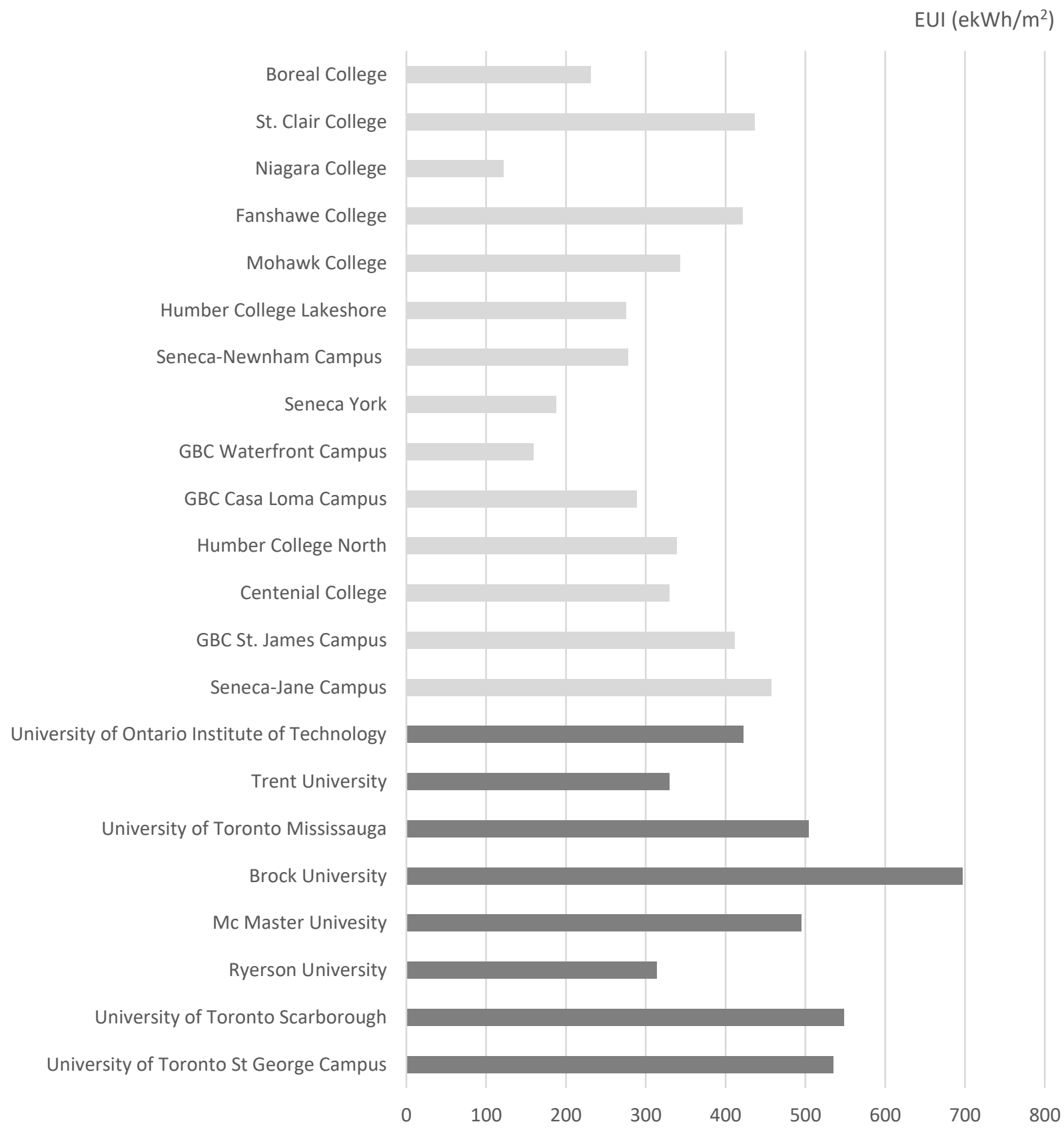

Figure 12. EUI of selected college and university institutions 
First, college and university buildings were considered in the same category to replicate the "college/university" benchmark displayed in Energy Star Portfolio Manager 2016 data [24]. Equations (1) - (3) were applied to the EUI of the 22 post-secondary institutions displayed in Figure 12. No energy outliers were identified in the sample. The mean and median EUI derived from the MER college/university category are compared to the college/university EUI benchmark defined in Energy Star 2016 data, and the EUI of the other category defined in the Survey of Commercial and Institutional Energy Use: Buildings 2009 [22] in Figure 13.

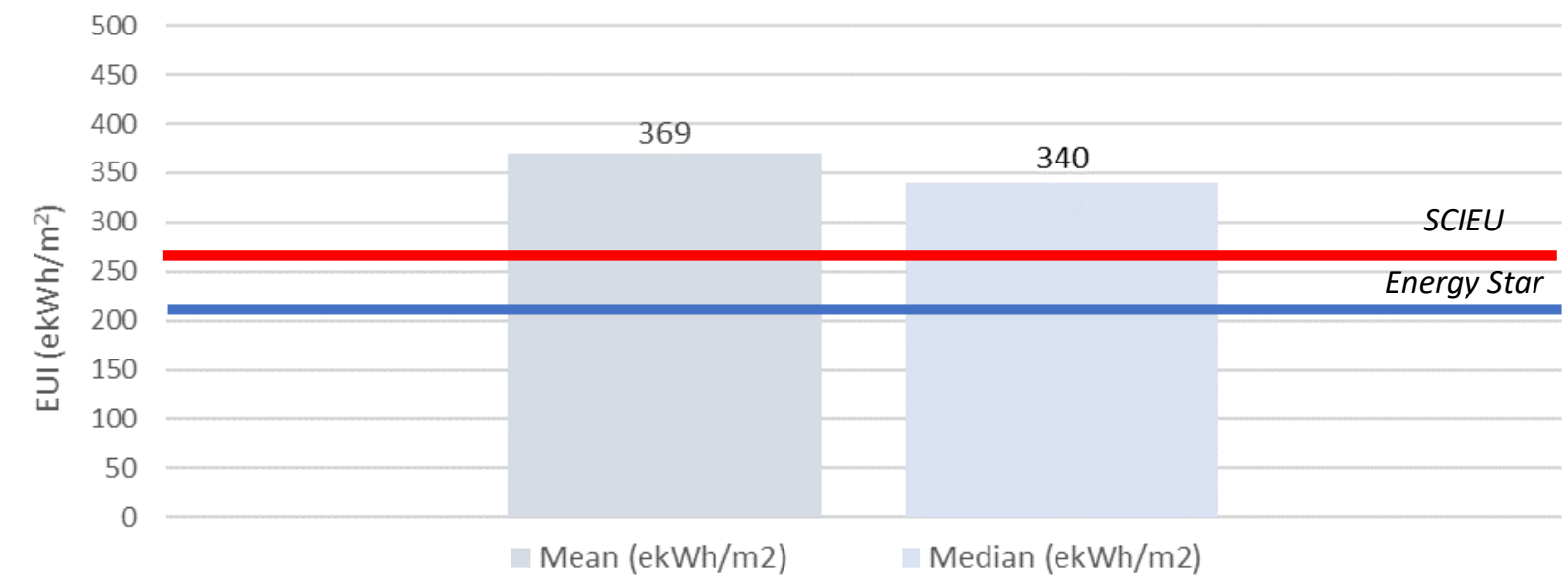

Figure 13. Mean and median EUI derived from the MER college/university category compared to the $212 \mathrm{ekWh} / \mathrm{m}^{2}$ (Energy Star) and the $264 \mathrm{ekWh} / \mathrm{m}^{2}$ (SCIEU) displayed in Canadian benchmarking studies

As stated in the Literature Review, universities and colleges in the SCIEU survey are grouped under the "other" category which includes entertainment, leisure, and shopping centres. This variation in building operation affects the accuracy of the benchmark as a building's function is a primary driver of its energy consumption. The "other" benchmark presented in the SCIEU survey has a median EUI for Ontario's Great Lakes region of $264 \mathrm{ekWh} / \mathrm{m}^{2}$ [22]. The "college/university" benchmark presented in Energy Star's Portfolio Manager Technical Reference document, which was derived from national surveys, shows a median value of 212 $\mathrm{ekWh} / \mathrm{m}^{2}$ [58]. The comparison of these values suggests that the developed median of $340 \mathrm{ekWh} / \mathrm{m}^{2}$ for Southern Ontario's college/university category exceeds the EUI found in Canadian benchmarking studies. It was noted that the mean and median values produced by MER data differ by $9 \%$, suggesting variance across the sample, illustrating that colleges and universities should be considered separately. 
Southern Ontario colleges were analyzed first, covering over 1.06 million $\mathrm{m}^{2}$ of conditioned floor area. Equations (1) - (3) were applied to EUIs of the 14 colleges displayed in Figure 12. No energy outliers were identified in the college category. The mean and median EUI derived from the college category are compared to Canadian benchmarking studies in Figure 14.

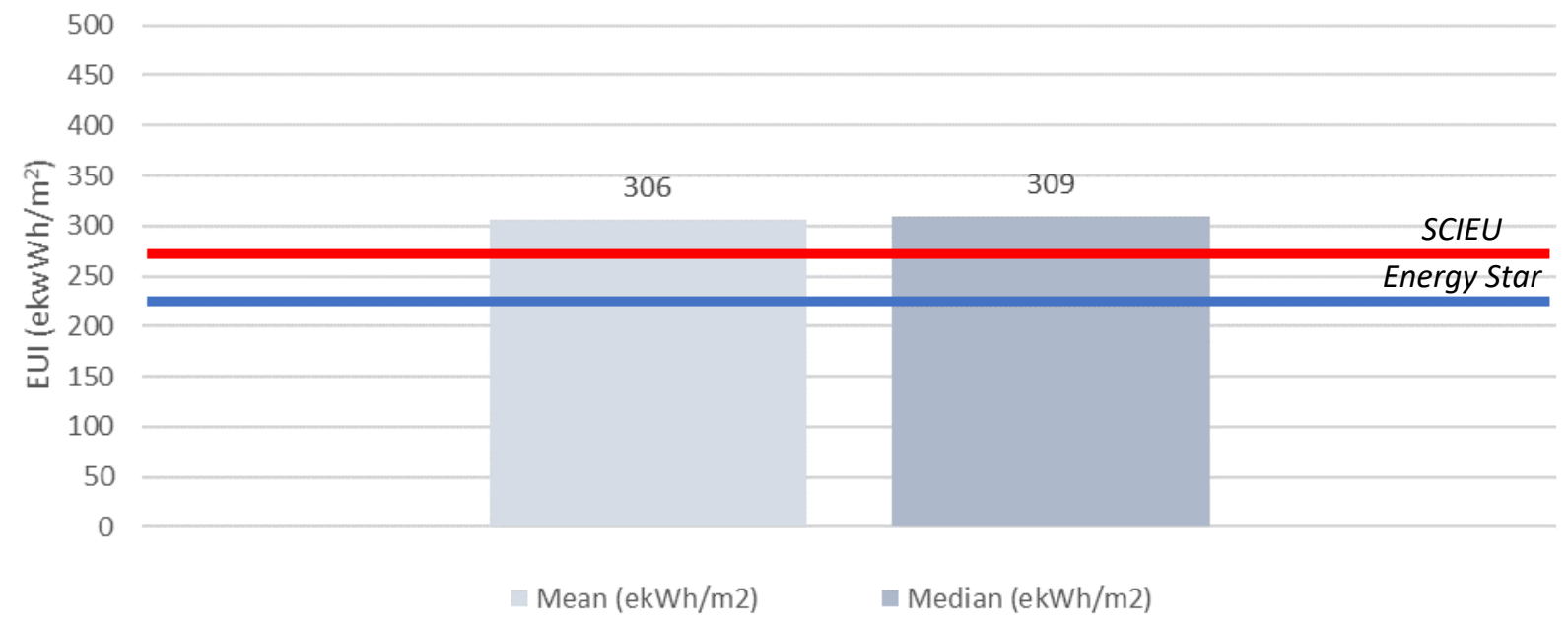

Figure 14. Mean and median EUI derived from the college sample compared to the $212 \mathrm{ekWh} / \mathrm{m}^{2}$ (Energy Star) and the $264 \mathrm{ekWh} / \mathrm{m}^{2}$ (SCIEU) displayed in Canadian benchmarking studies

Figure 14 shows that Canadian benchmarking studies exceed the average of the sample of buildings selected, however the difference between the developed EUI and the benchmark studies decreased. In addition, a 1\% difference in variation was noted between the mean and median, which suggests that considering colleges exclusively results in a more uniform sample.

Southern Ontario universities were then analyzed, covering over 2.75 million $\mathrm{m}^{2}$ of conditioned floor area. Equations (1) - (3) were applied to EUIs of the eight universities displayed in Figure 12. No energy outliers were identified in the university sample. The mean and median EUI derived from sampled Ontario universities is compared to the EUIs defined in North American benchmarking studies in Figure 15. 


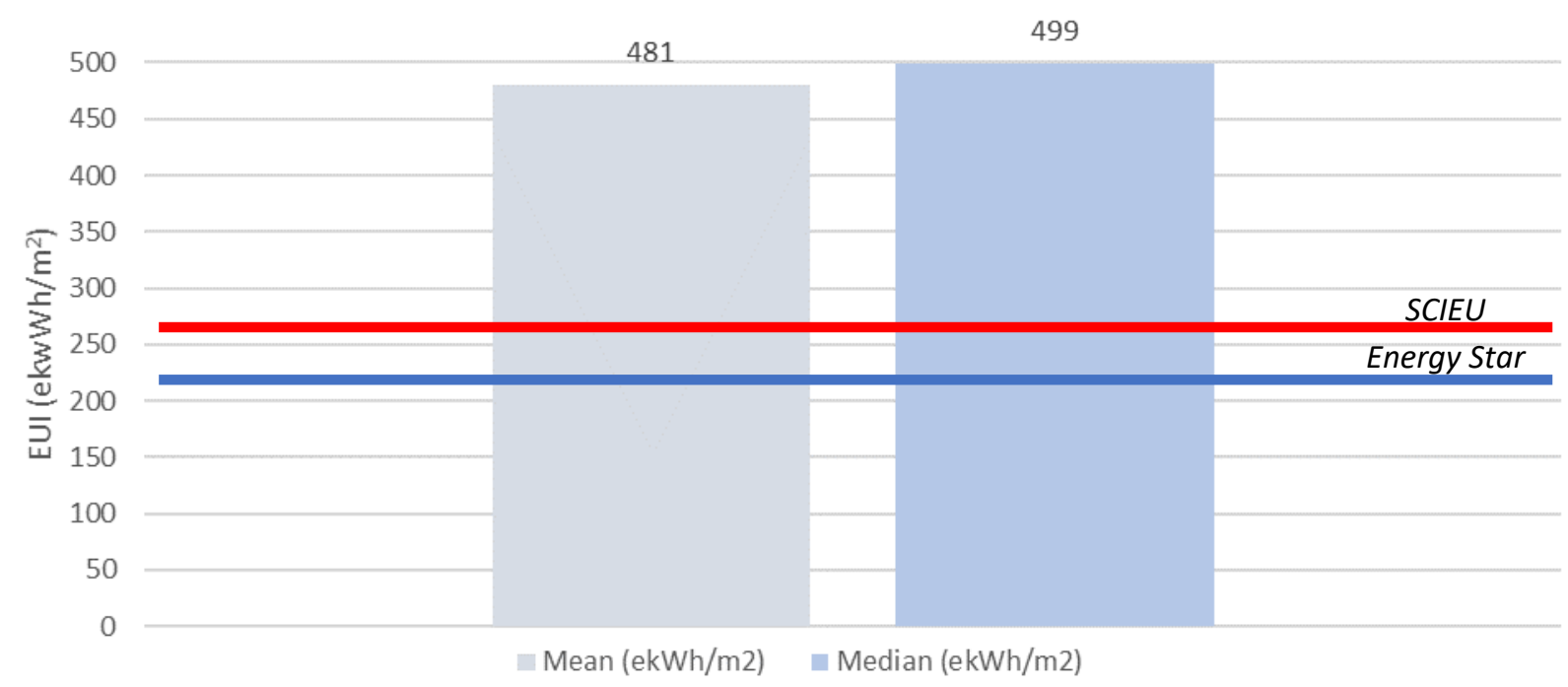

Figure 15. Mean and median EUI derived from the MER university sample compared to the $212 \mathrm{ekWh} / \mathrm{m}^{2}$ (Energy Star) and the $264 \mathrm{ekWh} / \mathrm{m}^{2}$ (SCIEU) displayed in Canadian benchmarking studies

Figure 15 shows that Canadian benchmarking studies exceed the average of the sample of buildings selected, however the difference between the developed EUI and the benchmark studies increased. In addition, a 1\% difference in variation was noted between the mean and median, which suggests that considering university exclusively results in a more uniform sample.

These results propose a measurement error in MER data, though it is important to note the limitations of the Canadian benchmarking studies. The Energy Star benchmark represents a national consumption average of colleges and universities and the SCIEU benchmark represents "other" buildings in climates similar to that of the Great Lakes. Therefore, it is challenging to determine which benchmarking survey is more accurate as neither study presents the required granularity. Additionally, the results of these studies may be skewed by the total floor area of the college and university buildings considered. It is possible that the SCIEU survey included more college conditioned floor area, while the Energy Star survey included more university conditioned floor area. Although both studies include the total conditioned floor areas considered in benchmark development, neither disclose the percentage attributed specifically to university, college or other operation buildings. Without this, it is challenging to present a definitive answer on which benchmark survey is more appropriate to validate MER data. However, when college and university institutions were considered as separate samples, the difference between their mean and median decreased when compared to the initial college/university sample. This suggests that 
considering college and university buildings separately does produce less scattered samples. The question that now arises is: Which college and university building operations differ the least in consumption? The answer will identify the building operation most ideal for comparing the bottom-up methods discussed later in this thesis. The building operations with the least EUI variation between colleges and universities will produce larger samples for the comparison. Additionally, if a sample compares well with existing benchmarks, it is assumed to be the best option for method comparison. This approach was necessary due to the limitations in considering only buildings part of the MER data.

\subsection{Data Validation for College and University Building Operations}

MOE requires universities and colleges to report their energy consumption based on the space's designated use using the following categories: (1) Administrative offices and related facilities, (2) Classrooms and related facilities, (3) Laboratories, (4) Student residences, (5) Recreational facilities, (6) Parking garages, and (7) Other. The reported consumption of these operations was reviewed in greater detail with the exception of Classrooms, Other and Parking categories due to their complexity and/or variability. The intention of this review is to analyze and validate in greater detail MER data by developing local energy benchmarks, comparing them to North American benchmarks, and determining the deviation between building operations at colleges and universities. The results of this review were used to validate the MER data and identify potential benchmarks and/or reference models applicable to both college and university buildings.

\subsubsection{Building Operation Data Cleaning}

Under MER regulations, building owners must submit an operation type based on the primary function given to a space. Many institutional buildings serve multiple operations per building, and this is clearly shown in MER data as some institutions submit multiple operations under one building address, as illustrated in Table 4. Although in the MER dataset buildings are presented with different operations and areas under the same location, the reported EUI is based on the total consumption of the building and not on a space-by-space basis. Knowing the multiple uses or operations that are given to a building serves a greater understanding of the variances in EUI. For example, Progress Residence has space allocated both for residences and for laboratories 
while also boasting the largest EUI in the College Residence data set. In this case, the energy required to power laboratory equipment is more than likely what is causing the variance in EUI when compared to the EUI reported under other Residence buildings.

Table 4. Buildings reported under the same location for college residences

\begin{tabular}{cccccc}
\hline Building Name & Operation Type & Address & Area $\left(\mathrm{m}^{2}\right)$ & EUI $\left(\mathrm{kWh} / \mathrm{m}^{2}\right)$ & Area $(\%)$ \\
\hline Lambton Inn & Residence & 1485 London Rd. & 5880 & 330 & 76 \\
Lambton Inn & Office & 1485 London Rd. & 1877 & 330 & 24 \\
\hline Progress Residence & Residence & 940 Progress Ave. & 10602 & 418 & 70 \\
Progress Residence & Laboratory & 940 Progress Ave. & 4520 & 418 & 30 \\
\hline Newnham Residence & Residence & 1760 Finch Ave. & 29990 & 241 & 83 \\
Newnham Residence & Office & 1760 Finch Ave. & 5991 & 241 & 17 \\
\hline
\end{tabular}

Information regarding the space type is useful, however EUIs on a space-by-space basis would be necessary for a more accurate analysis. Because considering each operation as an individual building creates duplicate buildings, buildings that reported multiple operations under one location are joined and classified under the main use that the building serves Table 5. This "main use" assumption allows buildings to be represented by their total area rather than segments and permits comparison on a building-by-building basis.

Table 5. Buildings with multiple operations after relevant data has been joined to form a building

\begin{tabular}{cccccc}
\hline Building Name & Operation Type & Address & Area $\left(\mathrm{m}^{2}\right)$ & EUI $\left(\mathrm{kWh} / \mathrm{m}^{2}\right)$ & Area (\%) \\
\hline Lambton Inn & Residence & 1485 London Rd. & 7757 & 330 & 100 \\
Progress Residence & Residence & 940 Progress Ave. & 15122 & 418 & 100 \\
Newnham Residence & Residence & 1760 Finch Ave. & 35982 & 241 & 100 \\
\hline
\end{tabular}

\subsubsection{Administrative Office Buildings - College Sample}

Administrative office buildings of eight college campuses were considered to develop the Administrative Office university benchmark, resulting an initial sample size of 36 buildings. The average EUI, total energy consumption, number of buildings (n), and area of considered administrative office buildings for college campuses are presented in Table 6. The median EUI derived from the initial sample $(n=36)$ can be seen in Table 7. 
Table 6. Initial sample of Administrative Office buildings considered for benchmarking study

\begin{tabular}{ccccccc}
\hline \multicolumn{7}{c}{ Administrative Offices - Colleges } \\
\hline College & Campus & $\mathrm{n}$ & $\Sigma(\mathrm{kWh})$ & $\Sigma$ Area $\left(\mathrm{m}^{2}\right)$ & $\mathrm{ekWh} / \mathrm{m}^{2}$ & $\mathrm{ekWh} / \mathrm{ft}^{2}$ \\
Seneca & York & 2 & 2318465 & 12642 & 183 & 17 \\
Seneca & Newnham & 11 & 8703744 & 31820 & 274 & 25 \\
Seneca & Jane & 1 & 179584 & 393 & 453 & 42 \\
Centennial & Scarborough & 10 & 9567871 & 39711 & 241 & 22 \\
St. Clair & Windsor & 1 & 201278 & 755 & 266 & 25 \\
Lambton & Sarnia & 6 & 7448914 & 50822 & 147 & 14 \\
Niagara & Welland & 4 & 14096310 & 115371 & 122 & 11 \\
Sheridan & Trafalgar & 1 & 1037231 & 2682 & 387 & 36 \\
\hline
\end{tabular}

Table 7. Administrative Office buildings results before outlier removal

\begin{tabular}{ccccccccc}
\hline \multicolumn{7}{c}{ Administrative Offices EUI $\left(\mathrm{ekWh} / \mathrm{m}^{2}\right)$} & - Before Outlier Removal \\
\hline Q1 & Mean & Median & Q3 & IQR & LAV & UAV & $\mathrm{s}$ & $\mathrm{s}(\%)$ \\
210 & 320 & 255 & 394 & 183 & -65 & 669 & 183 & $72 \%$ \\
\hline
\end{tabular}

As seen in Table 7 the initial sample of 36 buildings showed a $25 \%$ difference between its mean and median EUI and a sample standard deviation $(s)$ of $72 \%$. These findings suggest significant variation across the sample. Three buildings were then identified as outliers using Equations (1) - (3) and two buildings through data screening. Buildings removed through data screening were identified as erroneous entries as their area was suspiciously high (8-10 times larger than that of the average). Identified outliers were removed resulting in a new sample size of 31 buildings. The difference between the developed mean and median EUI decreased by $11 \%$ and the standard deviation by $33 \%$, compared to those developed before outlier removal. The results of the Administrative Office college benchmark after the removal of outliers can be seen in Table 8 .

Table 8. Administrative Office buildings after outliers have been removed

\begin{tabular}{ccccccccc}
\hline \multicolumn{7}{c}{ Administrative Offices EUI $\left(\mathrm{ekWh} / \mathrm{m}^{2}\right)$} & - After Outlier Removal \\
\hline Q1 & Mean & Median & Q3 & IQR & LAV & UAV & $\mathrm{s}$ & $\mathrm{s}(\%)$ \\
212 & 286 & 243 & 373 & 162 & -31 & 616 & 96 & $39 \%$ \\
\hline
\end{tabular}


The EUI and area of each administrative building considered in the development of the Administrative Office college benchmark can be seen in Figure 16. The horizontal line represents the developed $243 \mathrm{kWh} / \mathrm{m}^{2}$ median after outliers were removed.

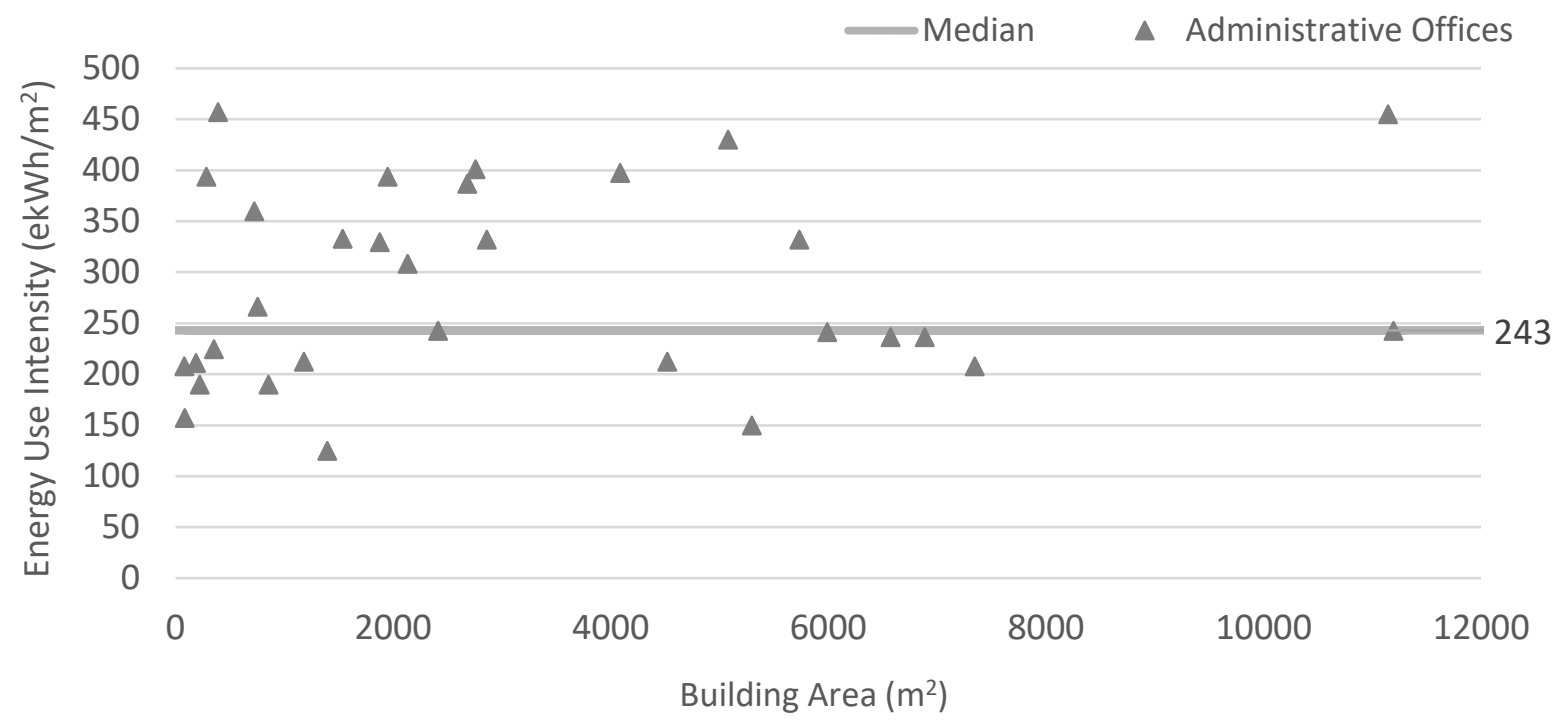

Figure 16. College Administrative Office buildings considered to develop the sample's EUI

\subsubsection{Administrative Office Buildings - University Sample}

Administrative office buildings of three university campus were considered to develop the Administrative Office university benchmark, totaling an initial sample size of 33 reported buildings. The average EUI, total energy consumption, number of buildings (n), and area of the studied administrative office buildings per campus are presented in Table 9. The median EUI derived from this initial can be seen in Table 10.

Table 9. Initial sample of University Administrative Office buildings considered for benchmarking study

\begin{tabular}{clccccc}
\hline \multicolumn{7}{c}{ Administrative Offices - University } \\
\hline University & Campus & $\mathrm{n}$ & $\Sigma(\mathrm{kWh})$ & $\Sigma$ Area $\left(\mathrm{m}^{2}\right)$ & $\mathrm{ekWh} / \mathrm{m}^{2}$ & $\mathrm{ekWh} / \mathrm{ft}^{2}$ \\
Ontario & Oshawa & 5 & 4274590 & 18691 & 229 & 21 \\
York & Toronto & 26 & 95160681 & 19425 & 490 & 45 \\
Brock & St. Catharines & 2 & 45944 & 870 & 53 & 5 \\
\hline
\end{tabular}

Table 10. University Administrative Office buildings results before outlier removal

\begin{tabular}{ccccccccc}
\hline \multicolumn{7}{c}{ Administrative Offices EUI $\left(\mathrm{ekWh} / \mathrm{m}^{2}\right)$} & - Before Outlier Removal \\
\hline Q1 & Mean & Median & Q3 & IQR & LAV & UAV & $\mathrm{s}$ & $\mathrm{s}(\%)$ \\
253 & 435 & 369 & 620 & 367 & -298 & 1171 & 246 & $67 \%$ \\
\hline
\end{tabular}


As seen in Table 10, the initial sample of 33 buildings showed an $18 \%$ difference between its mean and median EUI and a standard deviation of $67 \%$. One building was identified as an outlier using Equations (1) - (3) and two buildings were identified as outliers through screening process. The two buildings identified through the screening process are part of Brock University; while Equations (1) - (4) did not identify these buildings as outliers, they were removed due to a suspiciously low reported consumption (11-25\% of reported values for other institutions). Outliers were identified and removed, resulting in a new sample size of 30 university buildings. After this removal, the difference between the developed mean and median EUI decreased by $3 \%$ and standard deviation by $8 \%$. The results of the Administrative Office university benchmark free of outliers can be seen in Table 11.

Table 11. University Administrative Office buildings after outliers have been removed

\begin{tabular}{ccccccccc}
\hline \multicolumn{7}{c}{ Administrative Offices EUI $\left(\mathrm{ekWh} / \mathrm{m}^{2}\right)$} & - After Outlier Removal \\
\hline Q1 & Mean & Median & Q3 & IQR & LAV & UAV & $\mathrm{s}$ & $\mathrm{s}(\%)$ \\
290 & 438 & 380 & 610 & 320 & -190 & 1090 & 201 & $59 \%$ \\
\hline
\end{tabular}

The EUI and area of each administrative building considered in the development of the Administrative Office university benchmark can be seen in Figure 17.

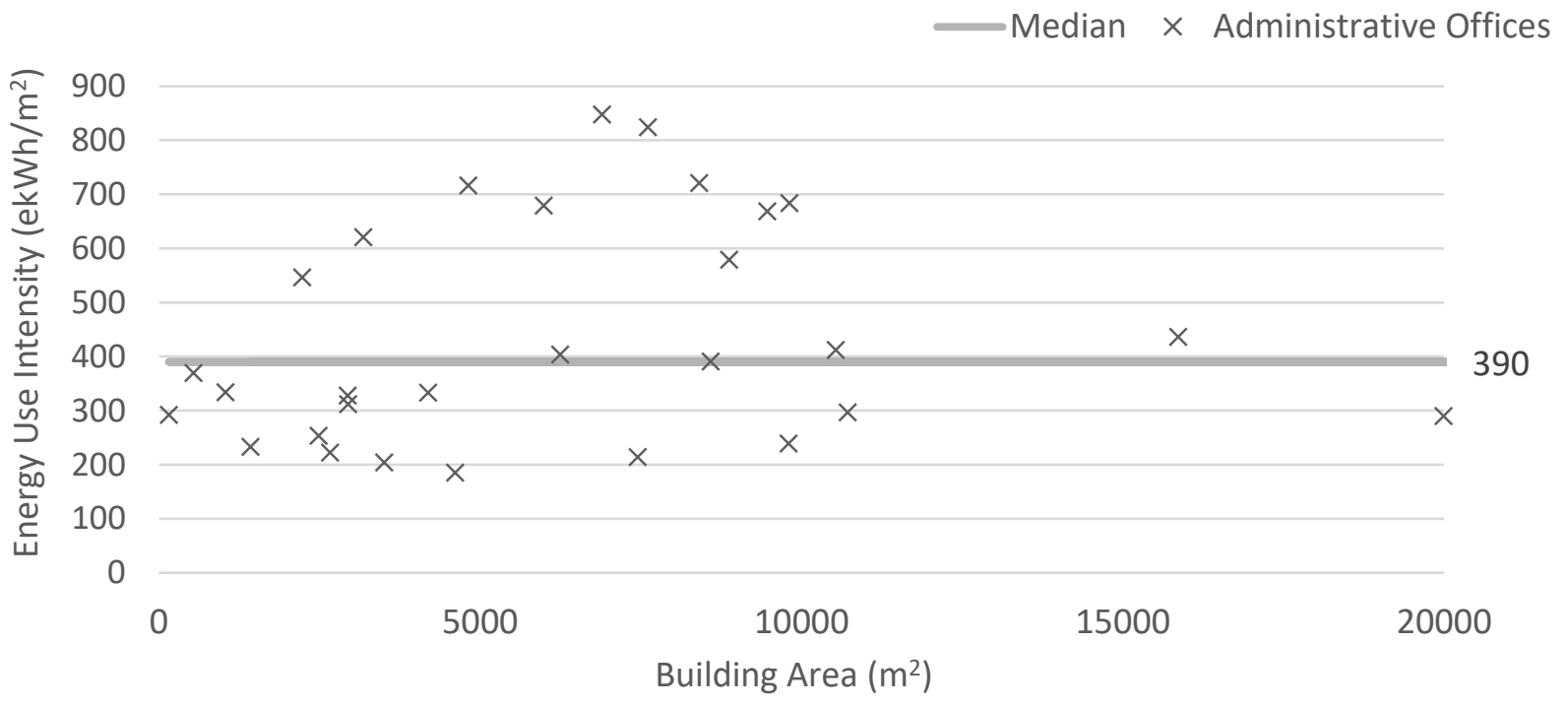

Figure 17. University Administrative Office buildings considered in the developed benchmark 


\subsubsection{Administrative Office Buildings - College and University Sample}

Administrative office buildings at three universities and eight colleges ( $\mathrm{n}=79$ buildings) were considered to develop the Administrative Office college \& university benchmark. The average EUI, total energy consumption, number of buildings, and area of the studied administrative office buildings per university and college campus are presented in Table 12. The median EUI derived from the initial sample can be seen in Table 13.

Table 12. Initial sample of university and college Administrative Office buildings considered for benchmarking study

\begin{tabular}{cccccc}
\hline \multicolumn{7}{c}{ Administrative Offices - Colleges and Universities } \\
\hline Campus & $\mathrm{n}$ & $\Sigma(\mathrm{kWh})$ & $\Sigma$ Area $\left(\mathrm{m}^{2}\right)$ & $\mathrm{ekWh} / \mathrm{m}^{2}$ & $\mathrm{ekWh} / \mathrm{ft}^{2}$ \\
Seneca - York & 2 & $2,318,465$ & 12,642 & 183 & 17 \\
Seneca - Newnham & 11 & $8,703,744$ & 31,820 & 274 & 25 \\
Seneca - Jane & 1 & 179,584 & 393 & 453 & 42 \\
Centennial - Scarborough & 10 & $9,567,871$ & 39,711 & 241 & 22 \\
St. Clair - Windsor & 1 & 201,278 & 755 & 266 & 25 \\
Lambton - Sarnia & 6 & $7,448,914$ & 50,822 & 147 & 14 \\
Niagara - Welland & 4 & $14,096,310$ & 115,371 & 122 & 11 \\
Sheridan - Trafalgar & 1 & $1,037,231$ & 2,682 & 387 & 36 \\
University of Ontario - Oshawa & 5 & $4,274,590$ & 18,691 & 229 & 21 \\
York University - Toronto & 26 & $9,516,0681$ & 19,425 & 490 & 45 \\
Brock University - St. Catharines & 2 & 45,944 & 870 & 53 & 5 \\
\hline
\end{tabular}

Table 13. College and university Administrative Office buildings results before outliers are removed

\begin{tabular}{ccccccccc}
\hline \multicolumn{7}{c}{ Administrative Offices EUI $\left(\mathrm{ekWh} / \mathrm{m}^{2}\right)$} & - Before Outlier Removal \\
\hline Q1 & Mean & Median & Q3 & IQR & LAV & UAV & $\mathrm{s}$ & $\mathrm{s}(\%)$ \\
237 & 386 & 333 & 456 & 219 & -90 & 784 & 185 & $56 \%$ \\
\hline
\end{tabular}

As seen in Table 13, the initial sample of 79 buildings showed a 15\% difference between its mean and median EUI and a standard deviation of 56\%. Four buildings were identified as energy outliers using Tukey's screening method. Identified outliers (4 total) were removed and resulted in a new sample size of 75 buildings. Once outliers were removed from the university sample, the difference between the developed mean and median EUI decreased by $6 \%$ and standard deviation by $7 \%$. The revised results of the Administrative Office college and university benchmarking can be seen in Table 14 . 
Table 14. College and university Administrative Office buildings after outliers have been removed

\begin{tabular}{ccccccccc}
\hline \multicolumn{7}{c}{ Administrative Offices EUI (ekWh/m $\left.{ }^{2}\right)$} & - After Outlier Removal \\
\hline Q1 & Mean & Median & Q3 & IQR & LAV & UAV & s & s (\%) \\
237 & 365 & 332 & 433 & 196 & -58 & 728 & 161 & $49 \%$ \\
\hline
\end{tabular}

The EUI and area of each administrative building considered in the development of the Administrative Office college and university benchmark can be seen in Figure 18. The horizontal line represents the developed $332 \mathrm{kWh} / \mathrm{m}^{2}$ median after outliers were removed.

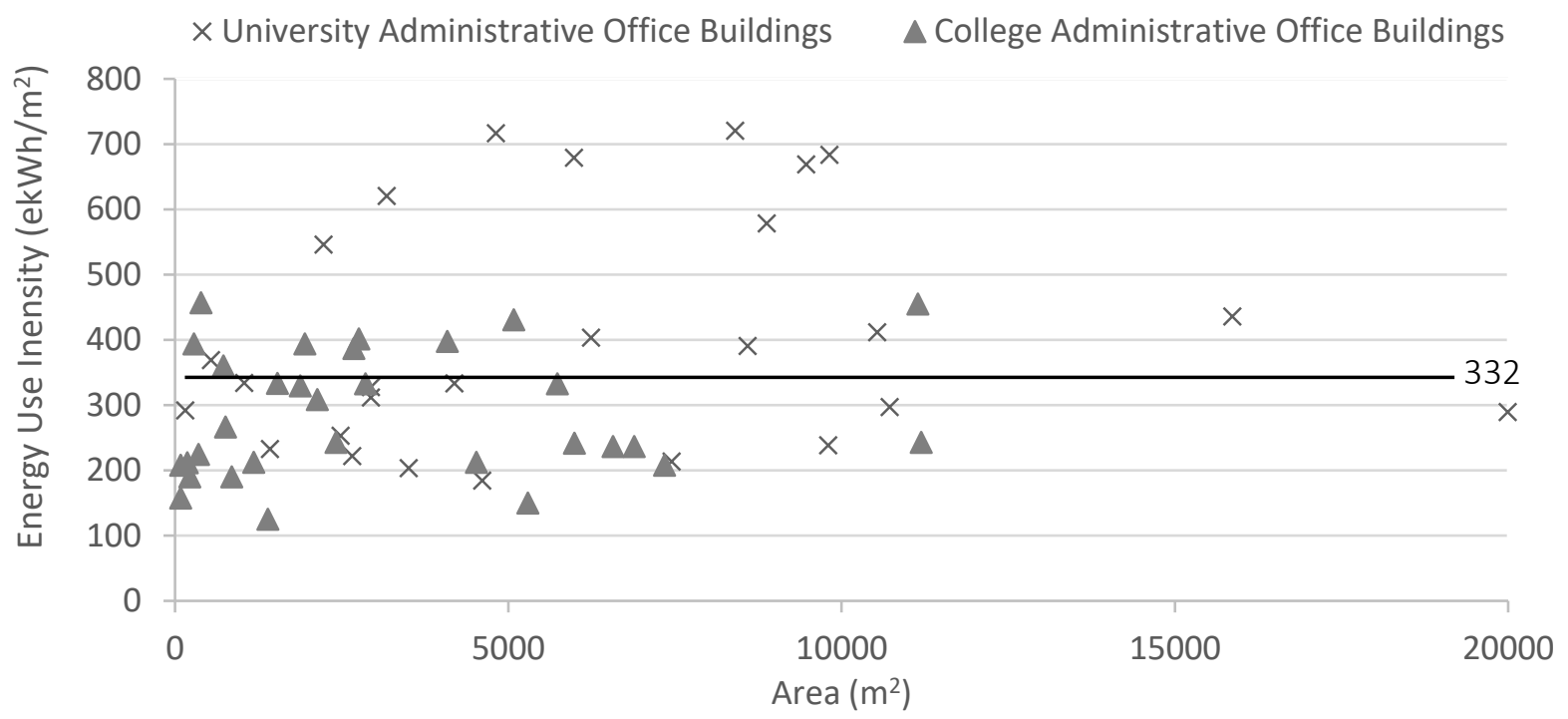

Figure 18 College and university Administrative Office buildings considered in the developed benchmark

\subsubsection{College and University Benchmarking by Building Operation}

Benchmarks for other building operations, such as residences, laboratories, and recreational facilities were subjected to the same analysis; the results are presented below in Figure 19. A summary of each analyzed building operation can be found in Appendix A.

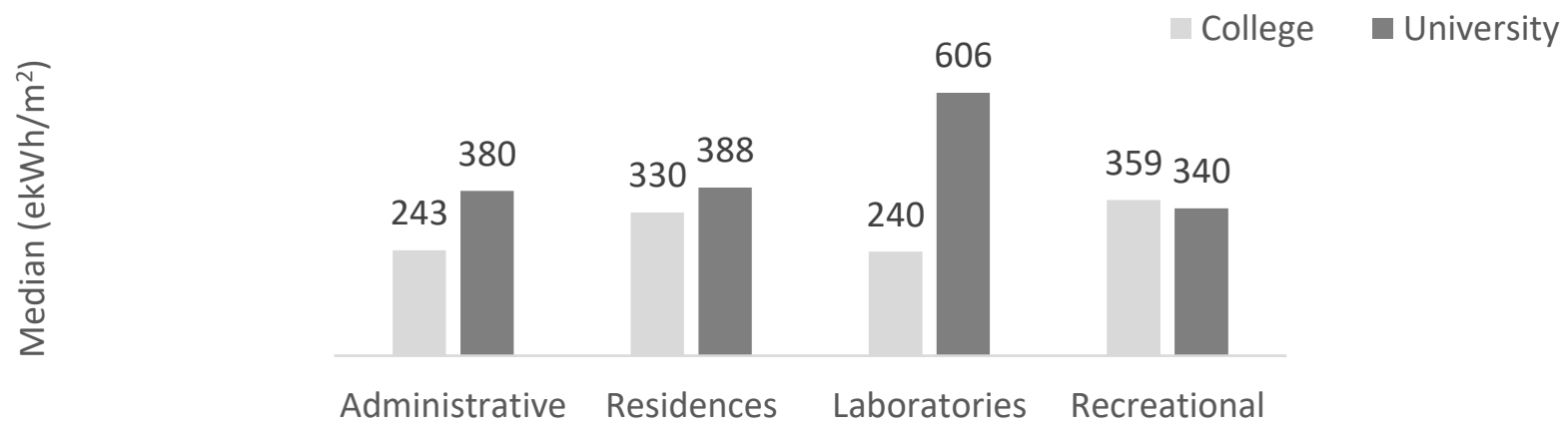

Figure 19. Developed Energy Benchmarks for College and University building operations 
Figure 20 presents the comparison of developed MER benchmarks to the Energy Star Portfolio Manager benchmark for Canadian Laboratories and SCIEU benchmarks for Great Lakes offices, lodgings and recreational buildings.

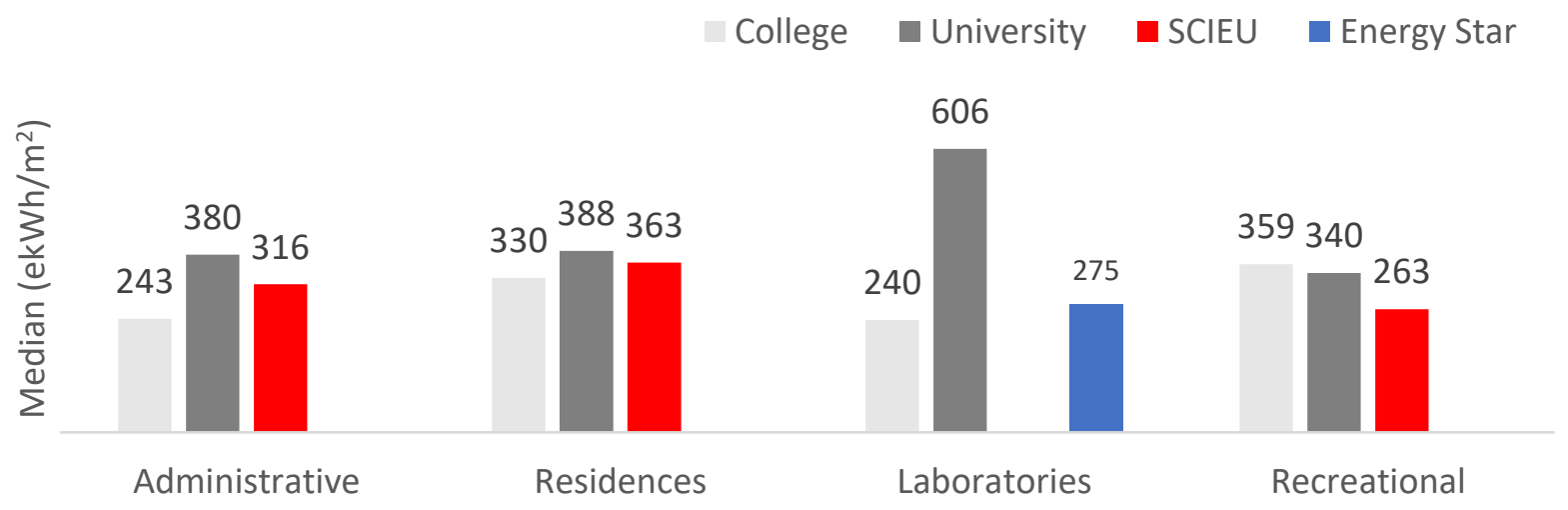

Figure 20. Developed MER Benchmarks of Administrative, Residence, and Recreational facilities are compared to SCIEU Energy Star Portfolio Manager Laboratory benchmark is compared to MER laboratories

As seen in Figure 20, student residences and recreational facilities vary the least in EUI between colleges and universities and can be represented with a single college/university benchmark, while post-secondary laboratories would require different benchmarks or reference models to represent each of colleges and universities. Additionally, SCIEU benchmarks were most similar to those developed for residence and administrative office operations. Because a reasonably consistent dataset was required to test the Wireframe and Reference methods to compare their results, student residences were selected for investigation. 


\section{Building Classification and Characterization}

In order to compare the Wireframe and Reference methods, it was necessary to develop a consistent set of template inputs (i.e. a preliminary reference model) to simulate those buildings whose reported data could be used for model validation and error analysis. Based on the investigation discussed in Section 4, student residences were the simplest dataset to consider. These buildings considered are easily categorized by size (Lowrise, Midrise, Highrise) and vintage (pre-1980 and post-1980), resulting in six building categories (Figure 21). These classes are consistent with the approach used in [26, 27, 28,29] and are assumed to capture major variations across student residence buildings in Southern Ontario and used as the basis for energy predictions and formed the set of reference models necessary for this analysis.

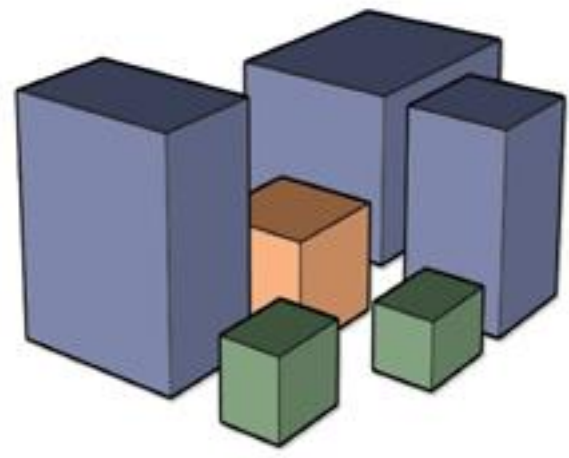

Student Residences

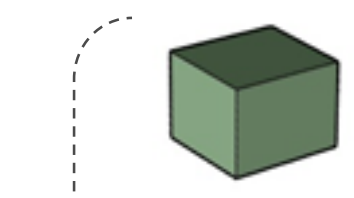

Lowrise

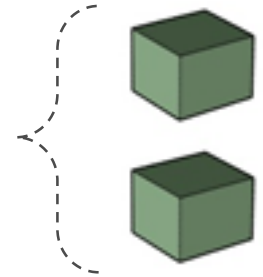

Pre-1980 (n=4)

Post $1980(n=8)$
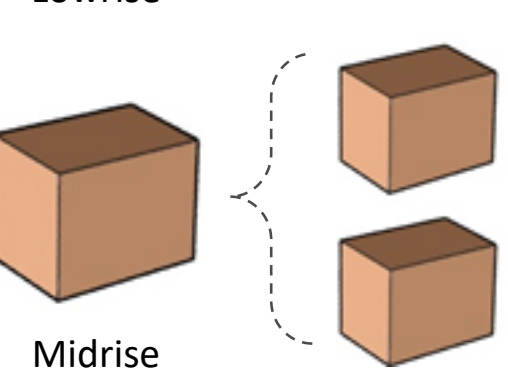

Pre-1980 $(n=0)$

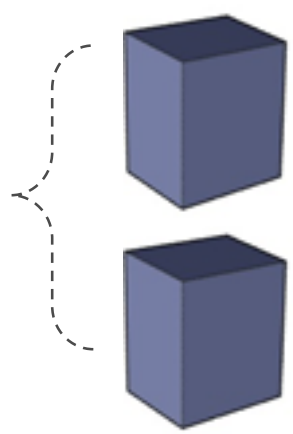

Midrise

Post $1980(n=6)$

Pre-1980 $(n=8)$

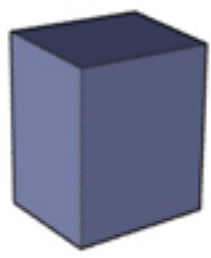

Highrise

Post $1980(n=1)$

Figure 21. Student residence segmentation using building size and vintage as variables. The number of buildings in the master dataset within each category are indicated in parentheses. 


\subsection{Cleaning of Data Sets}

To ensure that energy simulation results would not be skewed by the presence of outliers, Tukey's equations, as described in Section 3.1, were used to identify and remove atypical buildings from each category. These buildings are described below to provide insight on the rational for the exclusion of each.

Post-1980 Lowrise category: Four student residences were removed from the original post-1980 Lowrise dataset. The Lambton Inn Residence was eliminated because it was not purely a residence, containing significant areas for other uses (classrooms, administrative, etc.), which cannot be accurately represented with a student residence characterization template. Quarryview Residence was first identified as an energy outlier using Tukey's equations (Eq. 1-3) due to its EUI being suspiciously low. After the building was inspected, it was determined that it should be removed as it was the only building that looked like a townhouse complex in the dataset (Figure 22) Passy Gardens was removed as this residence is a complex that contains nine buildings and is thus inconsistent with the defined typology. Finally, Calumet Residence was removed as its area is much lower $\left(5271 \mathrm{~m}^{2}\right)$ than the rest of the residences part of this sample $\left(7218 \mathrm{~m}^{2}, 9290 \mathrm{~m}^{2}, 10\right.$ $796 \mathrm{~m}^{2}$, and $\left.11166 \mathrm{~m}^{2}\right)$.
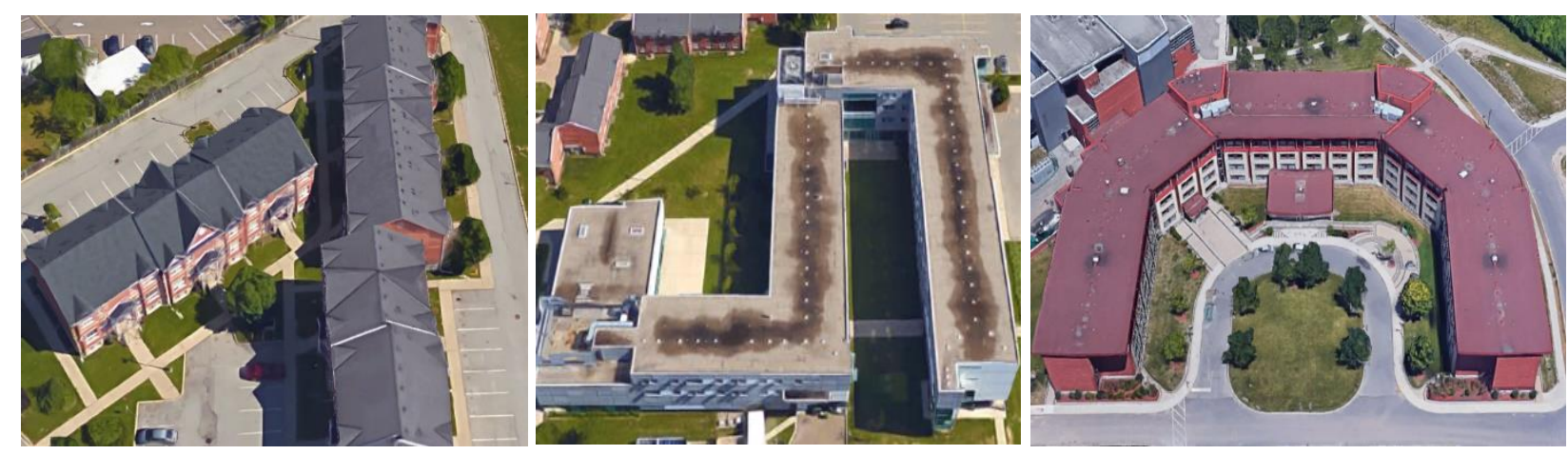

Figure 22. Quarryview residence (left) was removed due to its typology difference and resultant low EUI compared with the remaining post-1980 Lowrise dataset

Post-1980 Midrise category: Progress Student Residence was removed from the original post1980 Midrise dataset. This building was identified as an outlier using Tukey's equations (Eq. 1-3) due to its suspiciously high EUI. After close examination, it was determined that some of its conditioned area was designated for Laboratory use, preventing its inclusion in the residences 
dataset North 2 Residence was removed as its area is much lower $\left(6166 \mathrm{~m}^{2}\right)$ than the rest of the residences part of this sample $\left(11762 \mathrm{~m}^{2}, 12152 \mathrm{~m}^{2}, 13702 \mathrm{~m}^{2}\right.$, and $\left.16279 \mathrm{~m}^{2}\right)$.

Post-1980 Highrise category: The post-1980 Highrise dataset only included one building; therefore, this dataset was not used to evaluate the prediction methods.

After the inspection of student residences was finalized, the initial dataset decreased from 27 to 21 buildings, categorized into four groups: pre-1980 Lowrise, post-1980 Lowrise, post-1980 Midrise and pre-1980 Highrise. The energy benchmarks and average descriptors of each of these student residence categories can be seen in Table 15.

Table 15. Samples derived from the classification process with average descriptors. Note that the post-1980 Lowrise category has the largest standard deviation as one of its buildings was identified as an outlier but not removed.

\begin{tabular}{cccccccc}
\hline Category & $\mathrm{n}$ & ekWh/m & S. dev & Floors & Height & Area & WWR \\
\hline Pre-1980 Lowrise & 4 & 397 & $3 \%$ & 4 & $13 \mathrm{~m}$ & $6053 \mathrm{~m}^{2}$ & $30 \%$ \\
Post1980 Lowrise & 4 & 339 & $12 \%$ & 4 & $13 \mathrm{~m}$ & $9618 \mathrm{~m}^{2}$ & $30 \%$ \\
Post1980 Midrise & 4 & 312 & $19 \%$ & 7 & $21 \mathrm{~m}$ & $13474 \mathrm{~m}^{2}$ & $30 \%$ \\
Pre-1980 Highrise & 8 & 388 & $17 \%$ & 15 & $43 \mathrm{~m}$ & $8396 \mathrm{~m}^{2}$ & $30 \%$ \\
\hline
\end{tabular}

With the classification process complete, the next step for predicting aggregate consumption was the characterization of reference templates capable of representing each category (dataset) of buildings, which required a complete set of thermal properties and building systems to be defined for each. The following section summarizes characterization templates defined for classified datasets. 


\subsection{Building Stock Characterization}

To simulate the consumption using the Wireframe and Reference methods, it was necessary to define characterization templates (sets of inputs that represent a type of buildings) for each of the four categories presented in Section 5.1. Collected building characteristics were averaged for each student residence category and compared to U.S. DOE commercial reference models. For review were those DOE models that were built to represent existing buildings in climates like that of Toronto, and that have a similar vintage and operation to that of student residences. The results determined that DOE Small Hotel and Midrise Apartment reference models were most characteristically similar to buildings part of the Lowrise student residence categories, while DOE Large Hotel and Highrise Apartment models were most similar to buildings part of the Midrise and Highrise residence categories. These DOE lodging and apartment models were chosen for review as the models have a similar use to student residences, while also having similar conditioned floor areas. All DOE models (except the Highrise Apartment) were developed to represent pre-1980 and post-1980 existing buildings. DOE refers to these models as reference building models and they are used to represent the consumption of existing buildings. As only the Large Hotel reference model is comparable to Midrise and Highrise residences, a Highrise Apartment prototype model was considered. The Highrise Apartment prototype represents a building that "just meets" minimum ASHRAE 2004 requirements. The DOE refers to these types of models as prototype building models and they are used to measure improvements in the building code. Figure 23 presents the 3D geometries of reviewed DOE models.
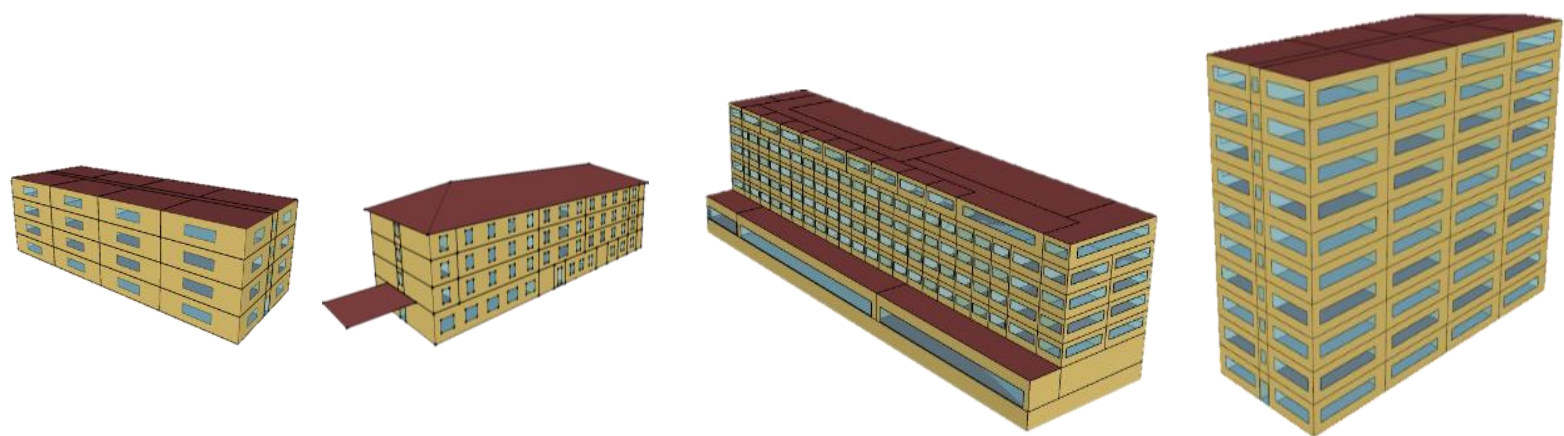

Figure 23. Building geometry and shading devices from of U.S. DOE models (from left to right): Midrise Apartment, Small Hotel, Large Hotel and Highrise Apartment

Note that the templates presented in this section are not fully representative of student residences as no building audit data or survey data were used in their development 


\subsection{Student Residence Characterization Values}

The process for selecting the inputs for the pre-1980 Lowrise residence models is explained in detail in this section; several values are consistent across the remaining three categories, and these along with key differences will be discussed in Section 5.4. The full comparison of DOE model inputs and sources for each of the four classified residence categories may be found in Appendix B.

Based on the lodging industry practice, hotel guest rooms maintain a $21^{\circ} \mathrm{C}$ setpoint for both heating and cooling year around [59]. As student rooms predominate in student residence building, it was decided that the models would maintain $21^{\circ} \mathrm{C}$ for cooling and $21^{\circ} \mathrm{C}$ for heating year around. Additionally, a floor-to-floor height of 3m, a 30\% glazing ratio and a "perimeter/core" offset of $3 \mathrm{~m}$ have been set for all templates.

5.3.1 Form inputs: pre-1980 Lowrise residence models

The aspect ratio of the U.S. DOE Small Hotel model and the average area derived from the pre-1980 Lowrise residence sample were used to represent the Reference method model, while the Wireframe method models use real building area footprints and heights to represent the form of student residence buildings. The aspect ratio of the Small Hotel was selected as its shape was more representative of student residences in the pre-1980 Lowrise category. Form characterization inputs defined for the pre-1980 Lowrise category can be seen in Table 16.

Table 16. Pre1980 Lowrise Form characterization inputs

\begin{tabular}{ccc}
\hline Characterization inputs & Reference method & Wireframe method \\
\hline Total conditioned area & $6053 \mathrm{~m}^{2 *}$ & GIS defined \\
Number of floors & 4 & GIS defined \\
Building height & $12 \mathrm{~m}$ & GIS defined \\
Aspect Ratio & 3 & GIS defined \\
Window to wall ratio & $30 \%$ & $30 \%$ \\
Shading & None & None \\
Floor to floor height & $3 \mathrm{~m}$ & $3 \mathrm{~m}$ \\
Building shape & Rectangle & GIS defined
\end{tabular}

*Value used to determine the building EUI, which is multiplied by the actual building area to estimate the energy use 
5.3.2 Fabric inputs: pre-1980 Lowrise residence models

Between the selected U.S. DOE models, the construction assemblies with the most significant differences were the exterior roof, the ceiling, and the interior floor. The Small Hotel has an unconditioned insulated attic space while the Midrise Apartment has an Insulated Entirely Above Deck (IEAD) roof type. This variation does not affect the thermal performance of the assembly as the presented resistivity values are identical for both models. As most pre-1980 Lowrise residences in the sample seem to have a flat roof (Figure 24) the IEAD construction assembly was used to characterize the exterior roof of pre-1980 Lowrise residences.
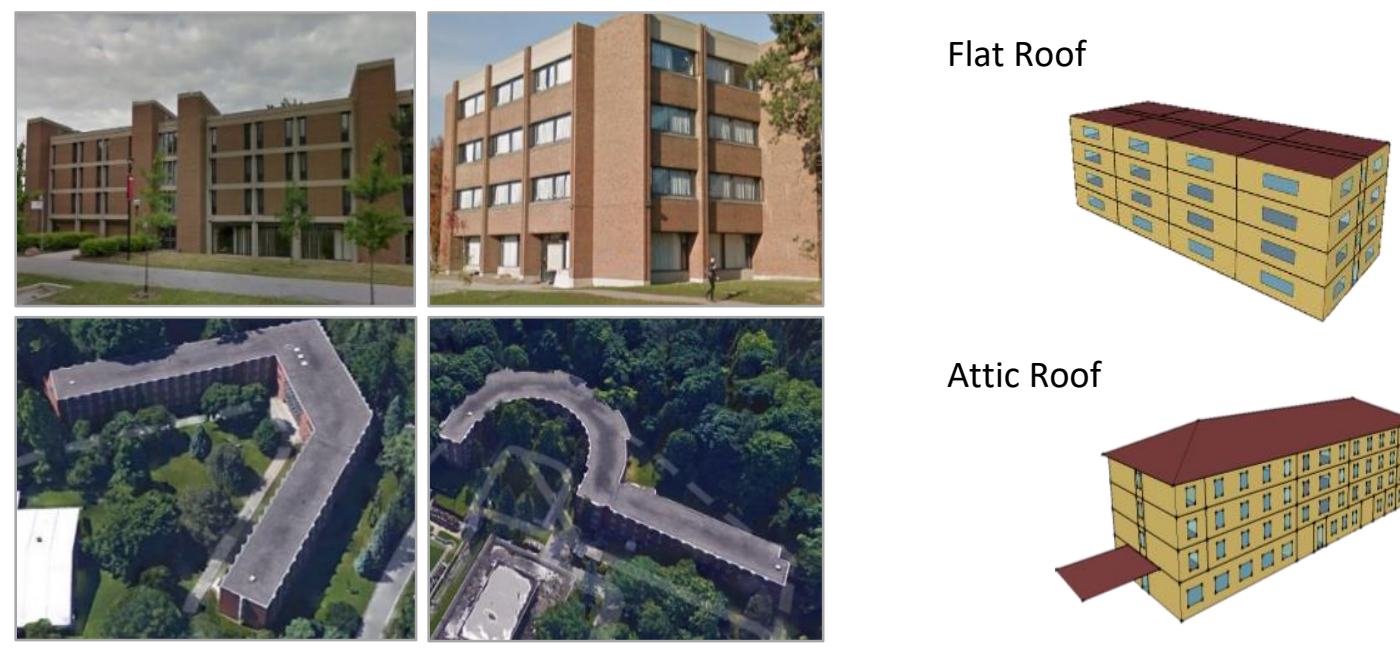

Attic Roof

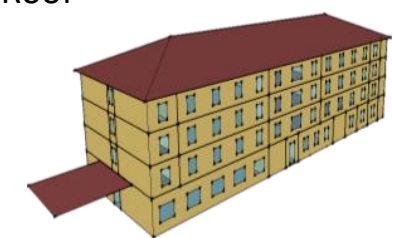

Figure 24. Pre1980 Lowrise Residence buildings showing typical flat roof condition

The Midrise Apartment model considers the outermost layer of its ceilings and interior floors to be adiabatic, therefore, there is no heat transfer happening between the levels of the building. This assumption is inappropriate, as adiabatic conditions are a simplifying assumption rather than a real condition and contradict observed heat transfer between floors. The ceiling and interior floor assemblies from the Small Hotel model were thus used to characterize the same assemblies of the pre-1980 Lowrise residence models. The internal mass properties of the Small Hotel and Midrise models are identical and were therefore used without modification to characterize the internal mass of the pre-1980 Lowrise models. An internal mass is used to specify material parameters and area of items within a space that are important to heat transfer calculations (i.e. furniture within a space). A summary of fabric inputs selected for pre-1980 Lowrise residence buildings can be seen in Table 17. 
Table 17. Pre-1980 Lowrise Residence Fabric characterization inputs for both, the Reference and Wireframe models

\begin{tabular}{ccc}
\hline Characterization inputs & Assembly name & Assembly details \\
\hline Ground floor slab & ext-slab-mass & $1.22 \mathrm{~m}^{2 *} \mathrm{~K} / \mathrm{W}$ \\
Exterior roof & Typical IEAD Roof R-16.67 & $2.99 \mathrm{~m}^{2 *} \mathrm{~K} / \mathrm{W}$ \\
Exterior wall & Insulated Steel Framed Exterior Wall R-6.9 & $1.22 \mathrm{~m}^{2 *} \mathrm{~K} / \mathrm{W}$ \\
Ceiling & Typical Interior Ceiling & - \\
Interior walls & Typical Interior Wall & - \\
Interior floor & Typical Interior Floor & - \\
Internal mass & Interior Furnishings & 3.53 W/m \\
Glazing & U-Factor & 0.41 \\
Air tightness & SHGC & 0.32 \\
\hline
\end{tabular}

The Small Hotel has a set infiltration rate of 0.95 Air Changes per Hour (ACH) while the Midrise Apartment has $0.92 \mathrm{ACH}$. Given that the infiltration rates for the Small Hotel are from previous air tightness studies performed on buildings of various operations and climates [31] while those for the Midrise Apartment are based on audits performed in New York Apartments (climate similar to Toronto) [60], the $0.92 \mathrm{ACH}$ of the Midrise model was used to characterize the infiltration rate of the pre-1980 Lowrise residence models.

\subsubsection{Program inputs: Space activity for pre-1980 Lowrise residence models}

Space activities of the Midrise Apartment model were selected to represent Lowrise residence building activities. From the review, it was determined that the Small Hotel model and Ryerson's Pitman Hall residence activities such as parking structures, gym, and food services, are less common in smaller residence buildings. Although laundry and washroom activities (seen in both buildings) are likely to be seen in Lowrise residences, inputs of the Midrise Apartment model already consider laundry and washroom loads. For this reason, Lowrise residence reference models were characterized with the activity breakdowns seen in the Midrise Apartment model (87\% apartment (student rooms), 10\% corridors and 3\% office space).

Table 18. Space activity breakdown for Lowrise residence reference models

\begin{tabular}{cc}
\hline Space activity name & Area \\
\hline Student rooms & $87 \%$ \\
Corridors & $10 \%$ \\
Office space & $3 \%$ \\
\hline
\end{tabular}


5.3.4 Program input: Occupant densities for pre-1980 Lowrise residence models

Occupant densities found in the DOE Midrise Apartment model were used to characterize the occupancy rates of Lowrise residence models. Midrise Apartment occupancy rates assume higher occupancy densities than the Small Hotel model, and therefore selected as these better represent occupancy patterns seen in student residences. In the Lowrise models, $87 \%$ of the space is designated to student room use, $10 \%$ to corridors and $3 \%$ to office space. Taking the weighted average of the occupancy density of these spaces resulted in a $32 \mathrm{~m}^{2} /$ person density (Table 19).

Table 19. Occupancy for pre-1980 Lowrise residence models

\begin{tabular}{lccc}
\hline \multicolumn{1}{c}{ Space activity } & Area (\%) & $\begin{array}{c}\text { Occupancy from DOE } \\
\text { models }\left(\mathrm{m}^{2} / \text { pax }\right)\end{array}$ & Weighted Occupancy $\left(\mathrm{m}^{2} /\right.$ pax $)$ \\
\hline Student room & 87 & 35.3 & 30.7 \\
Office & 3 & 44 & 1.3 \\
Corridor & 10 & 0 & 0.0 \\
\hline Weighted Average Pre-1980 Lowrise total peak occupancy density & 32 \\
\hline
\end{tabular}

5.3.5 Program input: Ventilation rates for pre-1980 Lowrise residence models

The Small Hotel and Midrise Apartment reference models assume that all vintages meet ventilation requirements of Standard 62-2001. This assumption was set by DOE model developers as there were no reliable data for older buildings at the time of the models' development. Ventilation rates found in the DOE Midrise Apartment model were used to characterize ventilation requirements of the Lowrise residence models as these were assumed to better represent the space activities seen in pre-1980 Lowrise residence models. Taking the weighted average of the ventilation requirements for each space (apartment, office, and corridor) resulted in a continuous ventilation rate calculated at $0.45 \mathrm{~L} / \mathrm{s} / \mathrm{m}^{2}$ (Table 20).

Table 20. Ventilation rates for pre-1980 Lowrise residence models

\begin{tabular}{lccc}
\hline \multicolumn{1}{c}{ Space activity } & Area (\%) & $\begin{array}{c}\text { Ventilation rate from DOE } \\
\text { models }\left(\mathrm{L} / \mathrm{s} / \mathrm{m}^{2}\right)\end{array}$ & $\begin{array}{c}\text { Weighted Ventilation rate } \\
\left(\mathrm{L} / \mathrm{s} / \mathrm{m}^{2}\right)\end{array}$ \\
\hline Student dormitory & 87 & 0.48 & 0.42 \\
Office & 3 & 0.23 & 0.01 \\
Corridor & 10 & 0.25 & 0.03 \\
\hline Weighted Average Pre-1980 Lowrise total ventilation rate & 0.45 \\
\hline
\end{tabular}


5.3.6 Program input: Lighting loads for pre-1980 Lowrise residence model

Lighting loads for pre-1980 Lowrise student residence models are based on activities seen in both the Small-hotel and Midrise Apartment models. The Small Hotel guest room and Midrise apartment lighting power densities were added and averaged out, resulting in $11.29 \mathrm{~W} / \mathrm{m}^{2}$ loads. This value was used to represent student room loads, while office and corridor loads were the same for both Midrise and Small Hotel models. Taking the weighted average of selected lighting power densities (LPD) resulted in a calculated load $11.40 \mathrm{~W} / \mathrm{m}^{2}$ (Table 21).

Table 21. Lighting rates for pre-1980 Lowrise residence models

\begin{tabular}{lccc}
\hline \multicolumn{1}{c}{ Space activity } & Area (\%) & $\begin{array}{c}\text { LPD from DOE models } \\
\left(\mathrm{W} / \mathrm{m}^{2}\right)\end{array}$ & Weighted LPD $\left(\mathrm{W} / \mathrm{m}^{2}\right)$ \\
\hline Student dormitory & 87 & 11.29 & 9.82 \\
Office & 3 & 22 & 0.66 \\
Corridor & 10 & 9.2 & 0.92 \\
\hline Weighted Average Pre-1980 Lowrise total lighting power density & 11.40 \\
\hline
\end{tabular}

5.3.7 Program input: Plug and process loads for pre-1980 Lowrise residence model

Plug and process loads for pre-1980 Lowrise student residence models are based on activities seen in both the Small-hotel and Midrise Apartment models. The Small Hotel guest room and Midrise apartment space plug load densities were added and averaged out, resulting in 9.85 $\mathrm{W} / \mathrm{m}^{2}$ loads. This value was used to represent student room loads, while office and corridor loads had the same values in both Midrise and Small Hotel models. Taking the weighted average of selected plug load densities and adding a daily elevator load of $0.07 \mathrm{~W} / \mathrm{m}^{2}$ resulted in a calculated peak plug load density of $9 \mathrm{~W} / \mathrm{m}^{2}$ (Table 22).

Table 22. Plug and process loads for pre-1980 Lowrise residence models

\begin{tabular}{lccc}
\hline \multicolumn{1}{c}{ Space activity } & Area (\%) & $\begin{array}{c}\text { Plug load from DOE } \\
\text { models }\left(\mathrm{W} / \mathrm{m}^{2}\right)\end{array}$ & Weighted Plug load $\left(\mathrm{W} / \mathrm{m}^{2}\right)$ \\
\hline Student dormitory & $87 \%$ & 9.85 & 8.57 \\
Office & $3 \%$ & 12.9 & 0.39 \\
Corridor & $10 \%$ & 0 & 0.00 \\
\hdashline Weighted Average Pre-1980 Lowrise total plug load $\left(\mathrm{W} / \mathrm{m}^{2}\right)$ & 9 \\
\hline
\end{tabular}

Electricity consumption of the elevators used in Low-rise residence models are based on a study by Sachs [61]. The study demonstrates that Low-rise hydraulic elevators doing 100,000 door 
openings consume $1,900 \mathrm{kWh}$ per year. Sachs results were used to characterize Lodging Commercial reference models [59] and all student residence models.

5.3.8 Program input: Water system rates for pre-1980 Lowrise residence model

Hot water usage is modelled based on a defined peak hot water flow rate and hot water usage schedules. The peak hot water flow rates for DOE reference models were calculated using “typical" daily water usage rates. The Small Hotel guest room space activity has a typical hot water use of $53 \mathrm{~L} /$ day as described in the 2007 ASHRAE Handbook: HVAC Applications [62]. The Small Hotel model has a gas-fired storage water heater with a hot water recirculation loop to provide hot water to guest rooms and laundry space types. This assumption is based on 2003 CBECS data, which shows that the most typical fuel for service hot water in hotels with less than 80 rooms is natural gas [59]. Domestic hot water rates (DHW) for the Midrise Apartment model represent the use of showers, baths, sinks, dishwasher, and clothes washer. The average daily water consumption of each DHW use of the model is based on Building America equations. DHW usage for the clothes washer and dryer are based on studies by NREL while showers, baths, and sinks are based on the average of three domestic hot water studies [63].

Water system rates selected for pre-1980 Lowrise models (Table 23) are based on rates of the Small Hotel, which are higher than the Midrise Apartment rates. The larger water system rate was chosen to consider inefficient water systems which are more likely to be seen in older buildings. It was later decided to use a higher rate $\left(0.19 \mathrm{~L} / \mathrm{h} / \mathrm{m}^{2}\right)$ as models were underpredicting water system loads.

Table 23. Water system rates for pre-1980 Lowrise residence models

\begin{tabular}{lccc}
\hline \multicolumn{1}{c}{ Space activity } & Area (\%) & $\begin{array}{c}\text { Water system load from } \\
\text { DOE models }\left(\mathrm{L} / \mathrm{h} / \mathrm{m}^{2}\right)\end{array}$ & $\begin{array}{c}\text { Weighted Water system Load } \\
\left(\mathrm{L} / \mathrm{h} / \mathrm{m}^{2}\right)\end{array}$ \\
\hline Student dormitory & $87 \%$ & 0.20 & 0.17 \\
Office & $3 \%$ & 0 & 0.00 \\
Corridor & $10 \%$ & 0 & 0.00 \\
\hdashline Weighted Average Pre-1980 Lowrise total water system rate & 0.17 \\
\hline
\end{tabular}

5.3.9 Equipment input: HVAC system characteristics for pre-1980 Lowrise residence model

The Small Hotel has a COP 3.4 for cooling and 0.8 for heating [59]. The Midrise Apartment model specifies a 0.8 efficiency for gas furnaces and a COP of 3.4 for cooling [63] Equipment 
COP for pre-1980 Lowrise models was set as 0.8 for heating, and 3.4 for cooling as both DOE modes had these efficiencies. No economizer or natural ventilation was defined for the models.

\subsection{Additional Template Development}

The remaining three templates were developed following a similar approach to that presented for the pre-1980 Lowrise. All Lowrise residence templates consistently use an aspect ratio of 3 (based on the Midrise Apartment), while the Midrise and Highrise residences use an aspect ratio of 3.9. The 3.9 aspect ratio represents the average ratio of the Large Hotel and Highrise Apartment DOE models.

As mentioned above, the infiltration rates for the Midrise Apartment are based on audits performed in New York Apartments and were therefore selected to characterize the rates of pre1980 Lowrise residences. As the infiltration rates of the Midrise Apartment did not vary with vintage, the same $0.92 \mathrm{ACH}$ of the pre-1980 Lowrise models is specified for post-1980 Lowrise models. The infiltration rate of $0.60 \mathrm{ACH}$ from the Large Hotel model was used for both Midrise and Highrise models. The infiltration rate of the Highrise Apartment was not considered as this DOE model was built to meet minimum 2004 ASHRAE requirements and most student residences studied in this thesis were built prior to 2004.

According to reviewed DOE model inputs, construction assemblies vary based on the model type (i.e. Midrise Apartment, Small Hotel). However, the thermal resistivity properties of the construction assemblies only vary according to a model's vintage. Although the pre-1980 Small Hotel model has a different construction assembly for exterior walls (Insulated Steel Framed Exterior Wall R-6.9) to that of the pre-1980 Large Hotel (TYPICAL INSULATED EXTERIOR MASS WALL R-6.9), their thermal efficiency remains the same. This was the case for all construction assemblies, including glazing, roof, and slabs. Therefore, all pre-1980 student residences have the same thermal resistivity values, and all post-1980 student residences have the same thermal resistivity values. As only pre-1980 thermal resistivities have been presented, below are the post-1980 Midrise construction assemblies with their thermal properties (Table 24). Note that all DOE models, regardless of their operation or vintage, had an internal mass with standard 6-inch wood properties. Therefore, the same properties were applied to the floors of all student residence models. 
Table 24. Post-1980 Midrise residence fabric inputs

\begin{tabular}{ccc}
\hline Characterization inputs & Assembly name & Assembly details \\
\hline Ground floor slab & ext-slab & $0.54 \mathrm{~m}^{2 *} \mathrm{~K} / \mathrm{W}$ \\
Exterior roof & IEAD Res Roof & $3.97 \mathrm{~m}^{2 *} \mathrm{~K} / \mathrm{W}$ \\
Exterior wall & Steel Frame Res Ext Wall & $2.48 \mathrm{~m}^{2 *} \mathrm{~K} / \mathrm{W}$ \\
Ceiling & INT-FLOOR-UNDERSIDE & - \\
Interior walls & Int-walls & - \\
Interior floor & INT-FLOOR-TOPSIDE & - \\
Internal mass & Interior Furnishings & - \\
\hline & U-Factor & $2.95 \mathrm{~W} / \mathrm{m}^{2 *} \mathrm{~K}$ \\
Glazing system & SHGC & 0.39 \\
& Visible transmittance & 0.31 \\
\hline Air tightness & ACH@75Pa & 0.6 \\
\hline
\end{tabular}

The HVAC systems of compared DOE models vary based on model vintage, operation, and size. However, the thermal efficiency of the models does not necessarily vary. No economizer or natural ventilation was defined in DOE models nor student residences.

The following subsections highlight key differences between residence models. The resultant templates for all four categories are provided in Appendix C.

\subsubsection{Post-1980 Lowrise}

The post-1980 Lowrise template differs from the pre-1980 Lowrise in that post-1980 Midrise Apartment and Small Hotel reference models were used to inform its input values. Several input values remain the same, such as infiltration rates, aspect ratio, and space activity breakdown. The post-1980 Lowrise model has $87 \%$ of its space designated to student rooms, $10 \%$ to corridors and $3 \%$ to offices. Because space activity breakdowns are used to define internal load values, many remain the same as those specified in pre-1980 Lowrise templates. For example, the occupancy of the pre-1980 and post-1980 Small Hotel and Midrise Apartment model are based on ASHRAE 62.1-2004. Therefore, if the space activity is the same as that of pre-1980 Lowrise models, and they also use ASHRAE 62.1-2004 to define occupancy, the same value will result (32 $\left.\mathrm{m}^{2} / \mathrm{pax}\right)$. This was also the case for ventilation rates (ASHRAE 62-1999), lighting loads (ASHRAE 90.1 1989). However, to have the newer buildings be more energy efficient, rather than using the average LPD of Hotel guest rooms and Midrise apartments (as in pre-1980 Lowrise), only the lower LPD value of the two models was considered. 
Taking the weighted average of selected light load densities resulted in a calculated power density of $5 \mathrm{~W} / \mathrm{m}^{2}$ (Table 25), lower than the $11.40 \mathrm{~W} / \mathrm{m}^{2}$ specified in pre-1980 Lowrise templates.

Table 25. Lighting rates for pre-1980 Lowrise residence models

\begin{tabular}{lccc}
\hline \multicolumn{1}{c}{ Space activity } & Area (\%) & $\begin{array}{c}\text { LPD from DOE } \\
\text { models }\left(\mathrm{W} / \mathrm{m}^{2}\right)\end{array}$ & Weighted LPD $\left(\mathrm{W} / \mathrm{m}^{2}\right)$ \\
\hline Student dormitory & 87 & 3.88 & 3.38 \\
Office & 3 & 22 & 0.66 \\
Corridor & 10 & 9.2 & 0.92 \\
\hline Weighted Average Post-1980 Lowrise total lighting power density & 4.96 \\
\hline
\end{tabular}

Ventilation rates and water system rates, and process loads are the same for pre-1980 Lowrise models and post-1980 models, as shown above. Regarding the equipment of the DOE models, equipment type does vary, however, both pre-1980 and post-1980 DOE models have the same HVAC efficiencies (except the hot water system efficiency which is lower for post-1980 (0.78) models). The pre-1980 DOE hot water values come from analysis of existing buildings (Winiarski and Halverson, 2008) while the post-1980 DOE hot water values come from ASHRAE Standard 90.1 1989. Although one would expect newer buildings to be more efficient, studies suggest that post-1980 have slightly lower hot water efficiency. This could be because pre-1980 models have had system upgrades, while post-1980 have not. Therefore the 0.78 efficiency for hot water loads was specified for post-1980 Lowrise models.

\subsubsection{Post-1980 Midrise}

The post-1980 Midrise template combines the DOE 2004 Highrise Apartment and post1980 Large Hotel as these models were representative of buildings from the Midrise category (Figure 25). As discussed in Section 5.1, the 2004 Highrise Apartment prototype model was used as no other post-1980 reference model with similar operation to student residences was available.

Table 26 shows the comparison of the Large Hotel, Highrise Apartment and post-1980 Midrise Form values. As seen in this table, the Large Hotel is very similar to post-1980 Midrise residence characteristics. However, the Midrise residence is larger than both Large Hotel and Highrise Apartment DOE models. For simplicity's sake, it was decided not to include any underground walls in the 3D models. However, because basements are typical in these types of buildings, their internal loads were considered in estimating the total load of Midrise residences. 

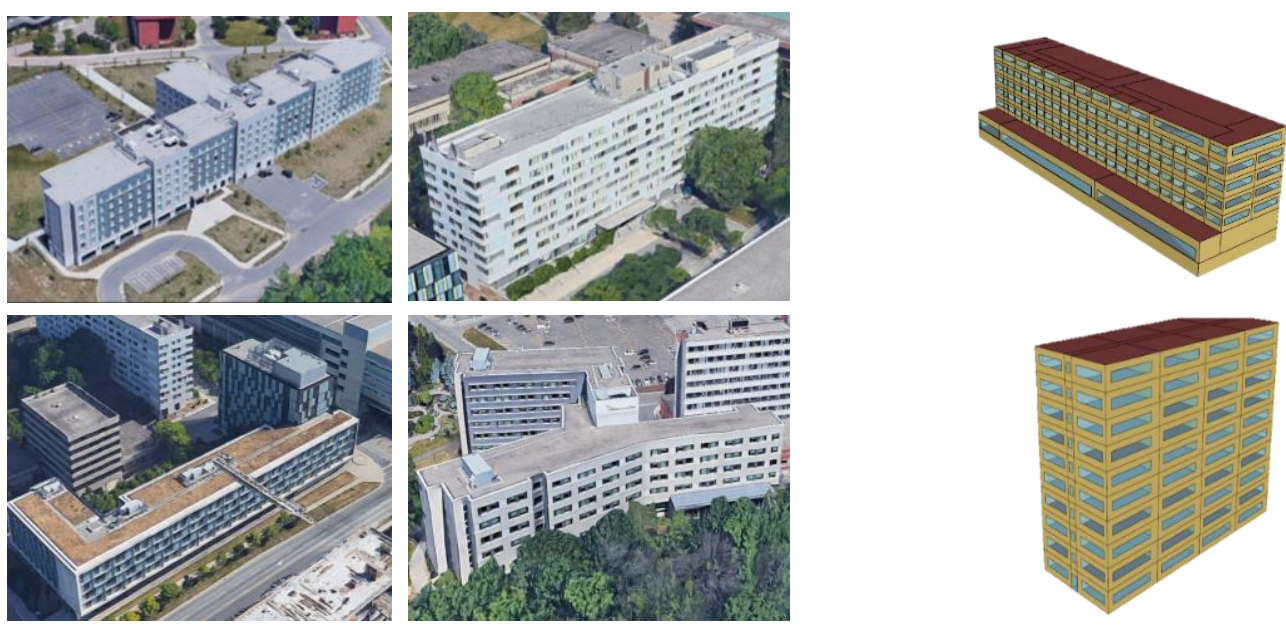

Figure 25. Post-1980 Midrise buildings compared to post-1980 Large Hotel (top) and 2004 Highrise DOE models

Table 26. Building Form comparison between DOE models and Midrise student residence values

\begin{tabular}{cccc}
\hline Building form variables & Large Hotel & Highrise Apartment & Midrise \\
\hline Vintage & Post 1980 & 2004 & Post 1980 \\
Total conditioned area & $11,345 \mathrm{~m}^{2}$ & $7836 \mathrm{~m}^{2}$ & $13474 \mathrm{~m}^{2}$ \\
Number of floors & $6+$ basement & 10 & 7 \\
Building height & $22 \mathrm{~m}$ & $30.5 \mathrm{~m}$ & $21 \mathrm{~m}$ \\
Aspect Ratio & 5.1 & 2.75 & $\mathrm{n} / \mathrm{a}$ \\
Window to wall ratio & $30 \%$ & $30 \%$ & $30 \%$ \\
Shading & None & None & None \\
Floor to floor height & $3.05 \mathrm{~m}$ & $3.05 \mathrm{~m}$ & $\mathrm{n} / \mathrm{a}$ \\
Building shape & Rectangle & Rectangle & $\mathrm{n} / \mathrm{a}$ \\
\hline
\end{tabular}

As mentioned previously, the variation of space activity in a building directly affects its energy consumption as the use given to a space influences its internal loads. Therefore, space activities between the Large Hotel and the High-rise models were compared to identify their differences (Table 27). Additionally, Pitman Hall space activities were reviewed (Table 28). All three sources were considered in the selection of space activities that represent Midrise student residences. 
Table 27. Programmatic breakdown of the Small Hotel and Mid-rise Apartment commercial reference models

\begin{tabular}{ccccc}
\hline Space activity & \multicolumn{2}{c}{ Large Hotel } & High-rise Apartment \\
\hline Basement & $1979 \mathrm{~m}^{2}$ & $17 \%$ & - & - \\
Retail & $145 \mathrm{~m}^{2}$ & $1 \%$ & - & - \\
Mechanical & $164 \mathrm{~m}^{2}$ & $1 \%$ & - & - \\
Storage & $95 \mathrm{~m}^{2}$ & $1 \%$ & - & - \\
Laundry & $78 \mathrm{~m}^{2}$ & $1 \%$ & - & - \\
Cafe & $189 \mathrm{~m}^{2}$ & $2 \%$ & - & - \\
Lobby / office & $1308 \mathrm{~m}^{2}$ & $12 \%$ & $88 \mathrm{~m}^{2}$ & $1 \%$ \\
Corridor & $1970 \mathrm{~m}^{2}$ & $17 \%$ & $776 \mathrm{~m}^{2}$ & $10 \%$ \\
Dining & $332 \mathrm{~m}^{2}$ & $3 \%$ & - & - \\
Banquet & $332 \mathrm{~m}^{2}$ & $3 \%$ & - & - \\
Kitchen & $103 \mathrm{~m}^{2}$ & $1 \%$ & - & - \\
Guest room/Apartment & $4650 \mathrm{~m}^{2}$ & $41 \%$ & $6971 \mathrm{~m}^{2}$ & $89 \%$ \\
Total building area & \multicolumn{1}{c}{$11,345 \mathrm{~m}^{2}$} & \multicolumn{2}{c}{$7836 \mathrm{~m}^{2}$} \\
\hline
\end{tabular}

Table 28. Pitman Hall space activity breakdown

\begin{tabular}{ccc}
\hline Space activity & Area $\left(\mathrm{m}^{2}\right)$ & Area $(\%)$ \\
\hline Administrative offices & 175 & $1 \%$ \\
Common use & 1251 & $6 \%$ \\
Food services & 741 & $3 \%$ \\
Residence living space & 9305 & $43 \%$ \\
Residence service space & 786 & $4 \%$ \\
Washrooms & 393 & $2 \%$ \\
Corridors & 4313 & $20 \%$ \\
Non- assignable space & 2148 & $10 \%$ \\
Parking structure & 2427 & $11 \%$ \\
Total building area & $21,538 \mathrm{~m}^{2}$ & $100 \%$ \\
\hline
\end{tabular}

Pitman Hall is much larger in size than reviewed DOE models, but many of its space activities are similar. For example, all models have administrative office spaces, living spaces, and corridors. The largest difference between DOE models is that the Highrise Apartment does not consider kitchen, banquets, or laundry space activities, which are commonly seen in student residences (Table 28). Considering this information, it was decided to define the space activity of post-1980 Midrise models as presented in Table 29. 
Table 29. Space activity breakdown for Midrise Residence reference models

\begin{tabular}{cc}
\hline Space activity & Area (\%) \\
\hline Student room & $45 \%$ \\
Corridors & $20 \%$ \\
Office space & $5 \%$ \\
Lobby & $5 \%$ \\
Kitchen & $5 \%$ \\
Banquet/Cafe & $8 \%$ \\
Basement & $10 \%$ \\
Washrooms & $2 \%$ \\
\hline
\end{tabular}

Occupancy values defined for Midrise student residences are based on values of three DOE models. Occupancy values of the Large Hotel and Highrise models are based on ASHRAE Standard 62.1-2004, therefore values do not differ significantly. Large Hotel values were used to define the Midrise occupancy of all activities except for office and washroom activities. The office activity specifications of the Large Hotel represent a front desk office/lobby, while the office space of the Highrise model represents a typical apartment complex office (more similar to that of a student residence). Therefore, the occupancy of the Highrise office activity was selected to represent the same activity in Midrise models. Although washrooms are common in most buildings, no space was assigned for this activity in the reviewed DOE models. To specify an occupancy density to the defined washroom space, the occupancy density of a DOE reference model for K-12 school washrooms was used Taking the weighted average of the occupancy density of Midrise spaces resulted in a $19 \mathrm{~m}^{2} /$ person density (Table 30).

Table 30. Occupancy density for post-1980 Midrise residence models

\begin{tabular}{cccc}
\hline Space activity & Area (\%) & $\begin{array}{c}\text { Occupancy from } \\
\text { DOE models }\left(\mathrm{m}^{2} / \text { pax }\right)\end{array}$ & Weighted Occupancy (m²/pax) \\
\hline Student dormitory & $45 \%$ & 26 & 11.7 \\
Office & $5 \%$ & 44 & 2.2 \\
Corridor & $20 \%$ & 0 & 0.0 \\
Lobby & $5 \%$ & 3 & 0.2 \\
Kitchen & $5 \%$ & 18.5 & 0.9 \\
Banquet/Cafe & $8 \%$ & 1.4 & 0.1 \\
Basement & $10 \%$ & 37.1 & 3.7 \\
Washroom & $2 \%$ & 10 & 0.2 \\
\hline Weighted Average Post-1980 Midrise total peak occupancy density & 19 \\
\hline
\end{tabular}

Like occupant densities, ventilation rates are based on the three DOE models. Ventilation rates of the Large Hotel and Highrise Apartment models are based on ASHRAE 62-1999; 
therefore, their values do not differ significantly. Large Hotel values were used to define ventilation rates of all activities except for office and washroom activities. Office and washroom ventilation rates are based on Highrise office and K-12 washroom rates respectively. Taking the weighted average of the ventilation requirements for each space resulted in an occupancy dependent ventilation rate of $0.93 \mathrm{~L} / \mathrm{s} / \mathrm{m}^{2}$. Occupancy dependent rates were selected for Midrise models as kitchen and banquet ventilation loads vary substantially with occupancy.

Lighting, process, and water system loads follow the same structure which was used for the occupancy and ventilation rates of the post-1980 Midrise models. The most noticeable difference is that to define LPD of student rooms, the apartment space of the Highrise model was used instead of the LPD of Large Hotel guest rooms. This decision was made so that the lighting load of post-1980 Midrise models was more representative of newer buildings. Regarding the process and plug load densities, a larger elevator load $(4,161 \mathrm{kWh} / \mathrm{yr})$ than that used in Lowrise residence models was used to represent elevators in Midrise models. This load is also based on Sachs elevator consumption study [59]. Selected characterization values resulted in a total peak load LPD of $9.43 \mathrm{~W} / \mathrm{m}^{2}$, a $14.6 \mathrm{~W} / \mathrm{m}^{2}$ for plug loads, and a $0.18 \mathrm{~L} / \mathrm{h} / \mathrm{m}^{2}$ for hot water consumption. Through initial simulations of post-1980 Midrise models, it was determined that peak loads should be adjusted. This resulted in a new total peak load LPD of $13 \mathrm{~W} / \mathrm{m}^{2}$, an $18 \mathrm{~W} / \mathrm{m}^{2}$ for plug loads, and a $0.2 \mathrm{~L} / \mathrm{h} / \mathrm{m}^{2}$ for hot water consumption.

Regarding the HVAC systems, a COP of 3.4 for cooling and 0.8 for heating were selected to represent post-1980 Midrise models. Although the selected COP of 3.4 is based on the 2004

Highrise Apartment efficiency (much better than the Large Hotel COP of 2.64), it was decided to apply the higher COP to Midrise models, so these would better represent newer buildings. Again, no economizer or natural ventilation was defined for the models.

\subsubsection{Pre-1980 Highrise}

The pre-1980 Highrise template was developed by combining the DOE 2004 Highrise Apartment and pre-1980 Large Hotel, as these models were representative of buildings from the Highrise category (Figure 26). The 2004 Highrise was used since no other pre-1980 reference model with similar operation to student residences was available. 

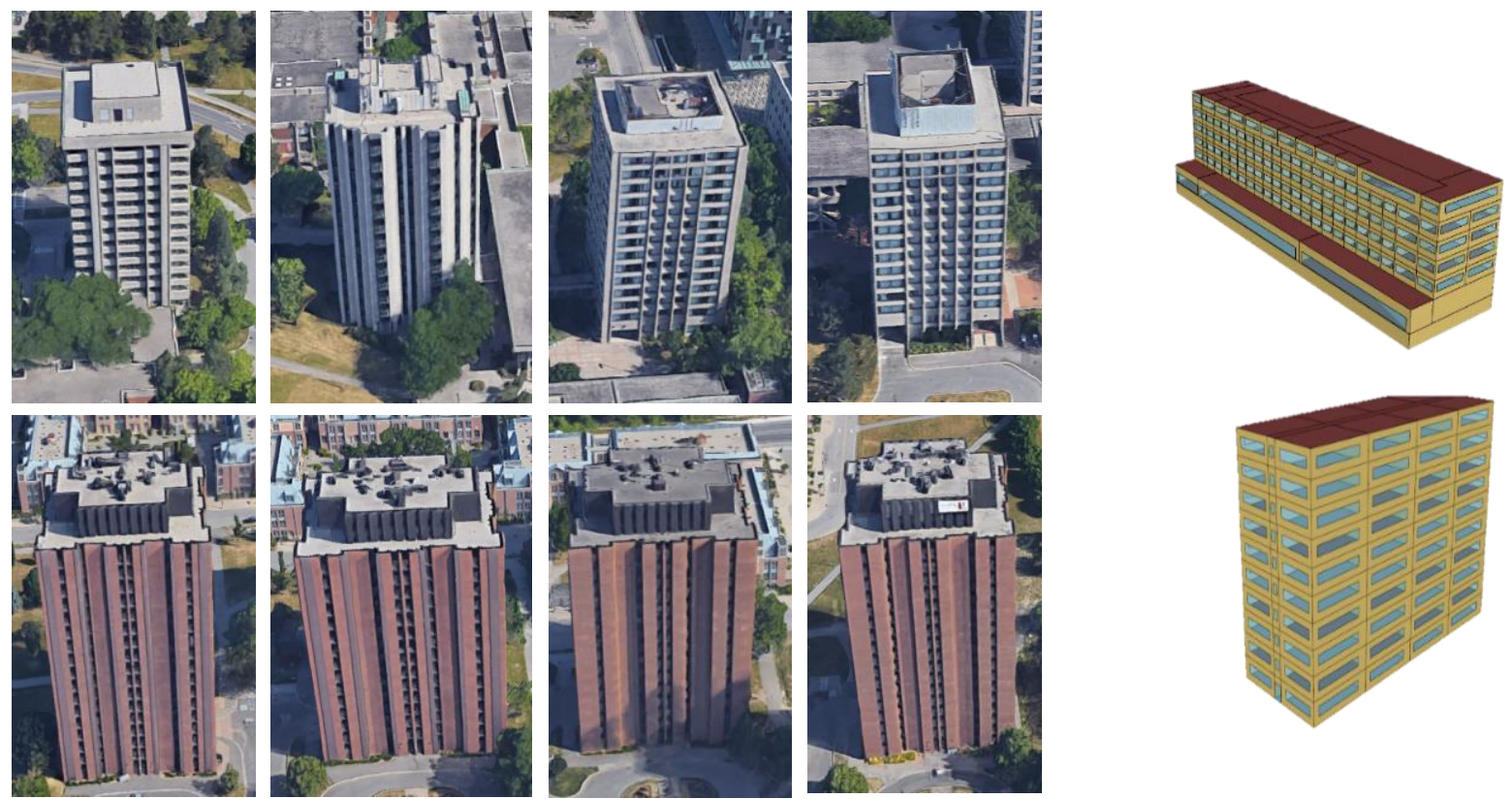

Figure 26. Pre-1980 Highrise buildings compared to pre-1980 Large Hotel (top) and 2004 Highrise DOE models

Table 31 shows the comparison of the Large Hotel, Highrise Apartment, and pre-1980 Highrise Form values. As seen in this table, the form of the Highrise Apartment is most like that of the pre-1980 Highrise student residence. For simplicity's sake, it was decided not to include any underground walls in the 3D models.

Table 31. Building form comparison between DOE models and Highrise student residence values

\begin{tabular}{cccc}
\hline Building form variables & Large Hotel & Highrise Apartment & Highrise \\
\hline Vintage & Post 1980 & 2004 & Pre 1980 \\
Total conditioned area & $11,345 \mathrm{~m}^{2}$ & $7836 \mathrm{~m}^{2}$ & $8396 \mathrm{~m}^{2}$ \\
Number of floors & $6+$ basement & 10 & 15 \\
Building height & $22 \mathrm{~m}$ & $30.5 \mathrm{~m}$ & $43 \mathrm{~m}$ \\
Aspect Ratio & 5.1 & 2.75 & $\mathrm{n} / \mathrm{a}$ \\
Window to wall ratio & $30 \%$ & $30 \%$ & $30 \%$ \\
Shading & None & None & None \\
Floor to floor height & $3.05 \mathrm{~m}$ & $3.05 \mathrm{~m}$ & $\mathrm{n} / \mathrm{a}$ \\
Building shape & Rectangle & Rectangle & $\mathrm{n} / \mathrm{a}$ \\
\hline
\end{tabular}

Space activities between Pitman Hall, the Large Hotel and the High-rise Apartment were compared to identify their differences. Although space activities and their percentages do not differ from those presented in Table 27 and Table 28, the percentage of space activities for Highrise residences are different to those used for Midrise residences. The difference simply represents the expected variation in area between Highrise and Midrise space activities. Space activities selected to represent pre-1980 Highrise buildings can be seen in Table 32. 
Table 32. Space activity breakdown for Highrise residence reference models

\begin{tabular}{cc}
\hline Space activity & Area (\%) \\
\hline Student dormitory & $50 \%$ \\
Corridors & $18 \%$ \\
Office space & $5 \%$ \\
Lobby & $2 \%$ \\
Kitchen & $3 \%$ \\
Banquet/Cafe & $10 \%$ \\
Basement & $8 \%$ \\
Washrooms & $4 \%$ \\
\hline
\end{tabular}

Occupancy densities defined for Highrise student residences are based on the same values used to represent post-1980 Midrise occupancy. Therefore, the occupancy density of the Highrise spaces resulted in the same $19 \mathrm{~m}^{2} /$ person density (Table 33 ).

Table 33. Occupancy density for post-1980 Midrise residence models

\begin{tabular}{cccc}
\hline Space activity & Area (\%) & $\begin{array}{c}\text { Occupancy from DOE } \\
\text { models }\left(\mathrm{m}^{2} / \mathrm{pax}\right)\end{array}$ & $\begin{array}{c}\text { Weighted Occupancy } \\
\left(\mathrm{m}^{2} / \text { pax }\right)\end{array}$ \\
\hline Student dormitory & $50 \%$ & 26 & 13.0 \\
Office & $5 \%$ & 44 & 2.2 \\
Corridor & $18 \%$ & 0 & 0.0 \\
Lobby & $2 \%$ & 3 & 0.1 \\
Kitchen & $3 \%$ & 18.5 & 0.6 \\
Banquet/Cafe & $10 \%$ & 1.4 & 0.1 \\
Basement & $8 \%$ & 37.1 & 3.0 \\
Washroom & $4 \%$ & 10 & 0.4 \\
\hline Weighted Average Pre-1980 Highrise total peak occupancy density & 19 \\
\hline
\end{tabular}

Ventilation rates are also based on the same sources used to represent Midrise residence rates. However, due to the percentage variation in space activities, the ventilation rate increased. The weighted average of the ventilation requirements for each space resulted in an occupancy dependent ventilation rate of $0.97 \mathrm{~L} / \mathrm{s} / \mathrm{m}^{2}$. Occupancy dependent ventilation rates were selected for Midrise models as kitchen and banquet loads vary substantially with occupancy.

Unlike ventilation and occupancy, lighting loads between the DOE models do differ as they use diverse sources to define their LPD. The pre-1980 Large Hotel lighting power densities are based on ASHRAE 90.1-1989, while the 2004 Highrise Apartment LPD are based on ASHRAE 90.1-2004. As the LPD of the Large Hotel are more representative of older buildings, these were primarily considered to represent pre-1980 Highrise residence lighting loads. The pre1980 Highrise student residence template uses lighting densities from the Large Hotel for all space 
activities except for student room, office, and washroom spaces. The lighting load of student rooms comes from the average of the Large Hotel guest room and the 2004 Highrise apartment space. The resultant student room LPD $\left(11.43 \mathrm{~W} / \mathrm{m}^{2}\right)$ better represents student residences as it assumes that some buildings have gone through lighting retrofits. The office LPD comes from the 2004 Highrise office space as it was more representative of student residences (explained in Section 5.4.2). To specify the lighting loads of the student washroom space, the LPD of DOE reference model for K-12 school washrooms was used. The weighted average of the lighting requirements for each space resulted in an LPD of $12.72 \mathrm{~W} / \mathrm{m}^{2}$. Regarding the process and plug load specifications, Large Hotel values were chosen for all spaces except for office and washroom activities. These were based on the 2004 Highrise office values and the K-12 school washroom values. An elevator load of 4,161 kWh/year was used [59], resulting in a total peak plug and process load of $14.6 \mathrm{~W} / \mathrm{m}^{2}$. Through initial simulations of pre-1980 Highrise models, it was determined that peak loads should be adjusted, resulting in a new total peak load LPD of $16 \mathrm{~W} / \mathrm{m}^{2}$ and $18 \mathrm{~W} / \mathrm{m}^{2}$ for plug loads. Regarding the HVAC systems, the efficiencies of the pre-1980 Large Hotel were considered as this model had the same vintage as the student residences. Therefore, a COP of 2.64 was chosen for cooling and 0.78 for heating No economizer or natural ventilation was defined for the models. 


\section{Student Residence Model Tuning}

The review of DOE commercial reference models resulted in the synthesis of characterization inputs that better represent Ontario student residences. In total, four baseline characterization templates were developed from selected inputs to represent pre-1980 Lowrise, post-1980 Lowrise, post-1980 Midrise and pre-1980 Highrise student residence buildings. Preliminary modeling using the Reference method (Figure 27) and baseline templates resulted in five end-use consumption values. These were normalized based on the area of the model and were compared to normalized end-use consumption values predicted with DOE reference models. If preliminary values were found to be drastically higher or lower than DOE values, models were adjusted accordingly. At this point, it is important to be aware of the intended scope of this study, which is to comprehend prediction differences between two bottom-up methods and understand why they occur. Although models were adjusted, the intention was not to make them equal to MER energy benchmarks but to ensure their end-use consumption was similar to the end-use consumption of reviewed DOE reference models. If models were adjusted according to MER benchmarks using the Reference method, it would skew the results for the Wireframe method. Therefore, models were adjusted so that the end-use consumption of the student reference models were like that of the DOE models, this to ensure that produced energy breakdowns were representative of buildings that serve as living spaces. The development of these models as reference models does not form part of this thesis but rather as future work, requiring field data studies to confirm these assumed inputs.

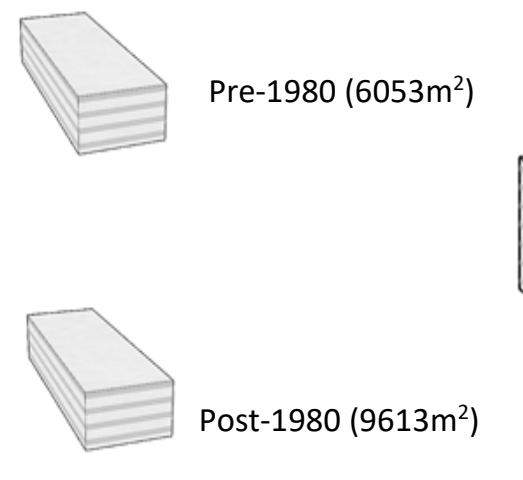

Lowrise models

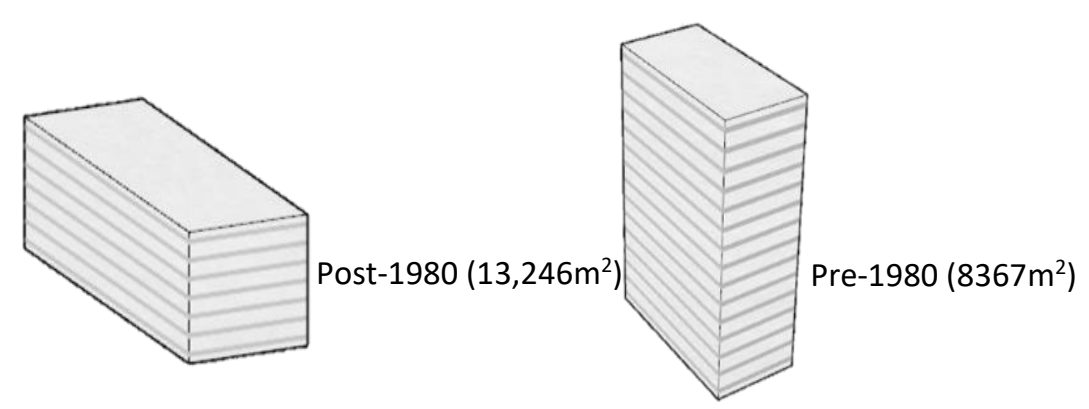

Midrise models
Highrise models

Figure 27. Visual representation of student Reference method models created with Rhinoceros and UMI 


\subsubsection{Pre-1980 Lowrise residence model adjustment}

The pre-1980 Lowrise baseline characterization template summarized in Section 5.3 was applied using the Reference method and resulted in a predicted EUI of $328 \mathrm{kWh} / \mathrm{m}^{2}$ for the pre1980 Lowrise Residence buildings. This predicted EUI is above both the calculated pre-1980 Small Hotel model EUI $\left(238 \mathrm{kWh} / \mathrm{m}^{2}\right)$ and the pre-1980 Midrise Apartment model EUI $\left(313 \mathrm{kWh} / \mathrm{m}^{2}\right)$ results. This is understandable because while the majority of inputs come from the Midrise Apartment model, the less efficient plug and lighting power densities of the Small Hotel guestrooms $\left(14.31 \mathrm{~W} / \mathrm{m}^{2}\right.$, compared with $5.38 \mathrm{~W} / \mathrm{m}^{2}$ for the Midrise Apartments) were incorporated into the pre-1980 Lowrise template, driving up the overall consumption. It is important for all new template creation to be aware of such significant differences between reference models, even for spaces of similar activity categories.

End-use EUIs of the baseline pre-1980 Lowrise, adjusted pre-1980 Lowrise, pre-1980 Small Hotel and pre-1980 Midrise Apartment models are compared in Figure 28, while the overall EUI comparison is summarized in Figure 29. By reviewing the end-use results, it was determined that the most significant difference between the baseline residence model and the DOE models regards to their hot water load, which is $8.6 \%$ and $11 \%$ lower than in the Midrise Apartment and Small Hotel models, respectively. Other end-uses are either very similar to those predicted by one of the DOE models (i.e. heating use) or fall somewhere between the predicted end-use consumption of both DOE models (i.e. equipment, lighting).

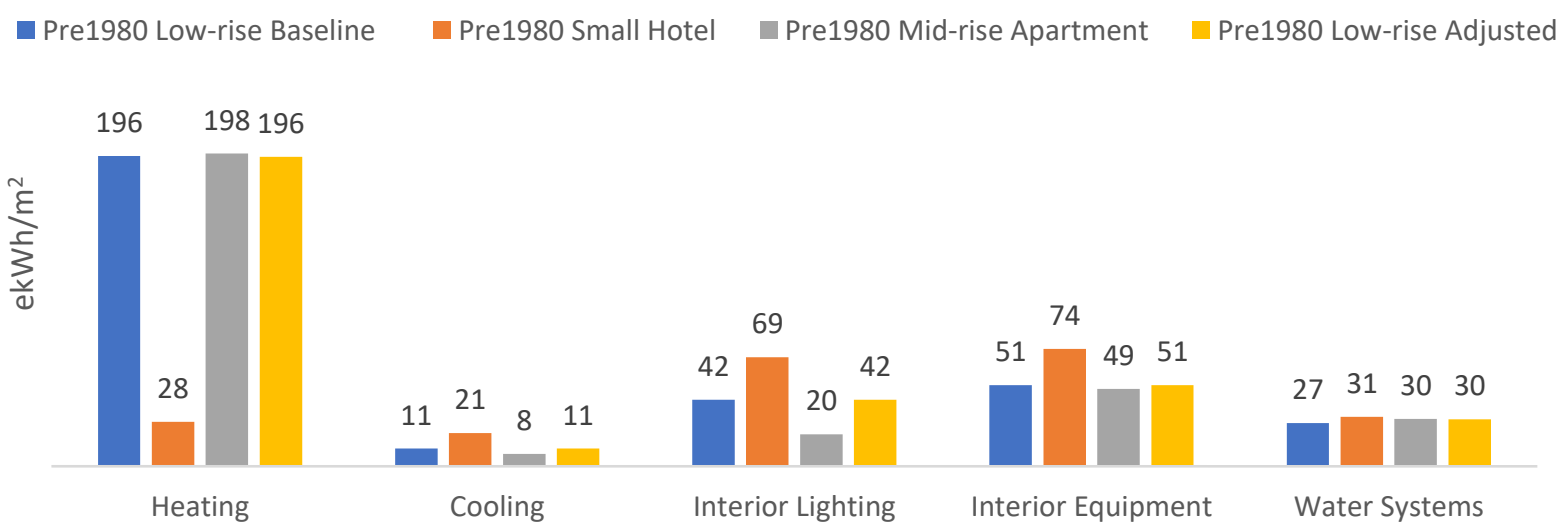

Figure 28. End-use comparison of reviewed DOE models and developed residence models. Cooling, lighting, and equipment EUls predicted with the baseline template are all between the EUI reported for the hotel and the apartment models, therefore, only the water systems end-use was adjusted. 
To ensure that pre-1980 Lowrise residences were predicting consumption with similar enduse EUIs to those seen in DOE models, the hot water use of the baseline template was increased from $0.17 \mathrm{~L} / \mathrm{h} / \mathrm{m}^{2}$ to $0.19 \mathrm{~L} / \mathrm{h} / \mathrm{m}^{2}$. This adjustment caused a $7.9 \%$ increase in water system consumption and $0.6 \%$ increase in total site consumption (Figure 29).

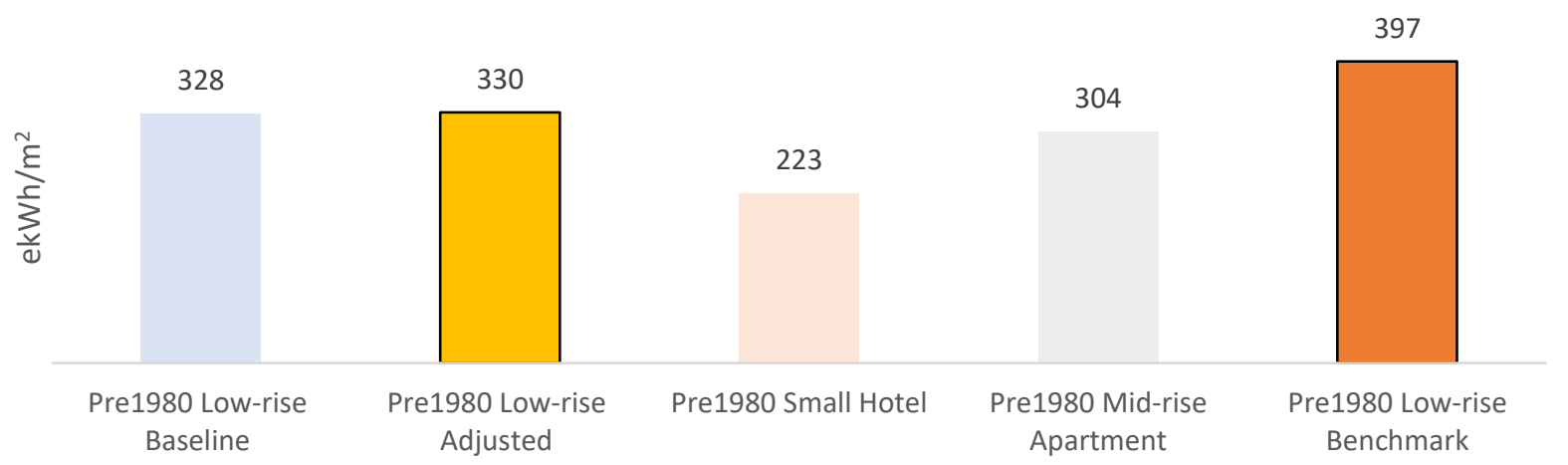

Figure 29. The predicted EUI of the adjusted pre-1980 Lowrise model is $17 \%$ lower than the EUI benchmark of the pre-1980 Lowrise dataset quantified at $397 \mathrm{ekWh} / \mathrm{m}^{2}$

Figure 30 reveals that the end-use breakdown predicted with the pre-1980 Lowrise residence model is comparable to the end-use breakdown predicted of the pre-1980 Midrise Apartment model. The discrepancy between the Small Hotel and Apartment models with regards to their heating consumption could not be determined from the analysis of the .IDF provided by DOE.

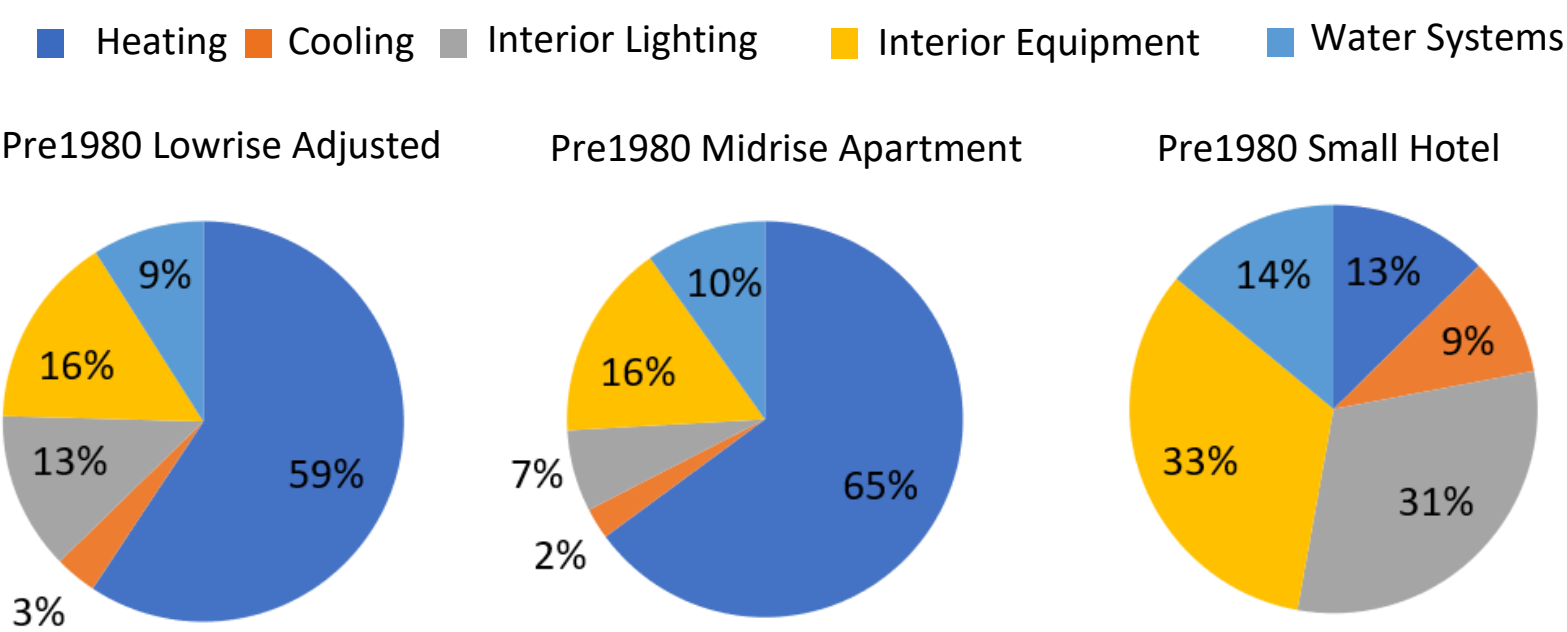

Figure 30. Differences between pre-1980 Lowrise adjusted model and the pre-1980 Midrise Apartment model are seen in heating, equipment and lighting uses 


\subsubsection{Post-1980 Lowrise residence model adjustment}

The post-1980 Lowrise baseline characterization template summarized in Section 5.3 was applied using the Reference method, resulting in a predicted EUI of $319 \mathrm{kWh} / \mathrm{m}^{2}$ for post-1980 Lowrise Residence buildings, which is above the post-1980 Small Hotel EUI $\left(269 \mathrm{kWh} / \mathrm{m}^{2}\right)$ and the post-1980 Midrise Apartment EUI $\left(275 \mathrm{kWh} / \mathrm{m}^{2}\right)$, respectively.

End-use EUIs of the baseline post-1980 Lowrise, adjusted post-1980 Lowrise, post-1980 Small Hotel and post-1980 Midrise Apartment models are compared in Figure 31, while the overall EUI comparison is summarized in Figure 32. By reviewing the end-use results, it was determined that the most variation between the baseline residence model and the DOE models regards to their heating, lighting, and equipment uses. The heating EUI of the baseline model is $213 \mathrm{kWh} / \mathrm{m}^{2}$, larger than the apartment model $\left(170 \mathrm{kWh} / \mathrm{m}^{2}\right)$ and much larger than the hotel model $\left(59 \mathrm{kWh} / \mathrm{m}^{2}\right)$. The baseline lighting EUI consumption is $20 \mathrm{kWh} / \mathrm{m}^{2}$ similar to that seen in the apartment model $\left(20 \mathrm{kWh} / \mathrm{m}^{2}\right)$ and lower than that seen in the hotel model $\left(69 \mathrm{kWh} / \mathrm{m}^{2}\right)$. The baseline equipment EUI is $51 \mathrm{kWh} / \mathrm{m}^{2}$ higher than that seen in the apartment model $\left(48 \mathrm{kWh} / \mathrm{m}^{2}\right)$ and lower than the hotel model $\left(86 \mathrm{kWh} / \mathrm{m}^{2}\right)$. Additionally, the baseline water system EUI consumption is roughly $25 \%$ lower than the water system EUI predicted by both DOE models.

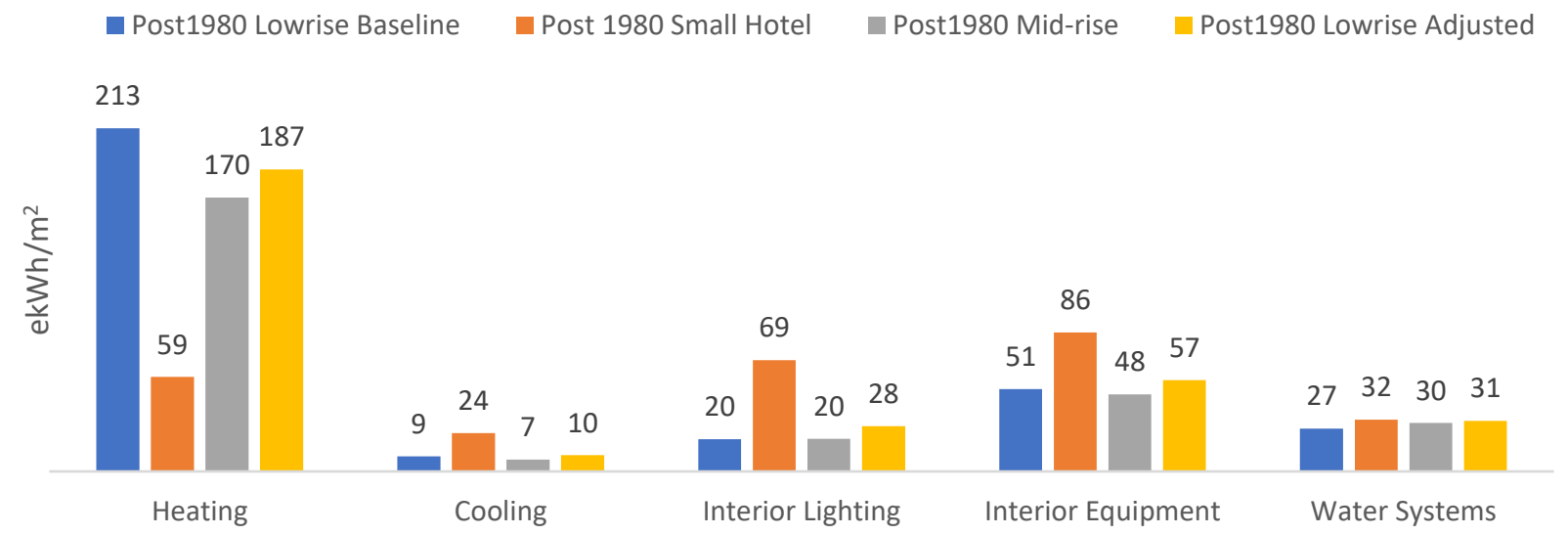

Figure 31. End-use comparison of reviewed DOE models and developed student residence models. Baseline heating EUI is larger than the heating EUI of both DOE models while water system EUIs is lower than both DOE models.

To ensure that post-1980 Lowrise residence models predicted consumption with similar end-use EUIs to those seen in DOE models, the following changes were made to the post-1980 Lowrise characterization template:

- Heating COP was increased from 0.78 to 0.83 to make the models heating more efficient 
- Lighting power density was increased from $5 \mathrm{~W} / \mathrm{m}^{2}$ to $7 \mathrm{~W} / \mathrm{m}^{2}$

- Plug load density was increased from $9 \mathrm{~W} / \mathrm{m}^{2}$ to $10 \mathrm{~W} / \mathrm{m}^{2}$

- Hot water use was increased from .17 L/h/m $/ \mathrm{m}^{2}$ to $.20 \mathrm{~L} / \mathrm{h} / \mathrm{m}^{2}$

These adjustments resulted in a $12 \%$ decrease in heating, an $8 \%$ increase in cooling, a $41 \%$ increase in lighting, a $10 \%$ increase in equipment, an $18 \%$ increase in water system use, and a $2 \%$ decrease in total site consumption (Figure 32). Although the adjustments brought the EUI of the Lowrise residence $\left(313 \mathrm{ekWh} / \mathrm{m}^{2}\right)$ further away from the developed benchmark $\left(339 \mathrm{ekWh} / \mathrm{m}^{2}\right)$ it was decided that it was more important to have the models predict end-use consumption like the DOE models as their end-uses are more reliable than arbitrary end-uses that would result in a higher model EUI.

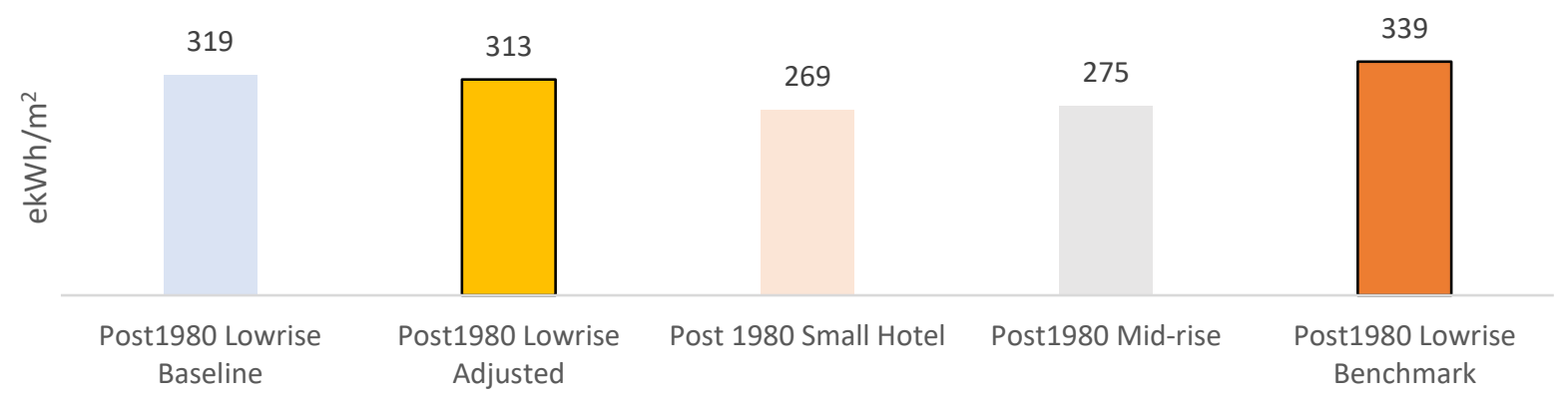

Figure 32. The predicted EUI of the adjusted post-1980 Lowrise model is $7 \%$ lower than the EUI benchmark of the post-1980 Lowrise Category quantified at $339 \mathrm{ekWh} / \mathrm{m}^{2}$

Figure 33 reveals that the end-use breakdown predicted with the post-1980 residence model is comparable to the end-use breakdown produced by the post-1980 Midrise model. The discrepancy between the Small Hotel and Apartment models with regards to their heating consumption could not be determined from the analysis of the .IDF provided by DOE.

Heating Cooling $\square$ Interior Lighting $\square$ Interior Equipment $\quad$ Water Systems
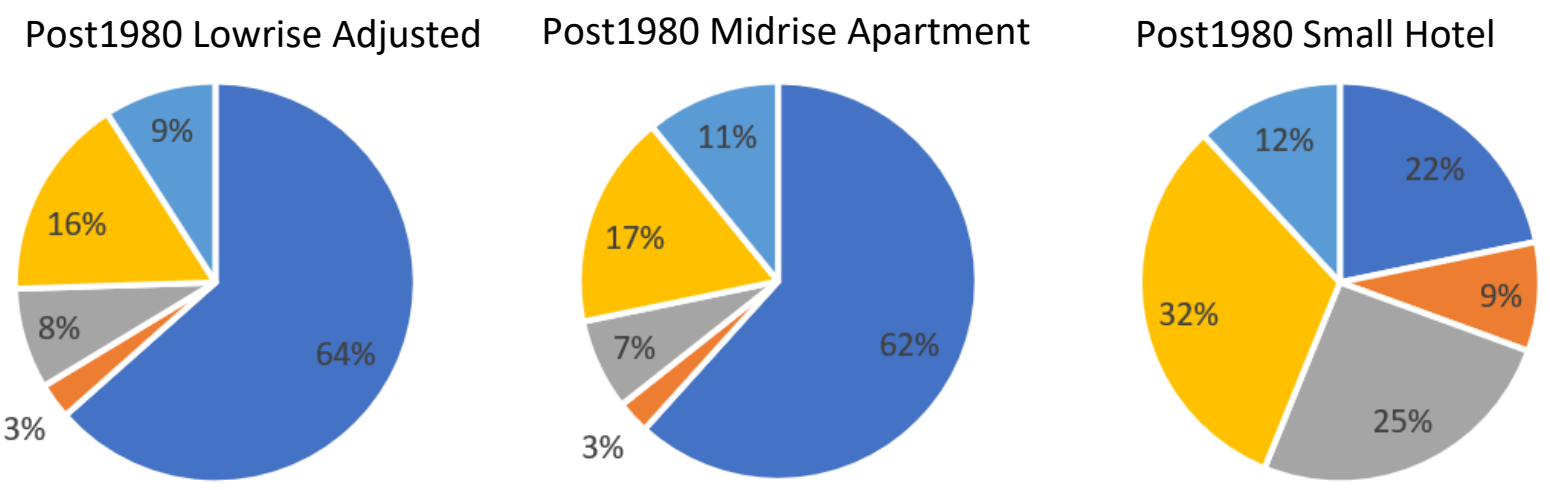

Figure 33. Adjusted post-1980 Lowrise and post-1980 Midrise Apartment end-use breakdown 


\subsubsection{Post-1980 Midrise residence model adjustment}

The post-1980 Midrise baseline characterization template summarized in Section 5.3 was applied using the Reference method, resulting in a predicted EUI of $258 \mathrm{kWh} / \mathrm{m}^{2}$ for post- 1980 Midrise Residence buildings, which falls between the post-1980 Large Hotel EUI (688kWh/m²) and the 2004 Highrise Apartment EUI $\left(226 \mathrm{kWh} / \mathrm{m}^{2}\right)$.

End-use EUIs of the baseline post-1980 Midrise, adjusted post-1980 Midrise, post-1980 Large Hotel and 2004 Highrise Apartment models are compared in Figure 34 while the overall EUI comparison is summarized in Figure 35. By reviewing the end-use results, it was determined that the most variation between the baseline residence model and the DOE models regards to their cooling, lighting, and water system uses. The cooling EUI of the baseline model is $9 \mathrm{kWh} / \mathrm{m}^{2}$, equal to the $9 \mathrm{kWh} / \mathrm{m}^{2}$ seen in the apartment model and much lower than the $213 \mathrm{kWh} / \mathrm{m}^{2}$ predicted with the hotel model. Difference in cooling EUI is partially due to the Highrise Apartment having a cooling COP of 3.4 while the Large Hotel has a cooling COP of 2.5. The Large Hotel model also has the largest equipment and lighting EUIs, which result in higher heat gains. Additionally, construction assemblies of DOE models were built to represent buildings of different time periods, resulting in different thermal efficiencies. The baseline lighting EUI consumption is $27 \mathrm{kWh} / \mathrm{m}^{2}$, lower than the $55 \mathrm{kWh} / \mathrm{m}^{2}$ predicted by the hotel model and larger than the $11 \mathrm{kWh} / \mathrm{m}^{2}$ predicted by the apartment model. The baseline water system EUI consumption is $44 \mathrm{kWh} / \mathrm{m}^{2}$, lower than the water system EUI predicted by the apartment model of $49 \mathrm{kWh} / \mathrm{m}^{2}$ and much lower than the $194 \mathrm{kWh} / \mathrm{m}^{2}$ predicted by the hotel model. In addition to this, the baseline equipment EUI is roughly $25 \%$ and $50 \%$ lower than the apartment and large hotel models respectively. The difference in cooling between the Large Hotel and Highrise models is due to different efficiency and construction assemblies when the models are compared to one another.

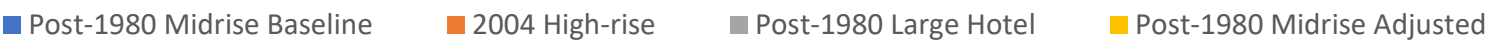

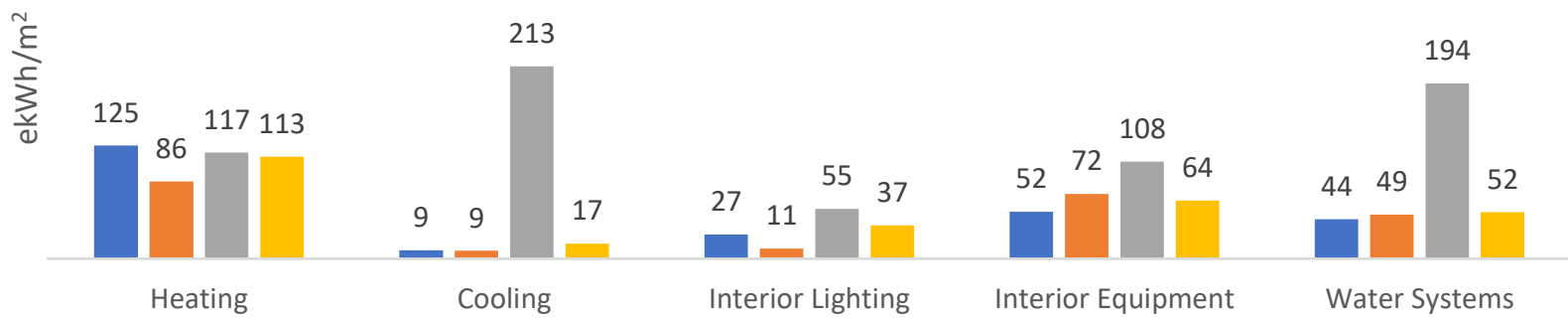

Figure 34. Comparison of the end-use EUIs predicted with reviewed DOE and developed residence models 
To ensure that post-1980 Midrise residences were predicting consumption with similar end use EUIs to those seen in DOE models, the following changes were done to the post-1980 Midrise characterization template:

- Cooling COP was decreased from 3.4 to 2.5 to match the Large Hotel COP of 2.5. The 3.4 COP is based on 2004 minimum requirements and student residences of this category have a post-1980 vintage which is better represented with the COP of the Large Hotel as it was built to represent post-1980 existing buildings.

- Lighting power density was increased from $9.43 \mathrm{~W} / \mathrm{m}^{2}$ to $13 \mathrm{~W} / \mathrm{m}^{2}$

- Plug load density was increased from $14.6 \mathrm{~W} / \mathrm{m}^{2}$ to $18 \mathrm{~W} / \mathrm{m}^{2}$

- Hot water use was increased from $.18 \mathrm{~L} / \mathrm{h} / \mathrm{m}^{2}$ to $.20 \mathrm{~L} / \mathrm{h} / \mathrm{m}^{2}$ to match the Large Hotel rate

These adjustments caused a 10\% decrease in heating EUI, a $79 \%$ increase in cooling EUI, a $38 \%$ increase in lighting EUI, a $23 \%$ increase in equipment EUI, an $18 \%$ increase in hot water EUI and an increase of $10 \%$ in total EUI (Figure 35).

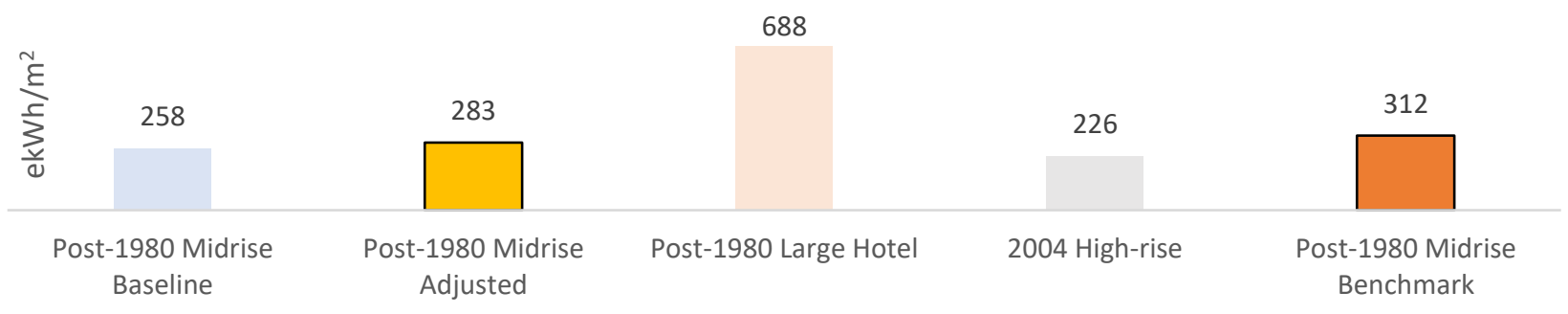

Figure 35. The predicted EUI of the adjusted post- 1980 Midrise model is $9 \%$ lower than the EUI benchmark of the post-1980 Midrise Category quantified at $312 \mathrm{ekWh} / \mathrm{m}^{2}$

Figure 36 reveals that the end-use breakdown predicted with the post-1980 residence model is comparable to the end-use breakdown produced with the 2004 Highrise apartment model.

Heating $\square$ Cooling $\square$ Interior Lighting $\square$ Interior Equipment $\square$ Water Systems

Post1980 Midrise Adjusted 2004 Highrise Apartment Post1980 Large Hotel
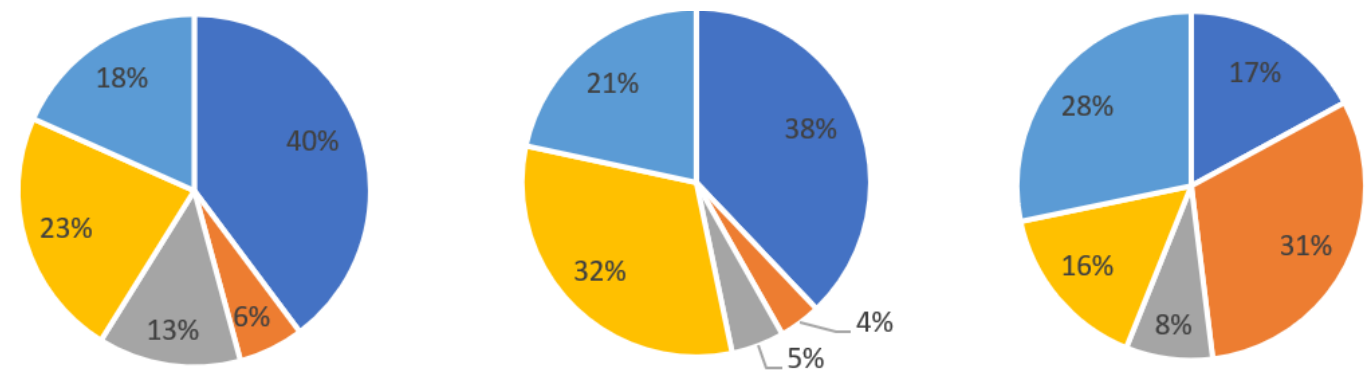

Figure 36. Adjusted post-1980 Midrise breakdown is most like the 2004 Highrise model 


\subsubsection{Pre-1980 Highrise residence model adjustment}

The pre-1980 Highrise baseline characterization template summarized in Section 5.3 was applied using the Reference method, resulting in a predicted EUI of $354 \mathrm{kWh} / \mathrm{m}^{2}$ for pre-1980 Highrise Residence buildings, which lies between the pre-1980 Large Hotel EUI $\left(583 \mathrm{kWh} / \mathrm{m}^{2}\right)$ and the 2004 Highrise Apartment EUI (226kWh/m²).

End-use EUIs of the baseline pre-1980 Highrise, adjusted pre-1980 Highrise, pre-1980 Large Hotel and 2004 Highrise Apartment models are compared in Figure 37 while the overall EUI comparison is summarized in Figure 38. By reviewing the end-use results, it was determined that the most variation between the baseline residence model and the DOE models arose due to discrepancies in cooling, lighting, and water system energy consumption. The cooling EUI of the baseline model is $22 \mathrm{kWh} / \mathrm{m}^{2}$, higher than the $9 \mathrm{kWh} / \mathrm{m}^{2}$ seen in the apartment model and much lower than the $189 \mathrm{kWh} / \mathrm{m}^{2}$ predicted with the hotel model. The difference in cooling EUI is due to the Highrise Apartment having a cooling COP of 3.4 while the Large Hotel has a cooling COP of 2.5. The Large Hotel model also has the largest equipment and lighting EUIs, which result in higher heat gains. Additionally, construction assemblies of DOE models were built to represent buildings of different time periods, resulting in different thermal efficiencies. The baseline lighting EUI consumption is $43 \mathrm{kWh} / \mathrm{m}^{2}$, lower than the $55 \mathrm{kWh} / \mathrm{m}^{2}$ predicted by the hotel model and larger than the $11 \mathrm{kWh} / \mathrm{m}^{2}$ predicted by the apartment model. The baseline water system EUI consumption is $37 \mathrm{kWh} / \mathrm{m}^{2}$, lower than the water system EUI predicted by the apartment model of $49 \mathrm{kWh} / \mathrm{m}^{2}$ and much lower than the $190 \mathrm{kWh} / \mathrm{m}^{2}$ predicted by the hotel model. In addition to this, the baseline equipment EUI is $13 \%$ and $72 \%$ lower than the apartment and large hotel models respectively.

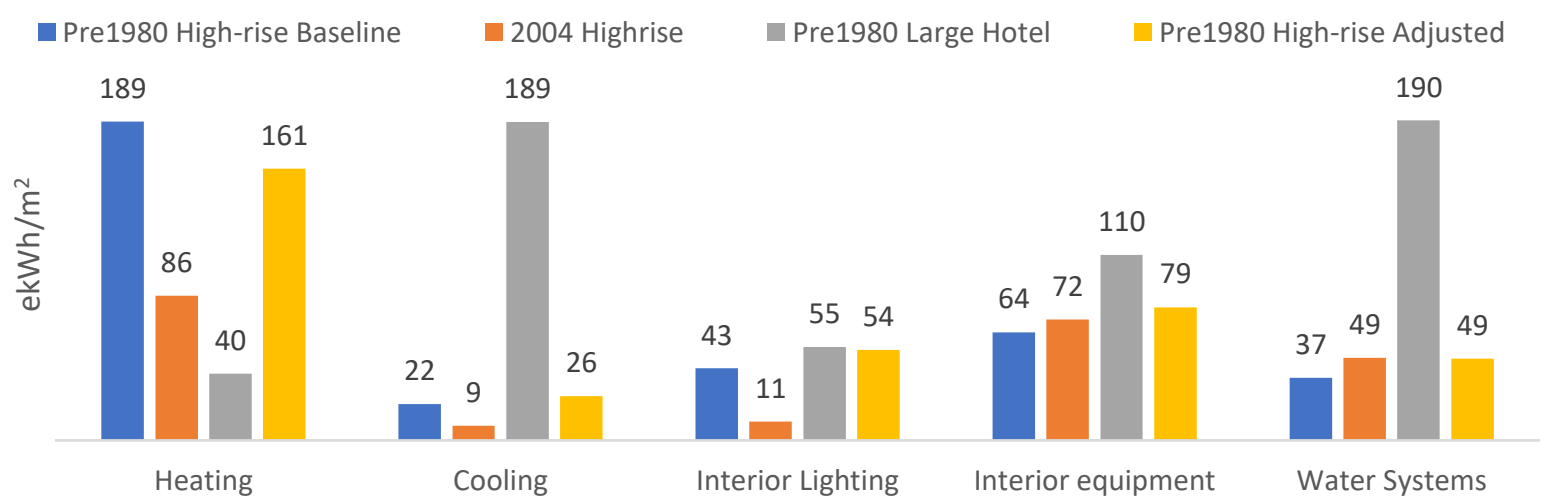

Figure 37. Comparison of the end-use EUIs predicted with reviewed DOE and developed residence models 
To ensure that pre-1980 Highrise residences were predicting consumption with similar end use EUIs to those seen in DOE models, the following changes were done to the pre-1980 Highrise characterization template:

- Heating efficiency was increased from 0.78 to 0.83 as the initial efficiency produced significantly larger heating loads than both DOE models

- Lighting power density was increased from $12.72 \mathrm{~W} / \mathrm{m}^{2}$ to $16 \mathrm{~W} / \mathrm{m}^{2}$ to better represent the loads of the Large hotel

- Plug load density was increased from $14.6 \mathrm{~W} / \mathrm{m}^{2}$ to $18 \mathrm{~W} / \mathrm{m}^{2}$ as the initial load produced lower plug loads than both DOE models

- Hot water use was increased to $0.20 \mathrm{~L} / \mathrm{h} / \mathrm{m}^{2}$ as selected rates were below both DOE models

These adjustments caused a 15\% decrease in heating EUI, an $18 \%$ increase in cooling EUI, a $37 \%$ increase in lighting EUI, a 23\% increase in equipment EUI, a 16\% increase in hot water EUI and an increase of $9 \%$ in total EUI (Figure 38)

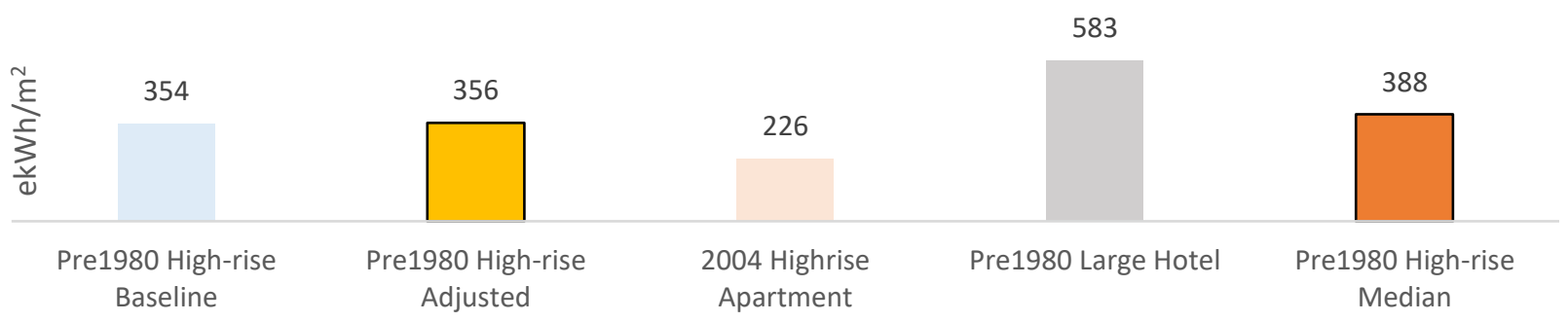

Figure 38.- The predicted EUI of the adjusted pre-1980 Highrise model is $9 \%$ lower than the EUI benchmark of the pre-1980 Highrise Category quantified at $388 \mathrm{ekWh} / \mathrm{m}^{2}$

Figure 39 reveals that the end-use breakdown predicted with the pre-1980 residence model is comparable to the end-use breakdown produced with the 2004 Highrise apartment model.

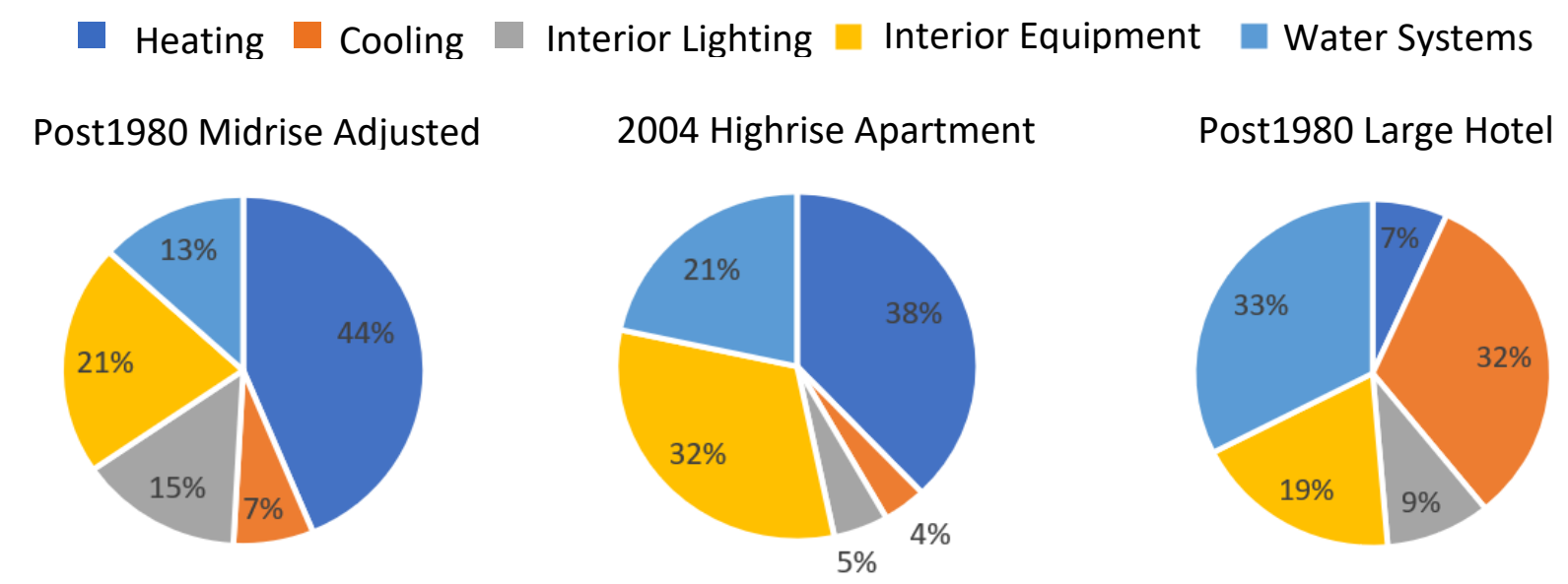

Figure 39. The adjusted pre-1980 Highrise predicted energy breakdown is most like the 2004 Highrise model 


\section{$7 \quad$ Energy Simulation Results}

As noted previously, a cleaned dataset consisting of 20 student residence buildings in Southern Ontario has been used to identify necessary classification categories and features of each. These have been used to develop four energy modeling characterization templates to permit simulation using both Wireframe and Reference methods. This section presents simulation results and their comparison against measured 2013 Ontario MER data. Additionally, a random sampling study is presented which was considered to evaluate the performance of each method at different sample sizes.

\subsection{Comparison of Reference and Wireframe Predictions}

This section presents the comparison of consumption predicted using the Reference and Wireframe methods to actual measured values. The comparison is done for each of the four previously defined categories: pre-1980 Lowrise, post-1980 Lowrise, post-1980 Midrise and pre1980 Highrise. Results predicted by both methods for each category are compared to measured energy, heating, electricity and area to validate them. In addition, this section will present:

1. Aerial images of student residences considered in this study

2. Wireframe models developed to predict student residence consumption

3. End-use consumption predicted with Wireframe and Reference method 


\subsubsection{Pre-1980 Lowrise}

Wireframe models used to predict the consumption of pre-1980 Lowrise buildings are presented in Figure 40, while their simulated annual heating, electricity, energy, and area are presented in Figure 41 - 44.

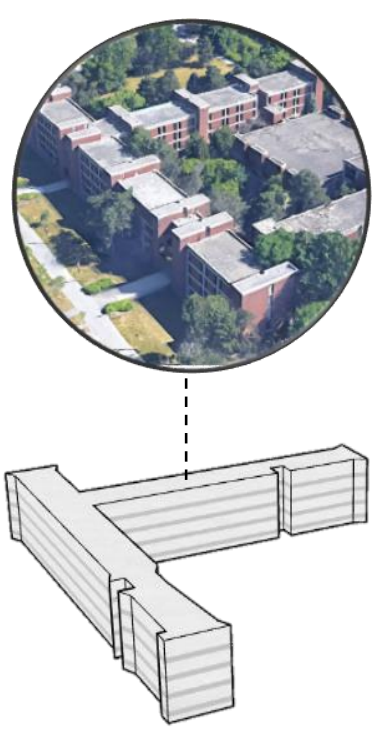

Founders

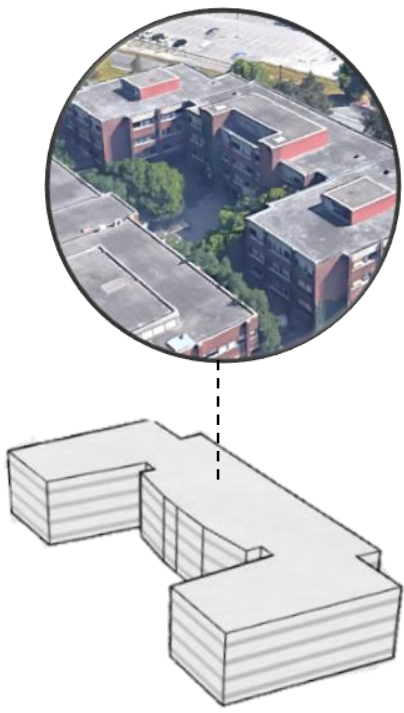

Winters

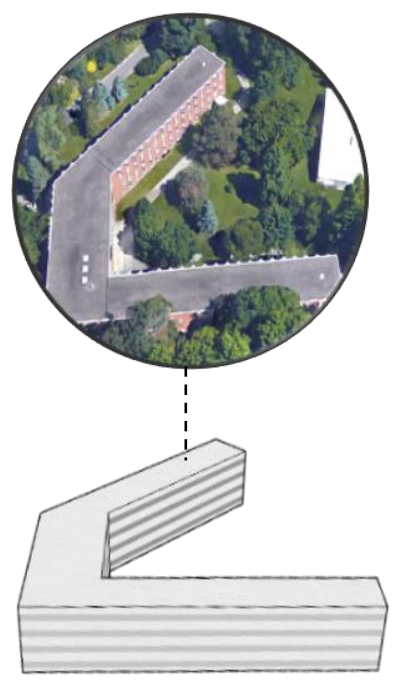

Hilliard

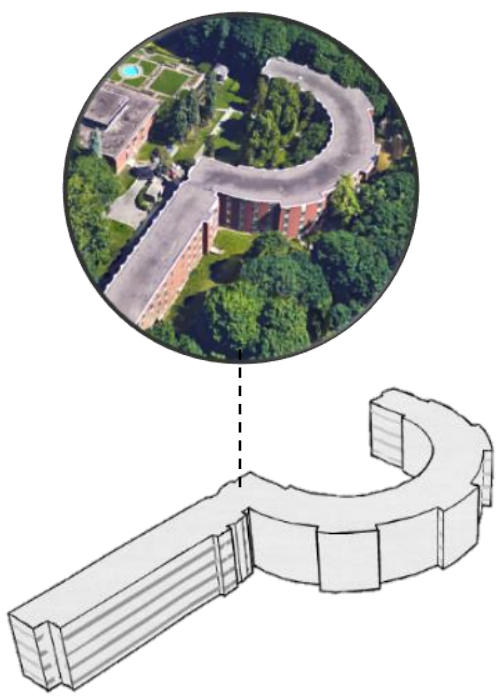

Woods

Figure 40. Building images and corresponding Wireframe method models for the pre-1980 Lowrise category 


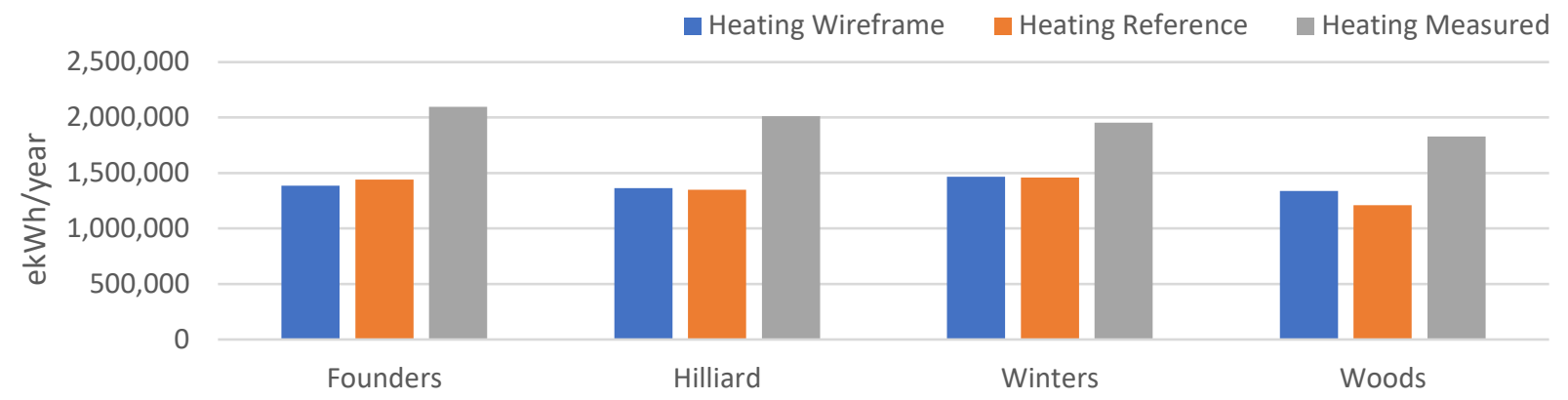

Figure 41. Pre-1980 Lowrise Heating comparison

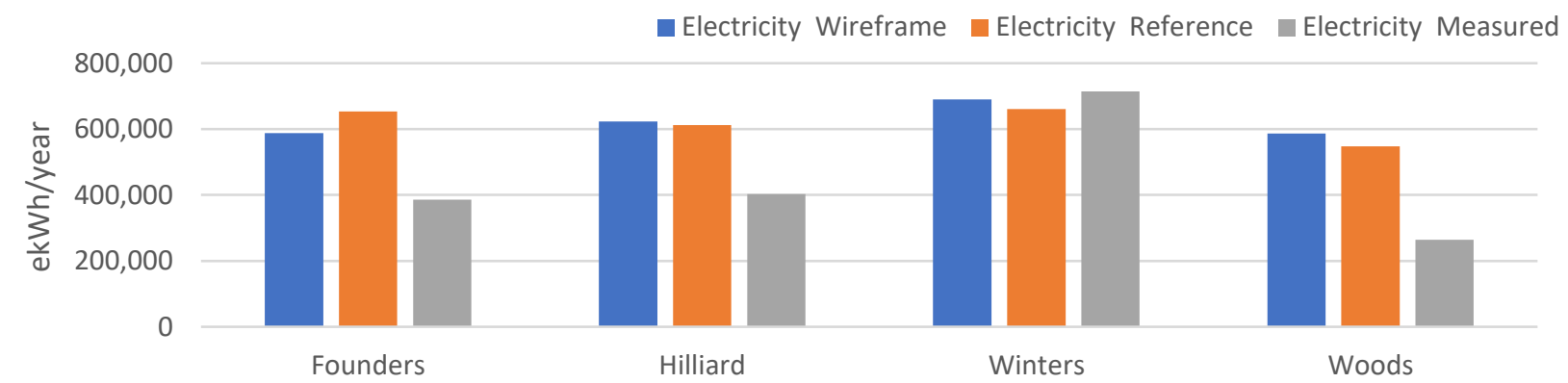

Figure 42. Pre-1980 Lowrise Electricity comparison

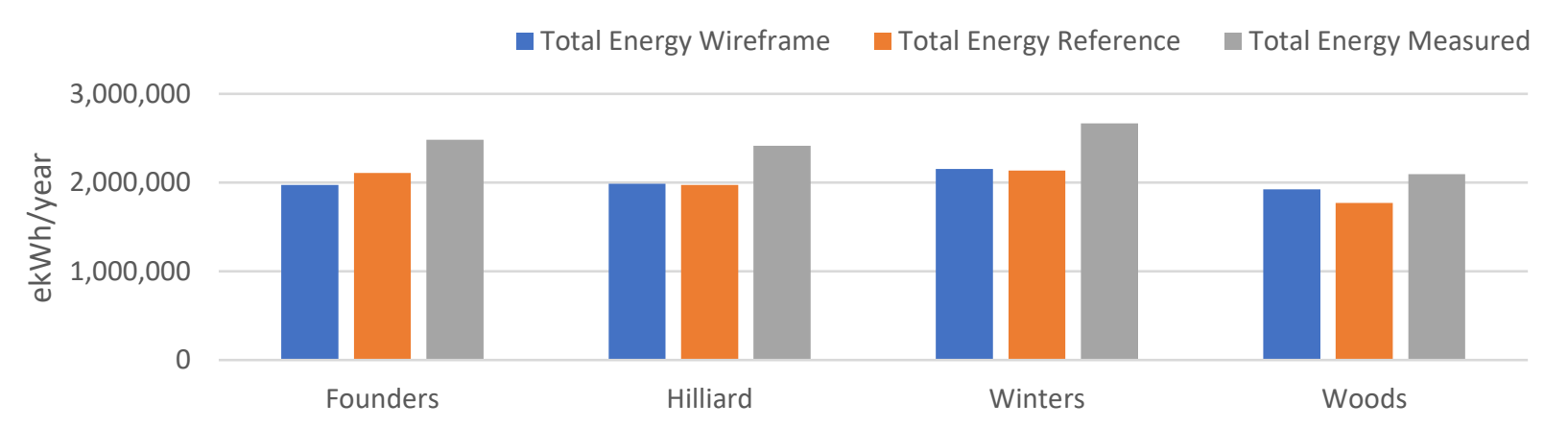

Figure 43. Pre-1980 Lowrise Total Energy comparison

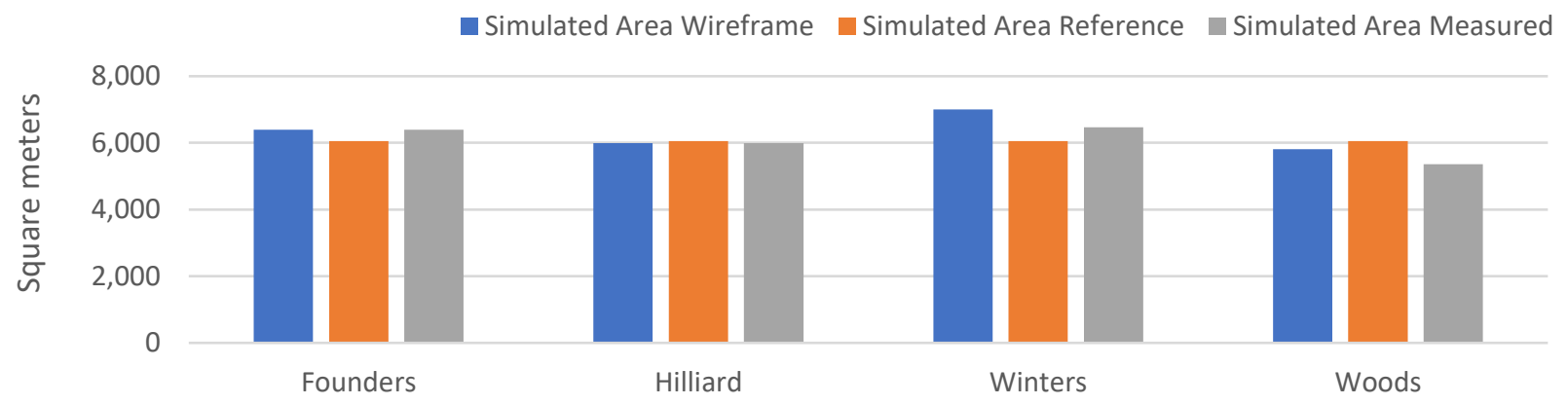

Figure 44. Pre-1980 Lowrise Area comparison. The simulated area for the Reference model does not change as the displayed area is the one used to predict the Reference EUI which is then scaled by multiplying by the measured area of the buildings. 
Figure 41 compares the total heating consumption predicted by both methods to measured heating. Prediction errors for individual building heating ranges from $-34 \%$ to $-25 \%$ with the Reference method and $-34 \%$ to $-25 \%$ with the Wireframe method. In Figure 42, the total electricity predictions for both methods are compared to measured electricity. Founders and Woods are the residence models with highest electricity error predictions. These models reported measured electricity but no district cooling, while Hilliard and Winters reported measured electricity and district cooling. All four residences belong to the same university, so it is suspicious that the two models that did not report district cooling (Founders and Woods) are also the models with highest errors. Errors for electricity predictions range from $-4 \%$ to $122 \%$ with the Wireframe method and $-8 \%$ to $107 \%$ with the Reference method. These are the highest range of predicted errors for this sample. Figure 43 compares the total energy consumption predicted by both methods to measured energy. Errors for energy predictions go from $-21 \%$ to $-8 \%$ with the Wireframe method and $-20 \%$ to $-15 \%$ with the Reference method. In Figure 44, areas used to predict consumption are compared to measured residence areas. Winters Wireframe model had the largest error as it uses an area $15 \%$ larger than what was measured. The area used for Wireframe predictions has a $0 \%$ to $8 \%$ error range, while the area used for Reference predictions has a $-6 \%$ to $13 \%$ error range.

Table 34 summarizes the pre-1980 Lowrise individual building percentage error ranges. Note that Reference method area errors are obtained by comparing the Reference model area to measured areas.

Table 34. Percentage error ranges for pre-1980 Lowrise buildings

\begin{tabular}{cccc|ccc}
\hline & \multicolumn{3}{c}{ Wireframe } & \multicolumn{3}{c}{ Reference } \\
\hline Heating & $-34 \%$ & to & $-25 \%$ & $-34 \%$ & to & $-25 \%$ \\
Electricity & $-4 \%$ & to & $122 \%$ & $-8 \%$ & to & $107 \%$ \\
Energy & $-21 \%$ & to & $-8 \%$ & $-20 \%$ & to & $-15 \%$ \\
Area & $0 \%$ & to & $8 \%$ & $-6 \%$ & to & $13 \%$ \\
\hline
\end{tabular}




\subsubsection{Post-1980 Lowrise}

Wireframe models used to predict the consumption of post-1980 Lowrise buildings are presented in Figure 45, while their simulated annual heating, electricity, energy, and area are presented in Figures $46-49$.

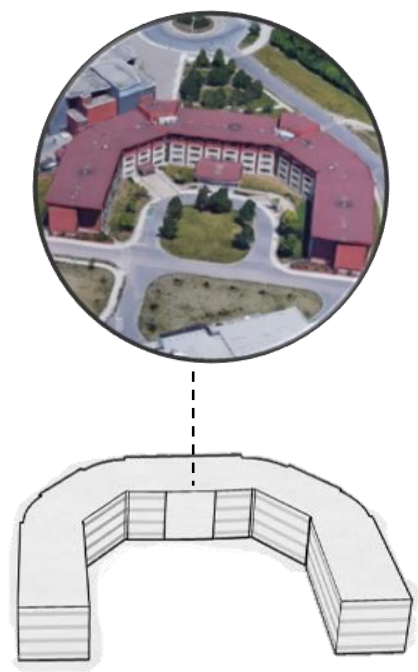

Trafalgar R1

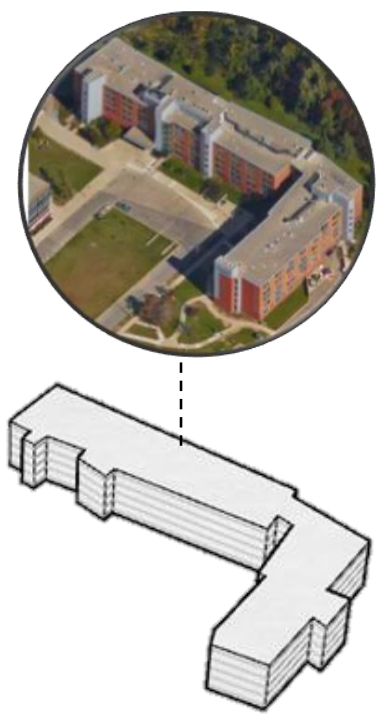

Davis

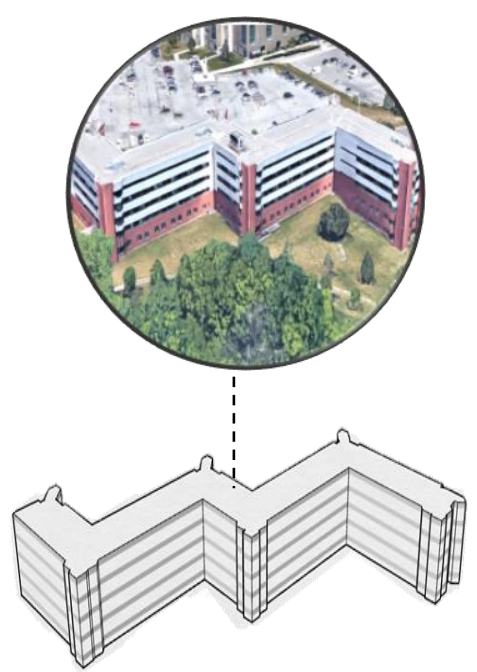

NR1

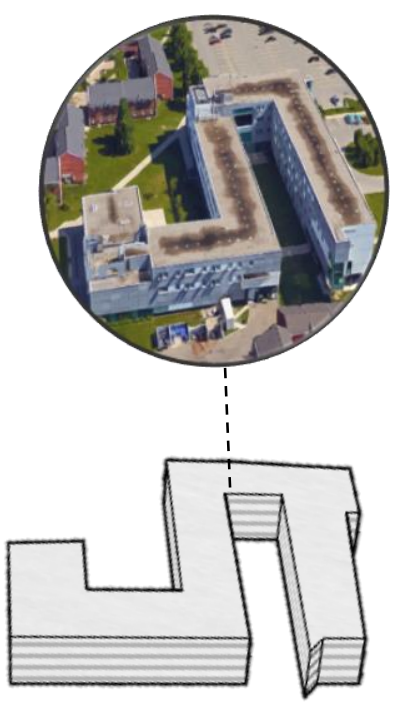

Lowenberger

Figure 45. Building images and corresponding Wireframe method models for the post-1980 Lowrise category 
- Heating Wireframe $\quad$ Heating Reference Heating Measured

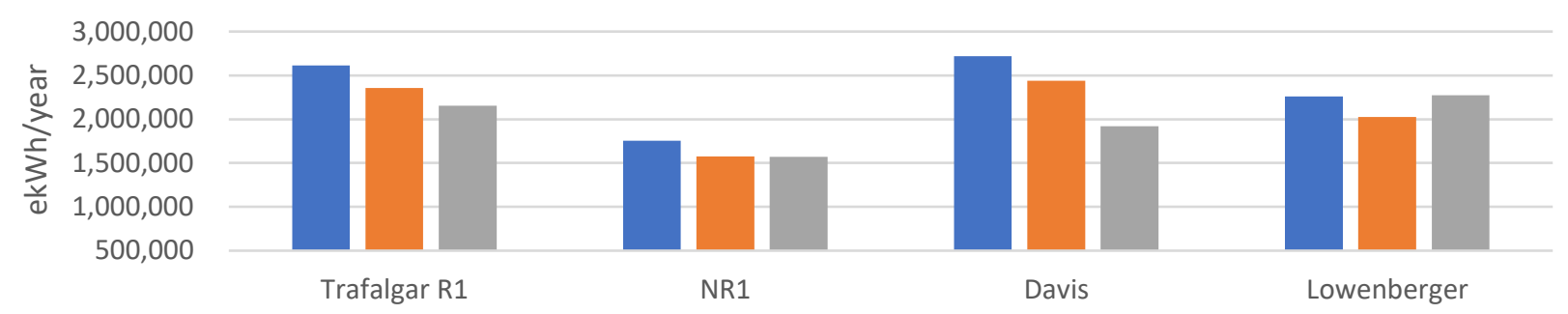

Figure 46. Post-1980 Lowrise Heating comparison

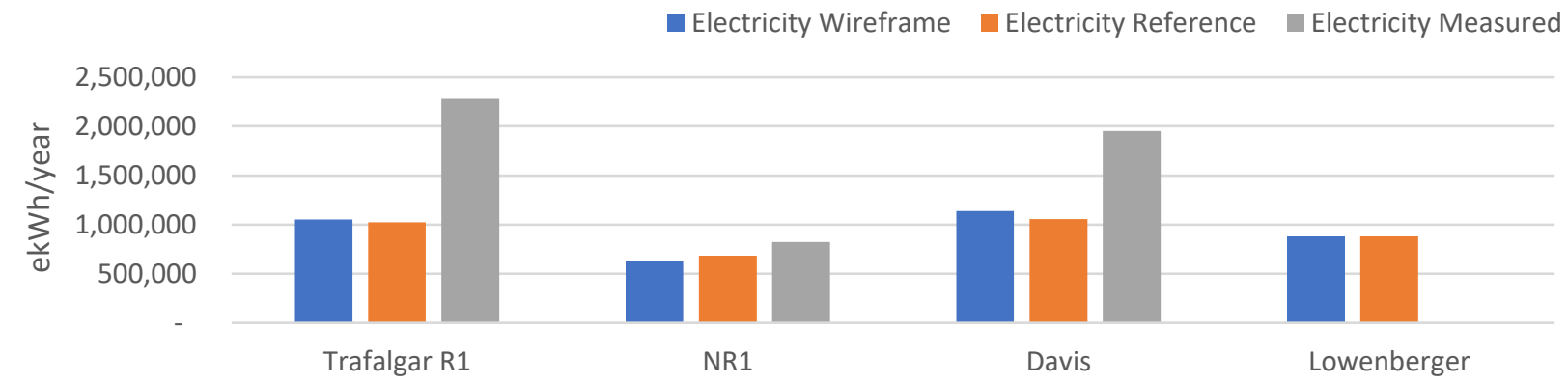

Figure 47. Post-1980 Lowrise Electricity comparison

a Total Energy Wireframe $\quad$ Total Energy Reference $\quad$ Total Energy Measured

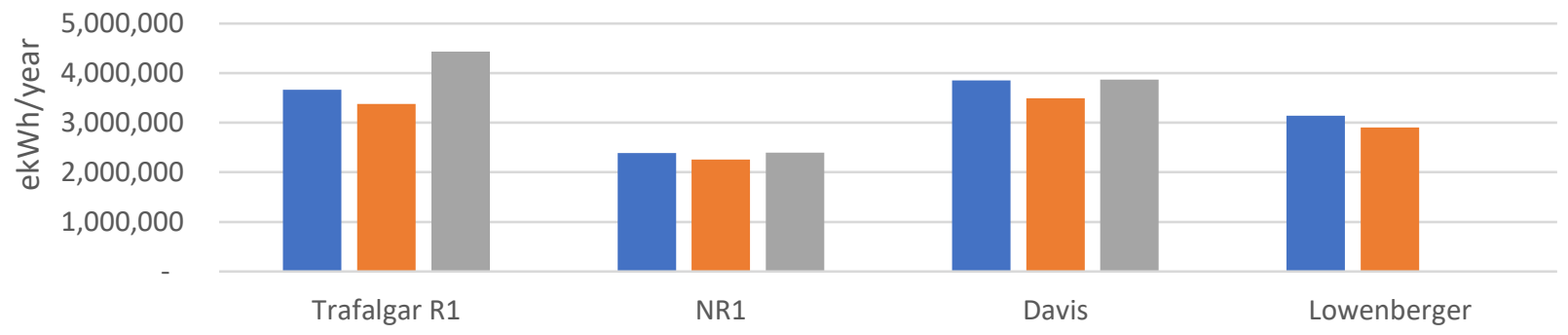

Figure 48. Post-1980 Lowrise Total Energy comparison

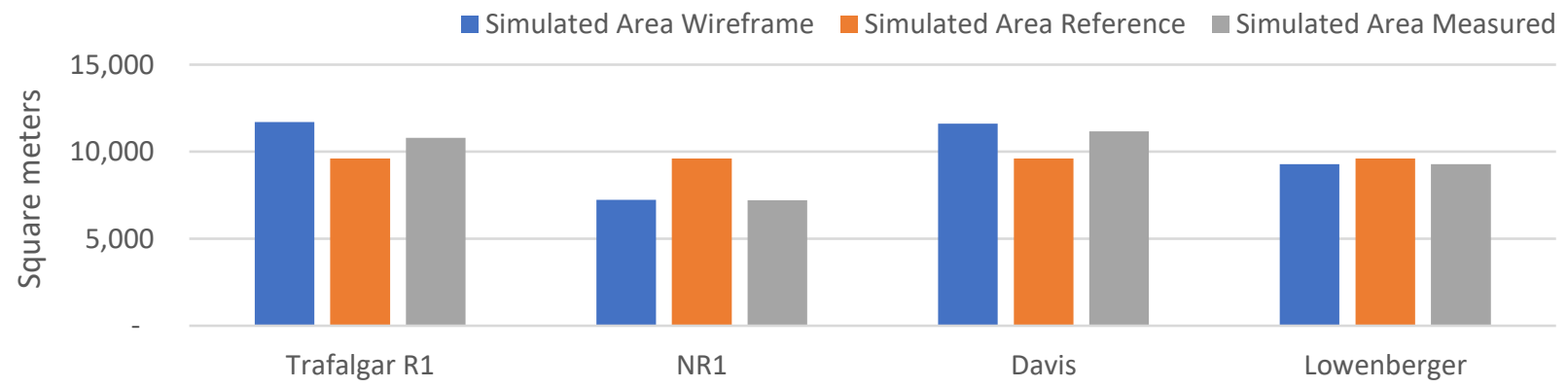

Figure 49. Post-1980 Lowrise Area comparison 
Figure 46 compares the total heating consumption predicted by both methods to measured heating. Prediction errors for individual building heating ranges from $-11 \%$ to $27 \%$ with the Reference method and $-1 \%$ to $42 \%$ with the Wireframe method. In Figure 47, the total electricity predicted by both methods are compared to measured electricity. Lowenberger has no reported measured consumption so only predicted consumption values are compared. Predictions errors for individual building electricity ranges from $-55 \%$ to $-17 \%$ with the Reference method and $-54 \%$ to $-23 \%$ with the Wireframe method. Figure 48 compares the total energy consumption predicted by both methods to measured energy. Measured energy reported for Lowenberger was ignored as it had the same value reported for heating consumption. Predictions errors for individual building total energy ranges from $-17 \%$ to $0 \%$ with the Wireframe method and $-24 \%$ to $-6 \%$ with the Reference method. In Figure 49 areas used to predict consumption are compared to measured areas. In most models, the area used for Wireframe predictions were more like measured values. The area used for Wireframe predictions has a $0 \%$ to $8 \%$ error range, while the area used for Reference predictions has a $-14 \%$ to $33 \%$ error range.

Table 35 summarizes post-1980 Lowrise individual building percentage error ranges. Note that Reference method area errors are obtained by comparing the Reference model area to measured areas.

Table 35. Percentage error ranges for post-1980 Lowrise buildings

\begin{tabular}{cccc|ccc}
\hline & \multicolumn{3}{c}{ Wireframe } & \multicolumn{3}{c}{ Reference } \\
\hline Heating & $-1 \%$ & to & $42 \%$ & $-11 \%$ & to & $27 \%$ \\
Electricity & $-54 \%$ & to & $-23 \%$ & $-55 \%$ & to & $-17 \%$ \\
Energy & $-17 \%$ & to & $0 \%$ & $-24 \%$ & to & $-6 \%$ \\
Area & $0 \%$ & to & $8 \%$ & $-14 \%$ & to & $33 \%$ \\
\hline
\end{tabular}




\subsubsection{Post-1980 Midrise}

Wireframe models used to predict the consumption of post-1980 Midrise buildings are presented in Figure 50, while their simulated annual heating, electricity, energy, and area are presented in Figures 51 - 54.

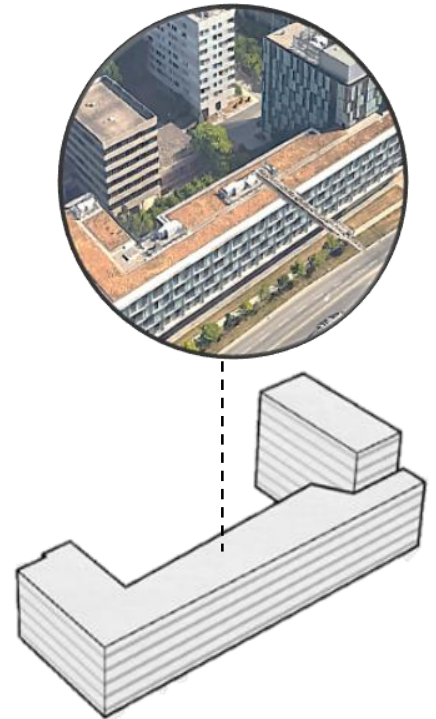

The Pond

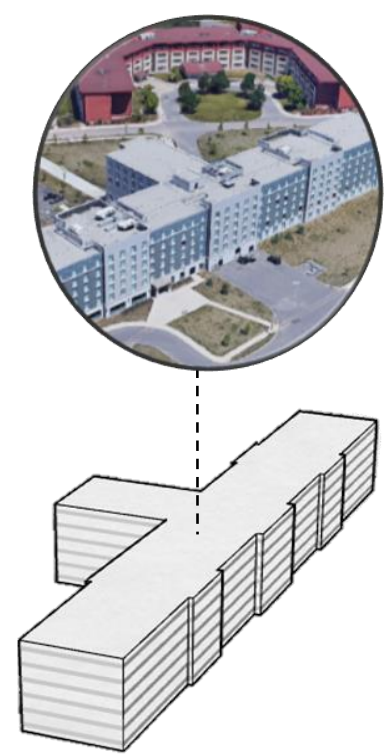

Trafalgar R2

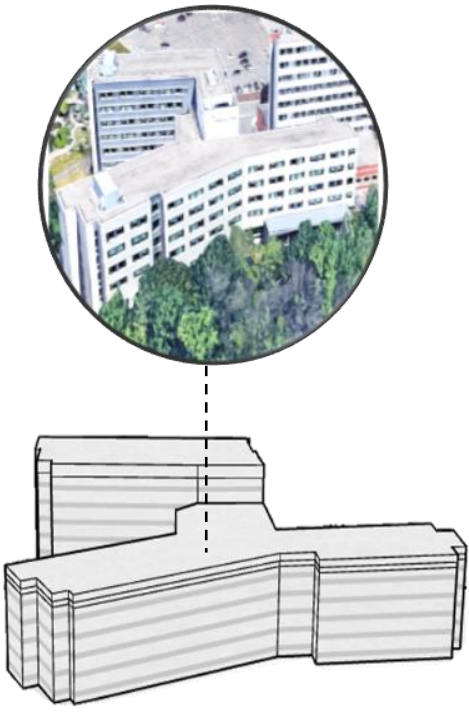

NR3

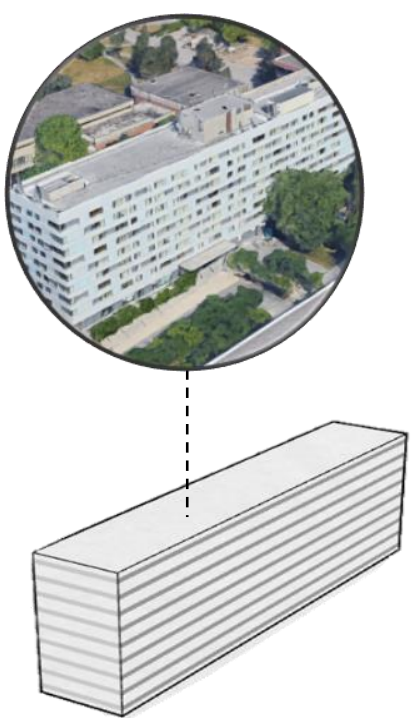

Atkinson

Figure 50. Building images and corresponding Wireframe method models for the post-1980 Midrise category 


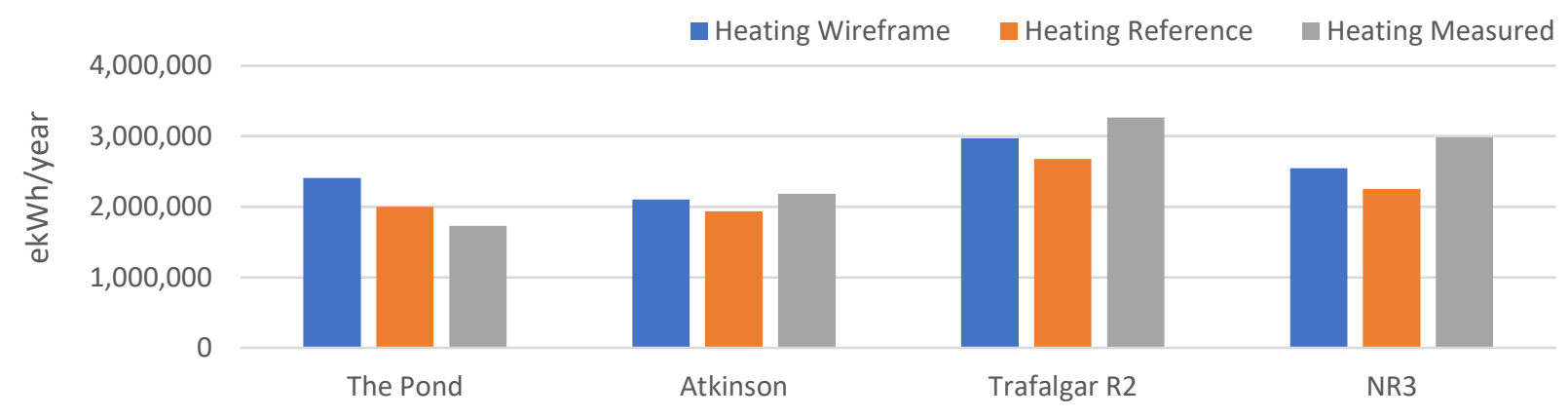

Figure 51. Post-1980 Midrise Heating comparison

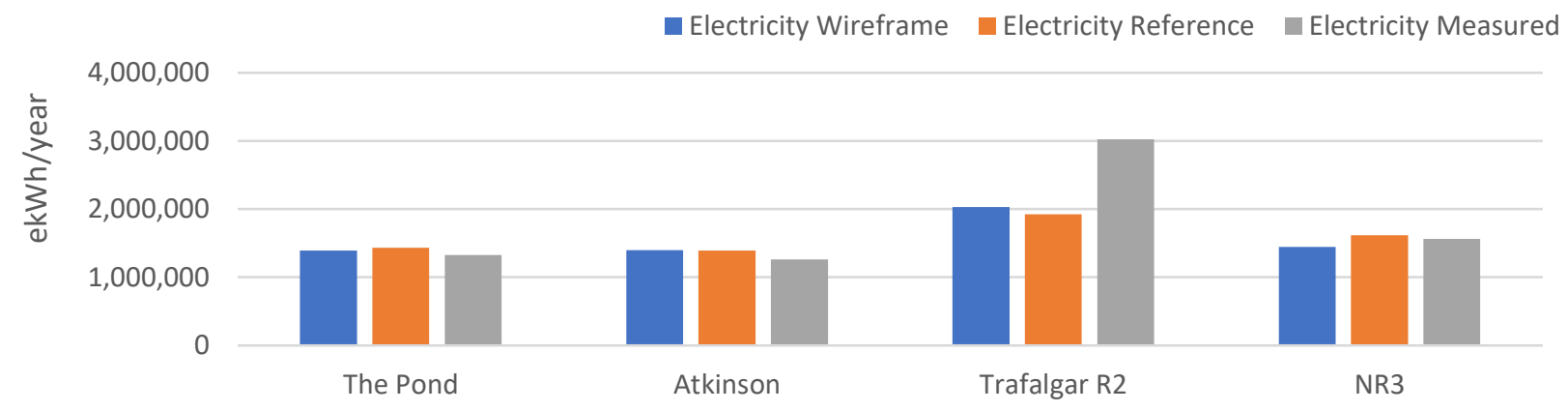

Figure 52. Post-1980 Midrise Electricity comparison

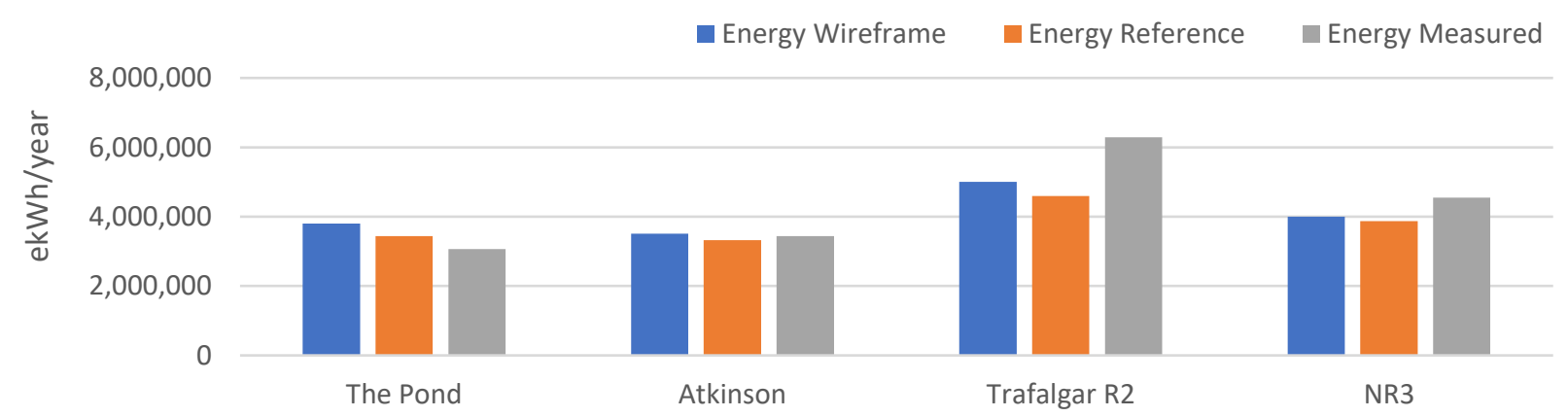

Figure 53. Post-1980 Midrise Total Energy comparison

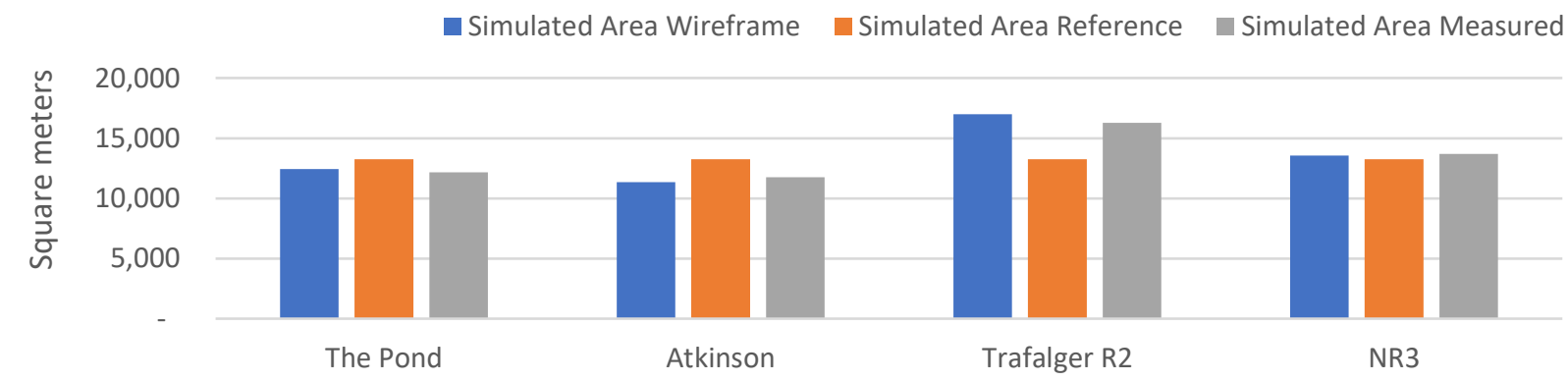

Figure 54. Post-1980 Midrise Area comparison 
Figure 51 compares the total heating predicted by both methods to measured heating consumption. Predictions errors for individual building heating ranges from $-24 \%$ to $15 \%$ with the Reference method and $-15 \%$ to $39 \%$ with the Wireframe method. The error seen with the Wireframe method is partially due to how the Pond Residence was modelled, this will be discussed in greater detail in the Discussion section of this thesis. In Figure 52, the total electricity predicted by both methods are compared to measured electricity. In this sample, electricity predictions are similar to measured consumption, except for the Trafalgar $R 2$ model, where measured loads are at least $33 \%$ higher than those predicted with either method. Predictions errors for individual building electricity ranges from $-36 \%$ to $10 \%$ with the Reference method and $-33 \%$ to $11 \%$ with the Wireframe method. Figure 53 compares the total energy consumption predicted by both methods to measured energy. The models with most variation between the Wireframe and Reference method predictions are The Pond and Trafalgar R2. Predictions errors for individual building total energy ranges from $-27 \%$ to $12 \%$ with the Reference method and $-20 \%$ to $24 \%$ with the Wireframe method. In Figure 54, areas used to predict consumption are compared to measured areas. The area used for Wireframe predictions have a $-4 \%$ to $4 \%$ error range, while the area used for Reference predictions has a $-19 \%$ to $13 \%$ error range.

Table 36 summarizes post-1980 Midrise individual building percentage error ranges. Note that Reference method area errors are obtained by comparing the Reference model area to measured areas.

Table 36. Percentage error ranges for post-1980 Midrise buildings

\begin{tabular}{cccc|ccc}
\hline & \multicolumn{3}{c}{ Wireframe } & \multicolumn{3}{c}{ Reference } \\
\hline Heating & $-15 \%$ & to & $39 \%$ & $-24 \%$ & to & $15 \%$ \\
Electricity & $-33 \%$ & to & $11 \%$ & $-36 \%$ & to & $10 \%$ \\
Energy & $-20 \%$ & to & $24 \%$ & $-27 \%$ & to & $12 \%$ \\
Area & $-4 \%$ & to & $4 \%$ & $-19 \%$ & to & $13 \%$ \\
\hline
\end{tabular}




\subsubsection{Pre-1980 Highrise}

Wireframe models used to predict the consumption of pre-1980 Highrise buildings are presented in Figure 55, while their simulated annual heating, electricity, energy, and area are presented in Figure 56 - 59.

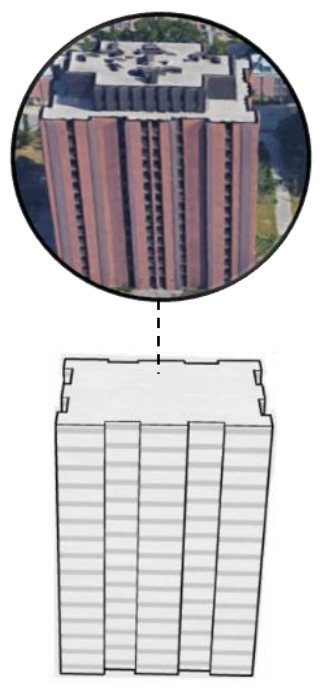

320 Assiniboine

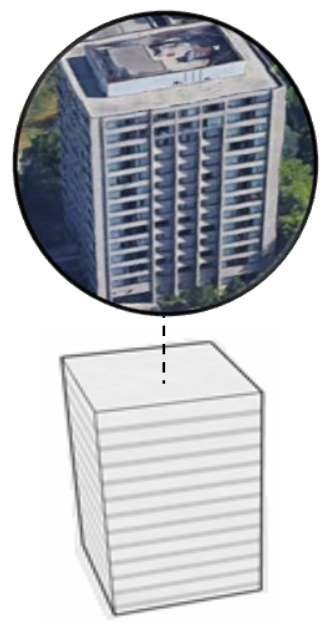

Norman Bethune

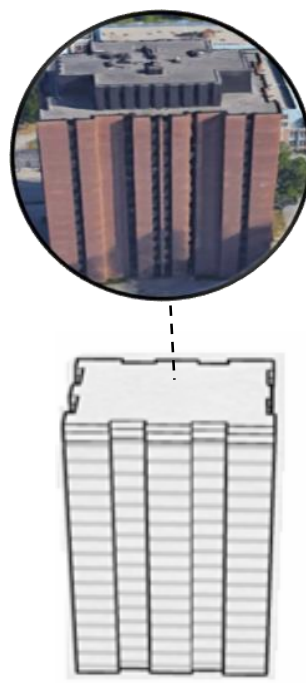

340 Assiniboine

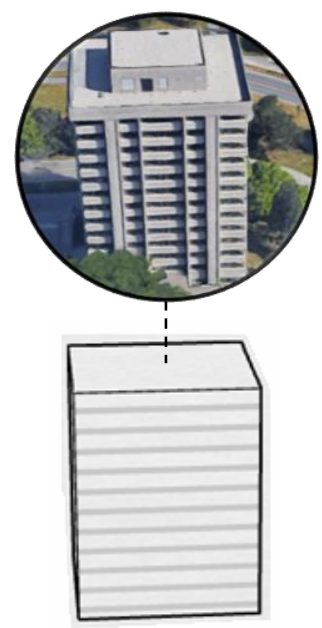

Tatham Hall

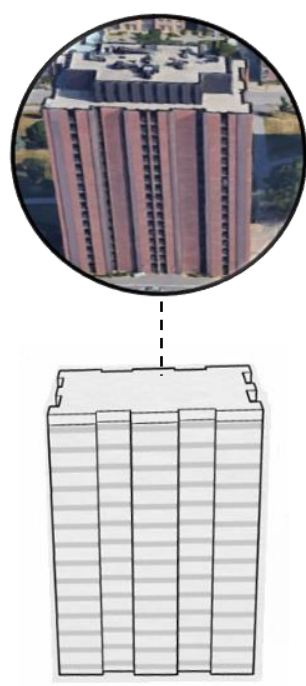

360 Assiniboine

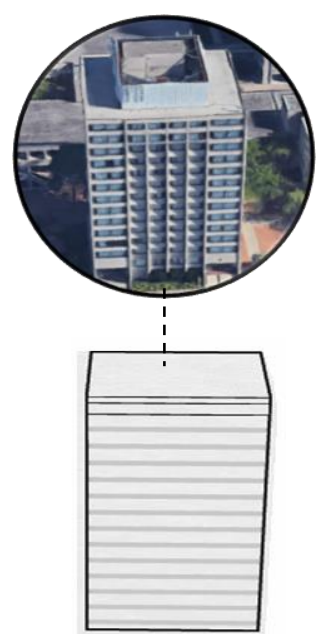

Stong

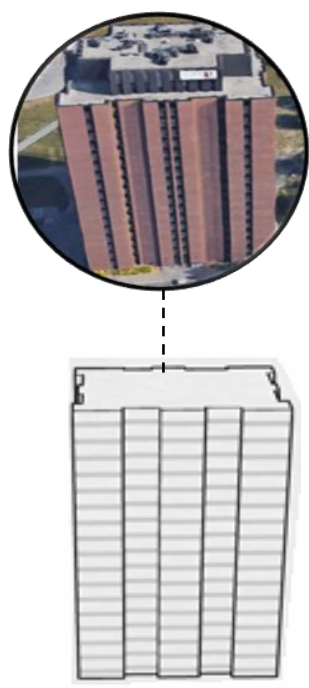

380 Assiniboine

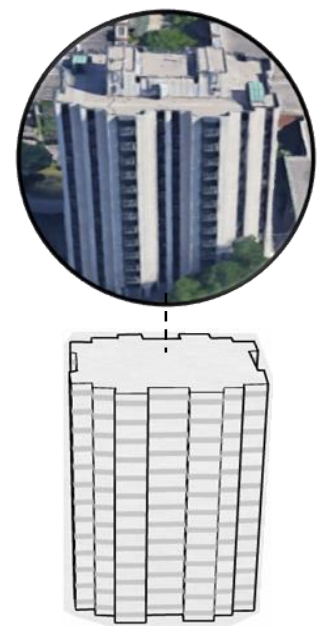

Vanier

Figure 55. Building images and corresponding Wireframe method models for the pre-1980 Highrise category 


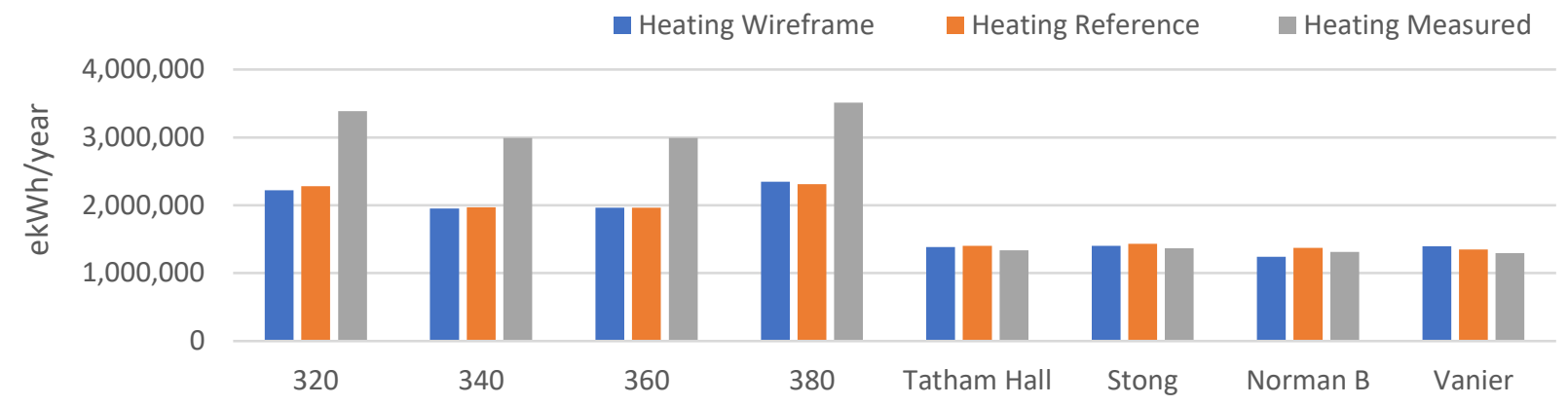

Figure 56. Pre-1980 Highrise Heating comparison

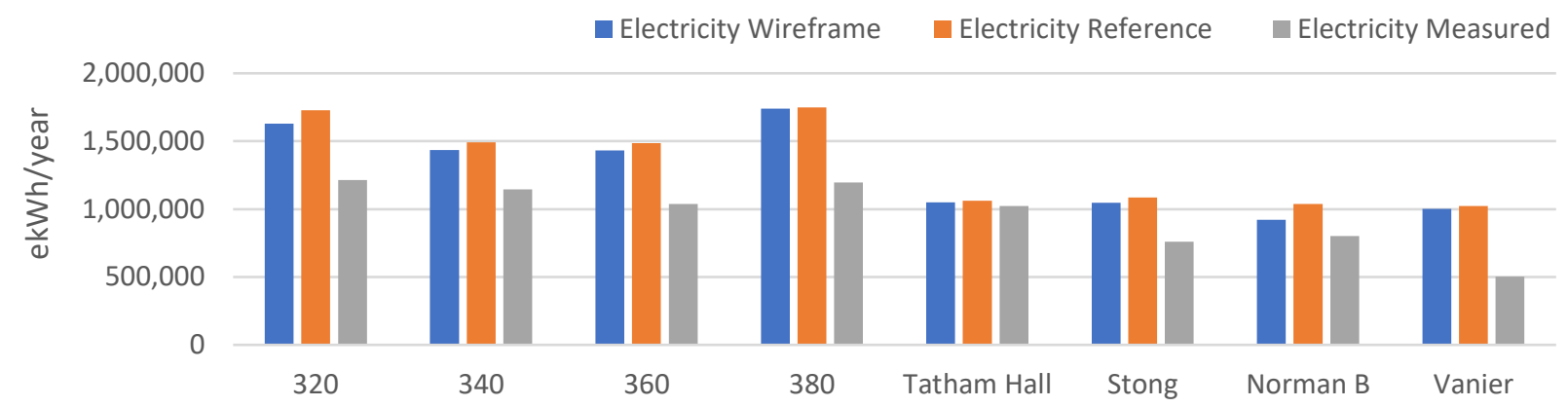

Figure 57. Pre-1980 Highrise Electricity comparison

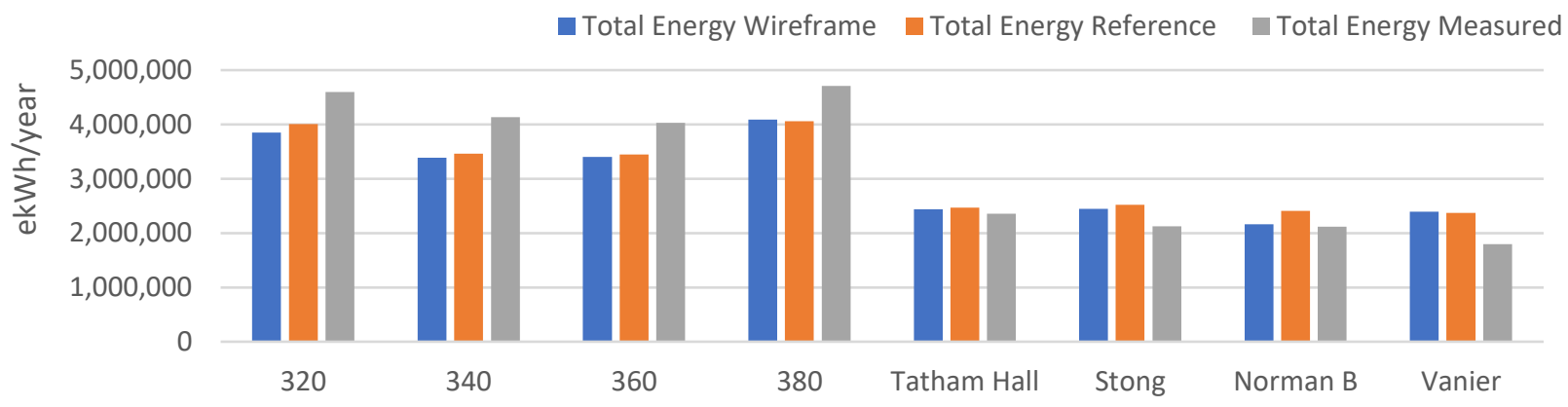

Figure 58. Pre-1980 Highrise Total Energy comparison

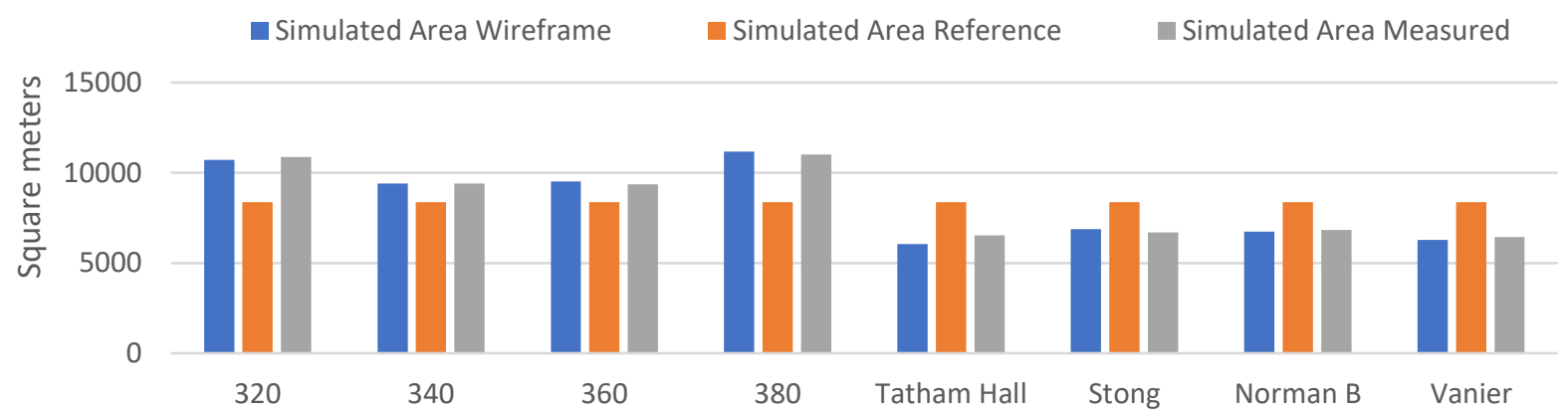

Figure 59. Pre-1980 Highrise Area comparison 
Figure 56 compares the total heating consumption predicted by both methods to measured heating. Not much variation is seen between heating predictions from either method. Predictions errors for individual building heating ranges from $-34 \%$ to $5 \%$ with the Reference method and $35 \%$ to $8 \%$ with the Wireframe method. In Figure 57, the total electricity predicted by both methods are compared to measured electricity. In most residences, the Wireframe method predicted more accurate electricity consumption, however, the differences are relatively small. The less complex models (Norman Bethune, Tatham Hall and Stong) appear to be better at predicting consumption when compared to buildings that have more complex geometry $(320,340,360,380$, and Vanier). Predictions errors for individual building electricity ranges from $4 \%$ to $104 \%$ with the Reference method and $3 \%$ to $99 \%$ with the Wireframe method. Figure 58 compares the total energy consumption predicted by both methods to measured energy. Not much variation is seen between the consumption predicted with either method. In this sample, Reference method models appear to predict total energy consumption with greater accuracy. Predictions errors for individual building total energy ranges from $-16 \%$ to $32 \%$ with the Reference method and $-18 \%$ to $33 \%$ with the Wireframe method. In Figure 59, areas used to predict consumption are compared to measured areas. The area used for Wireframe predictions had a $-7 \%$ to $3 \%$ error range, while the area used for Reference predictions had a $-24 \%$ to $30 \%$ error range.

Table 37 summarizes pre-1980 Highrise individual building percentage error ranges. Note that Reference method area errors are obtained by comparing the Reference model area to measured areas.

Table 37. Percentage Error ranges for pre-1980 Highrise buildings

\begin{tabular}{cccc|ccc}
\hline & \multicolumn{3}{c}{ Wireframe } & \multicolumn{3}{c}{ Reference } \\
\hline Heating & $-35 \%$ & to & $8 \%$ & $-34 \%$ & to & $5 \%$ \\
Electricity & $3 \%$ & to & $99 \%$ & $4 \%$ & to & $104 \%$ \\
Energy & $-18 \%$ & to & $33 \%$ & $-16 \%$ & to & $32 \%$ \\
Area & $-7 \%$ & to & $3 \%$ & $-24 \%$ & to & $30 \%$ \\
\hline
\end{tabular}




\subsection{End-use energy by building}

The end-use EUI predicted for student residences using Reference and Wireframe methods are compared in Figure 60- Figure 63. These figures present the end-use consumption predicted for each of the four previously defined categories. End-use intensities are compared by category provide insight regarding differences between prediction methods. Understanding what causes consumption differences allows identification of when buildings are better represented with the Wireframe method and where buildings will be equally represented with either bottom-up method.

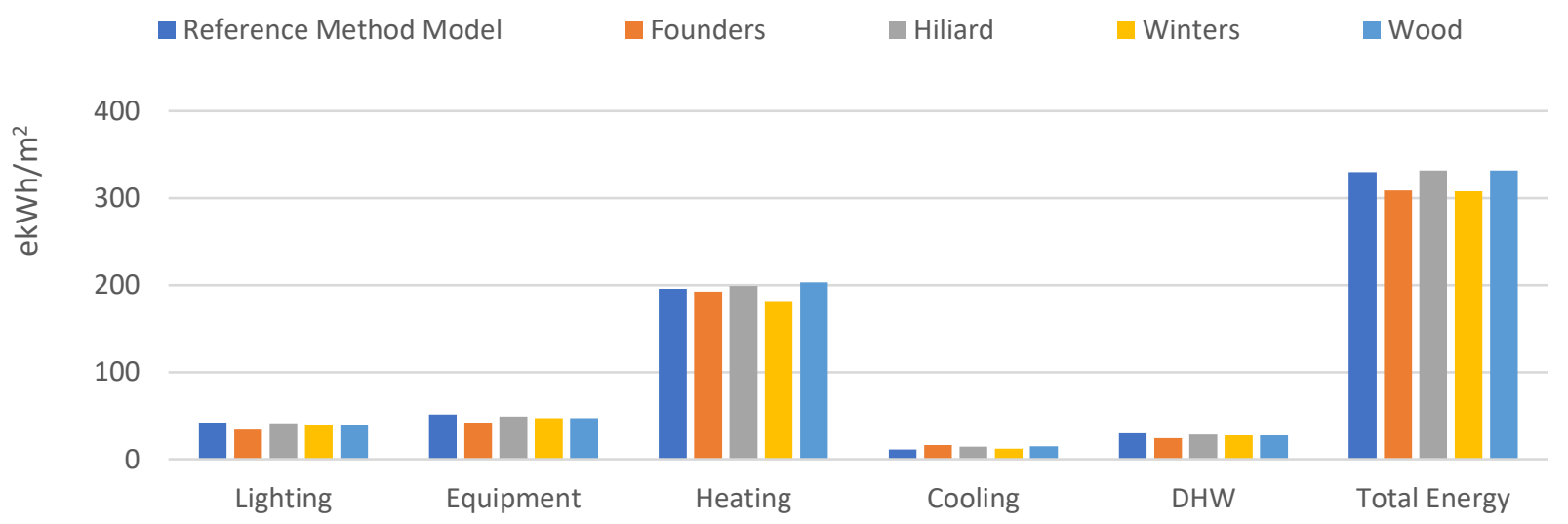

Figure 60. Pre-1980 Lowrise predicted energy end-use by building

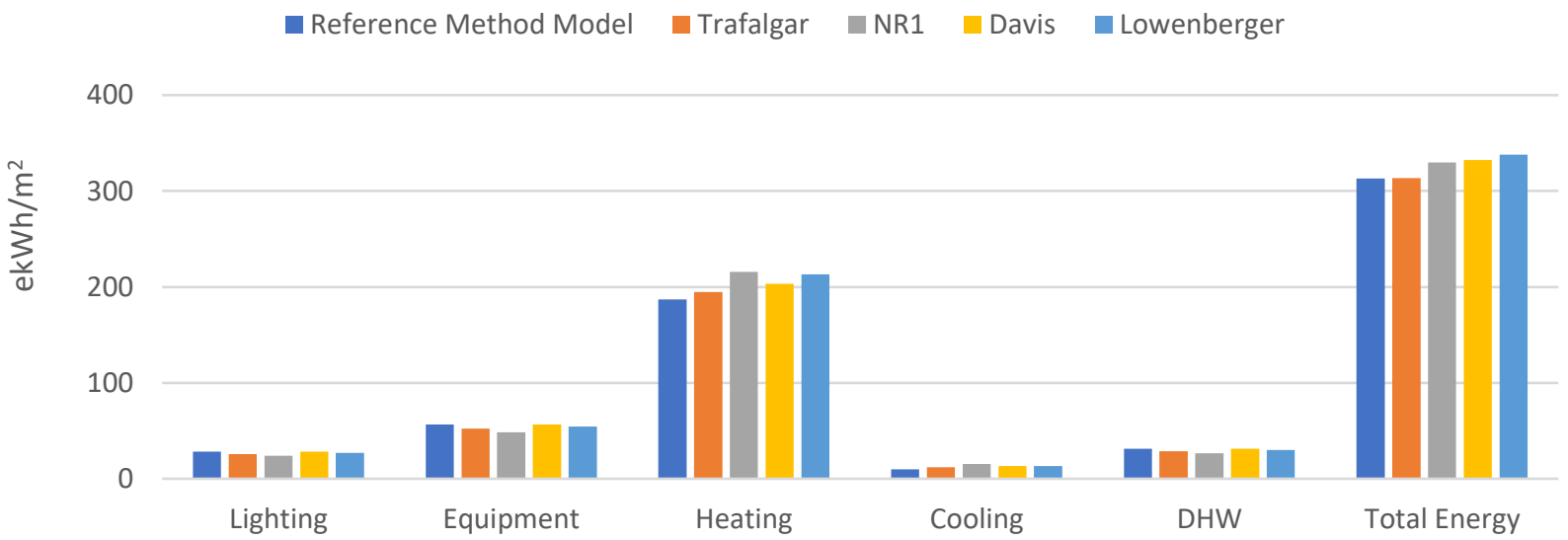

Figure 61. Post-1980 Lowrise predicted energy end-use by building 


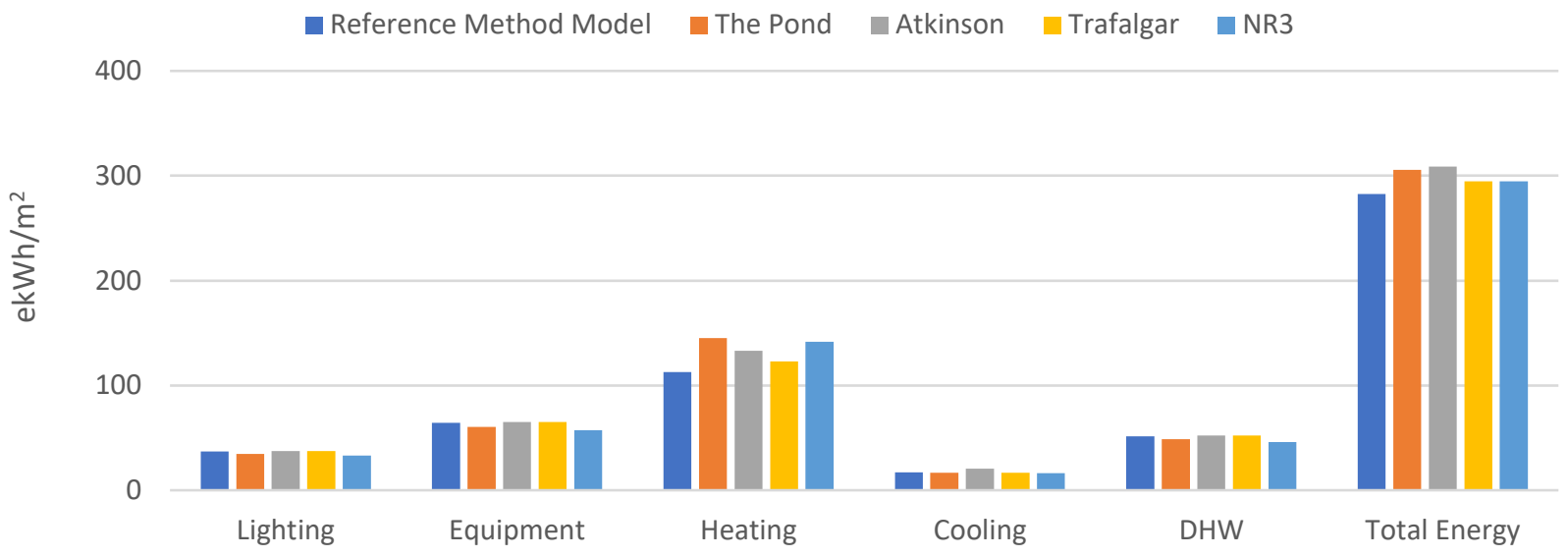

Figure 62. Post-1980 Midrise predicted energy end-use by building

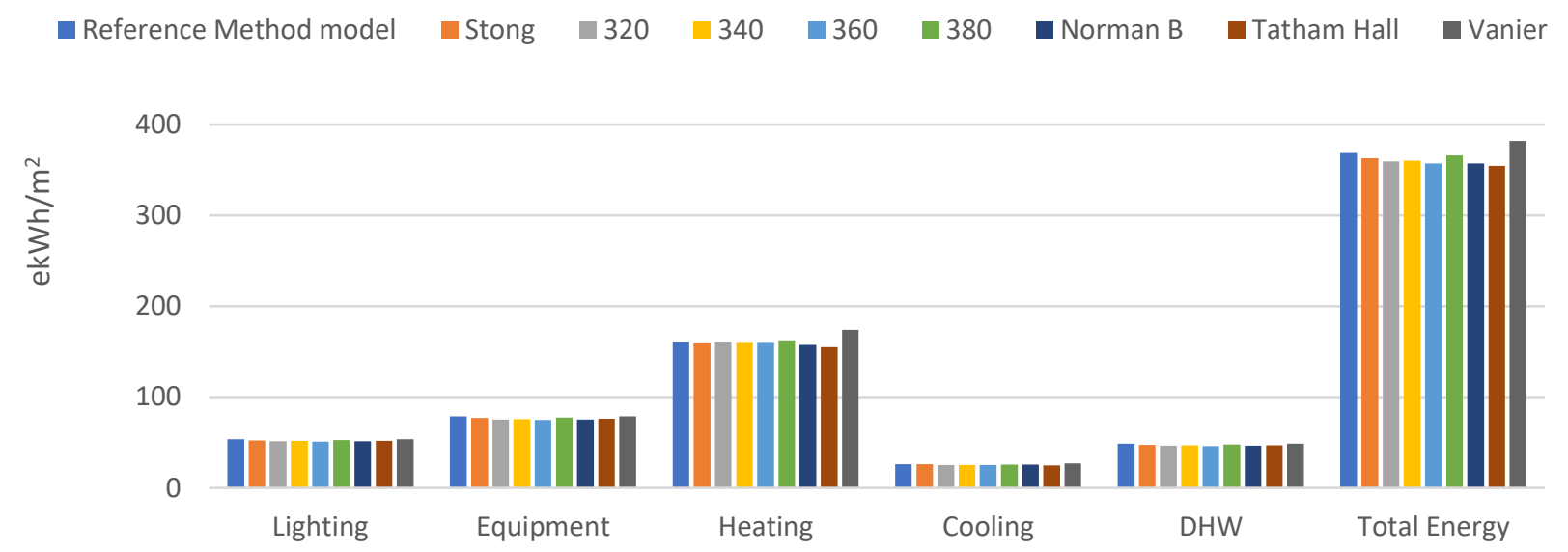

Figure 63. Pre-1980 Highrise predicted energy end-use by building

Building categories with least aggregate total energy variation between Reference and Wireframe predictions are the pre-1980 Lowrise (Figure 60; 1\%) and the pre-1980 Highrise (Figure 63; 2\%). Building categories with most consumption variation are the post-1980 Lowrise (Figure 61; 7\%) and the post-1980 Midrise (Figure 62; 7\%). Post-1980 models also presented highest error between measured areas and Reference model areas used to predict their EUI. This suggests that further dividing post-1980 categories by area size might decrease these errors, highlighting the importance of classifying the building stock by area. Not much variation is seen between the methods, if any, it is seen in conditioning end-uses, suggesting that these variations are related to the form of the models. 


\subsection{Error Analysis}

\subsubsection{Pre-1980 Lowrise}

The comparison between Wireframe and Reference method prediction accuracies for the pre-1980 Lowrise category is summarized in Table 38. Percentage error represents the accuracy of the models to predict the aggregate consumption of the sample while RMSE represents the sample standard deviation of the differences between predicted and measured values of the sample.

Table 38. Percentage error and RMSE of pre-1980 Lowrise buildings

\begin{tabular}{ccc|cc}
\hline & \multicolumn{2}{c}{ Percentage Error (\%) } & \multicolumn{2}{c}{ RMSE (\%) } \\
& Wireframe & Reference & Wireframe & Reference \\
\hline Heating & $-30 \%$ & $-31 \%$ & $30 \%$ & $31 \%$ \\
Electricity & $41 \%$ & $40 \%$ & $72 \%$ & $69 \%$ \\
Energy & $-17 \%$ & $-17 \%$ & $21 \%$ & $26 \%$ \\
Area & $4 \%$ & $0 \%$ & $6 \%$ & $8 \%$ \\
\hline
\end{tabular}

It is evident from this table that the Wireframe and Reference methods have very similar prediction accuracy. For example, when reviewing the aggregate heating consumption, the Wireframe method underpredicted by $30 \%$, while the Reference method under-predicted heating by $31 \%$. The RMSE of heating consumption is also very similar for both methods, $30 \%$ for the Wireframe and $31 \%$ for the Reference method. This means that both methods are as accurate at predicting heating consumption. The aggregate electricity predicted by both methods are over by $41 \%$ with the Wireframe and $40 \%$ with the Reference method, poor results but consistent with the accuracies of the methods being similar. The RMSE of predicted electricity shows that the Reference method (69\%) is slightly better than the Wireframe (72\%). As it was noted earlier, this error in electricity could be due to improper energy data reporting. The two buildings that had highest electricity prediction errors did not report cooling energy while others from this sample did, even though they are part of the same university. The other explanation for this error is that characterization templates of these models assume more energy inefficient appliances and lighting systems than what is used in these buildings. This over-prediction of electricity use might be responsible for the under-prediction of heating, as heating loads are influenced by internal gains caused by lighting and electric equipment. The percentage error of total energy is equal for both methods $(-17 \%)$ while the RMSE of total energy predicted with the Wireframe method being slightly better. 


\subsubsection{Post-1980 Lowrise}

The comparison between Wireframe and Reference method prediction accuracies for the post-1980 Lowrise category is summarized in Table 39.

Table 39. Percentage Error and RMSE of post-1980 Lowrise buildings

\begin{tabular}{ccc|cc}
\hline & \multicolumn{2}{c}{ Percentage Error (\%) } & \multicolumn{2}{c}{ RMSE (\%) } \\
& Wireframe & Reference & Wireframe & Reference \\
\hline Heating & $18 \%$ & $6 \%$ & $24 \%$ & $15 \%$ \\
Electricity & $-44 \%$ & $-45 \%$ & $42 \%$ & $43 \%$ \\
Energy & $-7 \%$ & $-15 \%$ & $10 \%$ & $15 \%$ \\
Area & $4 \%$ & $0 \%$ & $5 \%$ & $19 \%$ \\
\hline
\end{tabular}

It is evident from this table that for aggregate energy, the Wireframe method has noticeably better prediction accuracy than the Reference method. For example, the Wireframe method underpredicted total energy consumption by $7 \%$, while the Reference method under-predicted consumption by $15 \%$. The RMSE of predicted energy shows that for individual building prediction the Wireframe method (10\%) is slightly better than the Wireframe (15\%), but both with credible values. The Wireframe method used $4 \%$ more area than what was measured to predict consumption. This results in more energy being predicted as more space is considered. The difference in predicted energy between the Wireframe and Reference method could be due to the additional area considered. When reviewing aggregate heating predictions, the Reference method predicted consumption $6 \%$ above what was measured, much better than the $18 \%$ over-predicted with the Wireframe method. Heating RMSE support these results, however, with greater variation. The difference between the Reference and Wireframe heating predictions are likely related to the form of the buildings. Aggregate electricity predictions were also compared, both the Wireframe (-44\%) and Reference (-45\%) methods were extremely poor, likely due to defined equipment and lighting efficiencies. Equipment and lighting efficiencies come from post-1980 DOE reference models and not from audits performed on these buildings. It is possible that more energy inefficient appliances, lighting, and equipment are used in these buildings. The under-prediction of electricity use might be partially responsible for the over-prediction of heating, as heating loads are influenced by internal gains caused by lighting and electric equipment. 


\subsubsection{Post-1980 Midrise}

Table 40 presents the Percentage Error and Root Mean Square Error of post-1980 Lowrise buildings.

Table 40. Percentage error and RMSE of post-1980 Midrise buildings

\begin{tabular}{ccc|cc}
\hline & \multicolumn{2}{c}{ Percentage Error (\%) } & \multicolumn{2}{c}{ RMSE (\%) } \\
& Wireframe & Reference & Wireframe & Reference \\
\hline Heating & $-1 \%$ & $-13 \%$ & $21 \%$ & $18 \%$ \\
Electricity & $-13 \%$ & $-11 \%$ & $18 \%$ & $19 \%$ \\
Energy & $-6 \%$ & $-12 \%$ & $17 \%$ & $17 \%$ \\
Area & $1 \%$ & $-2 \%$ & $3 \%$ & $12 \%$ \\
\hline
\end{tabular}

It is evident from this table that for aggregate energy, the Wireframe method has noticeably better prediction accuracy than the Reference method. For example, the Wireframe method underpredicted total energy consumption by $6 \%$, while the Reference method under-predicted consumption by $12 \%$. The RMSE of predicted energy is $17 \%$, suggesting that for individual building consumption both methods predict energy with the same accuracy. When reviewing heating predictions, the Wireframe method under-predicted consumption by $1 \%$ of what was measured, much better than the $13 \%$ under-predicted with the Reference method. Heating RMSE suggests that Wireframe models have greater error variation when predicting individual building heating consumption. The $18 \%$ percentage error difference between the Reference and Wireframe heating predictions is partially due to the form of the buildings. Electricity predictions of both the Wireframe (-13\%) and Reference (-11\%) methods were good. Equipment and lighting efficiencies come from post-1980 DOE reference models and not from audits performed on these buildings, so some variation is expected. In this sample, the percentage error of the Reference area is off by $2 \%$. This means that the model developed to represent post-1980 Midrise Reference models was $2 \%$ below the area mean of the sample. This is simply a modeling issue; however, this does not affect significantly the results as the EUI of the Reference model is then multiplied by measured areas. 


\subsubsection{Pre-1980 Highrise}

The comparison between Wireframe and Reference method prediction accuracies for the pre-1980 Highrise category is summarized in Table 41.

Table 41. Percentage error and RMSE of pre-1980 Highrise buildings

\begin{tabular}{|c|c|c|c|c|}
\hline & \multicolumn{2}{|c|}{ Percentage Error (\%) } & \multicolumn{2}{|c|}{ RMSE (\%) } \\
\hline & Wireframe & Reference & Wireframe & Reference \\
\hline Heating & $-24 \%$ & $-23 \%$ & $24 \%$ & $24 \%$ \\
\hline Electricity & $34 \%$ & $39 \%$ & $46 \%$ & $50 \%$ \\
\hline Energy & $-7 \%$ & $-4 \%$ & $17.2 \%$ & $17.3 \%$ \\
\hline Area & $-1 \%$ & $0 \%$ & $3 \%$ & $23 \%$ \\
\hline
\end{tabular}

It is evident from this table that for aggregate energy, the Reference method has slightly better prediction accuracy than the Wireframe method. For example, the Wireframe method underpredicted consumption by $7 \%$ while the Reference method under-predicted consumption by $4 \%$. The RMSE values show no significant variation $(0.1 \%)$ between the methods. Suggesting that both methods predict consumption with similar accuracy even when comparing individual building consumption. The Wireframe method used 1\% less area to predict consumption than what was measured. The difference in predicted energy between the methods is partially due to the Wireframe method using less area to predict consumption while the Reference method considers that which was measured. Electricity predictions of both the Wireframe (34\%) and Reference (39\%) methods were poor, likely due to defined equipment and lighting efficiencies. Equipment and lighting efficiencies come from pre-1980 DOE reference models and not from audits performed on these buildings. It is possible that more energy efficient appliances, lighting and equipment are used in these buildings. Having inefficient appliances and lighting systems increase internal heat gains, which in turn decreases heating energy. Suggesting once again that the overprediction of electricity use being partially responsible for the under-prediction of heating, as heating loads are influenced by internal gains caused by lighting and electric equipment. 


\subsubsection{Random Sampling}

To further explore the merits of the Reference and Wireframe methods, final building results were imported into a database and randomly sampled (20 times) without replacement to generate building subsets of varying sizes $(n=3,5,7,9,11,13,15,17$ and 19) with replacement between subset generation. The predicted annual total energy of each building was then totaled for each subset and compared with actual totals for the same buildings. The average total energy error rate is plotted against sample size for each method in Figure 64.

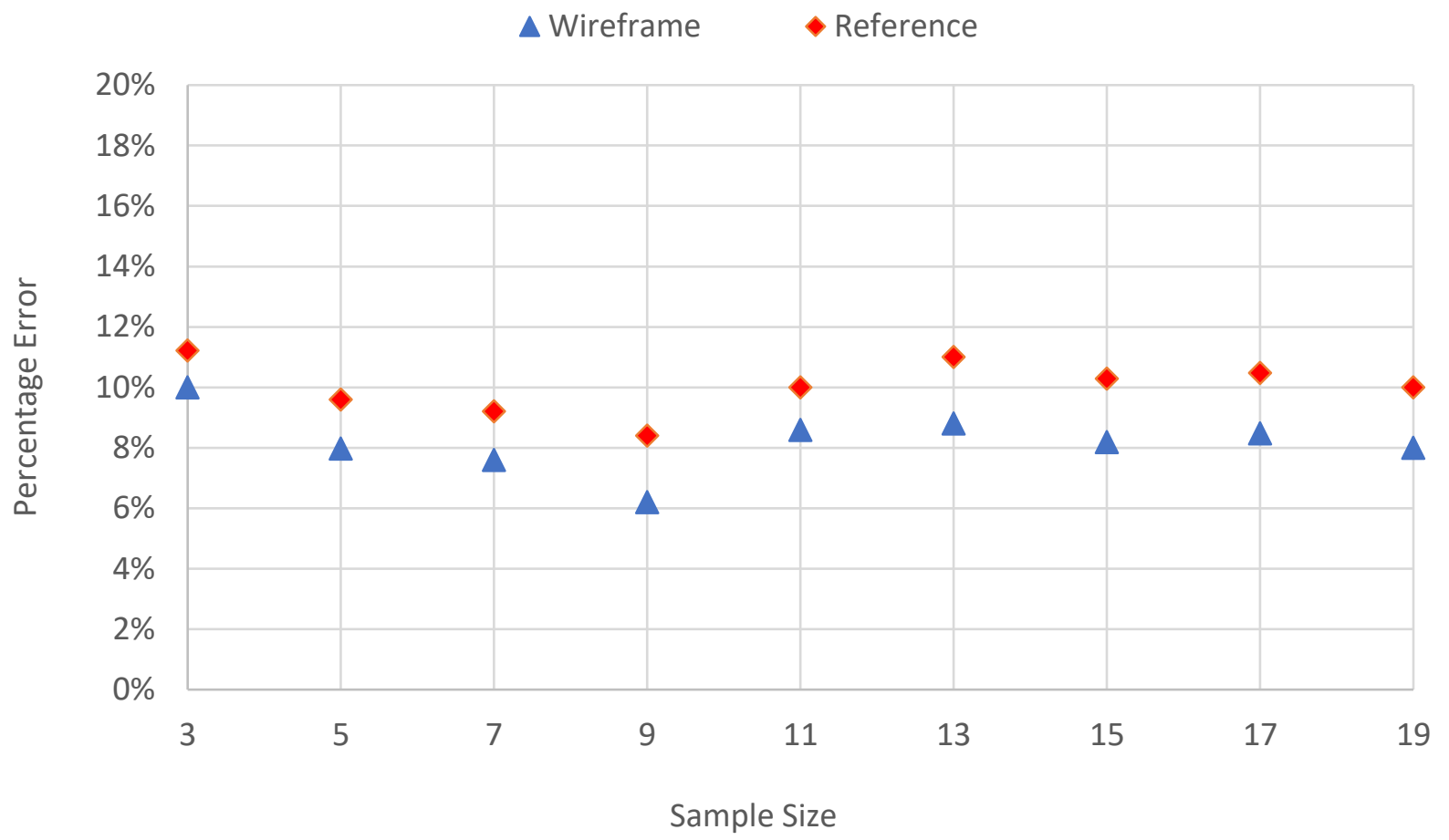

Figure 64. Average total energy error rate against sample size.

As seen in Figure 64, the error rates between the Wireframe and Reference methods do not seem to vary significantly with different sample sizes. Smaller samples seem to have more variation with error than larger sample sizes where the error finds a plateau state. In all samples the Reference method has a higher error, however the methods differ by less than $2 \%$, which raise questions as to the cost-benefit of accurately modeling the building's geometry and orientation as required in the Wireframe Method. 


\section{Discussion}

The findings of this study suggest that both the Reference and Wireframe methods can predict consumption with similar accuracy, including buildings which display high geometric complexity and low thermal resistivity envelopes. While the Wireframe method models tended to predict more heating energy usage than Reference method models, this difference is not substantial, particularly considering the incremental effort required for Wireframe modeling. Overall, the results of both methods are comparable in terms of total energy accuracy. Even when considering randomly generated sample sizes, both methods produced aggregate energy error between $6 \%$ and $12 \%$ which lie within acceptable parameters for large-scale energy reduction studies [54].

Individual BEM predictions can differ from measured data due to the uncertainty in occupancy patterns and it seemed therefore unlikely that the bottom-up methods would predict the energy use of Southern Ontario student residences with accuracy, particularly as the models were not based on building audits. However, the comparison of the aggregate annual measured consumption to simulated consumption resulted in percentage error ranges between $4 \%$ and $17 \%$ for total energy loads, and $6 \%$ to $31 \%$ for total heating loads in all four building categories. These error ranges are similar to the total aggregate energy range of $1 \%$ and $19 \%$ reported in $[64,65,66]$, and the total heating energy range of $7 \%$ and $21 \%$ reported in $[27,67,68,69]$. As one would expect, it is easier to predict aggregate energy than individual building energy with the use of reference models, which is why the total energy RMSE of all four building categories ranges from $10 \%$ to $26 \%$. This RMSE range is also comparable to building level results from a regional stock study which reported an error range of $12 \%$ to $55 \%$ [70] and urban model studies which reported error ranges between $5 \%$ to $99 \%[71,68,72]$. The ability of bottom-up methods to support energy and carbon reduction studies certainly depends on how reliable the simulation results are. Bottomup methods for large-scale analysis are not as effective at predicting individual building consumption due to occupancy and operational patterns. However, individual building energy results from Wireframe and Reference method predictions of this thesis only differed by a RMSE of 5\% in Lowrise models while both Midrise and Highrise models presented no statistically significant difference between the methods. Although bottom-up engineering methods using reference models to predict consumption are not commonly used for individual building 
consumption studies, this study proves that the accuracy of the Reference method is almost as good as the Wireframe method for individual building analysis.

Previous large-scale bottom-up consumption prediction studies have found that simulation error tends to decrease with higher construction standards [55]. Although predicted heating results of this thesis support previous findings (Figure 65), where post-1980 student residence categories had lower aggregate heating errors than those obtained with pre-1980 categories, it was also found that post-1980 categories had the largest variation between Reference and Wireframe predictions, contrary to the hypothesis, even though post-1980 categories had higher thermal resistivity values. This was unexpected, as one would assume that a model with high thermal resistivity values would be less influenced by the form and orientation of a building, since higher performance envelopes manage heat more effectively.

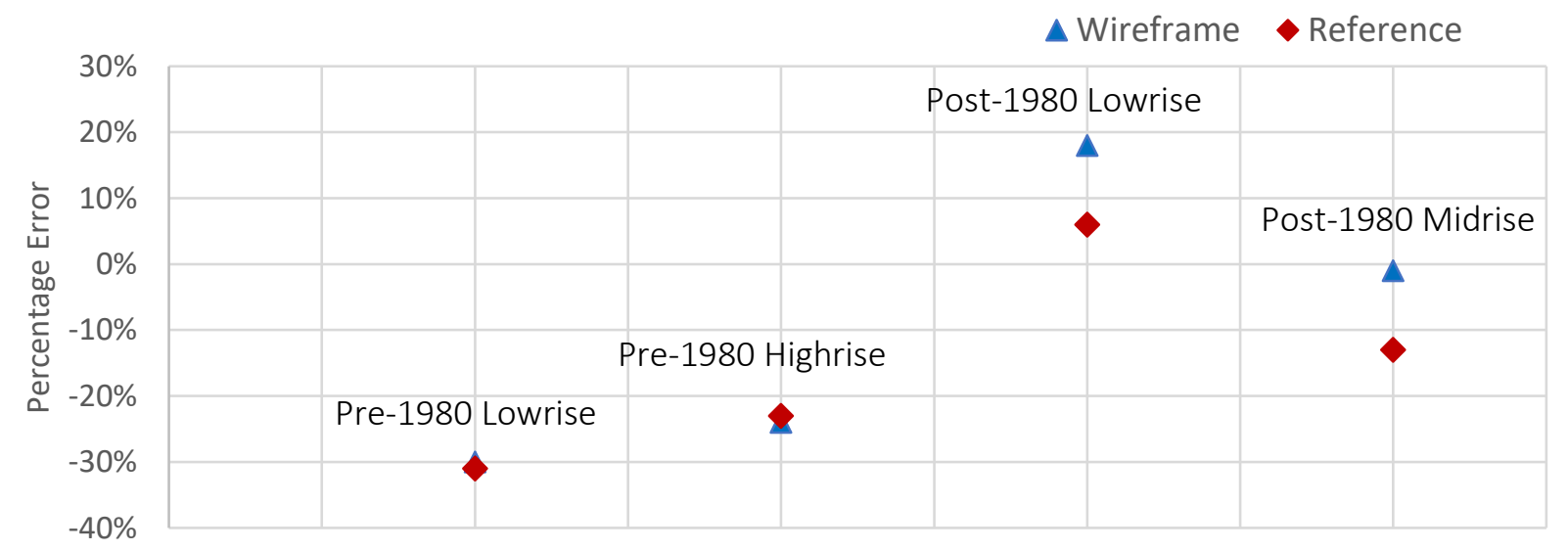

Figure 65. Heating Percentage Error produced by each category using Wireframe and Reference methods

After inspecting heating variation between Wireframe and Reference methods, it was determined that post-1980 Lowrise buildings had significant area variation between each other, resulting the Reference model area to have a larger Area RMSE 19\% when compared to that of other categories. This RMSE represents how similar the Reference model area is to individual measured building areas. A Reference model area with high RMSE suggests that the category, which the model represents, should be further subdivided by building area. It is a possible that if this is not addressed the heating percentage error between the methods will likely differ, which is the case in post-1980 Lowrise predictions, as the Reference model area does not accurately represent all buildings of the category. 
The other category with significant variation between Wireframe and Reference model heating predictions is the post-1980 Midrise. This category does not have an extremely high Area RMSE (12\% for Reference model), however it does have a Wireframe model (The Pond) that was identified as a potential limitation of the Wireframe approach The Pond residence has the highest heating use of the post-1980 Midrise category. This residence was modeled as two buildings as seen in (Figure 66). This is a modeling error; however, this is an issue that can be encountered by using the Wireframe method to predict consumption and should be discussed. In this scenario, The Pond residence was modelled with an increased surface area, which in turn increased heat loss.

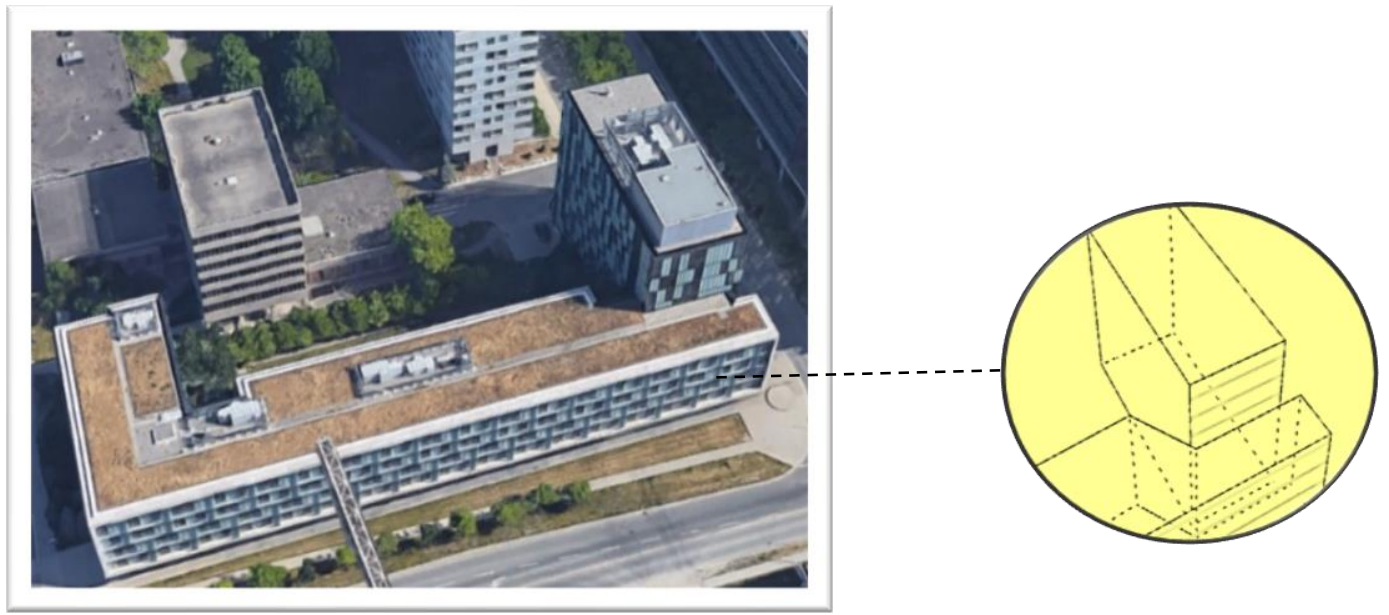

Figure 66. The Pond residence was modelled as two independent buildings rather than one.

Another limitation of the Wireframe method is that it tends to use larger or smaller areas than what is measured. Using different areas to those measured can produce an over-prediction or an under-prediction in consumption. For example, post-1980 Lowrise Wireframe models considered a $4 \%$ larger area than what was measured, which for this category caused the Wireframe model predictions to decrease their Percentage Error by increasing the category's total energy consumption. Originally, it was thought that the Wireframe method would be able to predict heating consumption with more accuracy for buildings with complex geometry, however, after encountering limitations of the Wireframe method, this does not appear to be true. To ensure the performance of Wireframe models, the modeler must ensure models accurately represent the building, which might be challenging when aiming to predict the consumption of dozens or hundreds of buildings. 
An interesting find of this thesis is that the Reference method predicted consumption with similar accuracy to that produced with the Wireframe method in Highrise buildings. This is likely due to the form of Highrise buildings, which tend to be relatively like each other. This suggests that for buildings with similar geometric complexity, the Reference method can predict consumption with similar or greater accuracy, as it considers measured areas to predict consumption, than by using an approach like the Wireframe method. As noted above, building categories that had high RMSE of Reference model area had the largest variation between Wireframe and Reference method predicted consumption, this was the case for all categories except the pre-1980 Highrise category. The reason why the pre-1980 Highrise category was not as affected by having high area deviations in its sample is due to the form of most buildings part of this category. Highrise buildings are tall structures that commonly follow a simple geometry. The large Area RMSE of the Highrise category is due to some of its buildings having a few more stories than the rest. Perhaps the Percentage Errors would have been greater if Highrise buildings considered in this study had significant height deviations, as a 50-floor building will most likely have different consumption levels when compared to a 20-floor building due to pressure differentials produced by the environment at different heights (Figure 67).

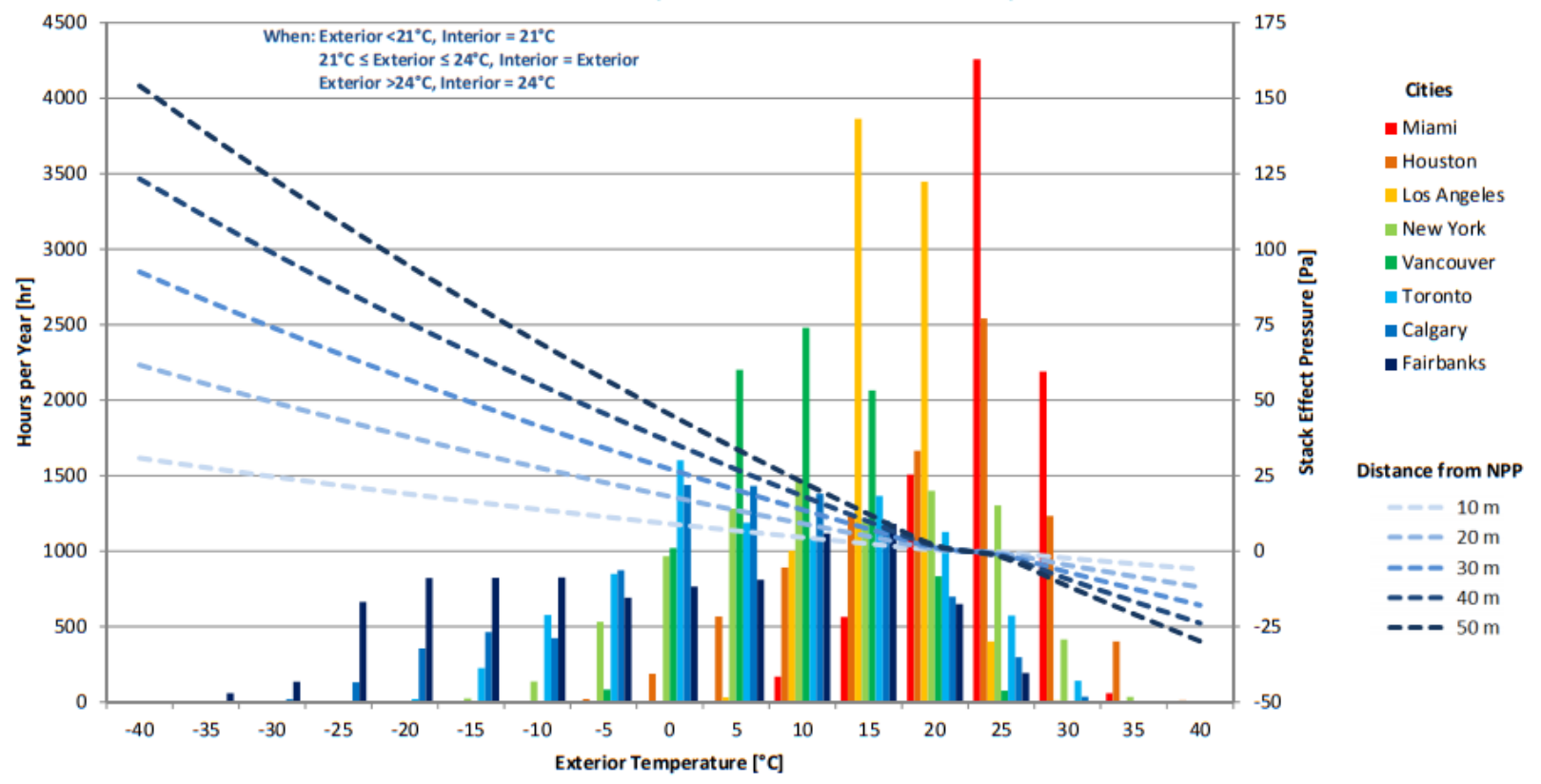

Figure 67. Stack effect pressure variability in buildings of different heights [73] 


\subsection{Error Discussion}

This section displays limitations of this study, particularly those related to model predictions. Reference models created for this study are quite simple. Developing simple energy models was decided early on, as many energy models needed to be simulated, in addition to the ability of creating characterization templates that could be easily applied to thermal zoning schemes. Energy models presented in this thesis were subdivided into five thermal zones, four perimeter zones and one core. Even though the models were divided into different thermal zones, all considered the same activity template. Therefore, the models could be considered as single zone energy models, that are known to have limitations in predicting accurate cooling loads [55]. Additionally, conditioning setpoints of the energy models were defined at $21^{\circ} \mathrm{C}$ for both cooling and heating. This setpoint is atypical in Canada, where it is more common to use $22^{\circ} \mathrm{C}$ heating and $24-26^{\circ} \mathrm{C}$ cooling setpoints. The difference in common conditioning setpoints and values used in the energy models can lead to an under-estimation of heating and an over-estimation of cooling loads, however this $21^{\circ} \mathrm{C}$ setpoint was taken from DOE model inputs and were therefore assumed suitable for this study. Another limitation of the simulation predictions is the Weather file selected for simulations. Models were compared against measured 2013 data and therefore a 2013 Weather file should have been selected to run simulations. The CWEC Toronto Weather file contains hourly weather observations to represent an artificial one-year period specifically designed for energy calculations. This weather file is required by the NECB to be used for energy performance path studies, however, a measured 2013 Toronto EPW weather file could have produced more accurate results. Other limitations of this study regard to their characterization inputs. For starters, not all buildings have their construction period disclosed, which results in vintage assumptions. Additionally, the vintages used to define templates are based on initial construction dates and do not consider if a building has been renovated or retrofitted. This assumption may cause the energy models to have lower performance than what is in place. Moreover, U.S. DOE reference models that use actual survey data were not available for the Highrise Apartment model and therefore the 2004 DOE prototypical model of Highrise Apartments had to be considered. Lastly, post-1980 buildings have larger variability than pre-1980 categories, this can alter results as pre-1980 buildings will all be relatively similar while post-1980 buildings can go from very efficient (2004 vintage) to very inefficient (1981 vintage). 


\subsection{Future Research}

This thesis evaluated two methods for estimating institutional building energy use to inform resource and emission reduction strategies. The purpose of this work was to identify an approach that would be suitable to inform better policy and incentives for Ontario's institutional sector. The methods that were explored are based on bottom-up engineering models that rely on reference energy models. Defined reference models were based on U.S. DOE commercial reference buildings due to data scarcity, however, this work could be improved by considering real data from the institutional sector. Institutional reference models will be necessary in years to come to better define policy and incentives, therefore, developing reference models that accurately represent the institutional building stock is of critical importance. A limitation of this study is that only one window-to-wall ratio was considered for all buildings. This was done be able to compare the methods across categories, however, considering different glazing ratios could change the results presented in this thesis and should be further explored. Thermal zoning was also a stationary value for all buildings. Considering more complex zoning layouts and assigning different activity templates to the zones would also build upon this research. One of the benefits of the Wireframe method is that it allows for multiple buildings to be simulated at once. Comparing Wireframe predictions that considered all buildings part of an institution against Reference predictions would also allow to better understand the merits of each method, as all buildings from an institution would be simulated at once, where microclimate phenomena and the effect of adjacent buildings would be considered in Wireframe method predictions but not in Reference method predictions.

\subsection{Research Implications}

To manage and reduce emissions caused from the built environment, cities and provinces need to better understand both which buildings generate those emissions and the potential effects of energy retrofit programs and energy infrastructure changes. This thesis demonstrates that there is significant value in the Reference method for large-scale simulation and that the results obtained with the approach are like those obtained through a more detailed geometric analysis. This research is now serving as the basis for a district-scale simulation project at Ryerson University.

In addition, this thesis lays the foundation for future institutional reference model development while also identifies post-secondary building operations which can be used to represent both colleges and universities. 


\section{Conclusions}

Through the analysis of these results, it was determined that there is no drastic difference between Wireframe and Reference methods. The Wireframe models need to be carefully revised to ensure no modeling geometric errors are encountered, while the classification or segmentation process of a building stock is of critical importance to predict consumption accurately with the Reference method.

The key findings of this research can be summarized as follow:

1. Area classifications are significantly important for the Reference method.

2. Wireframe models are prone to more simulation errors due to complex geometries.

3. For institutional carbon reduction studies, the Reference method can predict similar total energy results to those produced with the Wireframe method.

4. Random sampling study suggests that the methods differ by less than $2 \%$ for a range of sample sizes (up to 20).

5. Wireframe will tend to predict larger consumption as these models have larger surface-tovolume ratios when compared to Reference method models.

6. Student residences vary the least between college and university buildings.

7. Categories with high RMSE of Reference simulated area can produce prediction errors.

8. Wireframe and Reference method electricity predictions do not differ significantly.

9. Wireframe and Reference method predictions for total heating do differ, however, the difference between the methods is not substantial considering the difference in effort.

10. The Reference method can produce as good or better results than the Wireframe method for buildings with non-complex geometries.

For planners and policy makers, the Reference method could be used to analyze the existing institutional stock to inform retrofit policies and incentives. The only added benefit of considering the Wireframe method, which was not explored in this thesis, is the effect that adjacent buildings and micro-climate phenomena can have on buildings. For large scale energy efficiency studies, where measured data is available, which is the case for Ontario institutional buildings, the Reference method is recommended as it requires less simulation time, will always use the real area of a building to predict its consumption, and allows reference models to be created with more complex thermal zoning schemes. 


\section{References}

[1] Department of Economic and Social Affairs, "World Urbanization Prospects: The 2014 Revisions, Highlights," United Nations, New York, 2014.

[2] Environment and Climate Change Canada, "Canada's Second Biennial Report on Climate Change," Government of Canada, Quebec, 2016.

[3] International Energy Agency, "Transition to Sustainable Buildings - Strategies and Opportunities to 2050," OECD/IEA, Paris, 2013.

[4] NRCan, "High-Performance Commercial and Institutional Building Design Metric: Discussion Paper," Natural Resources Canada, Ottawa, 2016.

[5] Natural Resources Canada, "Survey of Commercial and Institutional Energy Use Buildings 2009," Natural Resources Canada's Office of Energy Efficiency, Ottawa, 2012.

[6] 2030 Districts, "Toronto 2030 District," 2030 Districts, 2018. [Online]. Available: http://www.2030districts.org/toronto. [Accessed 801 2018].

[7] Natural Resources Canada, "Improve Your Building's Energy Performance: Energy Benchmarking Primer," Natural Resources Canada, Ottawa, 2014.

[8] L. G. Swan and I. V. Ugursal, "Modeling of End-Use Energy Consumption in the Residential Sector: A Review of Modeling Techniques," Renewable and Sustainable Energy Reviews, vol. 13, pp. 1819-1835, 2009.

[9] A. A. Famuyibo, Duffy, Aidan and P. Strachan, "Developing Archetypes for Domestic Dwellings - An Irish Case Study," Energy and Buildings, vol. 50, pp. 150-157, 2012.

[10] S. Corgnati, E. Fabriztio, M. Filippi and V. Monetti, "Reference buildings for cost optimal analysis: Method of definition and application," Applied Energy, vol. 102, pp. 983-993, 2013.

[11] J. Huang, H. Akbari, L. Rainer and R. Ritschard, "481 Prototypical Commercial Buildings for 20 Urban Market Areas," Gas Research Institute, Springfield, 1991.

[12] C. Cerezo Davila, C. Reinhart and J. Bemis, "Modeling Boston: A Workflow for the Generation of Complete Urban Building Energy Demand Models from Existing Urban Geospatial Data," Energy, vol. 117, pp. 237-250, 2016. 
[13] J. M. Penman, "A Database and Model of Energy Use in Nondomestic Building Stock of England and Wales," in Environment and Planning B: Planning and Design, London, 2000.

[14] Bettelle Pacific Northwest Laboratory, "Recommendations for Energy Conservation Standards and Guidelines for New Commercial Buildings," Bettelle Pacific Northwest Laboratory, Richland, 1983.

[15] Synergic Resources Corporation, "Cool storage market assessment in Florida Power and Light's Service Area," Florida Power and Light, Miami, 1986.

[16] Government of Ontario, "O. Reg. 397/11: ENERGY CONSERVATION AND DEMAND MANAGEMENT PLANS," 23 August 2011. [Online]. Available: https://www.ontario.ca/laws/regulation/r11397. [Accessed 22 November 2017].

[17] J. Straube, "buildingscience," Building Science Corporation, 1506 2012. [Online]. Available: https://buildingscience.com/documents/insights/bsi-061-function-formbuilding-shape-and-energy. [Accessed 201610 2016].

[18] L. Perez-Lombard, J. Ortiz, R. Gonzalez and I. R. Maestre, "A review of benchmarking, rating and labelling concepts within the framework of building energy certification schemes," Energy and Buildings, vol. 41, pp. 272-278, 2008.

[19] Z. Hart, "The benefits of benchmarking building performance," Institute for Market Transformation and Pacific Coast, Washington, 2015.

[20] San Francisco Department of the Environment, "San Francisco Existing Commercial Buildings Performance Report," San Francisco Department of the Environment, San Francisco, 2015.

[21] "The Energy Reporting Requirement - A Background Report," 2014.

[22] Natural Resources Canada, "Survey of Commercial and Institutional Energy Use: Buildings 2009," Office of Energy Efficiency, Ottawa, 2013.

[23] Energy Star, "energystar.gov," [Online]. Available: https://www.energystar.gov/buildings/facility-owners-and-managers/existingbuildings/use-portfolio-manager. [Accessed 209 2017].

[24] Energy Star Portfolio Manager, "Canadian Energy Use Intensity by Property Type," Energy Star, 2016. 
[25] K. McCusker, "Measuring, Managing and Visualizing Building Energy Consumption \& Carbon Emissions: Benchmarking at the University of Massachusetts Amherst," Sustainable UMass, Amherst, 2013.

[26] TABULA, "Typology Approach for Building Stock Energy Assessment. Main Results of the TABULA project," Institut Wohnen und Umwelt GmbH, Darmstadt, 2012.

[27] G. Dall'O, A. Galante and M. Torri, "A methodology for the energy performance classification of residential building stock on an urban scale," Energy and Buildings, vol. 48, pp. 211-219, 2012.

[28] G. Panayiotoua, S. Kalogiroua, G. Floridesa, C. Maxoulisb, A. Papadopoulosc, M. Neophytoud, P. Fokaidesd, G. Georgioud, A. Symeoue and G. Georgakisf, "The characteristics and the energy behaviour of the residential building stock of Cyprus in view of Directive 2002/91/EC," Energy and Buildings, vol. 42, pp. 2083-2089, 2010.

[29] M. Benejam, E. Mata, A. Klagasidis and F. Johnson, "Bottom - up Characterization of the Spanish Building Stock for Energy Assessment and Model Validation," Chalmers University of Technology, Goteborg, 2012.

[30] H. Akbari, K. Heinemeier, P. LeConian and D. Flora, "An Algorithm to Disaggregate Commercial Whole-Building Hourly Electrical Load Into End Uses," Lawrence Berkeley Laboratory, Berkeley, 1988.

[31] A. K. Persily, "Airtightness of Commercial and Institutional Buildings: Blowing Holes in the Myth of Tight Buildings," in Thermal Envelopes VII, Clearwater, 1988.

[32] H. Akbari, J. Eto and I. Turiel, "Integrated Estimation of Commercial Sector End-Use Load Shapes and Energy Use Intensities," Lawrence Berkeley Laboratory, Berkeley, 1989.

[33] H. Akbari, J. Eto, S. Konopacki, A. Afzal, K. Heinmeier and L. Rainer, "A New Approach to Estimate Commercial Sector End-Use Load Shapes and Energy Use Intensities," Lawrence Berkeley Laboratory, Berkely, 1994.

[34] J. Huang and E. Franconi, "Commercial Heating and Cooling Loads Component Analysis," Lawrence Berkeley National Laboratory, Berkeley, 1999.

[35] M. Deru, B. Griffith and P. Torcellini, "Establishing Benchmarks for DOE Commercial Building R\&D and Program Evaluation," in ACEEE Summer Study, Pacific Grove, 2006.

[36] U.S. Census Bureau, "2000 US Census," U.S. Department of Commerce, Washington, 2002. 
[37] U.S. Census Bureau, "2002 Economic Census: Sector 23: Construction: Geographic Area Series: Value of Construction Work for Establishments by Type of Construction: 2002," U.S. Department of Commerce, Washington, 2005.

[38] Energy Information Administration, "2003 Commercial Building Energy Consumption Survey," EIA, Washington, 2006.

[39] R.S. Means Company, 2005 Square Foot Costs, Kingston: Gordian, 2004.

[40] K. Seryak and K. Kissock, "Occupancy and Behavioral Affects on Residential Energy Use," in Solar Conference, Austin, 2003.

[41] C. Cerezo, J. Sokol, C. Reinhart and A. Al-Mumin, "Three Methods for Characterizing Building Archetypes in Urban Energy Simulation," in 14th Conference of International Building Performance Simulation Association, Hyderabad, 2015.

[42] N. So and R. Richman, "A High Level Method to Disaggregate Electricity for ClusterMetered Buildings," Energy and Buildings, vol. 111, pp. 351-368, 2016.

[43] Y. Chen, H. Tan and U. Berardi, "Day-ahead Prediction of Hourly Electric Demand in NonStationary," Energy and Buildings, vol. 148, pp. 228-237, 2017.

[44] U. Wilke, F. Haldi, J.-L. Scartezzeni and D. Robinson, "A Bottom-up Schochastic Model to Predict Building Occupants' Time-Dependent Activities," Building and Environment, vol. 60, pp. 254-264, 2013.

[45] T. J. W., Exploratory Data Analysis, Addison-Wesley, 1977.

[46] C. F. Reinhart and C. Cerezo Davila, "Urban Building Energy Modeling - A Review of a Nascent Field," Buildings and Environment, vol. 97, pp. 196-202, 2015.

[47] City of Toronto, 2017. [Online]. Available: https://www1.toronto.ca/wps/portal/contentonly?vgnextoid=d431d477f9a3a410VgnVC M10000071d60f89RCRD\&vgnextchannel=1a66e03bb8d1e310VgnVCM10000071d60f89 RCRD.

[48] City of Oakville, "Open Data Catalogue," 2017. [Online]. Available: https://www.oakville.ca/data/catalogue.html.

[49] City of St. Catharines, "Open Data Catalogue," 2017. [Online]. Available: https://www.stcatharines.ca/en/Niagara-Open-Data.asp.

[50] Lambton County, "Lambton County GIS," 2017. [Online]. Available: https://www.lambtongis.ca/. 
[51] Daft Logic, "Distance Calculator," [Online]. Available:

https://www.daftlogic.com/projects-google-maps-distance-calculator.htm.

[52] Architectural Conservancy Ontario, "Architectural Conservancy Ontario," [Online]. Available: http://www.acotoronto.ca. [Accessed 0707 2017].

[53] Council of Ontario Universities, "Ontario Universities' Facilities Condition Assessment Program," Council of Ontario Universities, Toronto, 2016.

[54] C. F. Reinhart and D. C. Cerezo, "Urban building energy modeling - A review of a nascent field," Building and Environment, vol. 97, pp. 196-202, 2016.

[55] T. Doga and C. Reinhart, "Shoeboxer: An algorithm for abstracted rapid multi-zone urban," Energy and Buildings, vol. 140, pp. 140-153, 2017.

[56] Numerical Logics, "Canadian Weather for Energy Calculations, Users Manual and CDROM," Environment Canada, Downsview, 1999.

[57] NRC Construction, "The National Energy Code of Canada for Buildings 2011 (NECB)," National Research Council Canada, Ottawa, 2012.

[58] Portfolio Manager, "U.S. Energy Use Intensity by Property Type," Energy Star , 2016.

[59] W. Jiang, R. Jarnaging, K. Gowri, M. McBride and B. Liu, "Technical Support Document: The Development of the Advanced Energy Design Guide for Highway and Lodging Buildings," Pacific Nortwhest National Laboratory, Tennessee, 2008.

[60] K. Gowri, M. Halverson and E. Richman, "Analysis of Energy Savings Impacts of ASHRAE 90.1-2004 for the State of New York," Pacific Northwest National Laboratory, Richland, 2007.

[61] H. M. Sachs, "Opportunities for Elevator Energy Efficiency Improvements," American Council for an Energy-Efficient Economy (ACEEE), Washington , 2005.

[62] ASHRAE, Ashrae Handbook: Heating Ventilation and Air Conditioning Applications Si, Amer Society of Heating, 2007.

[63] R. Hendron, "Building America Research Benchmark Definition," NREL, Golden, 2008.

[64] S. Heiple and D. J. Sailor, "Using building energy simulation and geospatial modeling techniques to determine high resolution building sector energy consumption profiles," Energy and Buildings, vol. 40, no. 8, pp. 1426-1436, 2008. 
[65] Y. Shimoda and M. Mizuno, "Residential end-use energy simulation at city scale," Building and Environment, vol. 39, no. 8, pp. 959-967, 2004.

[66] P. Caputo, G. Costa and S. Ferrari, "A supporting method for defining energy strategies in the building sector at urban scale," Energy Policy, vol. 55, pp. 261-270, 2013.

[67] E. G.Dascalaki and S. Kontoyiannidis, "Building typologies as a tool for assessing the energy performance of residential buildings - A case study for the Hellenic building stock," Energy and Buildings, vol. 43, no. 12, pp. 3400-3409, 2011.

[68] R. Nouvel, C. Schulte, U. Eicker and D. Pietruschka, "CityGML-Based 3D City Model For Energy Diagnostics And Urban Energy Policy Support," in 13th Conference of International Building Performance Simulation Association, Chambery, 2013.

[69] K. Orehounig, G. Mavromatidis and R. Evins, "Predicting energy consumption of a neighbourhood using building performance simulations," in Building Simulation and Optimization (BSO), London, 2014.

[70] I. Theodoridou and M. Heggera, "A typological classification of the Greek residential building stock," Energy and Buildings, vol. 43, no. 10, pp. 2779-2787, 2011.

[71] P. Sehrawat and K. Kensek, "URBAN ENERGY MODELING: GIS AS AN ALTERNATIVE TO BIM," in ASHRAE/IBPSA-USA Bldg Simulation Conference, Atlanta, 2014.

[72] F. Koene, L. Bakker, D. Lanceta and S. Narmsara, "Simplified Building Model of Districts," in Fifth German-Austrian IBPSA Conference, 2014.

[73] L. Ricketts, G. Finch and J. Straube, "Pressure Differences and Airtightness in Tall Buildings - Theory and Reality," 2015.

[74] Energy Information Administration, "Commercial Building Characteristics 1989," U.S. Department of Energy, Washington, 1991.

[75] M. Raman, "Mitigating Climate Change: What America's Building Industry Must Do," Design Intelligence, Georgia, 2009.

[76] U.S. Department of Energy, "Building Energy Codes Program," Pacific Northwest National Laboratory, 14 April 2016. [Online]. Available: https://www.energycodes.gov/development/commercial/prototype_models. [Accessed 16 September 2017].

[77] B. Griffith, P. Torcellini and N. Long, "Assessment of the Technical Potential for Achieving Zero-Energy Commercial Buildings," in ACEEE Summer Study, Pacific Grove, 2006. 
[78] Collins English Dictionary - Complete \& Unabridged 10th Edition, "Dictionary.com: outlier," HarperCollins Publishers, [Online]. Available:

http://www.dictionary.com/browse/outlier. [Accessed 1906 2017]. 
Appendix A: Post-Secondary Energy Benchmarks by Building Type 


\section{Student Residence Buildings - Colleges}

Table A.1 - Initial sample of college residence buildings considered for benchmarking study.

\begin{tabular}{|c|c|c|c|c|c|c|}
\hline \multicolumn{7}{|c|}{ Student Residences - Colleges } \\
\hline College & Campus & n & $\Sigma(\mathbf{k W h})$ & SArea $\left(\mathrm{m}^{2}\right)$ & ekWh/m² & ekWh/ftt ${ }^{2}$ \\
\hline Seneca & Newnham & 1 & 8682045 & 35982 & 241 & 22 \\
\hline Centennial & Scarborough & 1 & 6321924 & 15122 & 418 & 39 \\
\hline St. Clair & Windsor & 2 & 49002 & 279 & 176 & 16 \\
\hline Humber & Lakeshore & 1 & 3253092 & 15538 & 209 & 19 \\
\hline Humber & North & 1 & 8865641 & 27087 & 327 & 30 \\
\hline Lambton & Sarnia & 1 & 2556997 & 7757 & 330 & 31 \\
\hline Niagara & Welland & 1 & 508040 & 6816 & 75 & 7 \\
\hline Sheridan & Oakville & 1 & 5713929 & 16279 & 351 & 33 \\
\hline
\end{tabular}

Table A.2 - Residence benchmarks without removing erroneous data entries.

\begin{tabular}{cccccccccc}
\hline \multicolumn{7}{c|}{ Student Residences EUI $\left(\mathrm{ekWh} / \mathrm{m}^{2}\right)$} & Before Outlier Removal \\
\hline Q1 & Mean & Median & Q3 & IQR & LAV & UAV & s & s (\%) \\
188 & 256 & 241 & 330 & 142 & -25 & 543 & 109 & $45 \%$ \\
\hline
\end{tabular}

Table A.3 - Residence benchmarks after removing erroneous data entries.

\begin{tabular}{|cccccccccc}
\hline \multicolumn{8}{c|}{ Residences EUI $\left(\mathrm{ekWh} / \mathrm{m}^{2}\right)$} & After & Outlier Removal \\
\hline Q1 & Mean & Median & Q3 & IQR & LAV & UAV & s & s (\%) \\
263 & 313 & 329 & 346 & 83 & 138 & 471 & 76 & $23 \%$ \\
\hline
\end{tabular}

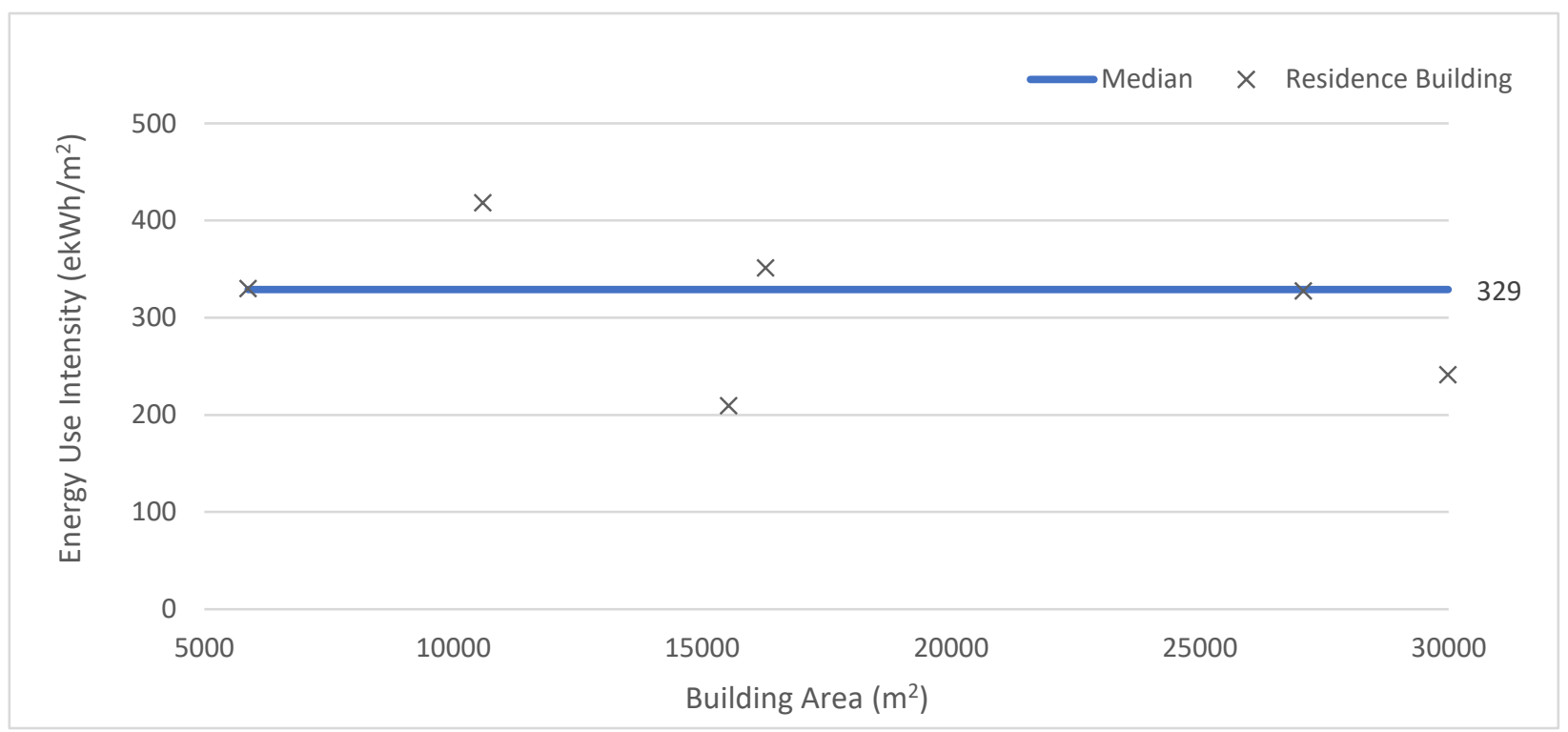

Figure A.1 - Residence buildings considered in the college developed benchmark 


\section{Student Residence Buildings - University}

Table A.4 - Initial sample of university residence buildings considered for benchmarking study.

\begin{tabular}{|c|c|c|c|c|c|c|}
\hline \multicolumn{7}{|c|}{ Residences - Universities } \\
\hline University & Campus & $\mathbf{n}$ & $\Sigma(\mathbf{k W h})$ & $\Sigma$ Area $\left(\mathbf{m}^{2}\right)$ & $\mathrm{ekWh} / \mathrm{m}^{2}$ & $\mathrm{ekWh} / \mathbf{f t}^{2}$ \\
\hline York & Toronto & 16 & 53468115 & 138655 & 386 & 36 \\
\hline Brock & St. Catharines & 3 & 6765013 & 38258 & 177 & 16 \\
\hline
\end{tabular}

Table A.5 - Residence benchmarks without removing erroneous data entries.

\begin{tabular}{ccccccccc}
\hline \multicolumn{8}{c|}{ Residences EUI $\left(\mathrm{ekWh} / \mathrm{m}^{2}\right)$} & Before Outlier Removal \\
\hline Q1 & Mean & Median & Q3 & IQR & LAV & UAV & s & s (\%) \\
302 & 364 & 388 & 450 & 148 & 80 & 672 & 107 & $27 \%$ \\
\hline
\end{tabular}

Table A.6 - Residence benchmarks after removing erroneous data entries

\begin{tabular}{cccccccccc|}
\hline \multicolumn{8}{c|}{ Residences EUI $\left(\mathrm{ekWh} / \mathrm{m}^{2}\right)$} & After & Outlier Removal \\
\hline Q1 & Mean & Median & $\mathbf{Q 3}$ & IQR & LAV & UAV & s & s (\%) \\
302 & 364 & 388 & 450 & 148 & 80 & 672 & 107 & $27 \%$ \\
\hline
\end{tabular}

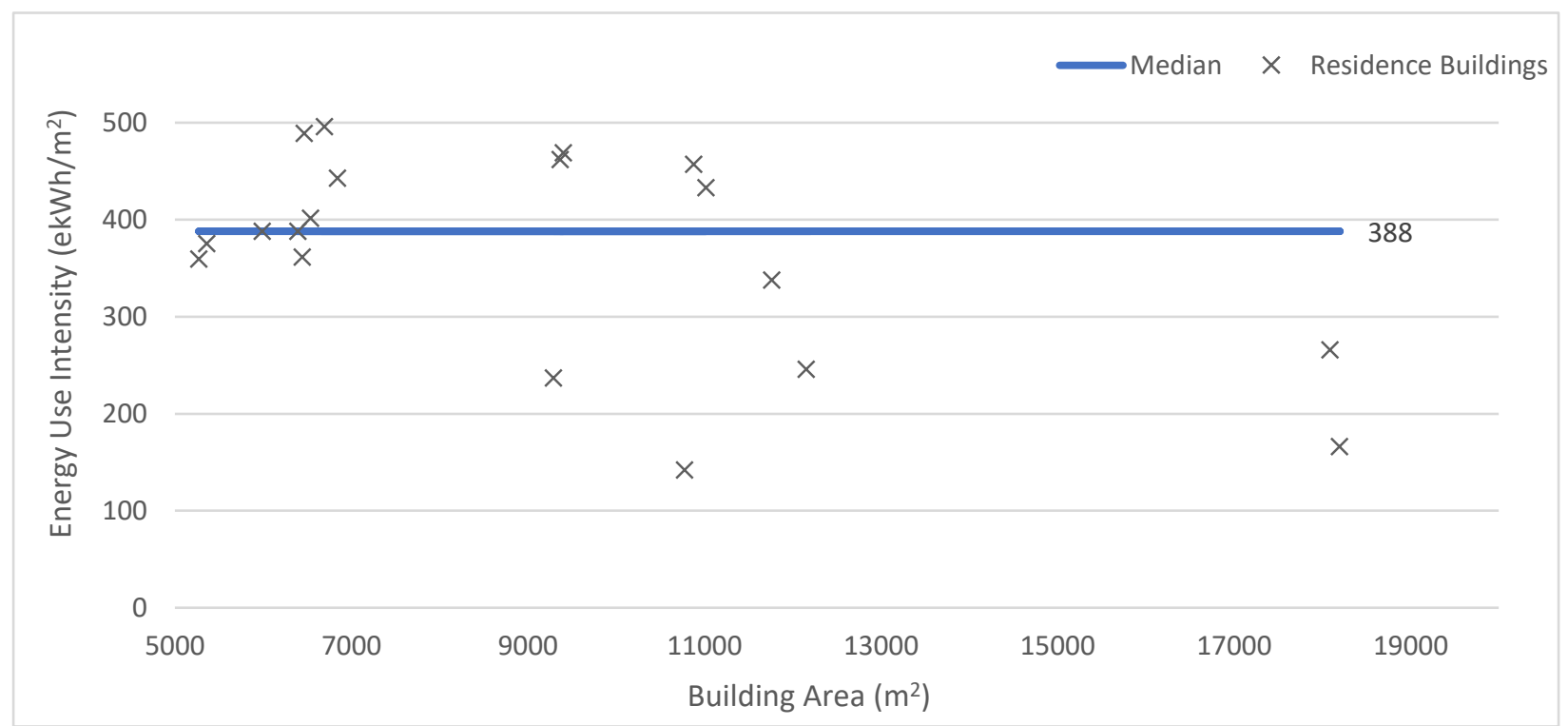

Figure A.2 - Residence buildings considered in the university developed benchmark. 


\section{Student Residence Buildings - College and University}

Table A.7 - Initial sample of university and college residence buildings considered for benchmarking study.

\begin{tabular}{|c|c|c|c|c|c|c|}
\hline \multicolumn{7}{|c|}{ Residences - Colleges and Universities } \\
\hline Operation & Campus & $\mathbf{n}$ & $\Sigma(\mathbf{k W h})$ & $\Sigma$ Area $\left(\mathbf{m}^{2}\right)$ & $\mathrm{ekWh} / \mathrm{m}^{2}$ & ekWh/ft ${ }^{2}$ \\
\hline Seneca & Newnham & 1 & 7236394 & 29990 & 241 & 22 \\
\hline Centennial & Scarborough & 1 & 4432239 & 10602 & 418 & 39 \\
\hline St. Clair & Windsor & 2 & 49002 & 279 & 176 & 16 \\
\hline St. Clair & Thames & 1 & 1977532 & 5506 & 359 & 33 \\
\hline Humber & Lakeshore & 1 & 3253092 & 15538 & 209 & 19 \\
\hline Humber & North & 1 & 8865641 & 27087 & 327 & 30 \\
\hline Lambton & Sarnia & 1 & 1938412 & 5880 & 330 & 31 \\
\hline Niagara & Welland & 1 & 508040 & 6816 & 75 & 7 \\
\hline Sheridan & Oakville & 1 & 5713929 & 16279 & 351 & 33 \\
\hline York & Toronto & 16 & 53468115 & 138655 & 386 & 36 \\
\hline Brock & St. Catharines & 3 & 6765013 & 38258 & 177 & 16 \\
\hline
\end{tabular}

Table A.8 - Residence benchmarks without removing erroneous data entries.

\begin{tabular}{|ccccccccc}
\hline \multicolumn{8}{|c|}{ Residences EUI $\left(\mathrm{ekWh} / \mathrm{m}^{2}\right)$} & Before Outlier Removal \\
\hline Q1 & Mean & Median & Q3 & IQR & LAV & UAV & s & s (\%) \\
241 & 331 & 359 & 418 & 177 & -24 & 683 & 115 & $32 \%$ \\
\hline
\end{tabular}

Table A.9 - Residence benchmarks after removing erroneous data entries

\begin{tabular}{|c|c|c|c|c|c|c|c|c|}
\hline \multicolumn{9}{|c|}{ Residences EUI (ekWh/m²) After Outlier Removal } \\
\hline Q1 & Mean & Median & Q3 & IQR & LAV & $\overline{\text { UAV }}$ & $\mathbf{S}$ & s (\%) \\
\hline 281 & 352 & 361 & 430 & 148 & 59 & 652 & 99 & $27 \%$ \\
\hline
\end{tabular}

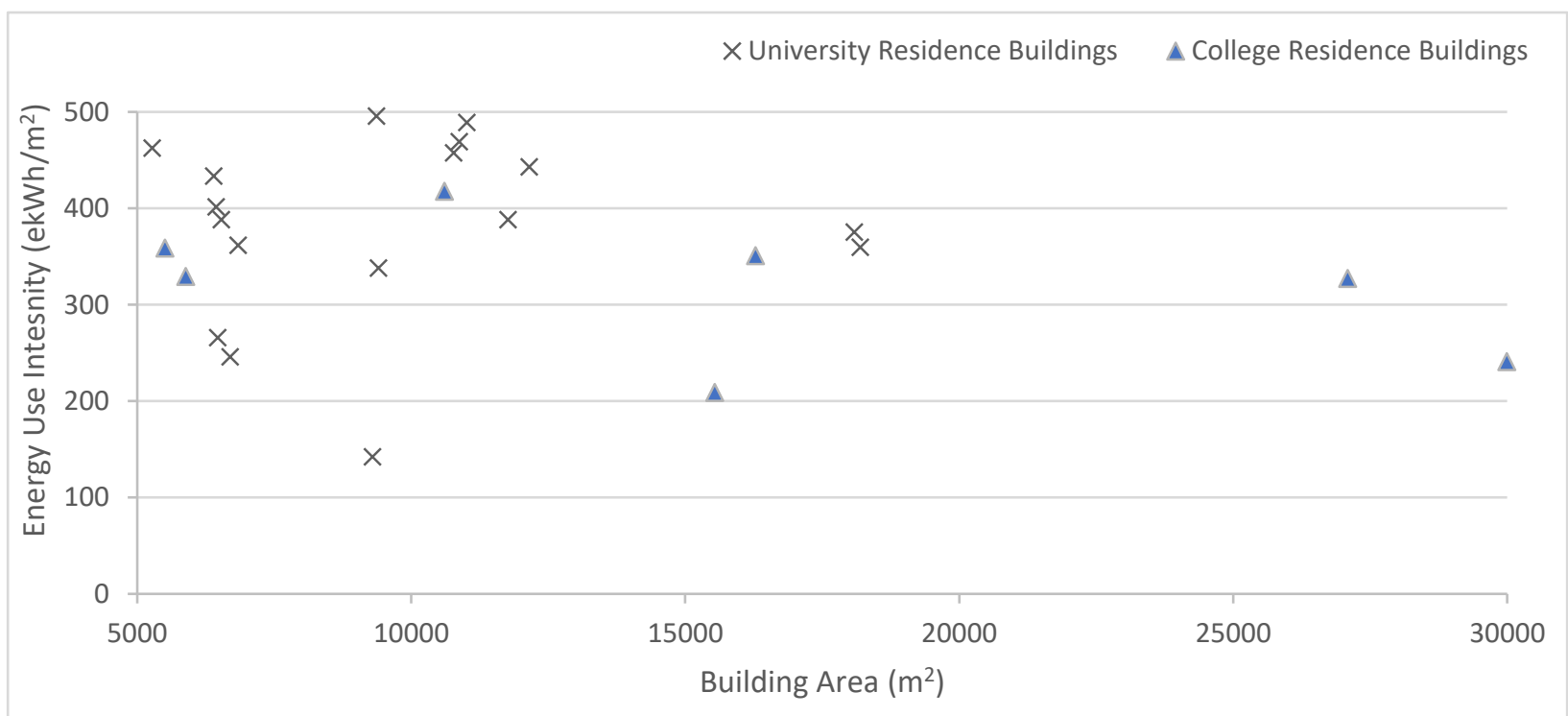

Figure A.3 - Residence buildings considered in the university and college developed benchmark. 


\section{Laboratory Buildings - College}

Table A.10 - Initial sample of college Laboratory buildings considered for benchmarking study.

\begin{tabular}{ccccccc|}
\hline \multicolumn{7}{c}{ Laboratories - Colleges } \\
\hline College & Campus & $\mathbf{n}$ & $\boldsymbol{\Sigma} \mathbf{( k W h )}$ & $\boldsymbol{\Sigma}$ Area $\left(\mathbf{m}^{\mathbf{2}}\right)$ & $\mathbf{e k W h} / \mathbf{m}^{\mathbf{2}}$ & $\mathbf{e k W h} / \mathbf{f t}^{\mathbf{2}}$ \\
Seneca & Newnham & 5 & 2605207 & 8914 & 292 & 27 \\
Centennial & Scarborough & 6 & 13459595 & 32814 & 410 & 38 \\
St. Clair & Windsor & 4 & 3302449 & 14649 & 225 & 21 \\
St. Clair & Thames & 1 & 199677 & 717 & 278 & 26 \\
Seneca & Jane & 1 & 475791 & 1041 & 457 & 42 \\
Seneca & York & 2 & 1472463 & 8047 & 183 & 17 \\
Lambton & Sarnia & 7 & 3580987 & 8645 & 414 & 38 \\
Niagara & Welland & 1 & 1010532 & 6823 & 148 & 14 \\
\hline
\end{tabular}

Table A.11 - Laboratory benchmarks without removing erroneous data entries.

\begin{tabular}{ccccccccc|}
\hline \multicolumn{8}{c|}{ Laboratories EUI $\left(\mathrm{ekWh} / \mathrm{m}^{2}\right)$} & Before Outlier Removal \\
\hline Q1 & Mean & Median & $\mathbf{Q 3}$ & IQR & LAV & UAV & s & s (\%) \\
211 & 343 & 278 & 410 & 198 & -86 & 707 & 208 & $75 \%$ \\
\hline
\end{tabular}

Table A.12 - Laboratory benchmarks after removing erroneous data entries

\begin{tabular}{ccccccccc|}
\hline \multicolumn{8}{c|}{ Laboratories EUI $\left(\mathrm{ekWh} / \mathrm{m}^{2}\right)$} & After Outlier Removal \\
\hline Q1 & Mean & Median & $\mathbf{Q 3}$ & IQR & LAV & UAV & s & s (\%) \\
210 & 281 & 240 & 336 & 126 & 22 & 525 & 98 & $41 \%$ \\
\hline
\end{tabular}

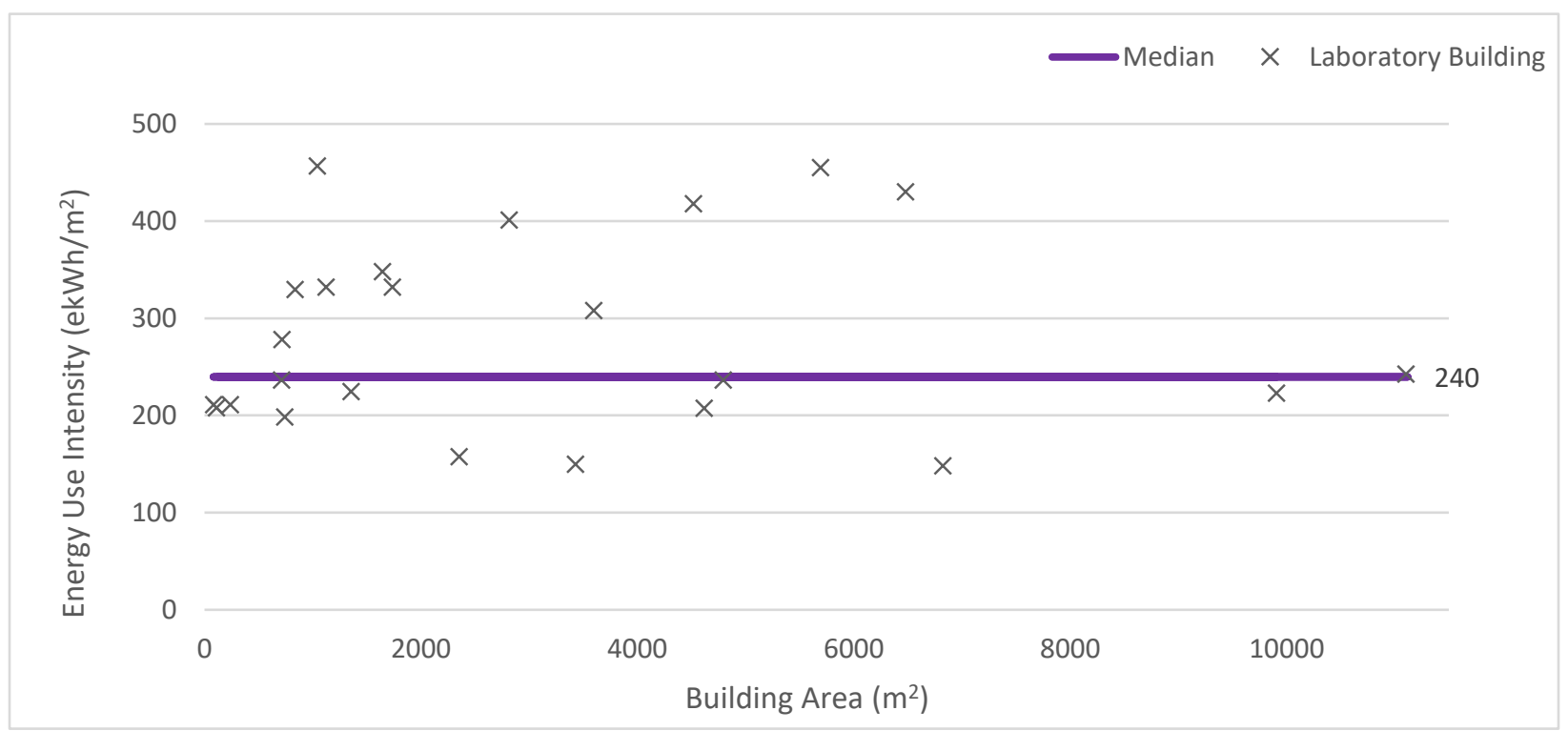

Figure A.4 - Laboratory buildings considered in the college developed benchmark. 


\section{Laboratory Buildings - University}

Table A.13 - Initial sample of university Laboratory buildings considered for benchmarking study.

\begin{tabular}{|c|c|c|c|c|c|c|}
\hline \multicolumn{7}{|c|}{ Laboratories - Universities } \\
\hline University & Campus & $\mathbf{n}$ & $\Sigma(\mathbf{k W h})$ & $\Sigma$ Area $\left(\mathbf{m}^{2}\right)$ & $\mathrm{ekWh} / \mathrm{m}^{2}$ & ekWh/ft ${ }^{2}$ \\
\hline York & Toronto & 6 & 61475596 & 93188 & 660 & 61 \\
\hline Brock & St Catharines & 1 & 17218666 & 16367 & 1052 & 98 \\
\hline Ontario & Oshawa & 1 & 6971337 & 11827 & 589 & 55 \\
\hline
\end{tabular}

Table A.14 - Laboratory benchmarks without removing erroneous data entries.

\begin{tabular}{ccccccccc}
\hline \multicolumn{8}{c|}{ Laboratories EUI $\left(\mathrm{ekWh} / \mathrm{m}^{2}\right)$} & Before Outlier Removal \\
\hline Q1 & Mean & Median & $\mathbf{Q 3}$ & IQR & LAV & UAV & s & s (\%) \\
502 & 619 & 623 & 644 & 141 & 290 & 856 & 190 & $31 \%$ \\
\hline
\end{tabular}

Table A.15 - Laboratory benchmarks after removing erroneous data entries

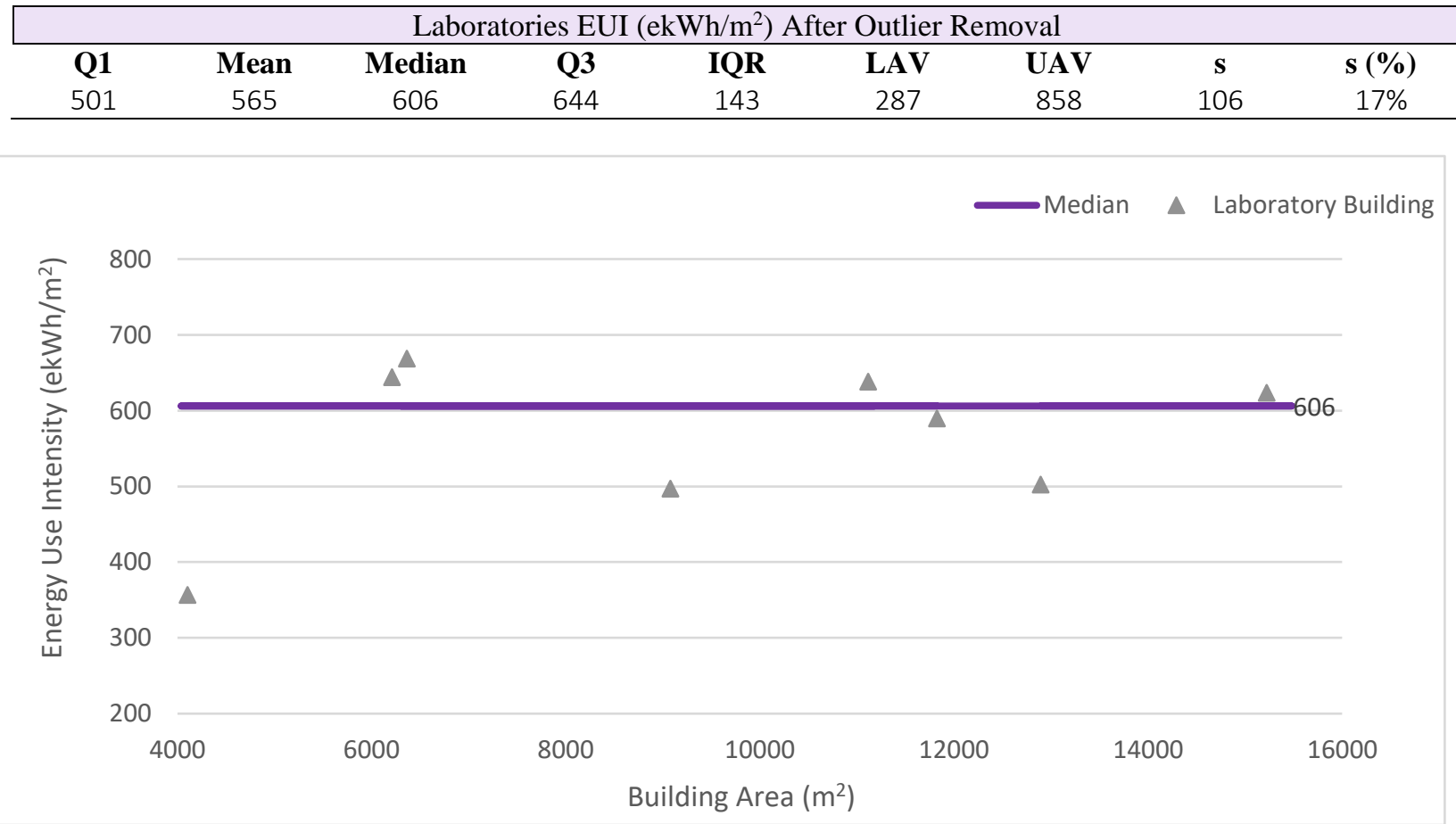

Figure A.5 - Laboratory buildings considered in the university developed benchmark. 


\section{Laboratory Buildings - College and University}

Table A.16 - Initial sample of college and university Laboratory buildings considered for benchmarking study.

\begin{tabular}{|c|c|c|c|c|c|c|}
\hline \multicolumn{7}{|c|}{ Laboratories - Colleges \& Universities } \\
\hline Operation & Campus & $\mathbf{n}$ & $\Sigma(\mathbf{k W h})$ & $\Sigma$ Area $\left(\mathrm{m}^{2}\right)$ & ekWh/m m $^{2}$ & ekWh/ft' \\
\hline Seneca & Newnham & 5 & 2605207 & 8914 & 292 & 27 \\
\hline Centennial & Scarborough & 6 & 13459595 & 32814 & 410 & 38 \\
\hline St. Clair & Windsor & 4 & 3302449 & 14649 & 225 & 21 \\
\hline St. Clair & Thames & 1 & 199677 & 717 & 278 & 26 \\
\hline Seneca & Jane & 1 & 475791 & 1041 & 457 & 42 \\
\hline Seneca & York & 2 & 1472463 & 8047 & 183 & 17 \\
\hline Lambton & Sarnia & 7 & 3580987 & 8645 & 414 & 38 \\
\hline Niagara & Welland & 1 & 1010532 & 6823 & 148 & 14 \\
\hline York & Toronto & 6 & 61475596 & 93188 & 660 & 61 \\
\hline Brock & St Catharines & 1 & 17218666 & 16367 & 1052 & 98 \\
\hline Ontario & Oshawa & 1 & 6971337 & 11827 & 589 & 55 \\
\hline
\end{tabular}

Table A.17 - Laboratory benchmarks without removing erroneous data entries.

\begin{tabular}{ccccccccc|}
\hline \multicolumn{8}{|c|}{ Laboratories EUI $\left(\mathrm{ekWh} / \mathrm{m}^{2}\right)$} & Before Outlier Removal \\
\hline Q1 & Mean & Median & $\mathbf{Q 3}$ & IQR & LAV & UAV & s & s (\%) \\
223 & 373 & 332 & 457 & 234 & -128 & 808 & 198 & $60 \%$ \\
\hline
\end{tabular}

Table A.18 - Laboratory benchmarks after removing erroneous data entries.

\begin{tabular}{ccccccccc}
\hline \multicolumn{8}{c|}{ Laboratories EUI $\left(\mathrm{ekWh} / \mathrm{m}^{2}\right)$} & After Outlier Removal \\
\hline Q1 & Mean & Median & $\mathbf{Q 3}$ & IQR & LAV & UAV & s & s (\%) \\
220 & 347 & 331 & 456 & 235 & -133 & 808 & 159 & $48 \%$ \\
\hline
\end{tabular}

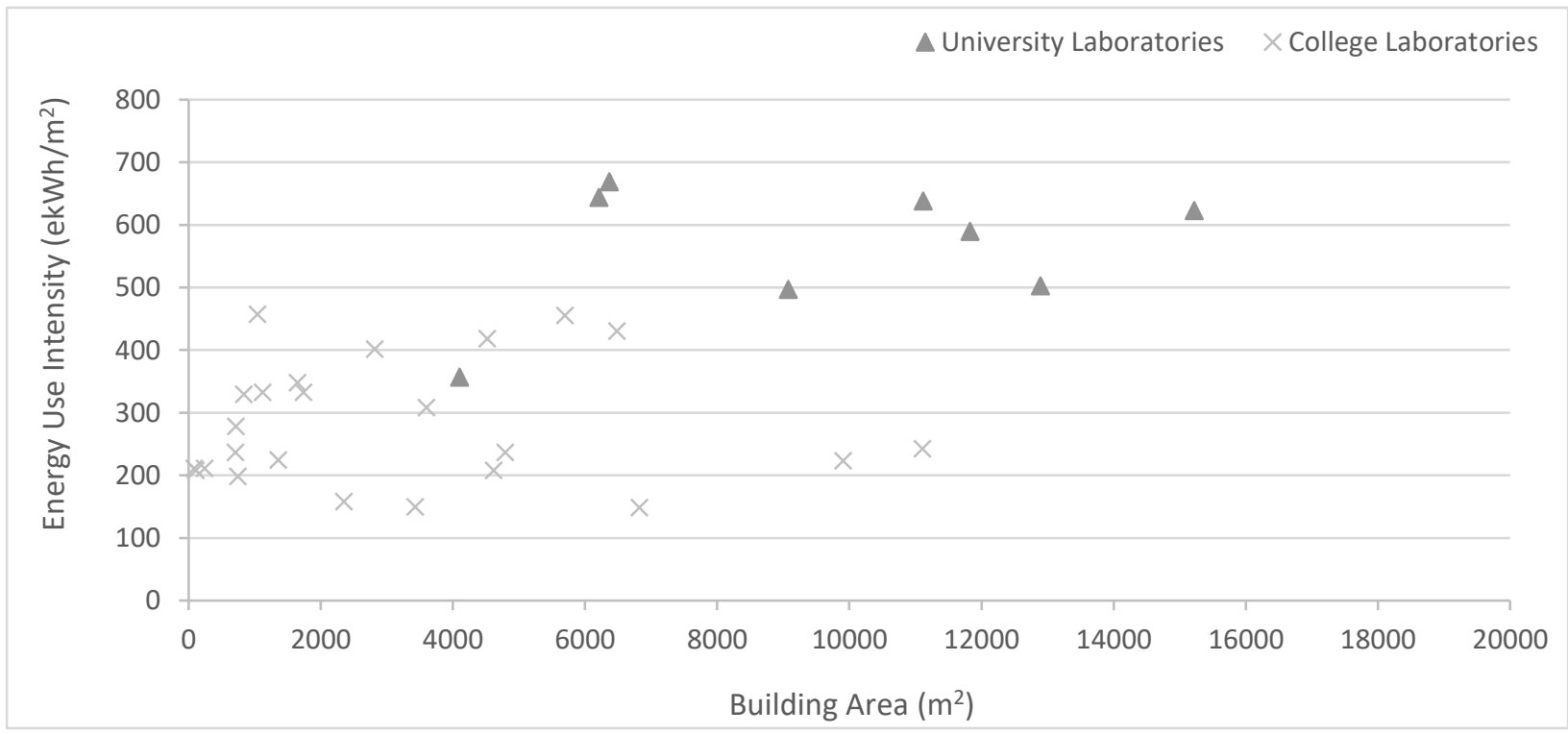

Figure A.6 - Laboratory buildings considered in the college and university developed benchmark. 


\section{Classroom and Related Facilities - College}

Table A.19 - Initial sample of college Classroom and Related Facilities considered for benchmarking study.

\begin{tabular}{ccccccc|}
\hline \multicolumn{7}{c}{ Classrooms and Related Facilities - Colleges } \\
\hline College & Campus & $\mathbf{n}$ & $\boldsymbol{\Sigma}(\mathbf{k W h})$ & $\boldsymbol{\Sigma}$ Area $\left(\mathbf{m}^{\mathbf{2}}\right)$ & $\mathbf{e k W h} / \mathbf{m}^{\mathbf{2}}$ & $\mathbf{e k W h} / \mathbf{f t}^{\mathbf{2}}$ \\
Lambton & Sarnia & 5 & 7056923 & 16516 & 427 & 40 \\
St. Clair & Thames & 1 & 2273758 & 6956 & 327 & 30 \\
St. Clair & Windsor & 2 & 53221552 & 109382 & 487 & 45 \\
Seneca & Newnham & 10 & 8512740 & 32965 & 258 & 24 \\
Seneca & Jane & 1 & 210831 & 461 & 457 & 42 \\
Seneca & York & 2 & 2775512 & 14706 & 189 & 17 \\
George Brown & Casa Loma & 4 & 17131034 & 59020 & 290 & 27 \\
George Brown & St. James & 5 & 25953198 & 63086 & 411 & 38 \\
George Brown & Waterfront & 1 & 5461829 & 34329 & 159 & 15 \\
Centennial & Scarborough & 9 & 10653618 & 34099 & 312 & 29 \\
Humber & North & 1 & 41020260 & 120329 & 341 & 32 \\
Humber & Lakeshore & 6 & 18449929 & 63404 & 291 & 27 \\
Sheridan & Trafalgar & 9 & 42694827 & 61384 & 696 & 64 \\
\hline
\end{tabular}

Table A.20 - Classrooms and Related Facility benchmarks without removing erroneous data entries.

\begin{tabular}{ccccccccc}
\hline \multicolumn{7}{c|}{ Classrooms and Related Facilities EUI $\left(\mathrm{ekWh} / \mathrm{m}^{2}\right)$ Before Outlier Removal } \\
\hline Q1 & Mean & Median & $\mathbf{Q 3}$ & IQR & LAV & UAV & s & s (\%) \\
234 & 394 & 328 & 447 & 213 & -86 & 766 & 292 & $89 \%$ \\
\hline
\end{tabular}

Table A.21 - Classrooms and Related Facility benchmarks after removing erroneous data entries.

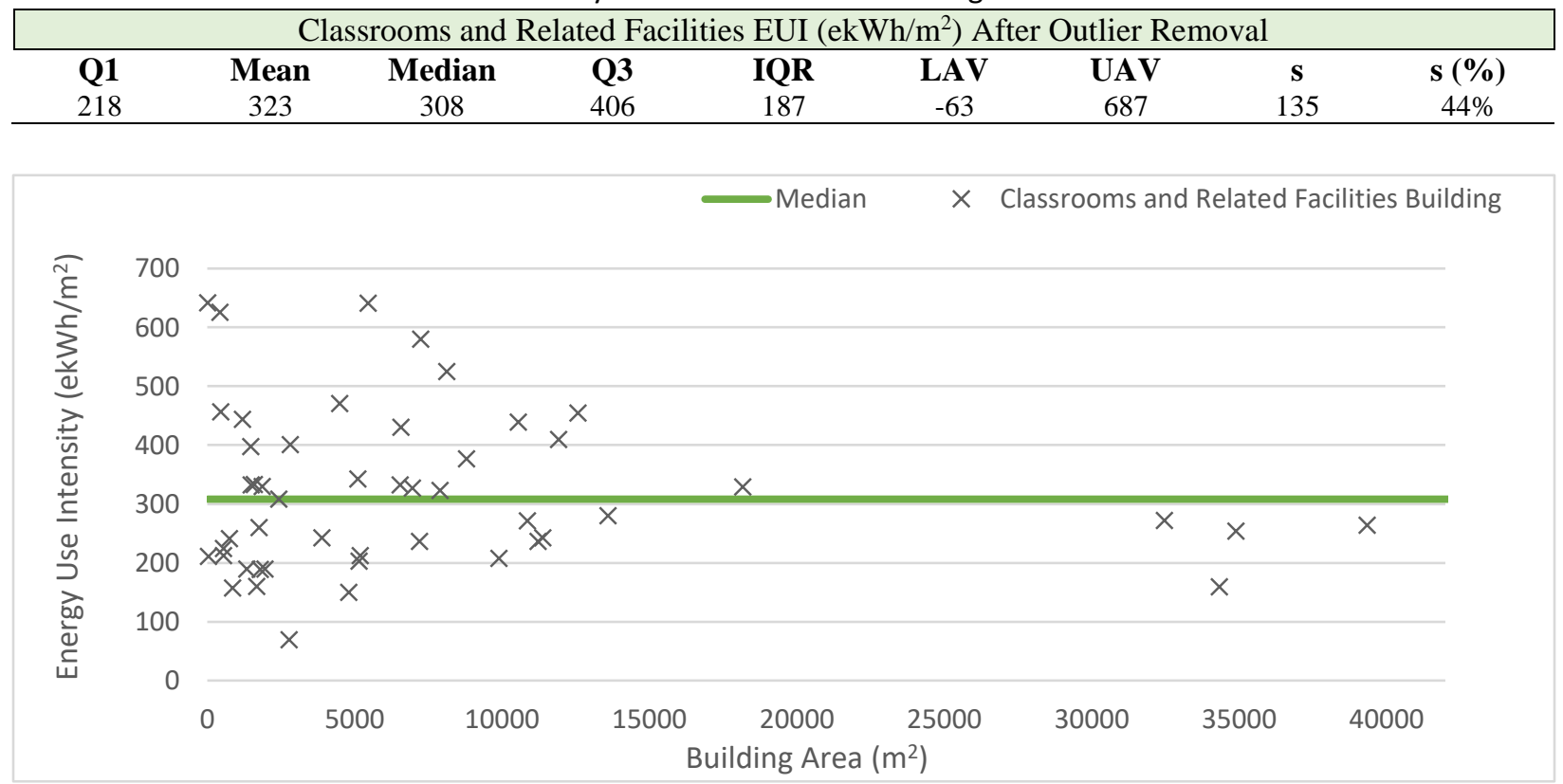

Figure A.7 - Classroom buildings considered in the college developed benchmark. 


\section{Classroom and Related Facilities - University}

Table A.22 - Initial sample of university Classroom and Related Facilities considered for benchmarking study.

\begin{tabular}{|c|c|c|c|c|c|}
\hline \multicolumn{6}{|c|}{ Classrooms and Related Facilities - University } \\
\hline Campus & $\mathbf{n}$ & $\Sigma(\mathbf{k W h})$ & $\Sigma$ Area $\left(\mathbf{m}^{2}\right)$ & ekWh/m $\mathbf{m}^{2}$ & ekWh/ft $\mathbf{t}^{2}$ \\
\hline Ontario Institute of Technology & 4 & 24160839 & 53594 & 451 & 42 \\
\hline Trent University & 1 & 1507708 & 4571 & 330 & 31 \\
\hline McMaster University & 1 & 1703829 & 8361 & 204 & 19 \\
\hline McMaster University & 1 & 215859877 & 431480 & 500 & 46 \\
\hline York University & 12 & 50195435 & 158555 & 317 & 29 \\
\hline Brock University & 1 & 3849143 & 6729 & 572 & 53 \\
\hline Brock University & 12 & 140063790 & 178707 & 784 & 73 \\
\hline University of Toronto - St George & 1 & 731480199 & 1367051 & 535 & 50 \\
\hline University of Toronto Scarborough & 1 & 71162965 & 129817 & 548 & 51 \\
\hline University of Toronto Mississauga & 1 & 93473003 & 185484 & 504 & 47 \\
\hline Ryerson University & 1 & 103099956 & 328515 & 314 & 29 \\
\hline
\end{tabular}

Table A.23 - Classrooms and Related Facility benchmarks without removing erroneous data entries.

\begin{tabular}{|ccccccccc|}
\hline \multicolumn{7}{|c|}{ Classrooms and Related Facilities EUI $\left(\mathrm{ekWh} / \mathrm{m}^{2}\right)$ Before Outlier Removal } \\
\hline Q1 & Mean & Median & $\mathbf{Q 3}$ & IQR & LAV & UAV & s & s (\%) \\
280 & 393 & 336 & 482 & 19 & -2 & 73 & 16 & $50 \%$ \\
\hline
\end{tabular}

Table A.24 - Classrooms and Related Facility benchmarks after removing erroneous data entries.

\begin{tabular}{cccccccccc|}
\hline \multicolumn{8}{c|}{ Classrooms and Related Facilities EUI $\left(\mathrm{ekWh} / \mathrm{m}^{2}\right)$} & After Outlier Removal \\
\hline Q1 & Mean & Median & Q3 & IQR & LAV & UAV & s & s (\%) \\
278 & 378 & 335 & 475 & 18 & -2 & 72 & 14 & $44 \%$ \\
\hline
\end{tabular}

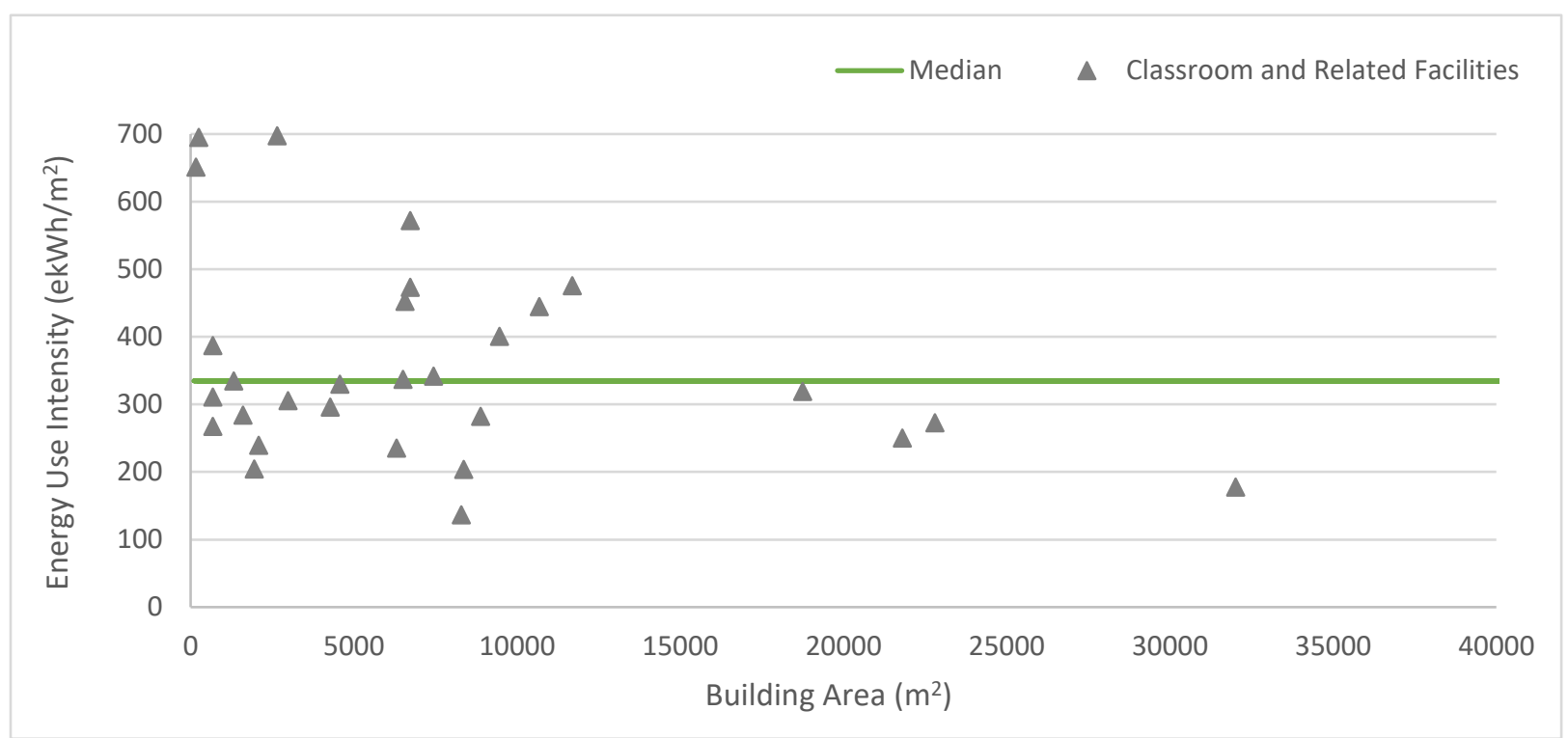

Figure A.8 - Classroom buildings considered in the university developed benchmark. 


\section{Student Recreational Facilities - College}

Table A.25 - Initial sample of college Student Recreational buildings considered for benchmarking study.

\begin{tabular}{ccccccc|}
\hline \multicolumn{7}{c|}{ Student Recreational Facilities - Colleges } \\
\hline College & Campus & $\mathbf{n}$ & $\boldsymbol{\Sigma}(\mathbf{k W h})$ & $\boldsymbol{\Sigma}$ Area $\left(\mathbf{m}^{\mathbf{2}}\right)$ & $\mathbf{e k W h} / \mathbf{m}^{\mathbf{2}}$ & $\mathbf{e k W h} / \mathbf{f t}^{\mathbf{2}}$ \\
Lambton & Sarnia & 1 & 512631 & 1127 & 455 & 42 \\
St. Clair & Thames & 1 & 1977532 & 5506 & 359 & 33 \\
Centennial & Scarborough & 5 & 6521464 & 21382 & 305 & 28 \\
Seneca & Newnham & 1 & 1843592 & 5535 & 333 & 31 \\
Seneca & York & 1 & 309932 & 1493 & 208 & 19 \\
Sheridan & Trafalgar & 2 & 2771206 & 4513 & 614 & 57 \\
Niagara & Welland & 1 & 200376 & 807 & 248 & 23 \\
\hline
\end{tabular}

Table A.26 - Student Recreational building benchmarks without removing erroneous data entries.

\begin{tabular}{ccccccccc|}
\hline \multicolumn{8}{c|}{ Student Recreational Facilities EUI $\left(\mathrm{ekWh} / \mathrm{m}^{2}\right)$ Before Outlier Removal } \\
\hline Q1 & Mean & Median & $\mathbf{Q 3}$ & IQR & LAV & UAV & s & s (\%) \\
293 & 382 & 376 & 436 & 143 & 78 & 651 & 139 & $37 \%$ \\
\hline
\end{tabular}

Table A.27 - Student Recreational building benchmarks after removing erroneous data entries.

\begin{tabular}{ccccccccc}
\hline \multicolumn{8}{c|}{ Student Recreational Facilities EUI $\left(\mathrm{ekWh} / \mathrm{m}^{2}\right)$ After Outlier Removal } \\
\hline Q1 & Mean & Median & $\mathbf{Q 3}$ & IQR & LAV & UAV & s & s (\%) \\
293 & 358 & 359 & 412 & 119 & 115 & 590 & 114 & $32 \%$ \\
\hline
\end{tabular}

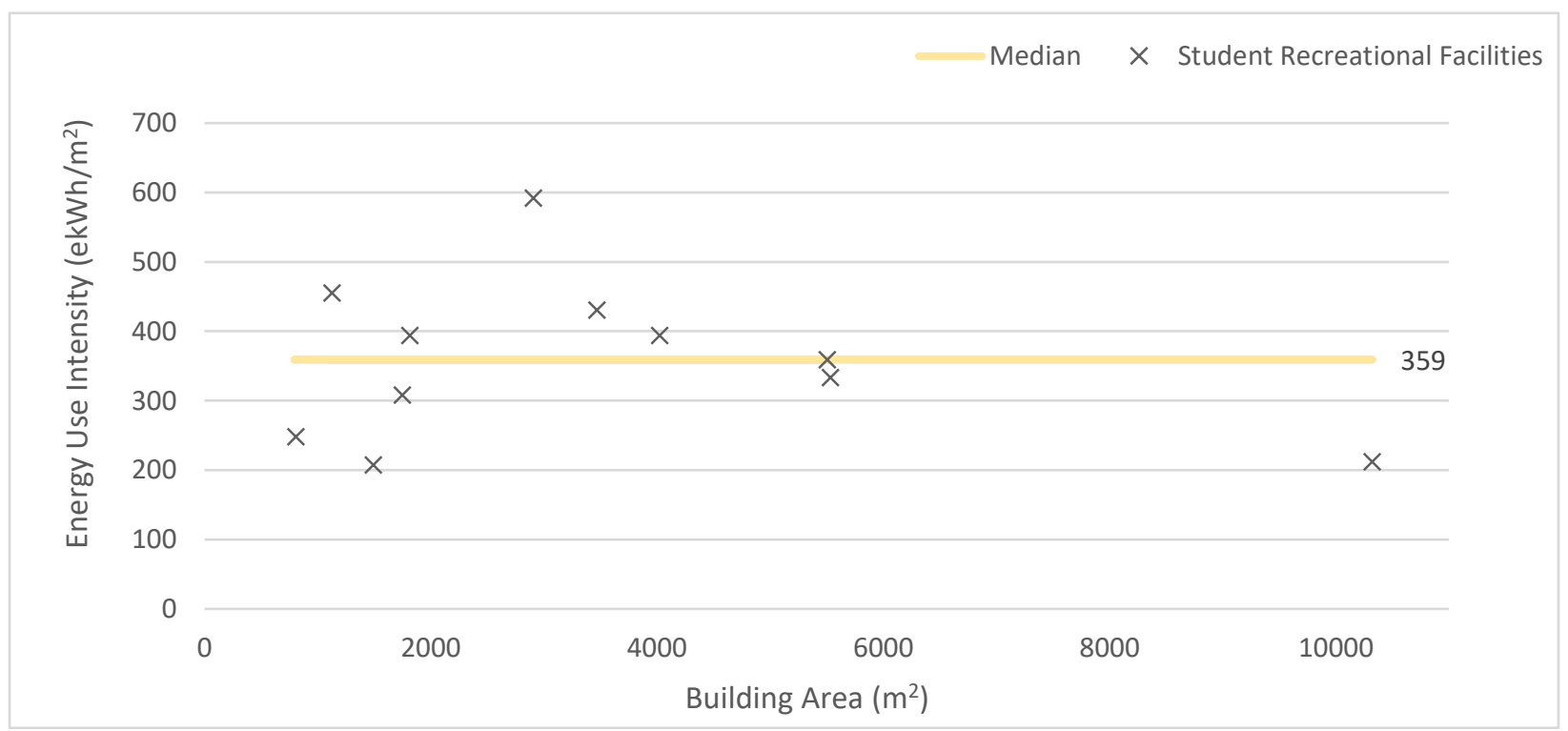

Figure A.9 - Student Recreational buildings considered in the college developed benchmark. 


\section{Student Recreational Facilities - University}

Table A.28 - Initial sample of university Student Recreational buildings considered for benchmarking study.

\begin{tabular}{|c|c|c|c|c|c|c|}
\hline \multicolumn{7}{|c|}{ Student Recreational Facilities - University } \\
\hline University & Campus & $\mathbf{n}$ & $\Sigma(\mathbf{k W h})$ & $\Sigma$ Area $\left(\mathbf{m}^{2}\right)$ & ekWh/m² & $\mathrm{ekWh} / \mathrm{ft}^{2}$ \\
\hline Of Ontario & Oshawa & 2 & 5730822 & 11654 & 492 & 46 \\
\hline York & Toronto & 3 & 7318887 & 18690 & 392 & 36 \\
\hline
\end{tabular}

Table A.29 - Student Recreational building benchmarks after removing erroneous data entries.

\begin{tabular}{|ccccccccc|}
\hline \multicolumn{7}{c|}{ Student Recreational Facilities EUI $\left(\mathrm{ekWh} / \mathrm{m}^{2}\right)$} & After Outlier Removal \\
\hline Q1 & Mean & Median & Q3 & IQR & LAV & UAV & s & s (\%) \\
299 & 402 & 340 & 561 & 262 & -94 & 954 & 203 & $60 \%$ \\
\hline
\end{tabular}

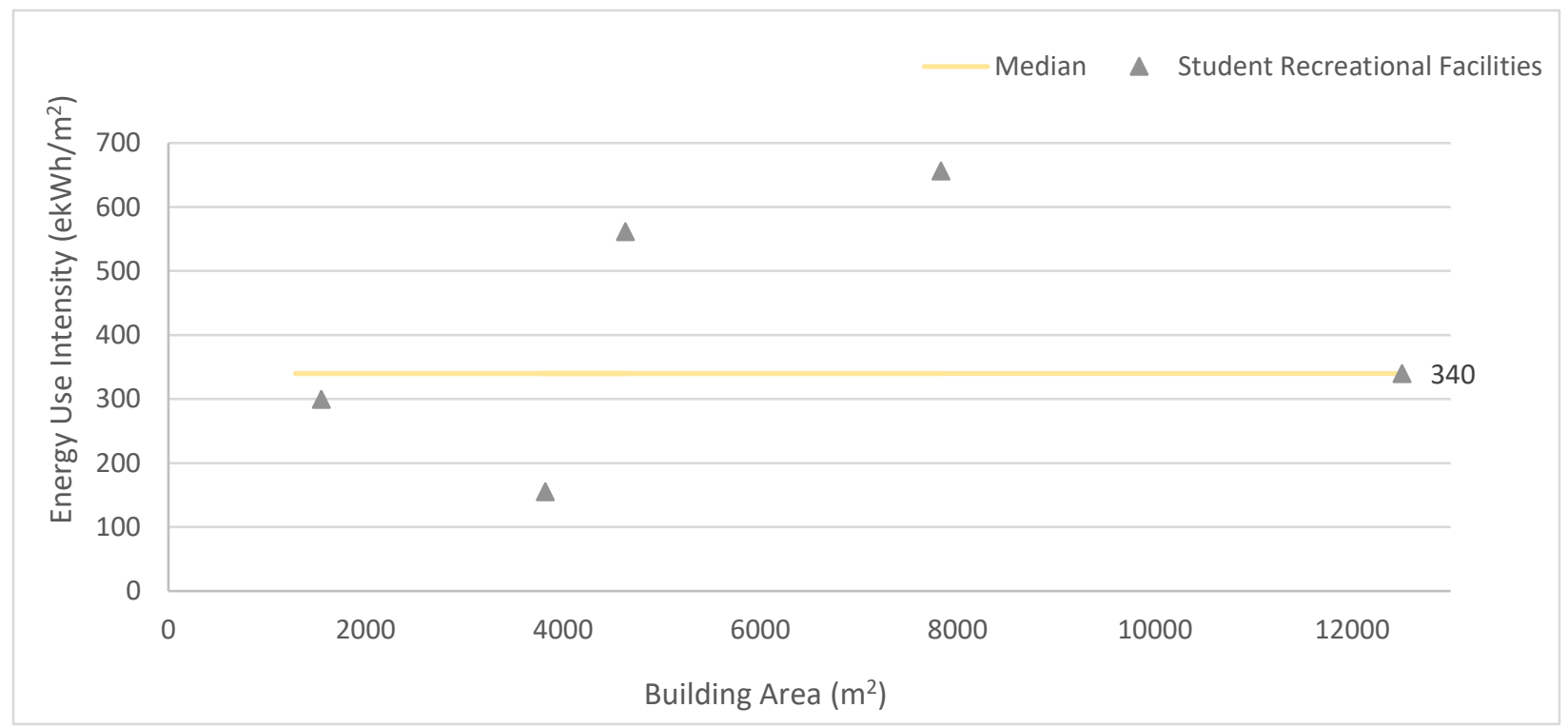

Figure A.10 - Student Recreational buildings considered in the university developed benchmark 


\section{Student Recreational Facilities - College and University}

Table A.30 - Initial sample of college and university Student Recreational buildings considered for benchmarking

\begin{tabular}{ccccccc|}
\hline \multicolumn{7}{c|}{ Student Recreational Facilities Colleges \& Universities } \\
\hline Operation & Campus & $\mathbf{n}$ & $\boldsymbol{\Sigma}(\mathbf{k W h})$ & $\boldsymbol{\Sigma}$ Area $\left(\mathbf{m}^{\mathbf{2}}\right)$ & $\mathbf{e k W h} / \mathbf{m}^{\mathbf{2}}$ & $\mathbf{e k W h} / \mathbf{f t}^{\mathbf{2}}$ \\
Lambton & Sarnia & 1 & 512631 & 1127 & 455 & 42 \\
St. Clair & Thames & 1 & 1977532 & 5506 & 359 & 33 \\
Centennial & Scarborough & 5 & 6521464 & 21382 & 305 & 28 \\
Seneca & Newnham & 1 & 1843592 & 5535 & 333 & 31 \\
Seneca & York & 1 & 309932 & 1493 & 208 & 19 \\
Sheridan & Trafalgar & 2 & 2771206 & 4513 & 614 & 57 \\
Niagara & Welland & 1 & 200376 & 807 & 248 & 23 \\
Ontario & Oshawa & 2 & 5730822 & 11654 & 492 & 46 \\
York & Toronto & 3 & 7318887 & 18690 & 392 & 36
\end{tabular}

Table A.31 - Student Recreational building benchmarks after removing erroneous data entries.

\begin{tabular}{|ccccccccc|}
\hline \multicolumn{7}{c|}{ Student Recreational Facilities EUI $\left(\mathrm{ekWh} / \mathrm{m}^{2}\right)$ After Outlier Removal } \\
\hline Q1 & Mean & Median & $\mathbf{Q 3}$ & IQR & LAV & UAV & s & s (\%) \\
299 & 388 & 359 & 455 & 156 & 66 & 688 & 154 & $43 \%$
\end{tabular}

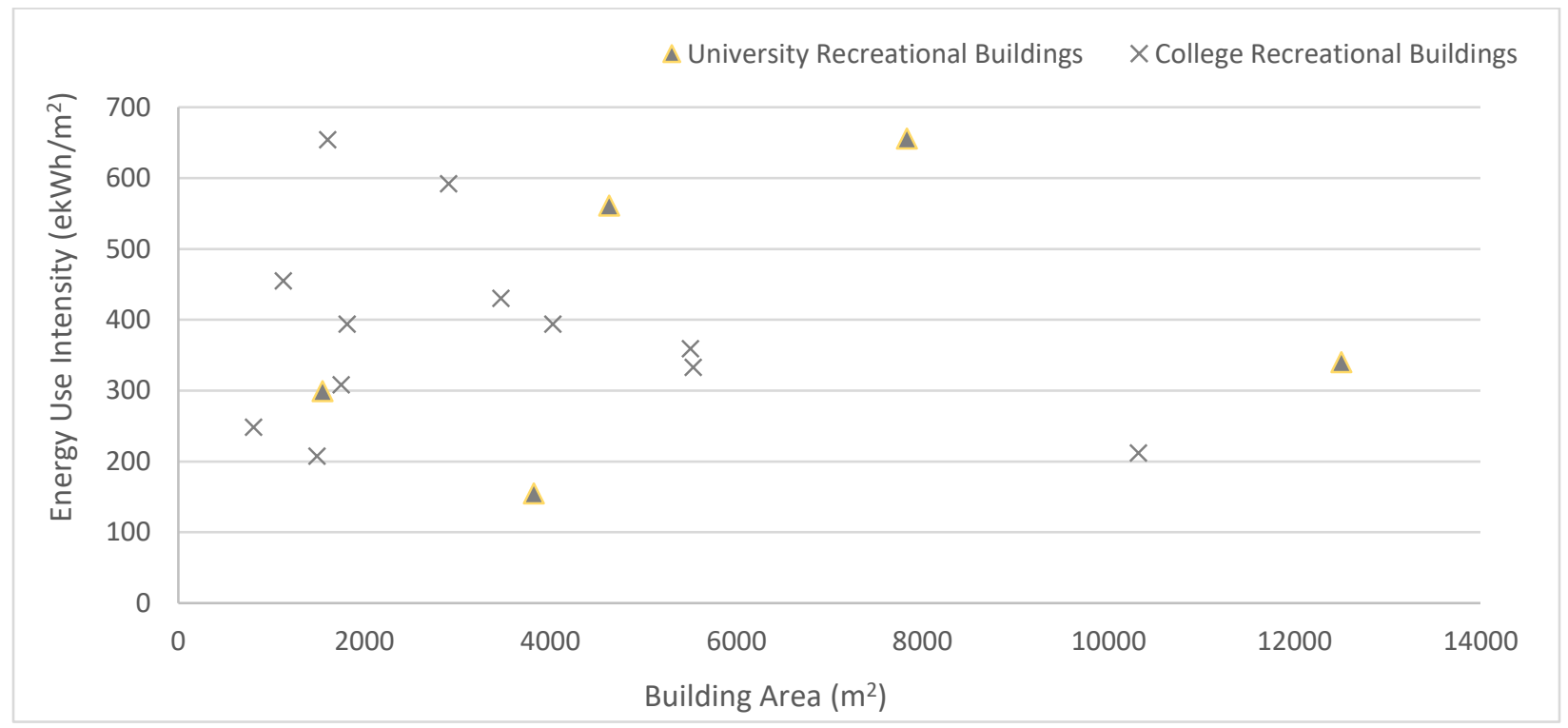

Figure A.11 - Student Recreational buildings considered in the college and university developed benchmark 
Appendix B: Reference Building Model Comparison and Sources 


\section{Pre-1980 Lowrise: Form Comparison}

\begin{tabular}{cccc}
\hline Building form variables & Small Hotel & Mid-rise Apartment & Low-rise \\
\hline Vintage & Pre 1980 & Pre 1980 & Pre 1980 \\
Total conditioned area & $4014 \mathrm{~m} 2$ & $3135 \mathrm{~m} 2$ & $6053 \mathrm{~m} 2$ \\
Number of floors & 4 & 4 & 4 \\
Building height & $11.6 \mathrm{~m}$ & $12.2 \mathrm{~m}$ & $12.7 \mathrm{~m}$ \\
Aspect Ratio & 3 & 2.7 & $\mathrm{n} / \mathrm{a}$ \\
Window to wall ratio & $11 \%$ & $15 \%$ & $\mathrm{n} / \mathrm{a}$ \\
Shading & None & None & None \\
Ground floor to ceiling height & $3.35 \mathrm{~m}$ & $3.05 \mathrm{~m}$ & $\mathrm{n} / \mathrm{a}$ \\
Floor to floor height & $2.74 \mathrm{~m}$ & $3.05 \mathrm{~m}$ & $\mathrm{n} / \mathrm{a}$ \\
Building shape & Rectangle & Rectangle & Rectangle \\
\hline Source & {$[1]$} & {$[2]$} & {$[3]$}
\end{tabular}

\section{Pre-1980 Lowrise: Form Selection}

\begin{tabular}{ccc}
\hline \multicolumn{3}{c}{ Pre-1980 Lowrise_student residence } \\
\hline Characterization inputs & Reference Method & Wireframe Method \\
\hline Total conditioned area & $6053 \mathrm{~m}^{2}$ & GIS/DaftLogic defined \\
Number of floors & 4 & DaftLogic defined \\
Building height & $12 \mathrm{~m}$ & GIS/DaftLogic defined \\
Aspect Ratio* & 3 & GIS/DaftLogic defined \\
Window to wall ratio* & $30 \%$ & $30 \%$ \\
Shading & None & None \\
Floor to floor height* & $3 \mathrm{~m}$ & $3 \mathrm{~m}$ \\
Building shape & Rectangle & GIS defined \\
\hline
\end{tabular}

* Aspect ratio of the DOE Small Hotel is considered to represent pre-1980 Lowrise models

* Window-to-wall ratio of $30 \%$ was defined as this ratio was common in student residence buildings

*Floor-to-floor height was set as $3 m$ in all categories. 


\section{Pre-1980 Lowrise: Fabric Comparison}

\begin{tabular}{|c|c|c|}
\hline & Pre-1980 Small Hotel & Pre-1980 Midrise Apartment \\
\hline & \multicolumn{2}{|c|}{ Ground floor slab } \\
\hline Name & ext-slab-mass & ext-slab-mass \\
\hline Layer 1 & HW CONCRETE & HW CONCRETE \\
\hline Layer 2 & CP02 CARPET PAD & CP02 CARPET PAD \\
\hline R-value & $0.54 \mathrm{~m}^{2 *} \mathrm{~K} / \mathrm{W}$ & $0.54 \mathrm{~m}^{2 *} \mathrm{~K} / \mathrm{W}$ \\
\hline \multicolumn{3}{|c|}{ Ceiling } \\
\hline Name & Typical interior ceiling & Floor Adiabatic construction \\
\hline Layer 1 & CPO2 CARPET PAD & CPO2 CARPET PAD \\
\hline Layer 2 & $100 \mathrm{~mm}$ Normalweight concrete floor & 100mm Normalweight concrete floor \\
\hline Layer 3 & - & Nonres_Floor_Insulation \\
\hline \multicolumn{3}{|c|}{ Exterior roof } \\
\hline Name & Typical Wood Joist Attic Floor R-16.67 & Typical IEAD Roof R-16.67 \\
\hline Layer 1 & 5/8 in. Gypsum Board & Roof Membrane \\
\hline Layer 2 & Typical Insulation R-15.03 & Typical Insulation R-15.55 \\
\hline Layer 3 & - & Metal Roof Surface \\
\hline R-value & $2.99 \mathrm{~m}^{2 *} \mathrm{k} / \mathrm{W}$ & $2.99 \mathrm{~m}^{2 *} \mathrm{~K} / \mathrm{W}$ \\
\hline \multicolumn{3}{|c|}{ Exterior wall } \\
\hline Name & Insulated Steel Framed Exterior Wall R-6.9 & Insulated Steel Framed Exterior Wall R-6.9 \\
\hline Layer 1 & $25 \mathrm{~mm}$ Stucco & $25 \mathrm{~mm}$ Stucco \\
\hline Layer 2 & 5/8 in. Gypsum Board & 5/8 in. Gypsum Board \\
\hline Layer 3 & Typical Insulation R-4.72 & Typical Insulation R-4.72 \\
\hline Layer 4 & 5/8 in. Gypsum Board & 5/8 in. Gypsum Board \\
\hline R-value & $1.22 \mathrm{~m}^{2 *} \mathrm{~K} / \mathrm{W}$ & $1.22 \mathrm{~m}^{2 *} \mathrm{~K} / \mathrm{W}$ \\
\hline \multicolumn{3}{|c|}{ Interior wall } \\
\hline Name & Typical Interior Wall & Typical Interior Wall \\
\hline Layer 1 & G01 13mm gypsum board & G01 13mm gypsum board \\
\hline Layer 2 & G01 13mm gypsum board & G01 13mm gypsum board \\
\hline \multicolumn{3}{|c|}{ Interior floor } \\
\hline Name & Typical Interior Floor & Floor Adiabatic construction \\
\hline Layer 1 & $100 \mathrm{~mm}$ Normalweight concrete floor & CPO2 CARPET PAD \\
\hline Layer 2 & CPO2 CARPET PAD & $100 \mathrm{~mm}$ Normalweight concrete floor \\
\hline Layer 3 & - & Nonres_Floor_Insulation \\
\hline \multicolumn{3}{|c|}{ Glazing System } \\
\hline Name & U 0.62 SHGC 0.41 Simple Glazing Window & U 0.62 SHGC 0.41 Simple Glazing Window \\
\hline Layer 1 & U 0.62 SHGC 0.41 Simple Glazing & U 0.62 SHGC 0.41 Simple Glazing \\
\hline U-Factor & $3.53 \mathrm{~W} / \mathrm{m}^{2 * \mathrm{~K}}$ & $3.53 \mathrm{~W} / \mathrm{m}^{2 * \mathrm{~K}}$ \\
\hline \multicolumn{3}{|c|}{ Internal mass } \\
\hline Name & Interior Furnishings & Interior Furnishings \\
\hline Layer 1 & Standard Wood 6inch & Standard Wood 6inch \\
\hline
\end{tabular}

Source

[1]

[2] 


\section{Pre-1980 Lowrise: Fabric Selection}

\begin{tabular}{ccc}
\hline & Pre-1980 Lowrise_student residence & \\
\hline Component name & Assembly name & Assembly details \\
Ground floor slab & ext-slab-mass & $1.22 \mathrm{~m}^{2 * \mathrm{~K} / \mathrm{W}}$ \\
Exterior roof & Typical IEAD Roof R-16.67 & $2.99 \mathrm{~m}^{2 * \mathrm{~K} / \mathrm{W}}$ \\
Exterior wall & Insulated Steel Framed Exterior Wall R-6.9 & $1.22 \mathrm{~m}^{2 * \mathrm{~K} / \mathrm{W}}$ \\
Ceiling & Typical Interior Ceiling & - \\
Interior walls & Typical Interior Wall & - \\
Interior floor & Typical Interior Floor & - \\
Internal mass & Interior Furnishings & - \\
& U-Factor & $3.53 \mathrm{~W} / \mathrm{m}^{2 * \mathrm{~K}}$ \\
Glazing system & SHGC & 0.41 \\
& Visible transmittance & 0.32 \\
Air tightness & ACH@ 75Pa & 0.92 \\
\hline
\end{tabular}

\section{Pre-1980 Lowrise: Space Activity Comparison}

\begin{tabular}{|c|c|c|c|c|c|}
\hline \multicolumn{2}{|c|}{ Pitman Hall } & \multicolumn{2}{|c|}{ Small Hotel } & \multicolumn{2}{|c|}{ Midrise Apartment } \\
\hline Space Activity & Area & Space Activity & Area & Space Activity & Area \\
\hline Administrative offices & $1 \%$ & Basement & $17 \%$ & Apartment & $87 \%$ \\
\hline Common use & $6 \%$ & Retail & $1 \%$ & Corridor & $10 \%$ \\
\hline Food services & $3 \%$ & Mechanical & $1 \%$ & Office & $3 \%$ \\
\hline Residence living & $43 \%$ & Storage & $1 \%$ & & \\
\hline Residence service & $4 \%$ & Laundry & $1 \%$ & & \\
\hline Washrooms & $2 \%$ & Cafe & $2 \%$ & & \\
\hline Corridors & $20 \%$ & Lobby & $12 \%$ & & \\
\hline Non- assignable space & $10 \%$ & Corridor & $17 \%$ & & \\
\hline Parking structure & $11 \%$ & Dining & $3 \%$ & & \\
\hline
\end{tabular}

Pre-1980 Lowrise: Space Activity Selection

\begin{tabular}{cc}
\hline \multicolumn{2}{c}{ Pre-1980 Lowrise_Student Residence } \\
\hline Space Activity & Area \\
Student room & $87 \%$ \\
Corridor & $10 \%$ \\
Office & $3 \%$ \\
\hline
\end{tabular}


Pre-1980 Lowrise: Occupancy Comparison

\begin{tabular}{cccc|cccc}
\hline \multicolumn{4}{c|}{ Pre-1980 Small Hotel } & \multicolumn{4}{c}{ Pre-1980 Mid-rise } \\
\hline Space & Occupancy & Occupancy & Source & Space & Occupancy & Occupancy & Source \\
activity & per space & density & & activity & per space & density & \\
Guest room & 1.5 pax & $26 \mathrm{~m}^{2} / \mathrm{pax}$ & {$[5]$} & Apartment & 2.5 pax & $35 \mathrm{~m}^{2} / \mathrm{pax}$ & {$[5]$} \\
Office & 2 pax & $44 \mathrm{~m}^{2} / \mathrm{pax}$ & {$[5]$} & Office & 2 pax & $44 \mathrm{~m}^{2} / \mathrm{pax}$ & {$[5]$} \\
\hline
\end{tabular}

Pre-1980 Lowrise: Occupancy Selection

\begin{tabular}{cccc}
\hline & Pre-1980 Lowrise_Student Residence & \\
\hline Space activity & Building area & Occupancy density from & Weighted Occupancy \\
Student room & $87 \%$ & DOE models & density \\
Office & $3 \%$ & $26 \mathrm{~m}^{2} /$ pax & 30.7 \\
Corridor & $10 \%$ & $44 \mathrm{~m}^{2} / \mathrm{pax}$ & 1.3 \\
\hline Weighted Average Pre-1980 Lowrise total peak occupancy density $\left(\mathrm{m}^{2} / \mathrm{pax}\right)$ & 0 \\
\hline
\end{tabular}

\section{Pre-1980 Lowrise: Ventilation Rate Comparison}

\begin{tabular}{ccc|ccc}
\hline \multicolumn{2}{c}{ Pre-1980 Small Hotel } & \multicolumn{3}{c}{ Pre-1980 Midrise } \\
\hline Space activity & Outdoor air & Source & Space activity & Outdoor air & Source \\
Hotel guest room & $0.43 \mathrm{~L} / \mathrm{s} / \mathrm{m}^{2}$ & {$[6]$} & Apartment & $0.48 \mathrm{~L} / \mathrm{s} / \mathrm{m}^{2}$ & {$[6]$} \\
Office & $0.77 \mathrm{~L} / \mathrm{s} / \mathrm{m}^{2}$ & {$[6]$} & Office & $0.23 \mathrm{~L} / \mathrm{s} / \mathrm{m}^{2}$ & {$[6]$} \\
\hline
\end{tabular}

Pre-1980 Lowrise: Ventilation Rate Selection

\begin{tabular}{|c|c|c|c|}
\hline \multicolumn{4}{|c|}{ Pre-1980 Lowrise_Student Residence } \\
\hline Space activity & Building area & $\begin{array}{l}\text { Outdoor air from } \\
\text { DOE models }\end{array}$ & $\begin{array}{l}\text { Weighted } \\
\text { Outdoor air }\end{array}$ \\
\hline Student room & $87 \%$ & $0.46 \mathrm{~L} / \mathrm{s} / \mathrm{m}^{2}$ & $0.42 \mathrm{~L} / \mathrm{s} / \mathrm{m}^{2}$ \\
\hline Office & $3 \%$ & $0.23 \mathrm{~L} / \mathrm{s} / \mathrm{m}^{2}$ & $0.01 \mathrm{~L} / \mathrm{s} / \mathrm{m}^{2}$ \\
\hline Corridor & $10 \%$ & $0.25 \mathrm{~L} / \mathrm{s} / \mathrm{m}^{2}$ & $0.03 \mathrm{~L} / \mathrm{s} / \mathrm{m}^{2}$ \\
\hline
\end{tabular}




\section{Pre-1980 Lowrise: Lighting Power Density Comparison}

\begin{tabular}{ccc|ccc}
\hline \multicolumn{2}{c}{ Pre-1980 Small Hotel } & \multicolumn{3}{c}{ Pre-1980 Midrise } \\
\hline Space activity & Lights & Source & Space activity & Lights & Source \\
Hotel guest room & $18.7 \mathrm{~W} / \mathrm{m}^{2}$ & {$[7]$} & Apartment & $3.88 \mathrm{~W} / \mathrm{m}^{2}$ & {$[7]$} \\
Office & $22 \mathrm{~W} / \mathrm{m}^{2}$ & {$[7]$} & Office & $22 \mathrm{~W} / \mathrm{m}^{2}$ & {$[7]$} \\
Corridor & $9.2 \mathrm{~W} / \mathrm{m}^{2}$ & {$[7]$} & Corridor & $9.2 \mathrm{~W} / \mathrm{m}^{2}$ & {$[7]$} \\
\hline
\end{tabular}

Pre-1980 Lowrise: Lighting Power Density Selection

\begin{tabular}{cccc}
\hline & \multicolumn{3}{c}{ Pre-1980 Lowrise Lighting Power Density } \\
\hline Space activity & Building area & Lights from & Weighted \\
Student room & $87 \%$ & DOE models & Lights \\
Office & $3 \%$ & $11.29 \mathrm{~W} / \mathrm{m}^{2}$ & $9.82 \mathrm{~W} / \mathrm{m}^{2}$ \\
Corridor & $10 \%$ & $22 \mathrm{~W} / \mathrm{m}^{2}$ & $0.66 \mathrm{~W} / \mathrm{m}^{2}$ \\
\hline Weighted Average Pre1980 Low-rise total lighting loads & $9.2 \mathrm{~W} / \mathrm{m}^{2}$ & $0.92 \mathrm{~W} / \mathrm{m}^{2}$ \\
\hline
\end{tabular}

Pre-1980 Lowrise: Plug and Process Loads Comparison

\begin{tabular}{ccc|ccc}
\hline \multicolumn{2}{c}{ Pre-1980 Small Hotel } & \multicolumn{3}{c}{ Pre-1980 Midrise } \\
\hline Space activity & Plug load & Source & Space activity & Plug load & Source \\
Hotel guest room & $14.31 \mathrm{~W} / \mathrm{m}^{2}$ & {$[8]$} & Apartment & $5.38 \mathrm{~W} / \mathrm{m}^{2}$ & {$[9]$} \\
Office & $12.9 \mathrm{~W} / \mathrm{m}^{2}$ & {$[8]$} & Office & $12.9 \mathrm{~W} / \mathrm{m}^{2}$ & {$[9]$} \\
Corridor & 0 & {$[8]$} & Corridor & 0 & {$[9]$} \\
\hline
\end{tabular}

Pre-1980 Lowrise: Plug and Process Loads Selection

\begin{tabular}{cccc}
\hline & \multicolumn{2}{c}{ Pre-1980 Lowrise_Student Residence } \\
\hline Space activity & Building area & Plug load from & Weighted \\
$9.85 \mathrm{~W} / \mathrm{m}^{2}$ & $8.57 \mathrm{~W} / \mathrm{m}^{2}$ & DOE models & Plug load \\
$12.9 \mathrm{~W} / \mathrm{m}^{2}$ & $0.39 \mathrm{~W} / \mathrm{m}^{2}$ & $9.85 \mathrm{~W} / \mathrm{m}^{2}$ & $8.57 \mathrm{~W} / \mathrm{m}^{2}$ \\
0 & 0 & $12.9 \mathrm{~W} / \mathrm{m}^{2}$ & $0.39 \mathrm{~W} / \mathrm{m}^{2}$ \\
& 0 & 0 & 0 \\
\hline Weighted Average Pre1980 Low-rise total plug loads (including elevator) & $8.95 \mathrm{~W} / \mathrm{m}^{2}$ \\
\hline
\end{tabular}

* Plug loads must add $1900 \mathrm{kWh} /$ year for elevators

* 1900kWh/365 day * hours of use * $(1000 \mathrm{~W} / 1 \mathrm{kWh}) /$ Reference Area $\left(\mathrm{m}^{2}\right)$

* 1900kWh/365 day * day/15.76 hours * $(1000 \mathrm{~W} / 1 \mathrm{kWh}) /\left(6035 \mathrm{~m}^{2}\right)=0.055 \mathrm{~W} / \mathrm{m}^{2}$ 


\section{Pre-1980 Lowrise: Water System Comparison}

\begin{tabular}{ccc|ccc}
\hline \multicolumn{2}{c}{ Pre-1980 Small Hotel } & \multicolumn{3}{c}{ Pre-1980 Midrise } \\
\hline Space activity & DHW & Source & Space activity & DHW & Source \\
Hotel guest room & $0.2 \mathrm{~L} / \mathrm{h} / \mathrm{m}^{2}$ & {$[8]$} & Apartment & $0.15 \mathrm{~L} / \mathrm{h} / \mathrm{m}^{2}$ & {$[9]$} \\
Office & 0 & & Office & 0 & \\
Corridor & 0 & & Corridor & 0 & \\
\hline
\end{tabular}

\section{Pre-1980 Lowrise: Water System Selection}

\begin{tabular}{cccc}
\hline & \multicolumn{2}{c}{ Pre-1980 Lowrise_Student Residence } & \\
\hline Space activity & Building area & DHW from & Weighted \\
Student room & $87 \%$ & DOE models & DHW \\
Office & $3 \%$ & 0.20 & $0.175 \mathrm{~L} / \mathrm{h} / \mathrm{m}^{2}$ \\
Corridor & $10 \%$ & 0 & 0 \\
Weighted Average Pre1980 Low-rise total water system loads & 0 \\
\hline
\end{tabular}

* Small Hotel water system loads are used to represent pre-1980 Lowrise student residence loads. The less efficient consumption was used for pre-1980 vintages.

\section{Pre-1980 Lowrise: Equipment Comparison}

\begin{tabular}{ccc}
\hline & Pre-1980 Small Hotel & \\
\hline Heating Type & Unit heater, PTAC electric heat & 2003 CBECS \\
Cooling Type & DX & 2003 CBECS \\
Fan Control & Constant & 2003 CBECS \\
SWH Type & gas water heater & \\
Fuel & gas & \\
Cooling Efficiency & 3.4 & IDF Small Hotel input \\
Thermal Efficiency (\%) & 80 & Winiarski and Halverson, 2008 \\
Temperature Setpoint (oC) & 60 & \\
\hline
\end{tabular}

\begin{tabular}{ccc}
\hline & Pre-1980 Midrise & \\
Heating Type & Gas furnace & 90.1 Mechanical Subcommittee \\
Cooling Type & Split system DX & 90.1 Mechanical Subcommittee \\
Fan Control & CAV & 90.1 Mechanical Subcommittee \\
SWH Type & Gas water heater & \\
Fuel & gas & \\
Cooling Efficiency & 3.4 & IDF Midrise Apartment input \\
Thermal Efficiency (\%) & 80 & Winiarski and Halverson, 2008 \\
Temperature Setpoint $(\stackrel{\circ}{ } \mathrm{C})$ & 60 & \\
\hline
\end{tabular}




\section{Pre-1980 Lowrise: Equipment Selection}

\begin{tabular}{cc}
\hline & Pre-1980 Lowrise student residence \\
\hline Heating Type & Unit heater, PTAC electric heat \\
Cooling Type & Split system DX \\
Fan Control & CAV \\
SWH Type & gas water heater \\
Fuel & gas \\
Cooling Efficiency & 3.4 \\
Thermal Efficiency (\%) & 80 \\
Temperature Setpoint (oC) & 60 \\
\hline
\end{tabular}

* The models will have a $21^{\circ} \mathrm{C}$ for both heating and cooling year around.

* Equipment COP will be set 8 for heating, and 3.4 for cooling (Pre1980 Small Hotel and Midrise).

* No economizer

* No natural ventilation is assigned 
Pre-1980 Lowrise: Schedule Selection
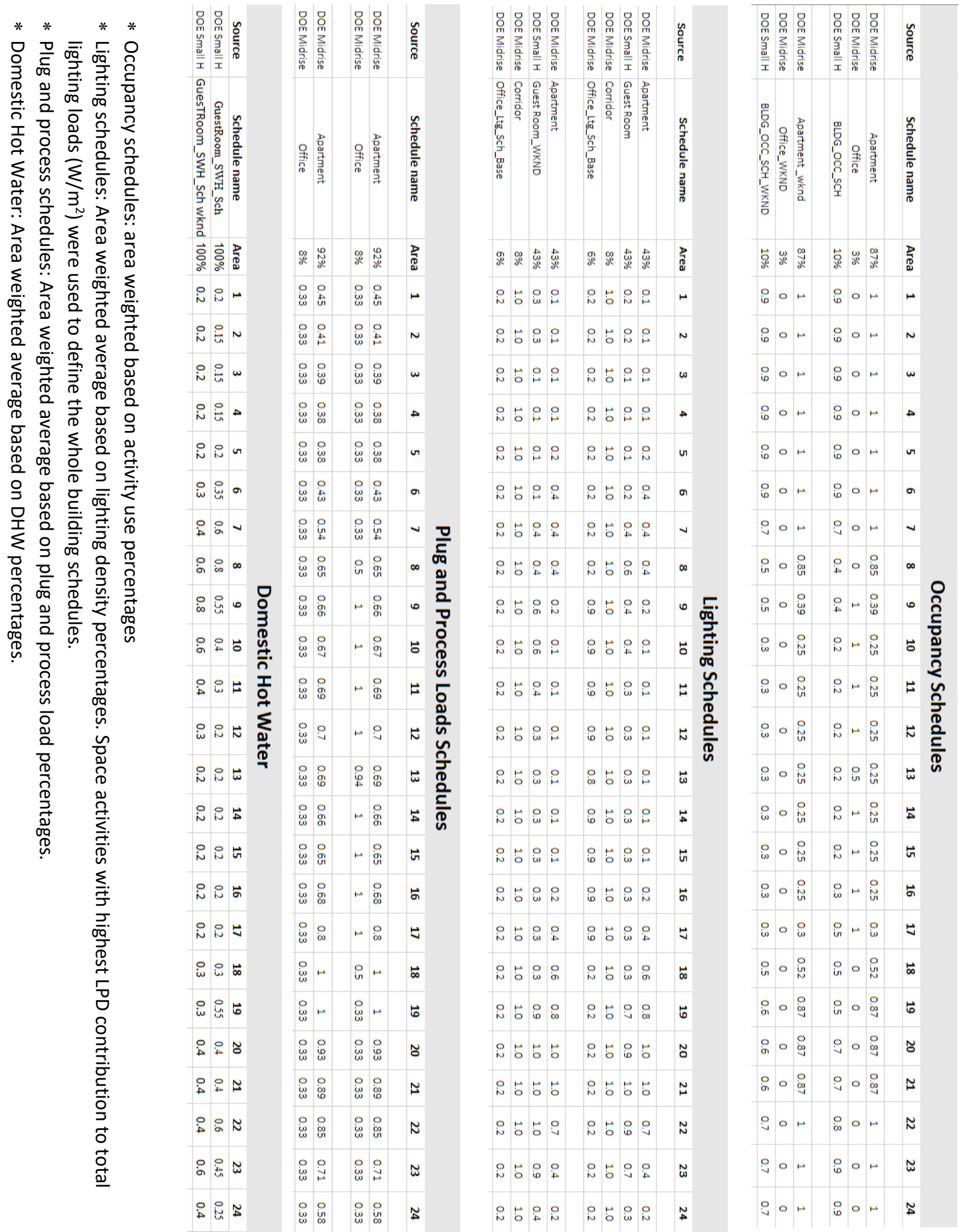


\section{Pre-1980 Lowrise: Sources}

[1] 2003 CBECS Data

[2] PNNL-16770: Analysis of Energy Saving Impacts of ASHRAE 90.1-2004 for the State of New York

[3] Mandatory Energy Reports 2013 - Ontario, Daft Logic, Visual Judgment, Geographical Information Systems, and the Architectural Conservancy of Ontario

[4] Ryerson Space Audit Data. URL: https://ryerson.iwmsapp.com/archibus/

[5] ASHRAE Standard 62.1-2004 Table 6-1, Atlanta, GA: American Society of Heating, Refrigerating and Air-Conditioning Engineers.

[6] ASHRAE Standard 62-1999 Table 6-1, Atlanta, GA: American Society of Heating, Refrigerating and Air-Conditioning Engineers.

[7] ASHRAE Standard 90.1-1989, Atlanta, GA: American Society of Heating, Refrigerating and Air-Conditioning Engineers.

[8] PNNL - 17875 Technical Support Document: The Development of the Advanced Energy Design Guide for Highway Lodging Buildings

[9] DOE Commercial Reference Building Report 
Post-1980 Lowrise: Form Comparison

\begin{tabular}{cccc}
\hline Building form variables & Small Hotel & Mid-rise Apartment & Low-rise \\
\hline Vintage & Post 1980 & Post1980 & Post1980 \\
Total conditioned area & $4014 \mathrm{~m} 2$ & $3135 \mathrm{~m} 2$ & $9618 \mathrm{~m} 2$ \\
Number of floors & 4 & 4 & 4 \\
Building height & $11.6 \mathrm{~m}$ & $12.2 \mathrm{~m}$ & $13.3 \mathrm{~m}$ \\
Aspect Ratio & 3 & 2.7 & $\mathrm{n} / \mathrm{a}$ \\
Window to wall ratio & $11 \%$ & $15 \%$ & $\mathrm{n} / \mathrm{a}$ \\
Shading & None & None & None \\
Ground floor to ceiling height & $3.35 \mathrm{~m}$ & $3.05 \mathrm{~m}$ & $\mathrm{n} / \mathrm{a}$ \\
Floor to floor height & $2.74 \mathrm{~m}$ & $3.05 \mathrm{~m}$ & $\mathrm{n} / \mathrm{a}$ \\
Building shape & Rectangle & Rectangle & $\mathrm{n} / \mathrm{a}$ \\
\hline Source & {$[1]$} & {$[2]$} & {$[3]$}
\end{tabular}

Post-1980 Lowrise: Form Selection

\begin{tabular}{ccc}
\hline \multicolumn{3}{c}{ Post-1980 Lowrise_student residence } \\
\hline Characterization inputs & Reference Method & Wireframe Method \\
\hline Total conditioned area & $9613 \mathrm{~m}^{2}$ & GIS/DaftLogic defined \\
Number of floors & 4 & DaftLogic defined \\
Building height & $12 \mathrm{~m}$ & GIS/DaftLogic defined \\
Aspect Ratio* & 3 & GIS/DaftLogic defined \\
Window to wall ratio* & $30 \%$ & $30 \%$ \\
Shading & None & None \\
Floor to floor height* & $3 \mathrm{~m}$ & $3 \mathrm{~m}$ \\
Building shape & Rectangle & GIS defined \\
\hline
\end{tabular}

* Aspect ratio of the DOE Small Hotel is considered to represent post-1980 Lowrise models

* Window-to-wall ratio of $30 \%$ was defined as this ratio was common in student residence buildings

*Floor-to-floor height was set as $3 \mathrm{~m}$ in all categories. 
Post-1980 Lowrise: Fabric Comparison

\begin{tabular}{|c|c|c|}
\hline & Post 1980 Small Hotel & Post 1980 Mid-rise Apartment \\
\hline \multicolumn{3}{|c|}{ Ground floor slab } \\
\hline Name & ext-slab-mass & ext-slab-mass \\
\hline Layer 1 & HW CONCRETE & HW CONCRETE \\
\hline Layer 2 & CP02 CARPET PAD & CPO2 CARPET PAD \\
\hline R-value & $0.54 \mathrm{~m} 2 * \mathrm{~K} / \mathrm{W}$ & $0.54 \mathrm{~m} 2 * \mathrm{~K} / \mathrm{W}$ \\
\hline \multicolumn{3}{|c|}{ Ceiling } \\
\hline Name & INT-FLOOR-UNDERSIDE & INT-FLOOR-UNDERSIDE \\
\hline Layer 1 & CP02 CARPET PAD & CPO2 CARPET PAD \\
\hline Layer 2 & MAT-CCO5 4 HW CONCRETE & MAT-CC05 4 HW CONCRETE \\
\hline \multicolumn{3}{|c|}{ Exterior roof } \\
\hline Name & Attic Res Floor & IEAD Res Roof \\
\hline Layer 1 & 1/2IN Gypsum & Roof Membrane \\
\hline Layer 2 & AtticFloor Res Insulation & IEAD RES Roof Insulation \\
\hline Layer 3 & 1/2IN Gypsum & Metal Decking \\
\hline R-value & $3.97 \mathrm{~m} 2 * \mathrm{~K} / \mathrm{W}$ & $3.97 \mathrm{~m} 2 * \mathrm{~K} / \mathrm{W}$ \\
\hline \multicolumn{3}{|c|}{ Exterior wall } \\
\hline Name & Steel Frame Res Ext Wall & Steel Frame Res Ext Wall \\
\hline Layer 1 & Wood Siding & Wood Siding \\
\hline Layer 2 & Steel Frame Res Wall & Steel Frame Res Wall \\
\hline Layer 3 & 1/2IN Gypsum & 1/2IN Gypsum \\
\hline R-value & $2.71 \mathrm{~m} 2 * \mathrm{~K} / \mathrm{W}$ & $2.71 \mathrm{~m} 2 * \mathrm{~K} / \mathrm{W}$ \\
\hline \multicolumn{3}{|c|}{ Interior wall } \\
\hline Name & Int-walls & Int-walls \\
\hline Layer 1 & s & 1/2IN Gypsum \\
\hline Layer 2 & 1/2IN Gypsum & 1/2IN Gypsum \\
\hline \multicolumn{3}{|c|}{ Interior floor } \\
\hline Name & INT-FLOOR-TOPSIDE & INT-FLOOR-TOPSIDE \\
\hline Layer 1 & MAT-CCO5 4 HW CONCRETE & MAT-CCO5 4 HW CONCRETE \\
\hline Layer 2 & CPO2 CARPET PAD & CPO2 CARPET PAD \\
\hline \multicolumn{3}{|c|}{ Glazing System } \\
\hline Name & Window Res Fixed & Window Res Operable \\
\hline Layer 1 & Res Fixed Assembly Window & Res Operable Assembly \\
\hline U-Factor & $2.95 \mathrm{~W} / \mathrm{m} 2 * \mathrm{~K}$ & $2.95 \mathrm{~W} / \mathrm{m} 2 * \mathrm{~K}$ \\
\hline \multicolumn{3}{|c|}{ Internal mass } \\
\hline Name & Interior Furnishings & Interior Furnishings \\
\hline Layer 1 & Standard Wood 6inch & Standard Wood 6inch \\
\hline
\end{tabular}


Post-1980 Lowrise: Fabric Selection

\begin{tabular}{ccc}
\hline & Post-1980 Lowrise_student residence & \\
\hline Component name & Assembly name & Assembly details \\
Ground floor slab & ext-slab & $0.54 \mathrm{~m} 2^{*} \mathrm{~K} / \mathrm{W}$ \\
Exterior roof & IEAD Res Roof & $3.97 \mathrm{~m} 2^{*} \mathrm{~K} / \mathrm{W}$ \\
Exterior wall & Steel Frame Res Ext Wall & $2.71 \mathrm{~m} 2^{*} \mathrm{~K} / \mathrm{W}$ \\
Ceiling & INT-FLOOR-UNDERSIDE & - \\
Interior walls & Int-walls & - \\
Interior floor & INT-FLOOR-TOPSIDE & - \\
Internal mass & Interior Furnishings & - \\
Glazing system & U-Factor & $2.95 \mathrm{~W} / \mathrm{m} 2 * \mathrm{~K}$ \\
& SHGC & 0.39 \\
Air tightness & Visible transmittance & 0.31 \\
& ACH@75Pa & 0.92 \\
\hline
\end{tabular}

Post-1980 Lowrise: Space Activity Comparison

\begin{tabular}{cc|cc|cc}
\hline Pitman Hall & & \multicolumn{2}{c}{ Small Hotel } & \multicolumn{2}{c}{ Midrise Apartment } \\
\hline Space Activity & Area & Space Activity & Area & Space Activity & Area \\
Administrative offices & $1 \%$ & Basement & $17 \%$ & Apartment & $87 \%$ \\
Common use & $6 \%$ & Retail & $1 \%$ & Corridor & $10 \%$ \\
Food services & $3 \%$ & Mechanical & $1 \%$ & Office & $3 \%$ \\
Residence living & $43 \%$ & Storage & $1 \%$ & \\
Residence service & $4 \%$ & Laundry & $1 \%$ & \\
Washrooms & $2 \%$ & Cafe & $2 \%$ & \\
Corridors & $20 \%$ & Lobby & $12 \%$ & \\
Non- assignable space & $10 \%$ & Corridor & $17 \%$ & \\
Parking structure & $11 \%$ & Dining & $3 \%$ & & \\
Source & {$[4]$} & & {$[1]$} & &
\end{tabular}

Post-1980 Lowrise: Space Activity Selection

\begin{tabular}{cc}
\hline \multicolumn{2}{c}{ Post-1980 Lowrise_Student Residence } \\
\hline Space Activity & Area \\
Student room & $87 \%$ \\
Corridor & $10 \%$ \\
Office & $3 \%$ \\
\hline
\end{tabular}


Post-1980 Lowrise: Occupancy Comparison

\begin{tabular}{cccc|cccc}
\hline \multicolumn{4}{c}{ Post-1980 Small Hotel } & \multicolumn{4}{c}{ Post-1980 Mid-rise } \\
\hline Space & Occupancy & Occupancy & \multirow{2}{*}{ Source } & Space & Occupancy & Occupancy & Source \\
activity & per space & density & & activity & per space & density & Sour \\
Guest room & 1.5 pax & $26 \mathrm{~m}^{2} / \mathrm{pax}$ & {$[5]$} & Apartment & $2.5 \mathrm{pax}$ & $35 \mathrm{~m}^{2} / \mathrm{pax}$ & {$[5]$} \\
Office & $2 \mathrm{pax}$ & $44 \mathrm{~m}^{2} / \mathrm{pax}$ & {$[5]$} & Office & $2 \mathrm{pax}$ & $44 \mathrm{~m}^{2} / \mathrm{pax}$ & {$[5]$} \\
\hline
\end{tabular}

Post-1980 Lowrise: Occupancy Selection

\begin{tabular}{cccc}
\hline & \multicolumn{3}{c}{ Post-1980 Lowrise_Student Residence } \\
\hline Space activity & Building area & Occupancy from & Weighted Occupancy \\
Student room & $87 \%$ & DOE models & 30.7 \\
Office & $3 \%$ & $26 \mathrm{~m}^{2} /$ pax & 1.3 \\
Corridor & $10 \%$ & $44 \mathrm{~m}^{2} / \mathrm{pax}$ & 0 \\
\hline Weighted Average Post-1980 Lowrise total peak occupancy density $\left(\mathrm{m}^{2} / \mathrm{pax}\right)$ & 32 \\
\hline
\end{tabular}

Post-1980 Lowrise: Ventilation Rate Comparison

\begin{tabular}{ccc|ccc}
\hline \multicolumn{2}{c}{ Post-1980 Small Hotel } & \multicolumn{3}{c}{ Post-1980 Midrise } \\
\hline Space activity & Outdoor air & Source & Space activity & Outdoor air & Source \\
Hotel guest room & $0.43 \mathrm{~L} / \mathrm{s} / \mathrm{m}^{2}$ & {$[6]$} & Apartment & $0.48 \mathrm{~L} / \mathrm{s} / \mathrm{m}^{2}$ & {$[6]$} \\
Office & $0.77 \mathrm{~L} / \mathrm{s} / \mathrm{m}^{2}$ & {$[6]$} & Office & $0.23 \mathrm{~L} / \mathrm{s} / \mathrm{m}^{2}$ & {$[6]$} \\
\hline
\end{tabular}

Post-1980 Lowrise: Ventilation Rate Selection

\begin{tabular}{cccc}
\hline \multicolumn{4}{c}{ Post-1980 Lowrise_Student Residence } \\
\hline Space activity & Building area & Outdoor air from & Weighted \\
Student room & $87 \%$ & DOE models & Outdoor air \\
Office & $3 \%$ & $0.46 \mathrm{~L} / \mathrm{s} / \mathrm{m}^{2}$ & $0.42 \mathrm{~L} / \mathrm{s} / \mathrm{m}^{2}$ \\
Corridor & $10 \%$ & $0.23 \mathrm{~L} / \mathrm{s} / \mathrm{m}^{2}$ & $0.01 \mathrm{~L} / \mathrm{s} / \mathrm{m}^{2}$ \\
\hline Weighted Average Post1980 Lowrise total ventilation rate & $0.25 \mathrm{~L} / \mathrm{s} / \mathrm{m}^{2}$ & $0.03 \mathrm{~L} / \mathrm{s} / \mathrm{m}^{2}$ \\
\hline
\end{tabular}

Post-1980 Lowrise: Lighting Power Density Comparison

\begin{tabular}{ccc|ccc}
\hline \multicolumn{2}{c|}{ Post-1980 Small Hotel } & \multicolumn{3}{c}{ Post-1980 Midrise } \\
\hline Space activity & Lights & Source & Space activity & Lights & Source \\
Hotel guest room & $18.7 \mathrm{~W} / \mathrm{m}^{2}$ & {$[7]$} & Apartment & $3.88 \mathrm{~W} / \mathrm{m}^{2}$ & {$[7]$} \\
Office & $22 \mathrm{~W} / \mathrm{m}^{2}$ & {$[7]$} & Office & $22 \mathrm{~W} / \mathrm{m}^{2}$ & {$[7]$} \\
Corridor & $9.2 \mathrm{~W} / \mathrm{m}^{2}$ & {$[7]$} & Corridor & $9.2 \mathrm{~W} / \mathrm{m}^{2}$ & {$[7]$} \\
\hline
\end{tabular}


Post-1980 Lowrise: Lighting Power Density Selection

\begin{tabular}{cccc}
\hline & \multicolumn{3}{c}{ Post-1980 Lowrise Lighting Power Density } \\
\hline Space activity & Building area & Lights from & Weighted \\
Student room & $87 \%$ & DOE models & Lights \\
Office & $3 \%$ & $3.88 \mathrm{~W} / \mathrm{m}^{2}$ & $3.38 \mathrm{~W} / \mathrm{m}^{2}$ \\
Corridor & $10 \%$ & $22 \mathrm{~W} / \mathrm{m}^{2}$ & $0.66 \mathrm{~W} / \mathrm{m}^{2}$ \\
\hline Weighted Average Post1980 Lowrise total lighting loads & $9.2 \mathrm{~W} / \mathrm{m}^{2}$ & $0.92 \mathrm{~W} / \mathrm{m}^{2}$ \\
\hline
\end{tabular}

Post-1980 Lowrise: Plug and Process Loads Comparison

\begin{tabular}{ccc|ccc}
\hline \multicolumn{2}{c}{ Post-1980 Small Hotel } & & \multicolumn{3}{c}{ Post-1980 Midrise } \\
\hline Space activity & Plug load & Source & Space activity & Plug load & Source \\
Hotel guest room & $14.31 \mathrm{~W} / \mathrm{m}^{2}$ & {$[8]$} & Apartment & $5.38 \mathrm{~W} / \mathrm{m}^{2}$ & {$[9]$} \\
Office & $12.9 \mathrm{~W} / \mathrm{m}^{2}$ & {$[8]$} & Office & $12.9 \mathrm{~W} / \mathrm{m}^{2}$ & {$[9]$} \\
Corridor & 0 & {$[8]$} & Corridor & 0 & {$[9]$} \\
\hline
\end{tabular}

Post-1980 Lowrise: Plug and Process Loads Selection

\begin{tabular}{|c|c|c|c|}
\hline \multicolumn{4}{|c|}{ Post-1980 Lowrise_Student Residence } \\
\hline Space activity & Building area & $\begin{array}{l}\text { Plug load from } \\
\text { DOE models }\end{array}$ & $\begin{array}{l}\text { Weighted } \\
\text { Plug load }\end{array}$ \\
\hline Student room & $87 \%$ & $9.85 \mathrm{~W} / \mathrm{m}^{2}$ & $8.57 \mathrm{~W} / \mathrm{m}^{2}$ \\
\hline Office & $3 \%$ & $12.9 \mathrm{~W} / \mathrm{m}^{2}$ & $0.39 \mathrm{~W} / \mathrm{m}^{2}$ \\
\hline \multirow{2}{*}{ Corridor } & $10 \%$ & 0 & 0 \\
\hline & & & $8.95 \mathrm{~W} / \mathrm{m}^{2}$ \\
\hline \multicolumn{3}{|c|}{ Weighted Average Post1980 Low-rise total plug loads (including elevator) } & $9 \mathrm{~W} / \mathrm{m}^{2}$ \\
\hline \multicolumn{4}{|c|}{ * Plug loads must add $1900 \mathrm{kWh/year} \mathrm{for} \mathrm{elevators}$} \\
\hline \multicolumn{4}{|c|}{ * 1900kWh/365 day * hours of use * $(1000 \mathrm{~W} / 1 \mathrm{kWh}) /$ Reference Area $\left(\mathrm{m}^{2}\right)$} \\
\hline \multicolumn{4}{|c|}{$*(1900 / 365) *($ day $/ 15.6$ hours $) *(1000 \mathrm{~W} / \mathrm{kW}) *\left(1 / 7428 \mathrm{~m}^{2}\right)=0.045 \mathrm{~W} / \mathrm{m}^{2}$} \\
\hline
\end{tabular}

\section{Post-1980 Lowrise: Water System Comparison}

\begin{tabular}{ccc|ccc}
\hline \multicolumn{2}{c}{ Post-1980 Small Hotel } & \multicolumn{3}{c}{ Post-1980 Midrise } \\
\hline Space activity & DHW & Source & Space activity & DHW & Source \\
Hotel guest room & $0.2 \mathrm{~L} / \mathrm{h} / \mathrm{m}^{2}$ & {$[8]$} & Apartment & $0.15 \mathrm{~L} / \mathrm{h} / \mathrm{m}^{2}$ & [9] \\
Office & 0 & & Office & 0 & \\
Corridor & 0 & & Corridor & 0 & \\
\hline
\end{tabular}

Post-1980 Lowrise: Water System Selection

\begin{tabular}{lccc}
\hline \multicolumn{4}{c}{ Post-1980 Lowrise_Student Residence } \\
\hline Space activity & Building area & DHW from & Weighted \\
Student room & $87 \%$ & DOE models & DHW \\
& & 0.20 & $0.175 \mathrm{~L} / \mathrm{h} / \mathrm{m}^{2}$
\end{tabular}




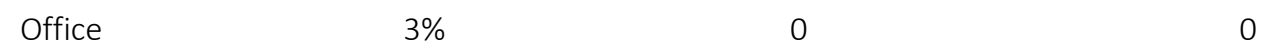

Corridor $10 \% \quad 0 \quad 0$

Weighted Average Pre1980 Low-rise total water system loads $\quad 0.19 \mathrm{~L} / \mathrm{h} / \mathrm{m}^{2}$

* Small Hotel water system loads are used to represent pre-1980 Lowrise student residence loads. The less efficient consumption was used for pre-1980 vintages.

\section{Post-1980 Lowrise: Equipment Comparison}

\begin{tabular}{ccc}
\hline & Post-1980 Small Hotel \\
\hline Heating Type & Gas furnace, unit heater, PTAC & \\
electric heat & 2003 CBECS \\
Cooling Type & DX & 2003 CBECS \\
Fan Control & Constant & 2003 CBECS \\
SWH Type & gas water heater & \\
Fuel & gas & \\
Cooling Efficiency & 3.4 & IDF Small Hotel input \\
Thermal Efficiency (\%) & 80 & Winiarski and Halverson, 2008 \\
Temperature Setpoint (으) & 60 & \\
\hline
\end{tabular}

\begin{tabular}{ccc}
\hline & Post-1980 Midrise Apartment & \\
Heating Type & Gas furnace & 90.1 Mechanical Subcommittee \\
Cooling Type & Split system DX & 90.1 Mechanical Subcommittee \\
Fan Control & CAV & 90.1 Mechanical Subcommittee \\
SWH Type & Gas water heater & \\
Fuel & gas & \\
Cooling Efficiency & 3.4 & IDF Midrise Apartment input \\
Thermal Efficiency (\%) & 78 & Winiarski and Halverson, 2008 \\
Temperature Setpoint (oC) & 60 & \\
\hline
\end{tabular}

\section{Post-1980 Lowrise: Equipment Selection}

\begin{tabular}{cc}
\hline & Post-1980 Lowrise student residence \\
\hline Heating Type & Gas furnace \\
Cooling Type & Split system DX \\
Fan Control & CAV \\
SWH Type & gas water heater \\
Fuel & gas \\
Cooling Efficiency & 3.4 \\
Thermal Efficiency (\%) & 78 \\
Temperature Setpoint (으) & 60 \\
\hline
\end{tabular}

* The models will have a $21^{\circ} \mathrm{C}$ for both heating and cooling year around.

* Equipment COP will be set 78 for heating, and 3.4 for cooling (Post1980 Small Hotel and Midrise).

* No economizer

* No natural ventilation is assigned 
Post-1980 Lowrise: Schedule Selection
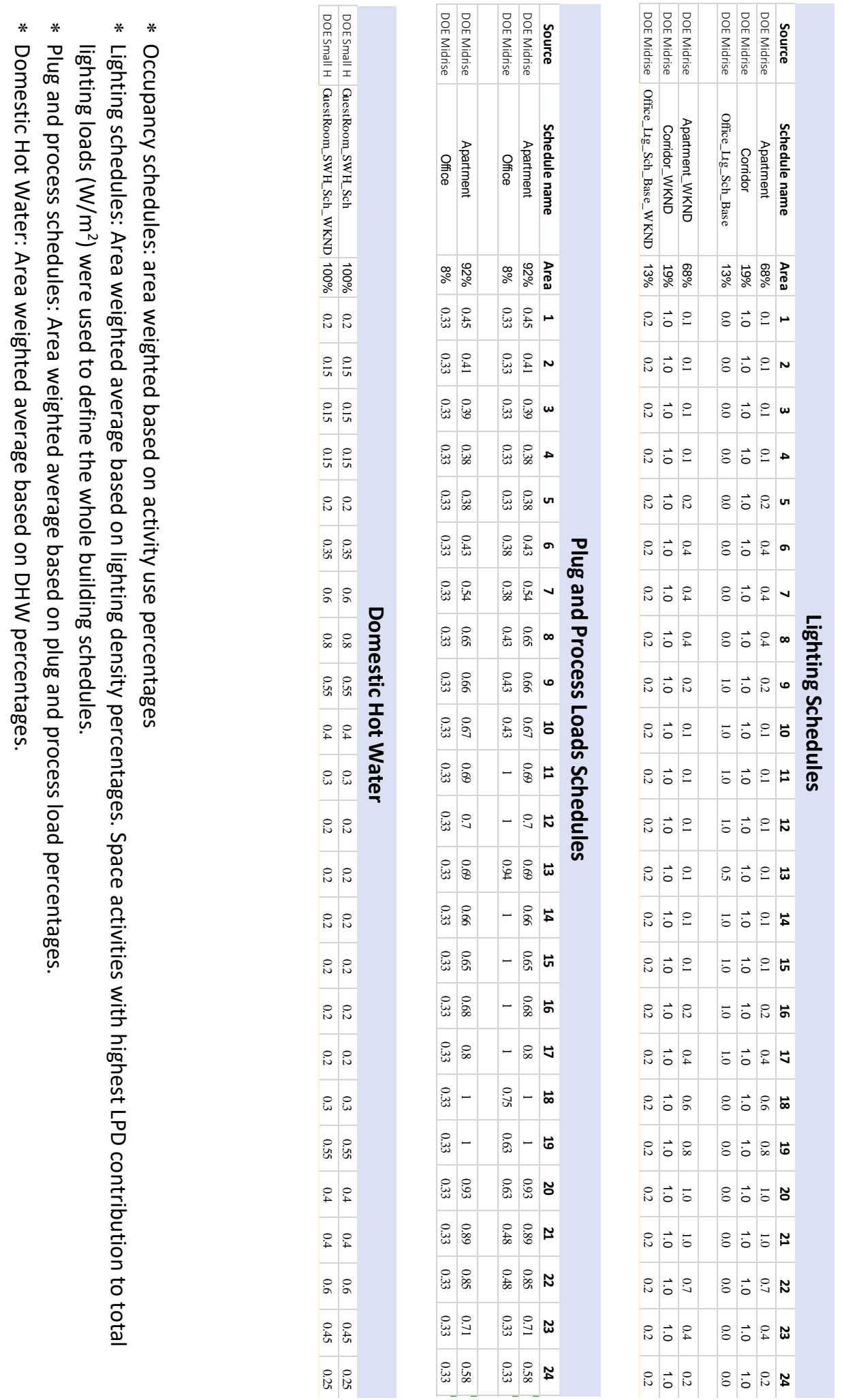

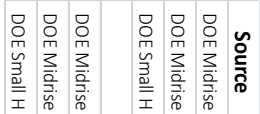

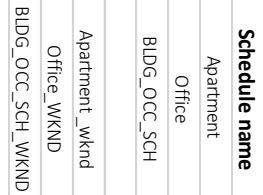

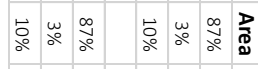

:०OH :OH

i. B. :0hn

:Or :O०

아 :0r

:०० :0r

i०० 80ra

jor ion

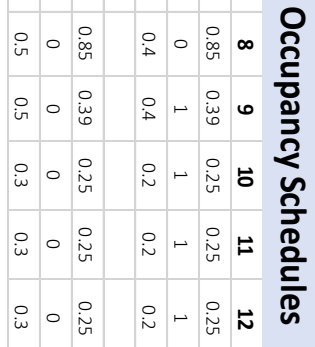

i。说 总 i

i。忌 总十总

调忌计总岛

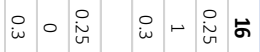

i 0 迹 int

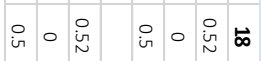

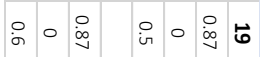

이용

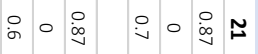

i.

아 :O०

i०or ior 


\section{Post-1980 Lowrise: Sources}

[1] 2003 CBECS Data

[2] PNNL-16770: Analysis of Energy Saving Impacts of ASHRAE 90.1-2004 for the State of New York

[3] Mandatory Energy Reports 2013 - Ontario, Daft Logic, Visual Judgment, Geographical Information Systems, and the Architectural Conservancy of Ontario

[4] Ryerson Space Audit Data. URL: https://ryerson.iwmsapp.com/archibus/

[5] ASHRAE Standard 62.1-2004 Table 6-1, Atlanta, GA: American Society of Heating, Refrigerating and Air-Conditioning Engineers.

[6] ASHRAE Standard 62-1999 Table 6-1, Atlanta, GA: American Society of Heating, Refrigerating and Air-Conditioning Engineers.

[7] ASHRAE Standard 90.1-1989, Atlanta, GA: American Society of Heating, Refrigerating and Air-Conditioning Engineers.

[8] PNNL - 17875 Technical Support Document: The Development of the Advanced Energy Design Guide for Highway Lodging Buildings

[9] DOE Commercial Reference Building Report 
Post-1980 Midrise: Form Comparison

\begin{tabular}{cccc}
\hline Building form variables & Large Hotel & Highrise Apartment & Midrise \\
\hline Vintage & Post 1980 & 2004 & Post 1980 \\
Total conditioned area & $11,345 \mathrm{~m}^{2}$ & $7836 \mathrm{~m}^{2}$ & $13474 \mathrm{~m}^{2}$ \\
Number of floors & $6+$ basement & 10 & 7 \\
Building height & $22 \mathrm{~m}$ & $30.5 \mathrm{~m}$ & $21 \mathrm{~m}$ \\
Aspect Ratio & 5.1 & 2.75 & $\mathrm{n} / \mathrm{a}$ \\
Window to wall ratio & $30 \%$ & $30 \%$ & $30 \%$ \\
Shading & None & None & $\mathrm{n} / \mathrm{a}$ \\
Ground floor to ceiling height & $3.96 \mathrm{~m}$ & $3.05 \mathrm{~m}$ & $\mathrm{n} / \mathrm{a}$ \\
Floor to floor height & $3.05 \mathrm{~m}$ & $3.05 \mathrm{~m}$ & $\mathrm{n} / \mathrm{a}$ \\
Building shape & Rectangle & Rectangle & $\mathrm{n} / \mathrm{a}$ \\
\hline Source & {$[1]$} & {$[2]$} & {$[3]$}
\end{tabular}

\section{Post-1980 Midrise: Form Selection}

\begin{tabular}{ccc}
\hline \multicolumn{3}{c}{ Post-1980 Midrise_student residence } \\
\hline Characterization inputs & Reference Method & Wireframe Method \\
\hline Total conditioned area & $13474 \mathrm{~m}^{2}$ & GIS/DaftLogic defined \\
Number of floors & 7 & DaftLogic defined \\
Building height & $21 \mathrm{~m}$ & GIS/DaftLogic defined \\
Aspect Ratio* & 3.9 & GIS/DaftLogic defined \\
Window to wall ratio* & $30 \%$ & $30 \%$ \\
Shading & None & None \\
Floor to floor height* & $3 \mathrm{~m}$ & $3 \mathrm{~m}$ \\
Building shape & Rectangle & GIS defined \\
\hline
\end{tabular}

* The Average aspect ratio of the DOE Large Hotel and Highrise Apartment is considered

* Window-to-wall ratio of $30 \%$ was defined as this ratio was common in student residence buildings

*Floor-to-floor height was set as $3 \mathrm{~m}$ in all categories. 
Post-1980 Midrise: Fabric Comparison

\begin{tabular}{|c|c|c|}
\hline & Post 1980 Large Hotel & 2004 Highrise Apartment \\
\hline \multicolumn{3}{|c|}{ Ground floor slab } \\
\hline Name & ext-slab & Typical Insulated Carpeted 6in Slab Floor \\
\hline Layer 1 & HW CONCRETE & 6 in. Normalweight Concrete floor \\
\hline Layer 2 & CPO2 CARPET PAD & Typical Carpet Pad \\
\hline R-value & $0.54 \mathrm{~m} 2 * \mathrm{~K} / \mathrm{W}$ & $\mathrm{m} 2 * \mathrm{~K} / \mathrm{W}$ \\
\hline \multicolumn{3}{|c|}{ Ceiling } \\
\hline Name & INT-FLOOR-UNDERSIDE & Typical Interior Ceiling \\
\hline Layer 1 & CPO2 CARPET PAD & CPO2 CARPET PAD \\
\hline Layer 2 & MAT-CCO5 4 HW CONCRETE & $100 \mathrm{~mm}$ Normalweight concrete floor \\
\hline \multicolumn{3}{|c|}{ Exterior roof } \\
\hline Name & IEAD Res Roof & Typical IEAD Roof R-15.87 \\
\hline Layer 1 & Roof Membrane & Roof Membrane \\
\hline Layer 2 & IEAD Res Roof Insulation & Typical Insulation R-14.76 \\
\hline Layer 3 & Metal decking & Metal Roof Surface \\
\hline R-value & $3.97 \mathrm{~m} 2 * \mathrm{~K} / \mathrm{W}$ & $2.79 \mathrm{~m} 2 * \mathrm{~K} / \mathrm{W}$ \\
\hline \multicolumn{3}{|c|}{ Exterior wall } \\
\hline Name & Mass Res Ext Wall & Typical Insulated Steel Framed Exterior Wall \\
\hline Layer 1 & IIN Stucco & $25 \mathrm{~mm}$ Stucco \\
\hline Layer 2 & 8IN Concrete HW & 5/8in. Gypsum Board \\
\hline Layer 3 & Mass Res Wall Insulation & Typical Insulation R-13.45 \\
\hline R-value & 1/2 IN Gypsum & 5/8in. Gypsum Board \\
\hline \multicolumn{3}{|c|}{ Interior wall } \\
\hline Name & Int-walls & Typical Interior Wall \\
\hline Layer 1 & 1/2IN Gypsum & 1/2IN Gypsum \\
\hline Layer 2 & 1/2IN Gypsum & 1/2IN Gypsum \\
\hline \multicolumn{3}{|c|}{ Interior floor } \\
\hline Name & INT-FLOOR-TOPSIDE & Typical Interior Floor \\
\hline Layer 1 & MAT-CCO5 4 HW CONCRETE & 100mm Normalweight concrete floor \\
\hline Layer 2 & CPO2 CARPET PAD & CPO2 CARPET PAD \\
\hline \multicolumn{3}{|c|}{ Glazing System } \\
\hline Name & Window Res Fixed & U 0.62 SHGC 0.39Dbl Blue $6 \mathrm{~mm} / 6 \mathrm{~mm}$ Air \\
\hline Layer 1 & Res Fixed Assembly Window & Blue $6 \mathrm{~mm}$ - Air $6 \mathrm{~mm}$ - Clear $6 \mathrm{~mm}$ \\
\hline U-Factor & $2.95 \mathrm{~W} / \mathrm{m} 2{ }^{*} \mathrm{~K}$ & $1.95 \mathrm{~W} / \mathrm{m} 2 * \mathrm{~K}$ \\
\hline \multicolumn{3}{|c|}{ Internal mass } \\
\hline Name & Interior Furnishings & Interior Furnishings \\
\hline Layer 1 & Standard Wood 6inch & Standard Wood 6inch \\
\hline
\end{tabular}


Post-1980 Midrise: Fabric Selection

\begin{tabular}{ccc}
\hline & Post-1980 Midrise student residence & \\
\hline Component name & Assembly name & Assembly details \\
Ground floor slab & ext-slab & $0.54 \mathrm{~m} 2 * \mathrm{~K} / \mathrm{W}$ \\
Exterior roof & IEAD Res Roof & $3.97 \mathrm{~m} 2{ }^{*} \mathrm{~K} / \mathrm{W}$ \\
Exterior wall & Mass Res Ext Wall & $2.48 \mathrm{~m} 2 * \mathrm{~K} / \mathrm{W}$ \\
Ceiling & INT-FLOOR-UNDERSIDE & - \\
Interior walls & Int-walls & - \\
Interior floor & INT-FLOOR-TOPSIDE & - \\
Internal mass & Interior Furnishings & - \\
Glazing system & U-Factor & $2.95 \mathrm{~W} / \mathrm{m} 2 * \mathrm{~K}$ \\
& SHGC & 0.39 \\
Air tightness & Visible transmittance & 0.31 \\
& ACH@75Pa & 0.6 \\
\hline
\end{tabular}

Post-1980 Midrise: Space Activity Comparison

\begin{tabular}{cc|cc|cc}
\hline Pitman Hall & & \multicolumn{2}{|c}{ Large Hotel } & \multicolumn{2}{c}{ Highrise Apartment } \\
\hline Space Activity & Area & Space Activity & Area & Space Activity & Area \\
Administrative offices & $1 \%$ & Basement & $17 \%$ & Apartment & $87 \%$ \\
Common use & $6 \%$ & Retail & $1 \%$ & Corridor & $10 \%$ \\
Food services & $3 \%$ & Mechanical & $1 \%$ & Office & $3 \%$ \\
Residence living & $43 \%$ & Storage & $1 \%$ & \\
Residence service & $4 \%$ & Laundry & $1 \%$ & \\
Washrooms & $2 \%$ & Cafe & $2 \%$ & \\
Corridors & $20 \%$ & Lobby & $12 \%$ & \\
Non- assignable space & $10 \%$ & Corridor & $17 \%$ & \\
Parking structure & $11 \%$ & Dining & $3 \%$ & \\
& & Banquet & $3 \%$ & \\
& & Kitchen & $1 \%$ & & \\
\hline Source & & Guest room & $41 \%$ & & \\
\hline
\end{tabular}

Post-1980 Midrise: Space Activity Selection

\begin{tabular}{cc}
\hline Post-1980 Midrise_Student Residence & \\
\hline Space Activity & Area \\
Student dormitory & $45 \%$ \\
Corridors & $20 \%$ \\
Office space & $5 \%$ \\
Lobby & $5 \%$ \\
Kitchen & $5 \%$ \\
Banquet/Cafe & $8 \%$
\end{tabular}




\section{Post-1980 Midrise: Occupancy Comparison}

\begin{tabular}{cccc|cccc}
\hline \multicolumn{4}{c|}{ Post-1980 Large Hotel } & \multicolumn{4}{c}{ 2004 Highrise Apartment } \\
\hline Space & Occupancy & Occupancy & Source & $\begin{array}{c}\text { Space } \\
\text { activity }\end{array}$ & $\begin{array}{c}\text { Occupancy } \\
\text { per space }\end{array}$ & $\begin{array}{c}\text { Occupancy } \\
\text { density }\end{array}$ & Source \\
activity & per space & density & & Apartment & $2.5 \mathrm{pax}$ & $35.3 \mathrm{~m}^{2} / \mathrm{pax}$ & {$[1]$} \\
Guest room & $1.5 \mathrm{pax}$ & $26 \mathrm{~m}^{2} / \mathrm{pax}$ & {$[1]$} & Office & $2 \mathrm{pax}$ & $44 \mathrm{~m}^{2} / \mathrm{pax}$ & {$[1]$} \\
Lobby & $422 \mathrm{pax}$ & $3 \mathrm{~m}^{2} / \mathrm{pax}$ & {$[1]$} & & & & \\
Kitchen & $6 \mathrm{pax}$ & $18.5 \mathrm{~m}^{2} / \mathrm{pax}$ & {$[1]$} & & & \\
Banquet & $238 \mathrm{pax}$ & $1.4 \mathrm{~m}^{2} / \mathrm{pax}$ & {$[1]$} & & & \\
Cafe & $135 \mathrm{pax}$ & $1.4 \mathrm{~m}^{2} / \mathrm{pax}$ & {$[1]$} & & & \\
Basement & $53 \mathrm{pax}$ & $37.1 \mathrm{~m}^{2} / \mathrm{pax}$ & {$[1]$} & & & \\
Washroom & $21 \mathrm{pax}$ & $10 \mathrm{~m}^{2} / \mathrm{pax}$ & {$[2]$} & & & \\
\hline
\end{tabular}

\section{Post-1980 Midrise: Occupancy Selection}

\begin{tabular}{cccc}
\hline & \multicolumn{3}{c}{ Post-1980 Midrise_Student Residence } \\
\hline Space activity & Building area & Occupancy from & Weighted Occupancy \\
Student dormitory & $45 \%$ & DOE models & $11.7 \mathrm{~m}^{2} /$ pax \\
Office & $5 \%$ & $26 \mathrm{~m}^{2} / \mathrm{pax}$ & $2.2 \mathrm{~m}^{2} / \mathrm{pax}$ \\
Corridor & $20 \%$ & $44 \mathrm{~m}^{2} / \mathrm{pax}$ & $0.0 \mathrm{~m}^{2} / \mathrm{pax}$ \\
Lobby & $5 \%$ & $0 \mathrm{~m}^{2} / \mathrm{pax}$ & $0.2 \mathrm{~m}^{2} / \mathrm{pax}$ \\
Kitchen & $5 \%$ & $3 \mathrm{~m}^{2} / \mathrm{pax}$ & $0.9 \mathrm{~m}^{2} / \mathrm{pax}$ \\
Banquet/Cafe & $18.5 \mathrm{~m}^{2} / \mathrm{pax}$ & $0.1 \mathrm{~m}^{2} / \mathrm{pax}$ \\
Basement & $1.4 \mathrm{~m}^{2} / \mathrm{pax}$ & $3.7 \mathrm{~m}^{2} / \mathrm{pax}$ \\
Washroom & $37.1 \mathrm{~m}^{2} / \mathrm{pax}$ & $0.2 \mathrm{~m} / \mathrm{pax}$ \\
Weighted Average Post-1980 Midrise total peak occupant density & $32 \mathrm{~m}^{2} / \mathrm{pax}$ \\
\hline
\end{tabular}

\section{Post-1980 Midrise: Ventilation Rate Comparison}

\begin{tabular}{|c|c|c|c|c|c|}
\hline \multicolumn{3}{|c|}{ Post-1980 Large Hotel } & \multicolumn{3}{|c|}{2004 Highrise } \\
\hline Space activity & Outdoor air & Source & Space activity & Outdoor air & Source \\
\hline Guest room & $0.36 \mathrm{~L} / \mathrm{s} / \mathrm{m}^{2}$ & [3] & Apartment & $0.29 \mathrm{~L} / \mathrm{s} / \mathrm{m}^{2}$ & [3] \\
\hline Corridor & $0.25 \mathrm{~L} / \mathrm{s} / \mathrm{m}^{2}$ & [3] & Office & $0.51 \mathrm{~L} / \mathrm{s} / \mathrm{m}^{2}$ & [3] \\
\hline Lobby & $0.9 \mathrm{~L} / \mathrm{s} / \mathrm{m}^{2}$ & [3] & Corridor & $0.25 \mathrm{~L} / \mathrm{s} / \mathrm{m}^{2}$ & [3] \\
\hline Kitchen & $0.43 \mathrm{~L} / \mathrm{s} / \mathrm{m}^{2}$ & [3] & & & \\
\hline Banquet & $7.17 \mathrm{~L} / \mathrm{s} / \mathrm{m}^{2}$ & [3] & & & \\
\hline Café & $7.17 \mathrm{~L} / \mathrm{s} / \mathrm{m}^{2}$ & [3] & & & \\
\hline Basement & $0.25 \mathrm{~L} / \mathrm{s} / \mathrm{m}^{2}$ & [3] & & & \\
\hline Washroom & $1.4 \mathrm{~L} / \mathrm{s} / \mathrm{m}^{2}$ & [3] & & & \\
\hline
\end{tabular}




\section{Post-1980 Midrise: Ventilation Rate Selection}

\begin{tabular}{cccc}
\hline & \multicolumn{2}{c}{ Post-1980 Midrise_Student Residence } \\
\hline Space activity & Building area & Outdoor air from & Weighted \\
DOE models & Outdoor air \\
Student dormitory & $45 \%$ & $0.36 \mathrm{~L} / \mathrm{s} / \mathrm{m}^{2}$ & $0.16 \mathrm{~L} / \mathrm{s} / \mathrm{m}^{2}$ \\
Office & $5 \%$ & $0.508 \mathrm{~L} / \mathrm{s} / \mathrm{m}^{2}$ & $0.03 \mathrm{~L} / \mathrm{s} / \mathrm{m}^{2}$ \\
Corridor & $20 \%$ & $0.25 \mathrm{~L} / \mathrm{s} / \mathrm{m}^{2}$ & $0.05 \mathrm{~L} / \mathrm{s} / \mathrm{m}^{2}$ \\
Lobby & $5 \%$ & $0.89 \mathrm{~L} / \mathrm{s} / \mathrm{m}^{2}$ & $0.04 \mathrm{~L} / \mathrm{s} / \mathrm{m}^{2}$ \\
Kitchen & $5 \%$ & $0.43 \mathrm{~L} / \mathrm{s} / \mathrm{m}^{2}$ & $0.02 \mathrm{~L} / \mathrm{s} / \mathrm{m}^{2}$ \\
Banquet/Cafe & $8 \%$ & $7.17 \mathrm{~L} / \mathrm{s} / \mathrm{m}^{2}$ & $0.57 \mathrm{~L} / \mathrm{s} / \mathrm{m}^{2}$ \\
Basement & $10 \%$ & $0.25 \mathrm{~L} / \mathrm{s} / \mathrm{m}^{2}$ & $0.03 \mathrm{~L} / \mathrm{s} / \mathrm{m}^{2}$ \\
Washroom & $1.4 \mathrm{~L} / \mathrm{m}^{2}$ & $0.03 \mathrm{~L} / \mathrm{s} / \mathrm{m}^{2}$ \\
\hline Weighted Average Post1980 Midrise total ventilation rate & $0.93 \mathrm{~L} / \mathrm{s} / \mathrm{m}^{2}$ \\
\hline
\end{tabular}

\section{Post-1980 Midrise: Lighting Power Density Comparison}

\begin{tabular}{ccc|ccc}
\hline \multicolumn{3}{c|}{ Post-1980 Large Hotel } & & \multicolumn{3}{c}{ 2004 Highrise } & \\
\hline Space activity & Lights & Source & Space activity & Lights & Source \\
Guest room & $19.1 \mathrm{~W} / \mathrm{m}^{2}$ & {$[4]$} & Apartment & $3.76 \mathrm{~W} / \mathrm{m}^{2}$ & {$[5]$} \\
Corridor & $13.08 \mathrm{~W} / \mathrm{m}^{2}$ & {$[4]$} & Office & $11.8 \mathrm{~W} / \mathrm{m}^{2}$ & {$[5]$} \\
Lobby & $20.29 \mathrm{~W} / \mathrm{m}^{2}$ & {$[4]$} & Corridor & $5.9 \mathrm{~W} / \mathrm{m}^{2}$ & {$[5]$} \\
Kitchen & $16.83 \mathrm{~W} / \mathrm{m}^{2}$ & {$[4]$} & & & \\
Banquet & $27.56 \mathrm{~W} / \mathrm{m}^{2}$ & {$[4]$} & & \\
Café & $15.74 \mathrm{~W} / \mathrm{m}^{2}$ & {$[4]$} & & \\
Basement & $7.53 \mathrm{~W} / \mathrm{m}^{2}$ & {$[4]$} & & & \\
Washroom & $9.61 \mathrm{~W} / \mathrm{m}^{2}$ & {$[4]$} & & & \\
\hline
\end{tabular}

Post-1980 Midrise: Lighting Power Density Selection

\begin{tabular}{cccc}
\hline & \multicolumn{2}{c}{ Post-1980 Midrise Lighting Power Density } & \\
\hline Space activity & Building area & Lights from & Weighted \\
Guest room & $45 \%$ & DOE models & Lights \\
Corridor & $5 \%$ & $3.76 \mathrm{~W} / \mathrm{m}^{2}$ & $1.69 \mathrm{~W} / \mathrm{m}^{2}$ \\
Lobby & $20 \%$ & $11.8 \mathrm{~W} / \mathrm{m}^{2}$ & $0.59 \mathrm{~W} / \mathrm{m}^{2}$ \\
Kitchen & $5 \%$ & $13.08 \mathrm{~W} / \mathrm{m}^{2}$ & $2.61 \mathrm{~W} / \mathrm{m}^{2}$ \\
Banquet & $5 \%$ & $20.29 \mathrm{~W} / \mathrm{m}^{2}$ & $1.01 \mathrm{~W} / \mathrm{m}^{2}$ \\
Café & $8 \%$ & $16.83 \mathrm{~W} / \mathrm{m}^{2}$ & $0.84 \mathrm{~W} / \mathrm{m}^{2}$ \\
Basement & $10 \%$ & $21.65 \mathrm{~W} / \mathrm{m}^{2}$ & $1.73 \mathrm{~W} / \mathrm{m}^{2}$ \\
Washroom & $7.53 \mathrm{~W} / \mathrm{m}^{2}$ & $0.75 \mathrm{~W} / \mathrm{m}^{2}$ \\
\multicolumn{2}{c}{ Weighted Average Post1980 Midrise total lighting loads } & $0.19 \mathrm{~W} / \mathrm{m}^{2}$ \\
\hline
\end{tabular}


Post-1980 Midrise: Plug and Process Loads Comparison

\begin{tabular}{ccc|ccc}
\hline \multicolumn{3}{c|}{ Post-1980 Large Hotel } & \multicolumn{3}{c}{ 2004 Highrise } \\
\hline Space activity & Plug load & Source & Space activity & Plug load & Source \\
Guest room & $14 \mathrm{~W} / \mathrm{m}^{2}$ & {$[6-7]$} & Apartment & 6.73 & {$[8]$} \\
Corridor & $0 \mathrm{~W} / \mathrm{m}^{2}$ & {$[6-7]$} & Office & 6.73 & {$[8]$} \\
Lobby & $8.07 \mathrm{~W} / \mathrm{m}^{2}$ & {$[6-7]$} & Corridor & 0 & {$[8]$} \\
Kitchen & $127 \mathrm{~W} / \mathrm{m}^{2}$ & {$[6-7]$} & & & \\
Banquet & $67.84 \mathrm{~W} / \mathrm{m}^{2}$ & {$[6-7]$} & & \\
Café & $5.38 \mathrm{~W} / \mathrm{m}^{2}$ & {$[6-7]$} & & \\
Basement & $5.38 \mathrm{~W} / \mathrm{m}^{2}$ & {$[6-7]$} & & & \\
Washroom & $4 \mathrm{~W} / \mathrm{m}^{2}$ & {$[6-7]$} & & & \\
\hline
\end{tabular}

Post-1980 Midrise: Plug and Process Loads Selection

\begin{tabular}{|c|c|c|c|c|c|}
\hline \multicolumn{6}{|c|}{ Post-1980 Midrise Student Residence } \\
\hline Space activity & Building area & \multicolumn{2}{|r|}{$\begin{array}{l}\text { Plug load from } \\
\text { DOE models }\end{array}$} & \multicolumn{2}{|c|}{$\begin{array}{l}\text { Weighted } \\
\text { Plug load }\end{array}$} \\
\hline Student dormitory & $45 \%$ & & $10.37 \mathrm{~W} / \mathrm{m}^{2}$ & \multicolumn{2}{|c|}{$4.66 \mathrm{~W} / \mathrm{m}^{2}$} \\
\hline Office & $5 \%$ & & $6.73 \mathrm{~W} / \mathrm{m}^{2}$ & \multicolumn{2}{|c|}{$0.34 \mathrm{~W} / \mathrm{m}^{2}$} \\
\hline Corridor & $20 \%$ & & $0 \mathrm{~W} / \mathrm{m}^{2}$ & \multicolumn{2}{|c|}{$0.00 \mathrm{~W} / \mathrm{m}^{2}$} \\
\hline Lobby & $5 \%$ & & $8.07 \mathrm{~W} / \mathrm{m}^{2}$ & \multicolumn{2}{|c|}{$0.40 \mathrm{~W} / \mathrm{m}^{2}$} \\
\hline Kitchen & $5 \%$ & & $127 \mathrm{~W} / \mathrm{m}^{2}$ & \multicolumn{2}{|c|}{$6.35 \mathrm{~W} / \mathrm{m}^{2}$} \\
\hline Banquet/Cafe & $8 \%$ & & $26.43 \mathrm{~W} / \mathrm{m}^{2}$ & \multicolumn{2}{|c|}{$2.11 \mathrm{~W} / \mathrm{m}^{2}$} \\
\hline Basement & $10 \%$ & & $5.38 \mathrm{~W} / \mathrm{m}^{2}$ & \multicolumn{2}{|c|}{$0.54 \mathrm{~W} / \mathrm{m}^{2}$} \\
\hline Washroom & $2 \%$ & & $4 \mathrm{~W} / \mathrm{m}^{2}$ & \multicolumn{2}{|c|}{$0.08 \mathrm{~W} / \mathrm{m}^{2}$} \\
\hline \multicolumn{4}{|c|}{ Weighted Average Post1980 Midrise total plug loads (including elevator) } & \multicolumn{2}{|c|}{$14.58 \mathrm{~W} / \mathrm{m}^{2}$} \\
\hline \multicolumn{6}{|c|}{$\begin{array}{l}\text { * Plug loads must add } 4161 \mathrm{kWh} / \text { year for elevators } \\
* 4161 \mathrm{kWh} / 365 \text { day * hours of use * }(1000 \mathrm{~W} / 1 \mathrm{kWh}) / \text { Reference Area }\left(\mathrm{m}^{2}\right) \\
*(4161 / 365) *(\text { day } / 15.6 \text { hours }) *(1000 \mathrm{~W} / \mathrm{kW}) *\left(1 / 11,213 \mathrm{~m}^{2}\right)=0.10 \mathrm{~W} / \mathrm{m}^{2}\end{array}$} \\
\hline \multicolumn{6}{|c|}{ Post-1980 Midrise: Water System Comparison } \\
\hline \multicolumn{3}{|c|}{ Post-1980 Large Hotel } & \multicolumn{3}{|c|}{2004 Highrise Apartment } \\
\hline Space activity & DHW & Source & Space activity & DHW & Source \\
\hline Guest room & $0.2 \mathrm{~L} / \mathrm{h} / \mathrm{m}^{2}$ & {$[6-7]$} & Apartment & $0.15 \mathrm{~L} / \mathrm{h} / \mathrm{m}^{2}$ & [8] \\
\hline Corridor & 0 & & Office & 0 & \\
\hline Lobby & 0 & & Corridor & 0 & \\
\hline Kitchen & $1.62 \mathrm{~L} / \mathrm{h} / \mathrm{m}^{2}$ & {$[6-7]$} & & & \\
\hline Banquet & 0 & & & & \\
\hline Café & 0 & & & & \\
\hline Basement & 0 & & & & \\
\hline Washroom & $0.3 \mathrm{~L} / \mathrm{h} / \mathrm{m}^{2}$ & {$[6-7]$} & & & \\
\hline
\end{tabular}




\section{Post-1980 Midrise: Water System Selection}

\begin{tabular}{cccc}
\hline & \multicolumn{2}{c}{ Post-1980 Midrise_Student Residence } \\
\hline Space activity & Building area & DHW from & Weighted \\
Student dormitory & $45 \%$ & DOE models & DHW \\
Kitchen & $5 \%$ & $0.20 \mathrm{~L} / \mathrm{h} / \mathrm{m}^{2}$ & $0.09 \mathrm{~L} / \mathrm{h} / \mathrm{m}^{2}$ \\
Washroom & $2 \%$ & $1.62 \mathrm{~L} / \mathrm{h} / \mathrm{m}^{2}$ & $0.08 \mathrm{~L} / \mathrm{h} / \mathrm{m}^{2}$ \\
Weighted Average Post1980 Midrise total water system loads & $0.3 \mathrm{~L} / \mathrm{h} / \mathrm{m}^{2}$ & $0.01 \mathrm{~L} / \mathrm{h} / \mathrm{m}^{2}$ \\
\hline
\end{tabular}

\section{Post-1980 Midrise: Equipment Comparison}

\begin{tabular}{ccc}
\hline & Post-1980 Large Hotel & \\
\hline Heating Type & Gas furnace, unit heater, PTAC & 2003 CBECS \\
electric heat & \\
Cooling Type & DX & 2003 CBECS \\
Fan Control & Constant & 2003 CBECS \\
SWH Type & gas water heater & \\
Fuel & gas & IDF Small Hotel input \\
Cooling Efficiency & 3.4 & Winiarski and Halverson, 2008 \\
Thermal Efficiency (\%) & 80 & \\
Temperature Setpoint (oC) & 60 & \\
\hline & & \\
\hline Heating Type & 2004 Highrise Apartment & \\
Cooling Type & Water source heat pumps & 90.1 Mechanical Subcommittee \\
Fan Control & Constant Volume & 90.1 Mechanical Subcommittee \\
SWH Type & 90.1 Mechanical Subcommittee \\
Fuel & Central water heater with & \\
Cooling Efficiency & storage tank & \\
Thermal Efficiency (\%) & Natural gas & \\
Temperature Setpoint (으) & 3.4 & IDF Highrise Apartment input \\
& 80 & Requirements in code \\
\hline
\end{tabular}

Post-1980 Midrise: Equipment Selection

\begin{tabular}{cc}
\hline & Post-1980 Midrise student residence \\
\hline Heating Type & Gas boiler \\
Cooling Type & 2 air cooled chillers \\
Fan Control & CAV \\
SWH Type & gas water heater \\
Fuel & gas \\
Cooling Efficiency & 3.4 \\
Thermal Efficiency $(\%)$ & 80 \\
Temperature Setpoint $(\stackrel{\circ}{ } \mathrm{C})$ & 60 \\
\hline
\end{tabular}

\footnotetext{
* No economizer

* No natural ventilation is assigned
} 
Post-1980 Midrise: Schedule Selection

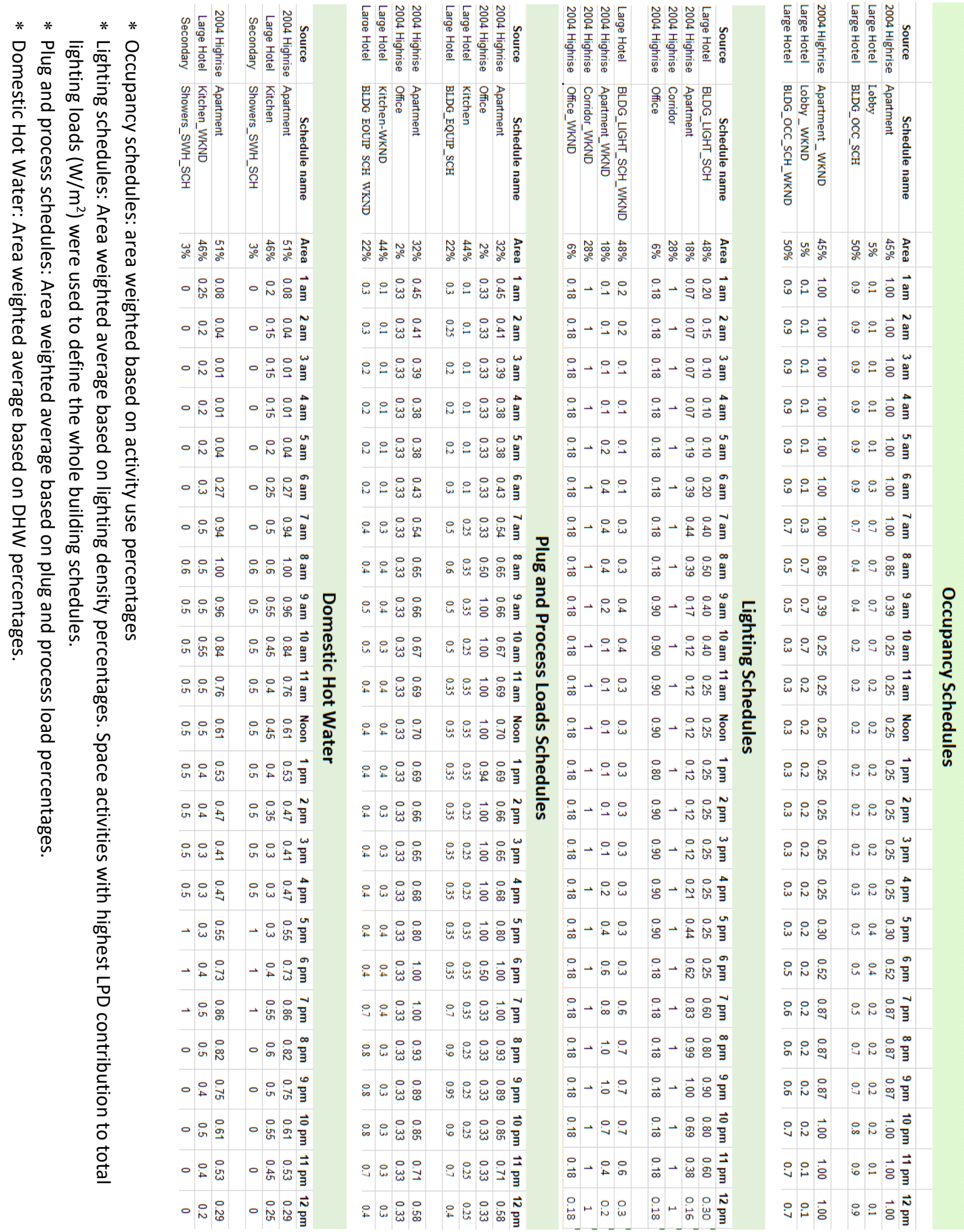




\section{Post-1980 Midrise: Sources}

[1] 2003 CBECS Data

[2] PNNL-16770: Analysis of Energy Saving Impacts of ASHRAE 90.1-2004 for the State of New York

[3] Mandatory Energy Reports 2013 - Ontario, Daft Logic, Visual Judgment, Geographical Information Systems, and the Architectural Conservancy of Ontario

[4] Ryerson Space Audit Data. URL: https://ryerson.iwmsapp.com/archibus/

[5] ASHRAE Standard 62.1-2004 Table 6-1, Atlanta, GA: American Society of Heating, Refrigerating and Air-Conditioning Engineers.

[6] ASHRAE Standard 62-1999 Table 6-1, Atlanta, GA: American Society of Heating, Refrigerating and Air-Conditioning Engineers.

[7] ASHRAE Standard 90.1-1989, Atlanta, GA: American Society of Heating, Refrigerating and Air-Conditioning Engineers.

[8] PNNL - 17875 Technical Support Document: The Development of the Advanced Energy Design Guide for Highway Lodging Buildings

[9] DOE Commercial Reference Building Report 
Pre-1980 Highrise: Form Comparison

\begin{tabular}{cccc}
\hline Building form variables & Large Hotel & Highrise Apartment & Highrise \\
\hline Vintage & Pre-1980 & 2004 & Pre-1980 \\
Total conditioned area & $11,345 \mathrm{~m}^{2}$ & $7836 \mathrm{~m}^{2}$ & $8396 \mathrm{~m} 2$ \\
Number of floors & 6 basement & 10 & 15 \\
Building height & $22 \mathrm{~m}$ & $30.5 \mathrm{~m}$ & $45 \mathrm{~m}$ \\
Aspect Ratio & 5.1 & 2.75 & $\mathrm{n} / \mathrm{a}$ \\
Window to wall ratio & $30 \%$ & $30 \%$ & $30 \%$ \\
Shading & None & None & None \\
Ground floor to ceiling height & $3.96 \mathrm{~m}$ & $3.05 \mathrm{~m}$ & $\mathrm{n} / \mathrm{a}$ \\
Floor to floor height & $3.05 \mathrm{~m}$ & $3.05 \mathrm{~m}$ & $\mathrm{n} / \mathrm{a}$ \\
Building shape & Rectangle & Rectangle & Tower \\
\hline Source & {$[1]$} & {$[2]$} & {$[3]$}
\end{tabular}

\section{Pre-1980 Highrise: Form Selection}

\begin{tabular}{ccc}
\hline \multicolumn{3}{c}{ Post-1980 Highrise Student Residence } \\
\hline Characterization inputs & Reference Method & Wireframe Method \\
\hline Total conditioned area & $8396 \mathrm{~m} 2$ & GIS/DaftLogic defined \\
Number of floors & 15 & DaftLogic defined \\
Building height & $45 \mathrm{~m}$ & GIS/DaftLogic defined \\
Aspect Ratio* & 3.9 & GIS/DaftLogic defined \\
Window to wall ratio* & $30 \%$ & $30 \%$ \\
Shading & None & None \\
Floor to floor height* & $3 \mathrm{~m}$ & $3 \mathrm{~m}$ \\
Building shape & Rectangle & GIS defined \\
\hline
\end{tabular}

* The Average aspect ratio of the DOE Large Hotel and Highrise Apartment is considered

* Window-to-wall ratio of $30 \%$ was defined as this ratio was common in student residence buildings

*Floor-to-floor height was set as $3 \mathrm{~m}$ in all categories. 


\section{Pre-1980 Highrise: Fabric Comparison}

\begin{tabular}{|c|c|c|}
\hline & Pre-1980 Large Hotel & 2004 Highrise Apartment \\
\hline \multicolumn{3}{|c|}{ Ground floor slab } \\
\hline Name & ext-slab & Typical Insulated Carpeted 6in Slab Floor \\
\hline Layer 1 & HW CONCRETE & 6 in. Normalweight Concrete floor \\
\hline Layer 2 & CP02 CARPET PAD & Typical Carpet Pad \\
\hline R-value & $0.54 \mathrm{~m} 2 * \mathrm{~K} / \mathrm{W}$ & $\mathrm{m} 2 * \mathrm{k} / \mathrm{W}$ \\
\hline \multicolumn{3}{|c|}{ Ceiling } \\
\hline Name & INT-FLOOR-UNDERSIDE & Typical Interior Ceiling \\
\hline Layer 1 & CPO2 CARPET PAD & CPO2 CARPET PAD \\
\hline Layer 2 & MAT-CCO5 4 HW CONCRETE & 100mm Normalweight concrete floor \\
\hline \multicolumn{3}{|c|}{ Exterior roof } \\
\hline Name & Typical IEAD Roof R-16.67 & Typical IEAD Roof R-15.87 \\
\hline Layer 1 & Roof Membrane & Roof Membrane \\
\hline Layer 2 & IEAD Res Roof Insulation R15.55 & Typical Insulation R-14.76 \\
\hline Layer 3 & Metal Roof Surface & Metal Roof Surface \\
\hline R-value & $2.99 \mathrm{~m}^{2 *} \mathrm{~K} / \mathrm{W}$ & $2.79 \mathrm{~m} 2 * \mathrm{~K} / \mathrm{W}$ \\
\hline \multicolumn{3}{|c|}{ Exterior wall } \\
\hline Name & $\begin{array}{l}\text { TYPICAL INSULATED EXTERIOR MASS WALL R- } \\
6.9\end{array}$ & Typical Insulated Steel Framed Exterior Wall \\
\hline Layer 1 & 1 IN Stucco & $25 \mathrm{~mm}$ Stucco \\
\hline Layer 2 & 8in CONCRETE HW Ref Bldg & 5/8in. Gypsum Board \\
\hline Layer 3 & Typical Insulation R-4.51 & Typical Insulation R-13.45 \\
\hline R-value & 1/2 IN Gypsum & 5/8in. Gypsum Board \\
\hline \multicolumn{3}{|c|}{ Interior wall } \\
\hline Name & Typical Interior Wall & Typical Interior Wall \\
\hline Layer 1 & G01 13mm gypsum board & 1/2IN Gypsum \\
\hline Layer 2 & G01 13mm gypsum board & 1/2IN Gypsum \\
\hline \multicolumn{3}{|c|}{ Interior floor } \\
\hline Name & Typical Interior Floor & Typical Interior Floor \\
\hline Layer 1 & $100 \mathrm{~mm}$ Normalweight concrete floor & $100 \mathrm{~mm}$ Normalweight concrete floor \\
\hline Layer 2 & CP02 CARPET PAD & CP02 CARPET PAD \\
\hline \multicolumn{3}{|c|}{ Glazing System } \\
\hline Name & U 0.62 SHGC 0.41 Simple Glazing Window & U 0.62 SHGC 0.39Dbl Blue $6 \mathrm{~mm} / 6 \mathrm{~mm}$ Air \\
\hline Layer 1 & U 0.62 SHGC 0.41 Simple Glazing & Blue $6 \mathrm{~mm}$ - Air $6 \mathrm{~mm}$ - Clear $6 \mathrm{~mm}$ \\
\hline U-Factor & $3.53 \mathrm{~W} / \mathrm{m} 2 * \mathrm{~K}$ & $1.95 \mathrm{~W} / \mathrm{m} 2 * \mathrm{~K}$ \\
\hline \multicolumn{3}{|c|}{ Internal mass } \\
\hline Name & Interior Furnishings & Interior Furnishings \\
\hline Layer 1 & Standard Wood 6inch & Standard Wood 6inch \\
\hline
\end{tabular}

Source

[1]

[2] 
Pre-1980 Highrise: Fabric Selection

\begin{tabular}{ccc}
\hline & Pre-1980 Highrise student residence & \\
\hline Component name & Assembly name & Assembly details \\
Ground floor slab & ext-slab & $0.54 \mathrm{~m} 2 * \mathrm{~K} / \mathrm{W}$ \\
Exterior roof & IEAD Res Roof & $2.9 \mathrm{~m} 2 * \mathrm{~K} / \mathrm{W}$ \\
Exterior wall & Mass Res Ext Wall & $1.22 \mathrm{~m} 2 * \mathrm{~K} / \mathrm{W}$ \\
Ceiling & INT-FLOOR-UNDERSIDE & - \\
Interior walls & Int-walls & - \\
Interior floor & INT-FLOOR-TOPSIDE & - \\
Internal mass & Interior Furnishings & - \\
Glazing system & U-Factor & $3.53 \mathrm{~W} / \mathrm{m} 2 * \mathrm{~K}$ \\
& SHGC & 0.41 \\
Air tightness & Visible transmittance & 0.32 \\
& ACH@75Pa & 0.6 \\
\hline
\end{tabular}

Pre-1980 Highrise: Space Activity Comparison

\begin{tabular}{cc|cc|cc}
\hline Pitman Hall & & \multicolumn{2}{c}{ Large Hotel } & \multicolumn{2}{c}{ Highrise Apartment } \\
\hline Space Activity & Area & Space Activity & Area & Space Activity & Area \\
Administrative offices & $1 \%$ & Basement & $17 \%$ & Apartment & $87 \%$ \\
Common use & $6 \%$ & Retail & $1 \%$ & Corridor & $10 \%$ \\
Food services & $3 \%$ & Mechanical & $1 \%$ & Office & $3 \%$ \\
Residence living & $43 \%$ & Storage & $1 \%$ & \\
Residence service & $4 \%$ & Laundry & $1 \%$ & \\
Washrooms & $2 \%$ & Cafe & $2 \%$ & \\
Corridors & $20 \%$ & Lobby & $12 \%$ & \\
Non- assignable space & $10 \%$ & Corridor & $17 \%$ & \\
Parking structure & $11 \%$ & Dining & $3 \%$ & \\
& & Banquet & $3 \%$ & \\
& & Kitchen & $1 \%$ & & \\
\hline Source & & Guest room & $41 \%$ & & \\
\end{tabular}

\section{Pre-1980 Highrise: Space Activity Selection}

\begin{tabular}{cc}
\hline \multicolumn{2}{|c}{ Pre-1980 Highrise Student Residence } \\
\hline Space Activity & Area \\
Student dormitory & $50 \%$ \\
Corridors & $18 \%$ \\
Office space & $5 \%$ \\
Lobby & $2 \%$ \\
Kitchen & $3 \%$ \\
Banquet/Cafe & $10 \%$
\end{tabular}




\section{Pre-1980 Highrise: Occupancy Comparison}

\begin{tabular}{cccc|cccc}
\hline \multicolumn{4}{c|}{ Pre-1980 Large Hotel } & \multicolumn{4}{c}{ 2004 Highrise Apartment } \\
\hline Space & Occupancy & Occupancy & Source & Space & Occupancy & Occupancy & Source \\
activity & per space & density & & activity & per space & density & \\
Guest room & 1.5 pax & $26 \mathrm{~m}^{2} /$ pax & {$[1]$} & Apartment & 2.5 pax & $35.3 \mathrm{~m}^{2} / \mathrm{pax}$ & {$[1]$} \\
Lobby & $422 \mathrm{pax}$ & $3 \mathrm{~m}^{2} / \mathrm{pax}$ & {$[1]$} & Office & $2 \mathrm{pax}$ & $44 \mathrm{~m}^{2} / \mathrm{pax}$ & {$[1]$} \\
Kitchen & $6 \mathrm{pax}$ & $18.5 \mathrm{~m}^{2} / \mathrm{pax}$ & {$[1]$} & & & & \\
Banquet & $238 \mathrm{pax}$ & $1.4 \mathrm{~m}^{2} / \mathrm{pax}$ & {$[1]$} & & & \\
Cafe & $135 \mathrm{pax}$ & $1.4 \mathrm{~m}^{2} / \mathrm{pax}$ & {$[1]$} & & & \\
Basement & $53 \mathrm{pax}$ & $37.1 \mathrm{~m}^{2} / \mathrm{pax}$ & {$[1]$} & & & \\
Washroom & $21 \mathrm{pax}$ & $10 \mathrm{~m}^{2} / \mathrm{pax}$ & {$[2]$} & & & \\
\hline
\end{tabular}

\section{Pre-1980 Highrise: Occupancy Selection}

\begin{tabular}{|c|c|c|c|}
\hline \multicolumn{4}{|c|}{ Pre-1980 Highrise Student Residence } \\
\hline Space activity & Building area & $\begin{array}{c}\text { Occupancy from } \\
\text { DOE models }\end{array}$ & $\begin{array}{c}\text { Weighted Average } \\
\text { Occupancy }\end{array}$ \\
\hline Student dormitory & $50 \%$ & $26 \mathrm{~m}^{2} / \mathrm{pax}$ & $13 \mathrm{~m}^{2} / \mathrm{pax}$ \\
\hline Office & $5 \%$ & $44 \mathrm{~m}^{2} / \mathrm{pax}$ & $2.2 \mathrm{~m}^{2} / \mathrm{pax}$ \\
\hline Corridor & $18 \%$ & 0 & 0 \\
\hline Lobby & $2 \%$ & $3 \mathrm{~m}^{2} / \mathrm{pax}$ & $0.1 \mathrm{~m}^{2} / \mathrm{pax}$ \\
\hline Kitchen & $3 \%$ & $18.5 \mathrm{~m}^{2} / \mathrm{pax}$ & $0.6 \mathrm{~m}^{2} / \mathrm{pax}$ \\
\hline Banquet/Cafe & $10 \%$ & $1.4 \mathrm{~m}^{2} /$ pax & $0.1 \mathrm{~m}^{2} / \mathrm{pax}$ \\
\hline Basement & $8 \%$ & $37.1 \mathrm{~m}^{2} / \mathrm{pax}$ & $3 \mathrm{~m}^{2} / \mathrm{pax}$ \\
\hline Washroom & $4 \%$ & $10 \mathrm{~m}^{2} / \mathrm{pax}$ & $0.4 \mathrm{~m}^{2} / \mathrm{pax}$ \\
\hline
\end{tabular}

\section{Pre-1980 Highrise: Ventilation Rate Comparison}

\begin{tabular}{ccc|ccc}
\hline \multicolumn{3}{c}{ Pre-1980 Large Hotel } & & \multicolumn{3}{c}{ 2004 Highrise } \\
\hline Space activity & Outdoor air & Source & Space activity & Outdoor air & Source \\
Guest room & $0.36 \mathrm{~L} / \mathrm{s} / \mathrm{m}^{2}$ & {$[3]$} & Apartment & $0.29 \mathrm{~L} / \mathrm{s} / \mathrm{m}^{2}$ & {$[3]$} \\
Corridor & $0.25 \mathrm{~L} / \mathrm{s} / \mathrm{m}^{2}$ & {$[3]$} & Office & $0.51 \mathrm{~L} / \mathrm{s} / \mathrm{m}^{2}$ & {$[3]$} \\
Lobby & $0.9 \mathrm{~L} / \mathrm{s}^{2}$ & {$[3]$} & Corridor & $0.25 \mathrm{~L} / \mathrm{s} / \mathrm{m}^{2}$ & {$[3]$} \\
Kitchen & $0.43 \mathrm{~L} / \mathrm{s} / \mathrm{m}^{2}$ & {$[3]$} & & & \\
Banquet & $7.17 \mathrm{~L} / \mathrm{s} / \mathrm{m}^{2}$ & {$[3]$} & & \\
Café & $7.17 \mathrm{~L} / \mathrm{s} / \mathrm{m}^{2}$ & {$[3]$} & & \\
Basement & $0.25 \mathrm{~L} / \mathrm{s} / \mathrm{m}^{2}$ & {$[3]$} & & \\
Washroom & $1.4 \mathrm{~L} / \mathrm{s} / \mathrm{m}^{2}$ & {$[3]$} & & & \\
\hline
\end{tabular}




\section{Pre-1980 Highrise: Ventilation Rate Selection}

\begin{tabular}{cccc}
\hline & \multicolumn{2}{c}{ Pre-1980 Highrise Student Residence } \\
\hline Space activity & Building area & Outdoor air from & Weighted \\
Student dormitory & $50 \%$ & DOE models & Outdoor air \\
Office & $5 \%$ & $13 \mathrm{~L} / \mathrm{s} /$ pax & $6.50 \mathrm{~L} / \mathrm{s} / \mathrm{pax}$ \\
Corridor & $18 \%$ & $9 \mathrm{~L} / \mathrm{s} /$ pax & $0.45 \mathrm{~L} / \mathrm{s} / \mathrm{pax}$ \\
Lobby & $2 \%$ & 0 & 0 \\
Kitchen & $3 \%$ & $10 \mathrm{~L} / \mathrm{s} / \mathrm{pax}$ & $0.20 \mathrm{~L} / \mathrm{s} / \mathrm{pax}$ \\
Banquet/Cafe & $10 \%$ & $8 \mathrm{~L} / \mathrm{s} /$ pax & $0.25 \mathrm{~L} / \mathrm{s} / \mathrm{pax}$ \\
Basement & $10 \mathrm{~L} / \mathrm{s} /$ pax & $1.00 \mathrm{~L} / \mathrm{s} / \mathrm{pax}$ \\
Washroom & $9 \%$ & $14 \mathrm{~L} / \mathrm{pax}$ & $0.75 \mathrm{~L} / \mathrm{s} / \mathrm{pax}$ \\
\hline Weighted Average Post1980 Midrise total ventilation rate & $0.56 \mathrm{~L} / \mathrm{s} / \mathrm{pax}$ \\
\hline
\end{tabular}

\section{Pre-1980 Highrise: Lighting Power Density Comparison}

\begin{tabular}{ccc|ccc}
\hline \multicolumn{3}{c}{ Pre-1980 Large Hotel } & & \multicolumn{3}{c}{2004 Highrise } \\
\hline Space activity & Lights & Source & Space activity & Lights & Source \\
Guest room & $19.1 \mathrm{~W} / \mathrm{m}^{2}$ & {$[4]$} & Apartment & $3.76 \mathrm{~W} / \mathrm{m}^{2}$ & {$[5]$} \\
Corridor & $13.08 \mathrm{~W} / \mathrm{m}^{2}$ & {$[4]$} & Office & $11.8 \mathrm{~W} / \mathrm{m}^{2}$ & {$[5]$} \\
Lobby & $20.29 \mathrm{~W} / \mathrm{m}^{2}$ & {$[4]$} & Corridor & $5.9 \mathrm{~W} / \mathrm{m}^{2}$ & {$[5]$} \\
Kitchen & $16.83 \mathrm{~W} / \mathrm{m}^{2}$ & {$[4]$} & & & \\
Banquet & $27.56 \mathrm{~W} / \mathrm{m}^{2}$ & {$[4]$} & & \\
Café & $15.74 \mathrm{~W} / \mathrm{m}^{2}$ & {$[4]$} & & \\
Basement & $7.53 \mathrm{~W} / \mathrm{m}^{2}$ & {$[4]$} & & \\
Washroom & $9.61 \mathrm{~W} / \mathrm{m}^{2}$ & {$[4]$} & & & \\
\hline
\end{tabular}

Pre-1980 Highrise: Lighting Power Density Selection

\begin{tabular}{cccc}
\hline & \multicolumn{3}{c}{ Pre-1980 Highrise Lighting Power Density } \\
\hline Space activity & Building area & Lights from & Weighted \\
Guest room & $50 \%$ & DOE models & Lights \\
Corridor & $5 \%$ & $11.43 \mathrm{~W} / \mathrm{m}^{2}$ & $5.72 \mathrm{~W} / \mathrm{m}^{2}$ \\
Lobby & $18 \%$ & $11.8 \mathrm{~W} / \mathrm{m}^{2}$ & $0.59 \mathrm{~W} / \mathrm{m}^{2}$ \\
Kitchen & $2 \%$ & $13.08 \mathrm{~W} / \mathrm{m}^{2}$ & $2.35 \mathrm{~W} / \mathrm{m}^{2}$ \\
Banquet & $3 \%$ & $20.29 \mathrm{~W} / \mathrm{m}^{2}$ & $0.41 \mathrm{~W} / \mathrm{m}^{2}$ \\
Café & $10 \%$ & $16.83 \mathrm{~W} / \mathrm{m}^{2}$ & $0.50 \mathrm{~W} / \mathrm{m}^{2}$ \\
Basement & $8 \%$ & $21.65 \mathrm{~W} / \mathrm{m}^{2}$ & $2.17 \mathrm{~W} / \mathrm{m}^{2}$ \\
Washroom & $4 \%$ & $7.53 \mathrm{~W} / \mathrm{m}^{2}$ & $0.60 \mathrm{~W} / \mathrm{m}^{2}$ \\
\hline Weighted Average Post1980 Midrise total lighting loads & $0.38 \mathrm{~W} / \mathrm{m}^{2}$ \\
\hline \multicolumn{4}{c}{}
\end{tabular}


Pre-1980 Highrise: Plug and Process Loads Comparison

\begin{tabular}{ccc|ccc}
\hline \multicolumn{3}{c|}{ Pre-1980 Large Hotel } & & \multicolumn{3}{c}{ 2004 Highrise } & \\
\hline Space activity & Plug load & Source & Space activity & Plug load & Source \\
Guest room & $14 \mathrm{~W} / \mathrm{m}^{2}$ & {$[6-7]$} & Apartment & 6.73 & {$[8]$} \\
Corridor & $0 \mathrm{~W} / \mathrm{m}^{2}$ & {$[6-7]$} & Office & 6.73 & {$[8]$} \\
Lobby & $8.07 \mathrm{~W} / \mathrm{m}^{2}$ & {$[6-7]$} & Corridor & 0 & {$[8]$} \\
Kitchen & $127 \mathrm{~W} / \mathrm{m}^{2}$ & {$[6-7]$} & & & \\
Banquet & $67.84 \mathrm{~W} / \mathrm{m}^{2}$ & {$[6-7]$} & & & \\
Café & $5.38 \mathrm{~W} / \mathrm{m}^{2}$ & {$[6-7]$} & & \\
Basement & $5.38 \mathrm{~W} / \mathrm{m}^{2}$ & {$[6-7]$} & & & \\
Washroom & $4 \mathrm{~W} / \mathrm{m}^{2}$ & {$[6-7]$} & & & \\
\hline
\end{tabular}

Pre-1980 Highrise: Plug and Process Loads Selection

\begin{tabular}{|c|c|c|c|c|c|}
\hline \multicolumn{6}{|c|}{ Pre-1980 Highrise Student Residence } \\
\hline Space activity & Building area & \multicolumn{2}{|c|}{ Plug load from } & \multicolumn{2}{|c|}{$\begin{array}{l}\text { Weighted } \\
\text { Plug load }\end{array}$} \\
\hline Student dormitory & $50 \%$ & \multicolumn{2}{|r|}{14.00} & \multicolumn{2}{|c|}{$\begin{array}{l}\text { Plug load } \\
7.00\end{array}$} \\
\hline Office & $5 \%$ & \multicolumn{2}{|r|}{6.73} & \\
\hline Corridor & $18 \%$ & \multicolumn{2}{|r|}{0} & \multicolumn{2}{|c|}{$\begin{array}{l}0.34 \\
0.00\end{array}$} \\
\hline Lobby & $2 \%$ & \multicolumn{2}{|r|}{8.07} & \multicolumn{2}{|c|}{0.16} \\
\hline Kitchen & $3 \%$ & \multicolumn{2}{|r|}{127.00} & \multicolumn{2}{|c|}{3.81} \\
\hline Banquet/Cafe & $10 \%$ & \multicolumn{2}{|r|}{26.43} & \multicolumn{2}{|c|}{2.64} \\
\hline Basement & $8 \%$ & \multicolumn{2}{|r|}{5.38} & \multicolumn{2}{|c|}{0.43} \\
\hline Washroom & $4 \%$ & \multicolumn{2}{|r|}{4} & \multicolumn{2}{|c|}{0.16} \\
\hline \multicolumn{4}{|c|}{ Weighted Average Pre1980 Highrise total plug loads (including elevator) } & 14.63 & \\
\hline \multicolumn{6}{|c|}{$\begin{array}{l}\text { * Plug loads must add } 4161 \mathrm{kWh} / \text { year for elevators } \\
* 4161 \mathrm{kWh} / 365 \text { day * hours of use * }(1000 \mathrm{~W} / 1 \mathrm{kWh}) / \text { Reference Area }\left(\mathrm{m}^{2}\right) \\
*(4161 / 365) *(\text { day } / 15.6 \text { hours }) *(1000 \mathrm{~W} / \mathrm{kW}) *\left(1 / 11,213 \mathrm{~m}^{2}\right)=0.10 \mathrm{~W} / \mathrm{m}^{2}\end{array}$} \\
\hline \multicolumn{6}{|c|}{ Pre-1980 Highrise: Water System Comparison } \\
\hline \multicolumn{2}{|c|}{ Pre-1980 Large Hotel } & \multicolumn{4}{|c|}{2004 Highrise Apartment } \\
\hline Space activity & DHW & Source & Space activity & $\mathrm{DHW}$ & Source \\
\hline Guest room & $0.2 \mathrm{~L} / \mathrm{h} / \mathrm{m}^{2}$ & {$[6-7]$} & Apartment & $0.15 \mathrm{~L} / \mathrm{h} / \mathrm{m}^{2}$ & [8] \\
\hline Corridor & 0 & & Office & 0 & \\
\hline Lobby & 0 & & Corridor & 0 & \\
\hline Kitchen & $1.62 \mathrm{~L} / \mathrm{h} / \mathrm{m}^{2}$ & {$[6-7]$} & & & \\
\hline Banquet & 0 & & & & \\
\hline Café & 0 & & & & \\
\hline Basement & 0 & & & & \\
\hline Washroom & $0.3 \mathrm{~L} / \mathrm{h} / \mathrm{m}^{2}$ & {$[6-7]$} & & & \\
\hline
\end{tabular}




\section{Pre-1980 Highrise: Water System Selection}

\begin{tabular}{cccc}
\hline & \multicolumn{2}{c}{ Pre-1980 Highrise Student Residence } \\
\hline Space activity & Building area & DHW from & Weighted \\
Student dormitory & $50 \%$ & DOE models & DHW \\
Kitchen & $3 \%$ & $0.20 \mathrm{~L} / \mathrm{h} / \mathrm{m}^{2}$ & $0.10 \mathrm{~L} / \mathrm{h} / \mathrm{m}^{2}$ \\
Washroom & $4 \%$ & $1.62 \mathrm{~L} / \mathrm{h} / \mathrm{m}^{2}$ & $0.05 \mathrm{~L} / \mathrm{h} / \mathrm{m}^{2}$ \\
Weighted Average Pre-1980 Highrise total water system loads & $0.3 \mathrm{~L} / \mathrm{h} / \mathrm{m}^{2}$ & $0.01 \mathrm{~L} / \mathrm{h} / \mathrm{m}^{2}$ \\
\hline
\end{tabular}

Pre-1980 Highrise: Equipment Comparison

\begin{tabular}{|c|c|c|}
\hline \multicolumn{3}{|c|}{ Pre-1980 Large Hotel } \\
\hline Heating Type & $\begin{array}{c}\text { FCU in rooms, } \mathrm{CV} \text { ventilation, MZCAV in } \\
\text { common areas }\end{array}$ & 2003 CBECS \\
\hline Cooling Type & 2 air cooled chillers & 2003 CBECS \\
\hline Fan Control & Constant & 2003 CBECS \\
\hline SWH Type & Gas boiler & \\
\hline Fuel & Natural gas & \\
\hline Cooling Efficiency & Requirements in codes or standards & IDF Small Hotel input \\
\hline Thermal Efficiency (\%) & 78 & Winiarski and Halverson, 2008 \\
\hline Temperature Setpoint ( $\mathrm{O} C)$ & 60 & \\
\hline \multicolumn{3}{|c|}{2004 Highrise Apartment } \\
\hline Heating Type & Water source heat pumps & 90.1 Mechanical Subcommittee \\
\hline Cooling Type & & 90.1 Mechanical Subcommittee \\
\hline Fan Control & Constant Volume & 90.1 Mechanical Subcommittee \\
\hline SWH Type & $\begin{array}{l}\text { Central water heater with } \\
\text { storage tank }\end{array}$ & \\
\hline Fuel & Natural gas & \\
\hline Cooling Efficiency & 3.4 & IDF Highrise Apartment input \\
\hline Thermal Efficiency (\%) & 80 & Requirements in code \\
\hline Temperature Setpoint (oㅡ) & 60 & \\
\hline
\end{tabular}

\section{Pre-1980 Highrise: Equipment Selection}

\begin{tabular}{cc}
\hline & Pre-1980 Highrise Student residence \\
\hline Heating Type & Gas boiler \\
Cooling Type & 2 air cooled chillers \\
Fan Control & CAV \\
SWH Type & gas water heater \\
Fuel & gas \\
Cooling Efficiency & 3.4 \\
Thermal Efficiency $(\%)$ & 78 \\
Temperature Setpoint (으) & 60 \\
\hline
\end{tabular}

\footnotetext{
* No economizer

* No natural ventilation is assigned
} 
Pre-1980 Highrise: Schedule Selection

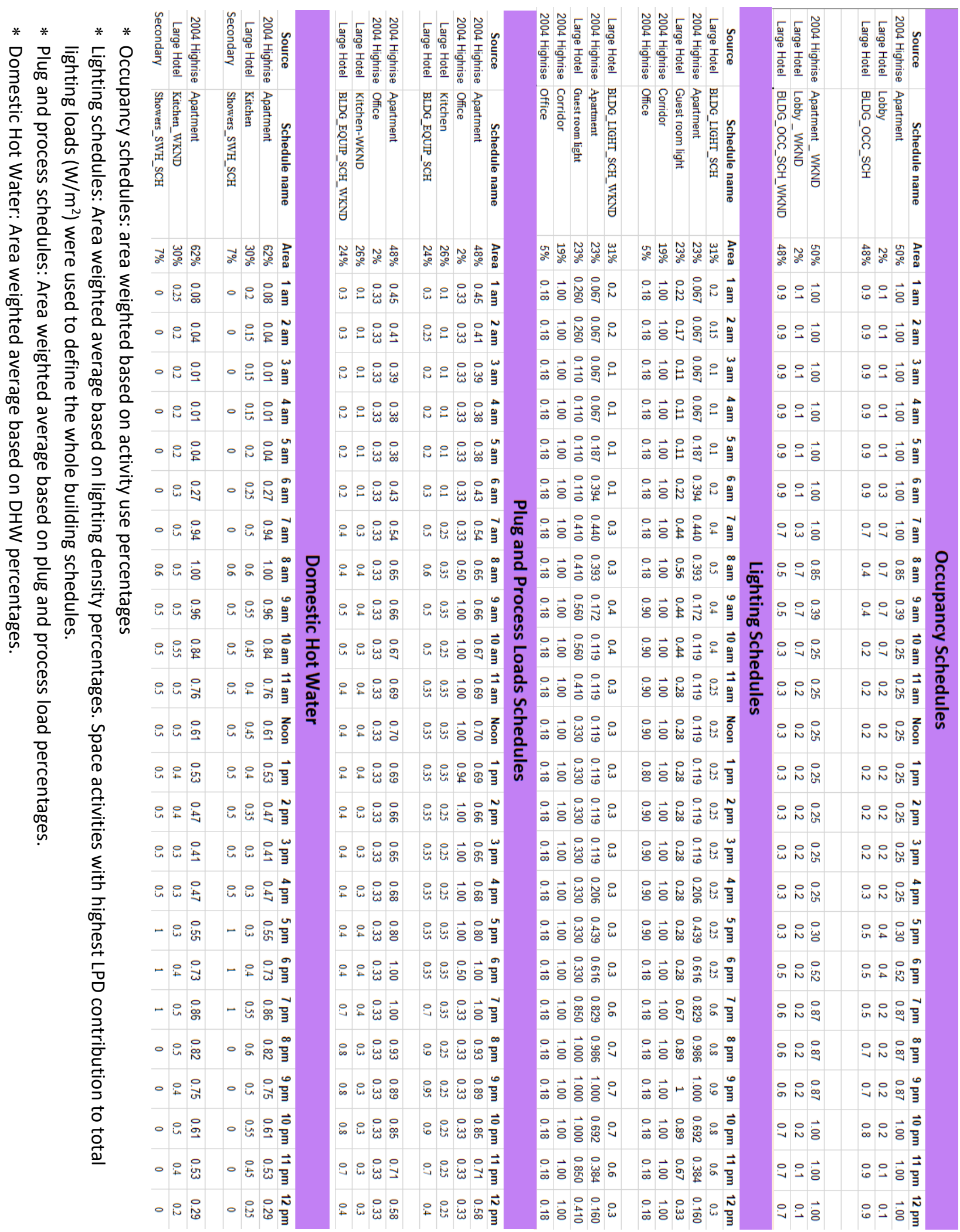




\section{Pre-1980 Highrise: Sources}

[1] 2003 CBECS Data

[2] PNNL-16770: Analysis of Energy Saving Impacts of ASHRAE 90.1-2004 for the State of New York

[3] Mandatory Energy Reports 2013 - Ontario, Daft Logic, Visual Judgment, Geographical Information Systems, and the Architectural Conservancy of Ontario

[4] Ryerson Space Audit Data. URL: https://ryerson.iwmsapp.com/archibus/

[5] ASHRAE Standard 62.1-2004 Table 6-1, Atlanta, GA: American Society of Heating, Refrigerating and Air-Conditioning Engineers.

[6] ASHRAE Standard 62-1999 Table 6-1, Atlanta, GA: American Society of Heating, Refrigerating and Air-Conditioning Engineers.

[7] ASHRAE Standard 90.1-1989, Atlanta, GA: American Society of Heating, Refrigerating and Air-Conditioning Engineers.

[8] PNNL - 17875 Technical Support Document: The Development of the Advanced Energy Design Guide for Highway Lodging Buildings

[9] DOE Commercial Reference Building Report 
Appendix C: Reference Building Model Characterization Templates 
Pre-1980 Lowrise: Characterization Templates Before Adjusting

\begin{tabular}{|l|l|l|l|l|l|l}
\hline Zones Loads & Constructions & Conditioning & Ventilation & Domestic Hot Water & Windows \\
\hline Setting & \multicolumn{2}{|c|}{ Value Units } \\
\hline Constructions & Pre1980_Low-rise & $\checkmark$ & & \\
\hline Loads & B_Res_0 loads & & \\
\hline Conditioning & Pre1980 Low-rise_Conditioning & $\checkmark$ & & \\
\hline Ventilation & Pre1980 Low-rise_Ventilation & $\checkmark$ & & \\
\hline Domestic hot water & Pre1980Low-rise_DHW & $\checkmark$ & & \\
\hline Daylight mesh resolution & & 1 & $\mathrm{~m}$ & \\
\hline Daylight workplane height & & 0.8 & $\mathrm{~m}$ & \\
\hline Internal mass construction & Std Wood 6inch & $\checkmark$ & & \\
\hline Internal mass exposed per floor area & & 1 & & \\
\hline
\end{tabular}

\begin{tabular}{|c|c|c|c|c|c|c|c|}
\hline Zones & Loads & \begin{tabular}{|l|l} 
Constructions & $\mathrm{C}$ \\
\end{tabular} & Conditioning & Ventilation & \multicolumn{2}{|c|}{ Domestic Hot Water } & Windows \\
\hline \multicolumn{3}{|c|}{ Setting } & \multicolumn{3}{|l|}{ Value } & Units & \\
\hline \multicolumn{3}{|c|}{ People } & \multicolumn{4}{|c|}{$\checkmark$} & \\
\hline \multicolumn{3}{|c|}{ Occupancy density } & \multicolumn{3}{|r|}{0.03125} & $\mathrm{p} / \mathrm{m} 2$ & \\
\hline \multicolumn{3}{|c|}{ Occupancy schedule } & \multicolumn{3}{|c|}{ B_Res_Y_Occ_Pre1980 Lowrise $\quad \checkmark$} & & \\
\hline \multicolumn{3}{|c|}{ Equipment } & \multicolumn{3}{|r|}{$\checkmark$} & & \\
\hline \multicolumn{3}{|c|}{ Equipment power density } & \multicolumn{3}{|r|}{9.01} & $\mathrm{~W} / \mathrm{m} 2$ & \\
\hline \multicolumn{3}{|c|}{ Equipment availability schedule } & \multicolumn{3}{|c|}{ B_Res_Y_Plg_Pre1980 Lowrise $\quad \checkmark$} & & \\
\hline \multicolumn{3}{|c|}{ Lighting } & \multicolumn{3}{|r|}{$\checkmark$} & & \\
\hline \multicolumn{3}{|c|}{ Lighting power density } & \multicolumn{3}{|r|}{11.4} & $\mathrm{~W} / \mathrm{m} 2$ & \\
\hline \multicolumn{3}{|c|}{ Lighting availability schedule } & \multicolumn{3}{|c|}{ B_Res_Y_Lgt pre 1980 Lowrise $\quad \checkmark$} & & \\
\hline \multicolumn{3}{|c|}{ Dimming type } & \multicolumn{3}{|l|}{ Off } & & \\
\hline \multicolumn{3}{|c|}{ Illuminance target } & \multicolumn{3}{|r|}{200} & lux & \\
\hline
\end{tabular}

\begin{tabular}{|c|c|c|c|c|c|c|c|c|}
\hline Zones & Loads & Const & ructions & Conditioning & Ventilation & \multicolumn{2}{|c|}{ Domestic Hot Water } & Windows \\
\hline \multicolumn{3}{|c|}{ Setting } & \multicolumn{3}{|l|}{ Value } & Units & & \\
\hline \multicolumn{3}{|c|}{ Enabled } & \multicolumn{3}{|r|}{$\checkmark$} & & & \\
\hline \multicolumn{3}{|c|}{ Schedule } & \multicolumn{3}{|c|}{ B_Res_Y_Dhw_Pre1980 Lowrise } & & & \\
\hline \multicolumn{3}{|c|}{ Supply temperature } & & & 60 & $\operatorname{deg} \mathrm{C}$ & & \\
\hline \multicolumn{3}{|c|}{ Inlet temperature } & & & 16 & $\operatorname{deg} \mathrm{C}$ & & \\
\hline \multicolumn{3}{|c|}{ Flow rate } & & & 0.000175 & $\mathrm{~m} 3 / \mathrm{h} / \mathrm{m} 2$ & & \\
\hline
\end{tabular}




\begin{tabular}{|c|c|c|c|c|c|c|}
\hline Zones Loads & Constructions & Conditioning & Ventilation & Dome: & stic Hot Water & Windows \\
\hline \multicolumn{2}{|l|}{ Setting } & \multicolumn{3}{|c|}{ Value } & \multicolumn{2}{|l|}{ Units } \\
\hline Facade & \multicolumn{4}{|c|}{ Insulated Steel Framed Exterior Wall R7 } & & \\
\hline Ground & \multicolumn{4}{|c|}{ ext-slab-mass } & & \\
\hline Partition & \multicolumn{4}{|c|}{ Typical interior wall } & & \\
\hline Roof & \multicolumn{4}{|c|}{ Typical IEAD Roof R17 } & & \\
\hline Slab & \multicolumn{4}{|c|}{ Typical interior floor } & & \\
\hline Facade is adiabatic & batic & & & $\square$ & & \\
\hline Ground is adiabatic & batic & & & $\square$ & & \\
\hline \multicolumn{2}{|c|}{ Partition is adiabatic } & & & $\square$ & & \\
\hline Roof is adiabatic & & & & $\square$ & & \\
\hline
\end{tabular}

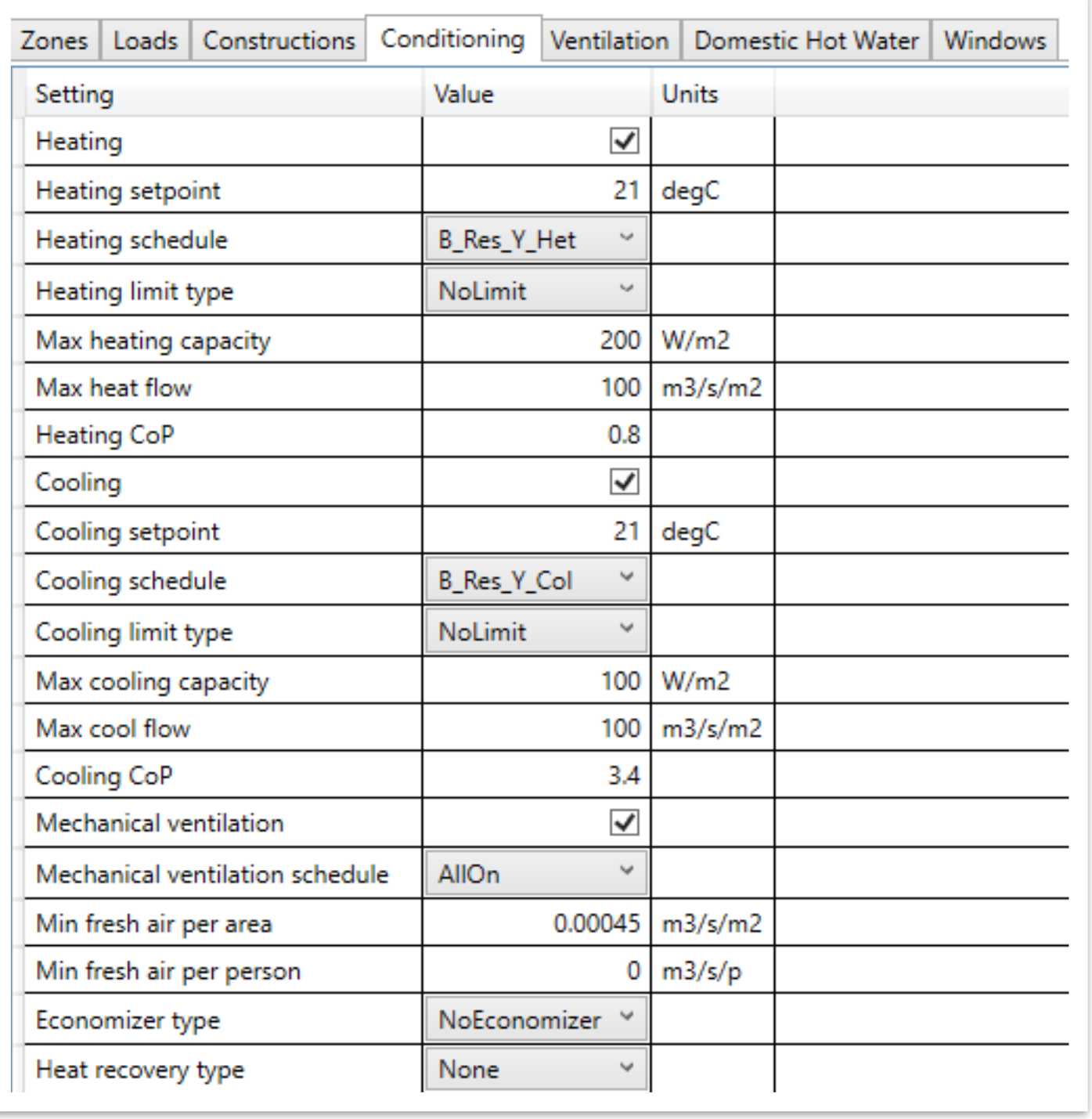




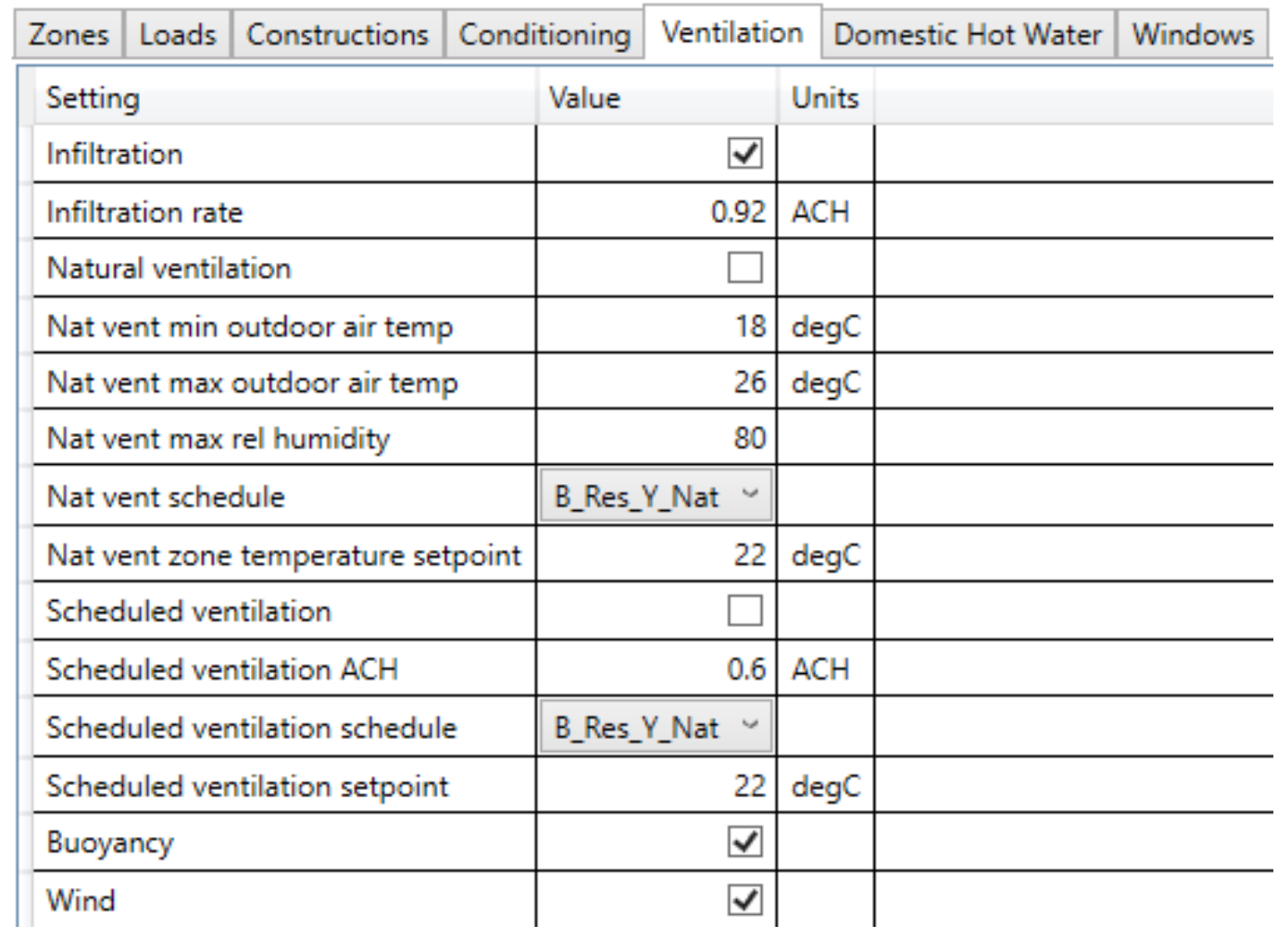

\begin{tabular}{|c|c|c|c|c|c|c|c|}
\hline Zones Loads & Constructions & Conditio & oning & Ventilation & Domestic Hot Wate & & indows \\
\hline Setting & & & Value & & & Units & \\
\hline Type & & & Extern & nal & 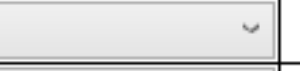 & & \\
\hline Construction & & & U 0.62 & 52 SHGC 0.41 & Simple Glazing ` & & \\
\hline Operable area & & & & & 0.5 & & \\
\hline Shading is use & & & & & $\square$ & & \\
\hline Shading syster & $\mathrm{m}$ availability sc & hedule & B_Res & S_Y_Occ & $\checkmark$ & & \\
\hline Shading syster & $\mathrm{m}$ setpoint & & & & 0.5 & $\mathrm{~W} / \mathrm{m} 2$ & \\
\hline Shading syster & $\mathrm{m}$ transmittance & & & & 0.5 & & \\
\hline Shading syster & m type & & Interic & iorShade & $\checkmark$ & & \\
\hline Zone mixing & & & & & $\checkmark$ & & \\
\hline Zone mixing a & vailability scheo & Iule & B_Res & S_Y_Occ & $\checkmark$ & & \\
\hline Zone mixing $d$ & elta temperatur & & & & 2 & & \\
\hline Zone mixing $\mathrm{fl}$ & low rate & & & & 0.001 & $\mathrm{~m} 3 / 2$ & \\
\hline Virtual partitio & & & & & $\square$ & & \\
\hline Airflow netwo & rk discharge coe & efficient & & & 0.65 & & \\
\hline Airflow netwo & rk temperature & setpoint & & & 20 & $\operatorname{deg} C$ & \\
\hline
\end{tabular}


Pre-1980 Lowrise: Characterization Templates After Adjusting

\begin{tabular}{|c|c|c|c|c|c|c|c|c|}
\hline Zones & Loads & Constructions & Condit & tioning & Ventilation & Domestic Hot V & Vater & Windows \\
\hline \multicolumn{4}{|c|}{ Setting } & \multicolumn{3}{|l|}{ Value } & \multicolumn{2}{|c|}{ Units } \\
\hline \multicolumn{4}{|c|}{ Constructions } & \multicolumn{3}{|c|}{ Pre1980_Low-rise } & & \\
\hline \multicolumn{4}{|c|}{ Loads } & \multicolumn{3}{|c|}{ B_Res_0 loads } & & \\
\hline \multicolumn{4}{|c|}{ Conditioning } & \multicolumn{3}{|c|}{ Pre1980 Low-rise_Conditioning $\checkmark$} & & \\
\hline \multicolumn{4}{|c|}{ Ventilation } & \multicolumn{3}{|c|}{ Pre1980 Low-rise_Ventilation } & & \\
\hline \multicolumn{4}{|c|}{ Domestic hot water } & \multicolumn{3}{|c|}{ Pre1980Low-rise_DHW } & & \\
\hline \multicolumn{4}{|c|}{ Daylight mesh resolution } & & & 1 & $\mathrm{~m}$ & \\
\hline \multicolumn{4}{|c|}{ Daylight workplane height } & & & 0.8 & $\mathrm{~m}$ & \\
\hline \multicolumn{4}{|c|}{ Internal mass construction } & \multicolumn{3}{|c|}{ Std Wood 6inch } & & \\
\hline \multicolumn{4}{|c|}{ Internal mass exposed per floor area } & & & 1 & & \\
\hline
\end{tabular}

\section{\begin{tabular}{|l|l|l|l|l|l|}
\hline Zones Loads & Constructions & Conditioning & Ventilation & Domestic Hot Water & Windows \\
\cline { 2 - 5 } \\
\hline
\end{tabular}}

\begin{tabular}{|c|c|c|}
\hline Setting & Value & Units \\
\hline People & $\checkmark$ & \\
\hline Occupancy density & 0.03125 & $\mathrm{p} / \mathrm{m} 2$ \\
\hline Occupancy schedule & B_Res_Y_Occ_Pre1980 Lowrise $\quad$ & \\
\hline Equipment & $\checkmark$ & \\
\hline Equipment power density & 9.01 & $\mathrm{~W} / \mathrm{m} 2$ \\
\hline Equipment availability schedule & B_Res_Y_Plg_Pre1980 Lowrise & \\
\hline Lighting & $\nabla$ & \\
\hline Lighting power density & 11.4 & $\mathrm{~W} / \mathrm{m} 2$ \\
\hline Lighting availability schedule & B_Res_Y_Lgt pre 1980 Lowrise & \\
\hline Dimming type & Off & \\
\hline Illuminance target & 200 & lux \\
\hline
\end{tabular}

\begin{tabular}{|c|c|c|c|c|c|c|c|c|}
\hline Zones & Loads & Const & ructions & Conditioning & Ventilation & \multicolumn{2}{|c|}{ Domestic Hot Water } & Windows \\
\hline \multicolumn{3}{|c|}{ Setting } & \multicolumn{3}{|l|}{ Value } & Units & & \\
\hline \multicolumn{3}{|c|}{ Enabled } & \multicolumn{3}{|r|}{$\nabla$} & & & \\
\hline \multicolumn{3}{|c|}{ Schedule } & \multicolumn{3}{|c|}{ B_Res_Y_Dhw_Pre1980 Lowrise $~$} & & & \\
\hline \multicolumn{3}{|c|}{ Supply temperature } & & & 60 & $\operatorname{deg} \mathrm{C}$ & & \\
\hline \multicolumn{3}{|c|}{ Inlet temperature } & & & 16 & $\operatorname{deg} \mathrm{C}$ & & \\
\hline \multicolumn{3}{|c|}{ Flow rate } & & & 0.00019 & $\mathrm{~m} 3 / \mathrm{h} / \mathrm{m} 2$ & & \\
\hline
\end{tabular}




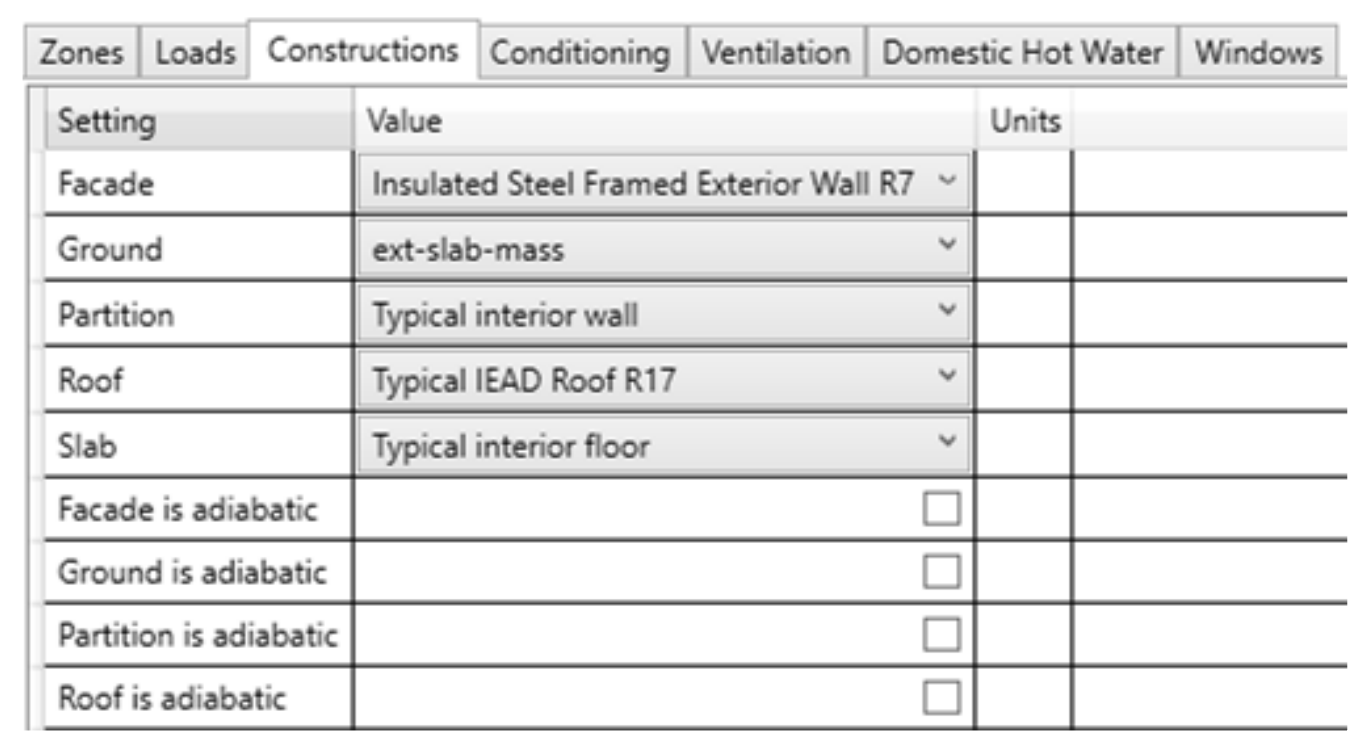

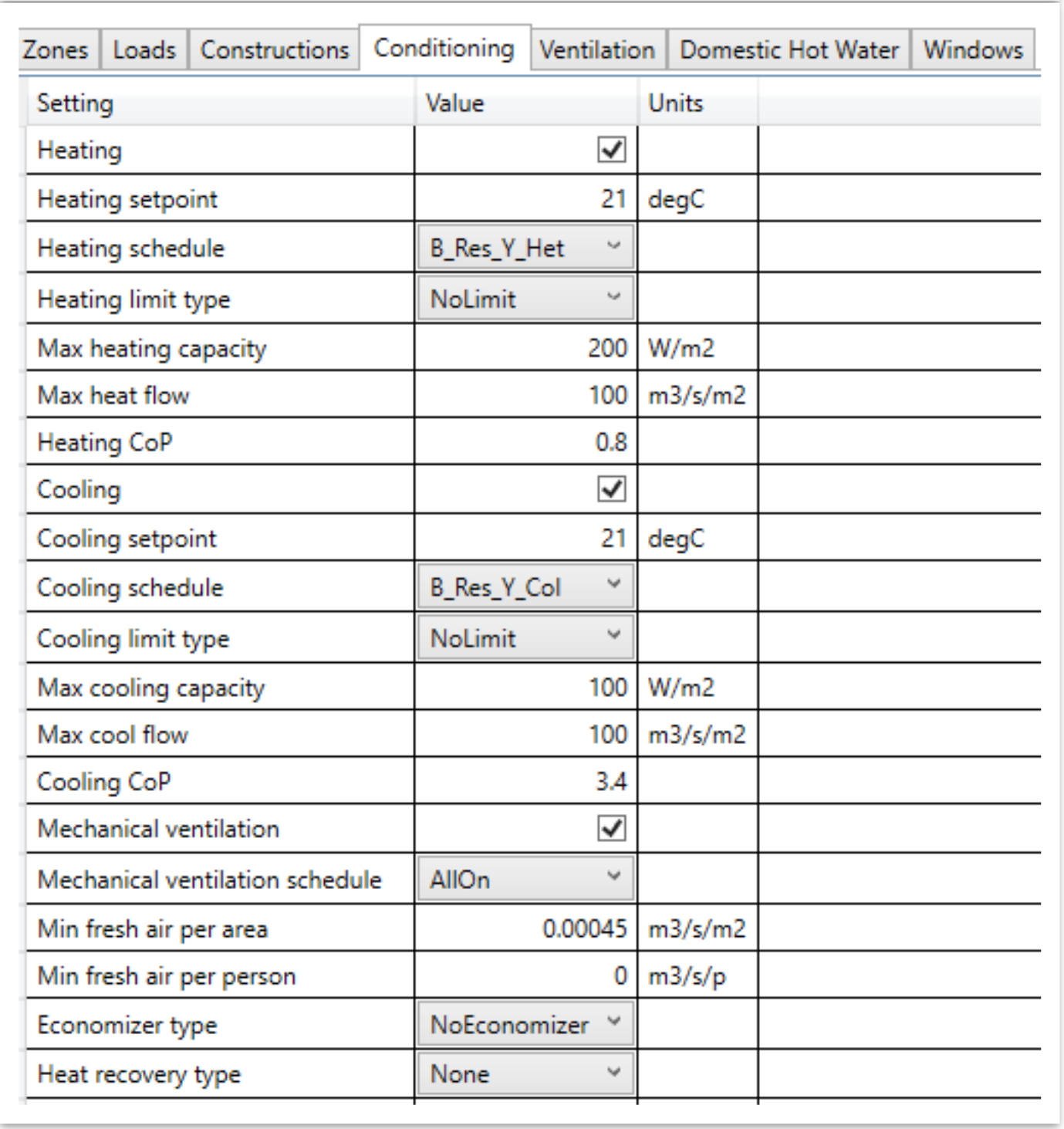




\begin{tabular}{|c|c|c|c|c|c|c|c|}
\hline Zones & Loads & Constructions Condi & itioning & Ventilatio & on $\mathrm{Dc}$ & Domestic Hot Water & Windows \\
\hline \multicolumn{3}{|c|}{ Setting } & \multicolumn{2}{|l|}{ Value } & \multicolumn{3}{|l|}{ Units } \\
\hline \multicolumn{3}{|c|}{ Infiltration } & & $\checkmark$ & & & \\
\hline \multicolumn{3}{|c|}{ Infiltration rate } & & 0.92 & $\mathrm{ACH}$ & & \\
\hline \multicolumn{3}{|c|}{ Natural ventilation } & & $\square$ & & & \\
\hline \multicolumn{3}{|c|}{ Nat vent min outdoor air temp } & & 18 & $\operatorname{deg} \mathrm{C}$ & & \\
\hline \multicolumn{3}{|c|}{ Nat vent max outdoor air temp } & & 26 & $\operatorname{deg} \mathrm{C}$ & & \\
\hline \multicolumn{3}{|c|}{ Nat vent max rel humidity } & & 80 & & & \\
\hline \multicolumn{3}{|c|}{ Nat vent schedule } & B_Res_Y & Y_Nat $\checkmark$ & & & \\
\hline \multicolumn{3}{|c|}{ Nat vent zone temperature setpoint } & & 22 & $\operatorname{deg} C$ & & \\
\hline \multicolumn{3}{|c|}{ Scheduled ventilation } & & $\square$ & & & \\
\hline \multicolumn{3}{|c|}{ Scheduled ventilation $\mathrm{ACH}$} & & 0.6 & $\mathrm{ACH}$ & & \\
\hline \multicolumn{3}{|c|}{ Scheduled ventilation schedule } & B_Res_Y & $Y_{-}$Nat $\sim$ & & & \\
\hline \multicolumn{3}{|c|}{ Scheduled ventilation setpoint } & & 22 & $\operatorname{deg} \mathrm{C}$ & & \\
\hline \multicolumn{3}{|c|}{ Buoyancy } & & $\checkmark$ & & & \\
\hline \multicolumn{3}{|l|}{ Wind } & & $\checkmark$ & & & \\
\hline
\end{tabular}

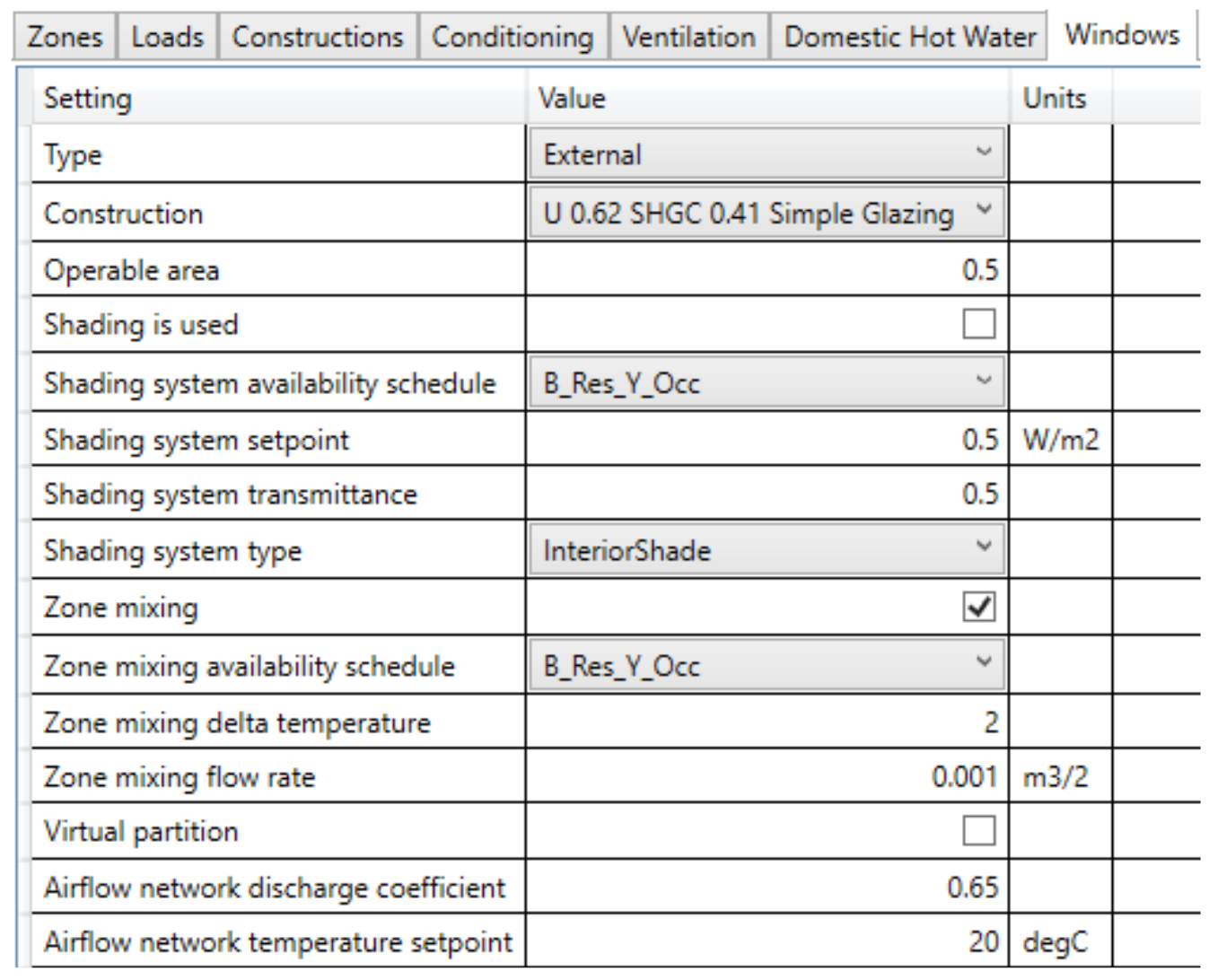




\section{Pre-1980 Lowrise: Daily Schedules}
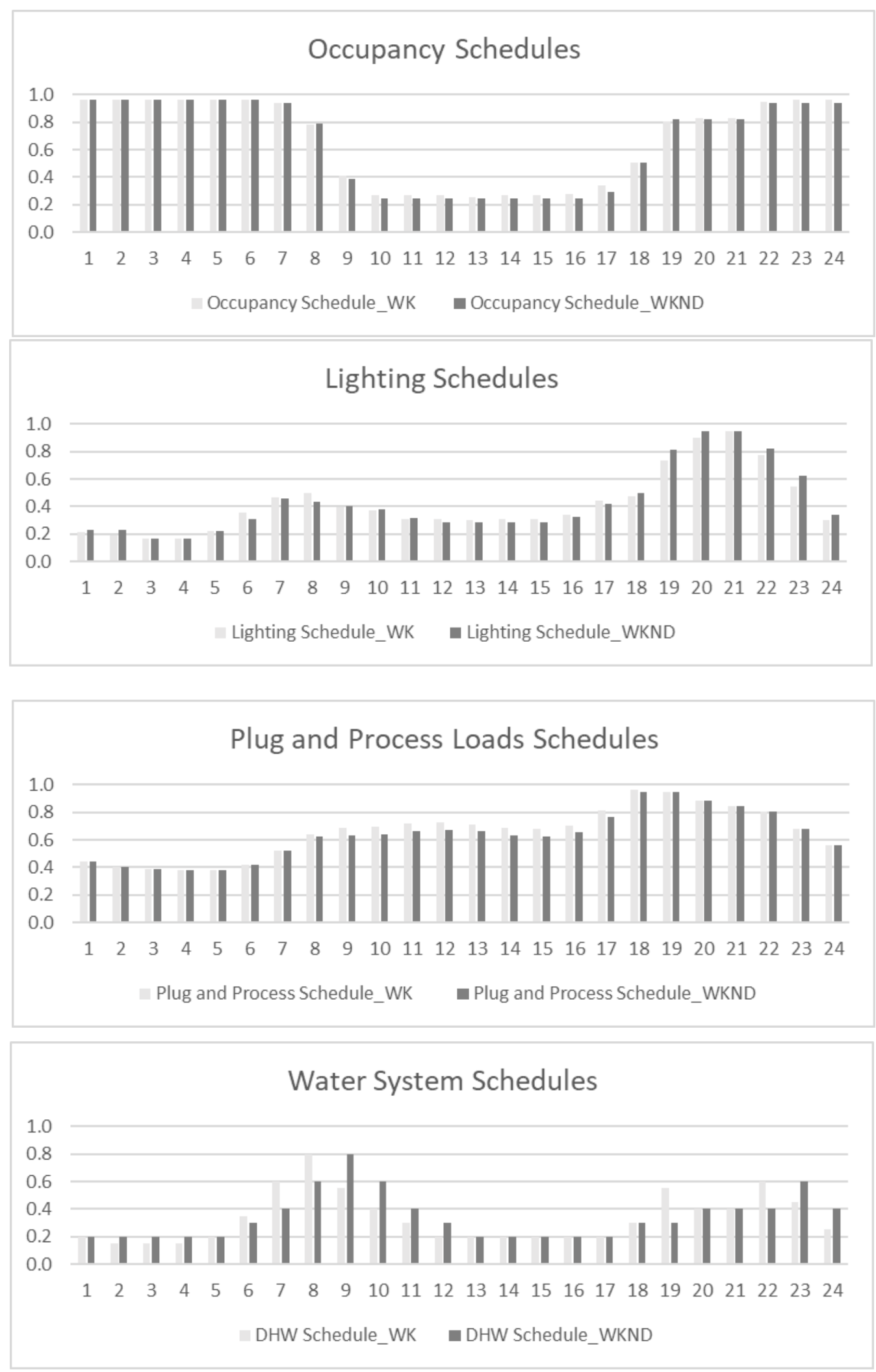
Post-1980 Lowrise: Characterization Templates Before Adjusting

\begin{tabular}{|c|c|c|c|c|c|c|c|c|c|}
\hline Zones & Loads & \multicolumn{2}{|c|}{ Constructions } & Condi & tioning & Ventilation & \multicolumn{2}{|c|}{ Domestic Hot Water } & Windows \\
\hline \multicolumn{4}{|c|}{ Setting } & & \multicolumn{4}{|l|}{ Value } & Units \\
\hline \multicolumn{5}{|c|}{ Constructions } & \multicolumn{4}{|c|}{ Post1980_Low-rise } & \\
\hline \multicolumn{5}{|l|}{ Loads } & \multicolumn{3}{|c|}{ B_Res_0 loads } & $\checkmark$ & \\
\hline \multicolumn{5}{|c|}{ Conditioning } & \multicolumn{4}{|c|}{ Post1980 Low-rise_Conditioning v } & \\
\hline \multicolumn{5}{|c|}{ Ventilation } & \multicolumn{4}{|c|}{ Post1980 Low-rise_Ventilation } & \\
\hline \multicolumn{5}{|c|}{ Domestic hot water } & \multicolumn{4}{|c|}{ Post1980Low-rise_DHW } & \\
\hline \multicolumn{5}{|c|}{ Daylight mesh resolution } & \multicolumn{4}{|c|}{\begin{tabular}{|l|l|}
1 & $\mathrm{~m}$ \\
\end{tabular}} & \\
\hline \multicolumn{5}{|c|}{ Daylight workplane height } & \multicolumn{4}{|c|}{\begin{tabular}{rr|r}
0.8 & $\mathrm{~m}$ \\
\end{tabular}} & \\
\hline \multicolumn{5}{|c|}{ Internal mass construction } & \multicolumn{4}{|c|}{ Std Wood 6inch } & \\
\hline \multicolumn{5}{|c|}{ Internal mass exposed per floor area } & \multicolumn{4}{|r|}{1} & \\
\hline Zones & Loads & \multicolumn{2}{|c|}{\begin{tabular}{|l|l} 
Constructions & $\mathrm{C}$ \\
\end{tabular}} & Condi & tioning & Ventilation & \multicolumn{2}{|c|}{ Domestic Hot Water } & Windows \\
\hline \multicolumn{4}{|c|}{ Setting } & \multicolumn{4}{|c|}{ Value } & \multicolumn{2}{|l|}{ Units } \\
\hline \multicolumn{4}{|c|}{ People } & & & & $\checkmark$ & & \\
\hline Occup & ancy de & nsity & & & & & $0.03125 \mathrm{P}$ & $\mathrm{p} / \mathrm{m} 2$ & \\
\hline Occup & ancy sch & hedule & & & les_Y_Occ. & C_post1980 Lo & owrise $\checkmark$ & & \\
\hline Equipn & ment & & & & & & $\checkmark$ & & \\
\hline Equipn & ment po & wer den & sity & & & & $9 \mathrm{~V}$ & $\mathrm{~W} / \mathrm{m} 2$ & \\
\hline Equipn & ment ava & ilability & schedule & & es_Y_Plg- & -post1980 Lov & wrise $\checkmark$ & & \\
\hline Lightin & & & & & & & $\checkmark$ & & \\
\hline Lightin & g powe & density & & & & & $4.96 \mathrm{~V}$ & $\mathrm{~W} / \mathrm{m} 2$ & \\
\hline Lightin & g availa & bility sch & hedule & & es_Y_Lgt_ & post1980 Lov & wrise $\checkmark$ & & \\
\hline Dimmi & ing type & & & Off & & & $\checkmark$ & & \\
\hline Illumin & lance tar & get & & & & & \begin{tabular}{l|l}
200 & I
\end{tabular} & lux & \\
\hline Zones & Loads & Constr & ructions & Cone & litioning & Ventilation & Domestic & Hot Wa & Wr Windows \\
\hline Settin & & & Value & & & & Units & & \\
\hline Enable & & & & & & $\checkmark$ & & & \\
\hline Sched & lule & & B_Res_Y & _Dhw. & post1980 & 0 Lowrise ${ }^{\circ}$ & & & \\
\hline Supply & $y$ tempe & rature & & & & 60 & $\operatorname{deg} C$ & & \\
\hline Inlet t & empera & ture & & & & 16 & $\operatorname{deg} C$ & & \\
\hline Flow $r$ & rate & & & & & 0.00017 & $\mathrm{~m} 3 / \mathrm{h} / \mathrm{m} 2$ & & \\
\hline
\end{tabular}




\begin{tabular}{|c|c|c|c|c|c|c|c|}
\hline \begin{tabular}{l|l} 
Zones & Loads
\end{tabular} & Constr & ructions & Conditioning & Vent & ilation & Domestic Hot Water & Windows \\
\hline \multicolumn{2}{|l|}{ Setting } & \multicolumn{3}{|l|}{ Value } & \multicolumn{3}{|l|}{ Units } \\
\hline \multicolumn{2}{|l|}{ Facade } & \multicolumn{3}{|c|}{ Steel Frame Res Ext Wall } & & & \\
\hline \multicolumn{2}{|l|}{ Ground } & \multicolumn{3}{|c|}{ ext-slab } & & & \\
\hline \multicolumn{2}{|l|}{ Partition } & \multicolumn{3}{|c|}{ Int-walls } & & & \\
\hline \multicolumn{2}{|l|}{ Roof } & \multicolumn{3}{|c|}{ IEAD Res Roof } & & & \\
\hline \multicolumn{2}{|l|}{ Slab } & \multicolumn{3}{|c|}{ INT-FLOOR-TOPSIDE } & & & \\
\hline \multicolumn{2}{|c|}{ Facade is adiabatic } & & & $\square$ & & & \\
\hline \multicolumn{2}{|c|}{ Ground is adiabatic } & & & $\square$ & & & \\
\hline \multicolumn{2}{|c|}{ Partition is adiabatic } & & & $\square$ & & & \\
\hline \multicolumn{2}{|c|}{ Roof is adiabatic } & & & $\square$ & & & \\
\hline
\end{tabular}

\begin{tabular}{|c|c|c|c|c|c|c|}
\hline Zones & Loads & Constructions & Conditioning & Ventilation & Domestic Hot Water & Windows \\
\hline
\end{tabular}

\begin{tabular}{|c|c|c|c|}
\hline Setting & Value & Units & \\
\hline Heating & $\checkmark$ & & \\
\hline Heating setpoint & 21 & $\operatorname{deg} C$ & \\
\hline Heating schedule & B_Res_Y_Het $\quad \checkmark$ & & \\
\hline Heating limit type & NoLimit & & \\
\hline Max heating capacity & 200 & $\mathrm{~W} / \mathrm{m} 2$ & \\
\hline Max heat flow & 100 & $\mathrm{~m} 3 / \mathrm{s} / \mathrm{m} 2$ & \\
\hline Heating CoP & 0.78 & & \\
\hline Cooling & $\checkmark$ & & \\
\hline Cooling setpoint & 21 & $\operatorname{deg} C$ & \\
\hline Cooling schedule & B_Res_Y_Col & & \\
\hline Cooling limit type & NoLimit & & \\
\hline Max cooling capacity & 150 & $\mathrm{~W} / \mathrm{m} 2$ & \\
\hline Max cool flow & 100 & $\mathrm{~m} 3 / \mathrm{s} / \mathrm{m} 2$ & \\
\hline Cooling CoP & 3.4 & & \\
\hline Mechanical ventilation & $\checkmark$ & & \\
\hline Mechanical ventilation schedule & AllOn & & \\
\hline Min fresh air per area & 0.00045 & $\mathrm{~m} 3 / \mathrm{s} / \mathrm{m} 2$ & \\
\hline Min fresh air per person & 0 & $\mathrm{~m} 3 / \mathrm{s} / \mathrm{p}$ & \\
\hline Economizer type & NoEconomizer $\checkmark$ & & \\
\hline Heat recovery type & None & & \\
\hline
\end{tabular}




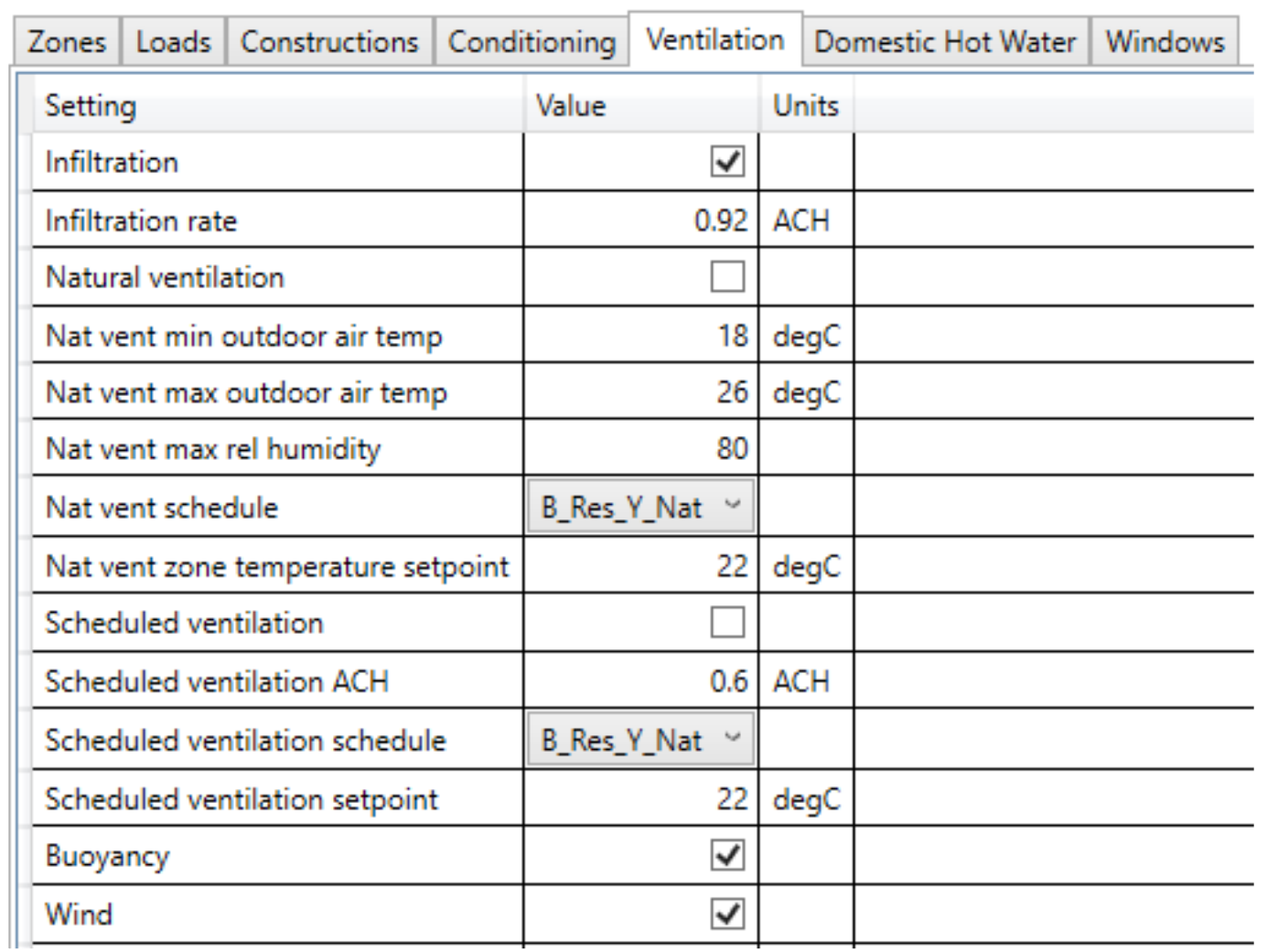

\begin{tabular}{|c|c|c|c|c|c|c|}
\hline Zones Loads & Constructions Conditic & oning Ventilation & \multicolumn{3}{|c|}{ Domestic Hot Water } & \multirow[t]{2}{*}{ Windows } \\
\hline \multicolumn{2}{|l|}{ Setting } & \multicolumn{2}{|l|}{ Value } & \multicolumn{2}{|l|}{ Units } & \\
\hline \multicolumn{2}{|l|}{ Type } & \multicolumn{2}{|l|}{ External } & & & \\
\hline \multicolumn{2}{|l|}{ Construction } & \multicolumn{2}{|c|}{ Window Res Operable $\vee$} & & & \\
\hline \multicolumn{2}{|l|}{ Operable area } & & 0 & & & \\
\hline \multicolumn{2}{|c|}{ Shading is used } & & $\square$ & & & \\
\hline \multicolumn{2}{|c|}{ Shading system availability schedule } & B_Res_Y_Occ & $\checkmark$ & & & \\
\hline \multicolumn{2}{|c|}{ Shading system setpoint } & & 0.5 & $\mathrm{~W} / \mathrm{m} 2$ & & \\
\hline \multicolumn{2}{|c|}{ Shading system transmittance } & & 0.5 & & & \\
\hline \multicolumn{2}{|c|}{ Shading system type } & InteriorShade & $\checkmark$ & & & \\
\hline \multicolumn{2}{|l|}{ Zone mixing } & & $\checkmark$ & & & \\
\hline \multicolumn{2}{|c|}{ Zone mixing availability schedule } & B_Res_Y_Occ & $\checkmark$ & & & \\
\hline \multicolumn{2}{|c|}{ Zone mixing delta temperature } & & 2 & & & \\
\hline \multicolumn{2}{|c|}{ Zone mixing flow rate } & & 0.001 & $\mathrm{~m} 3 / 2$ & & \\
\hline \multicolumn{2}{|c|}{ Virtual partition } & & $\square$ & & & \\
\hline \multicolumn{2}{|c|}{ Airflow network discharge coefficient } & & 0.65 & & & \\
\hline \multicolumn{2}{|c|}{ Airflow network temperature setpoint } & & 20 & $\operatorname{deg} C$ & & \\
\hline
\end{tabular}


Post-1980 Lowrise: Characterization Templates After Adjusting

\begin{tabular}{|c|c|c|c|c|c|c|c|c|c|}
\hline Zones & Loads & \multicolumn{2}{|c|}{ Constructions } & Condit & tioning & Ventilation & \multicolumn{2}{|c|}{ Domestic Hot Water } & Windows \\
\hline \multicolumn{5}{|c|}{ Setting } & \multicolumn{4}{|l|}{ Value } & Units \\
\hline \multicolumn{5}{|c|}{ Constructions } & \multicolumn{4}{|c|}{ Post1980_Low-rise } & \\
\hline \multicolumn{5}{|c|}{ Loads } & \multicolumn{4}{|c|}{ B_Res_0 loads } & \\
\hline \multicolumn{5}{|c|}{ Conditioning } & \multicolumn{4}{|c|}{ Post1980 Low-rise_Conditioning v } & \\
\hline \multicolumn{5}{|c|}{ Ventilation } & \multicolumn{4}{|c|}{ Post1980 Low-rise_Ventilation } & \\
\hline \multicolumn{5}{|c|}{ Domestic hot water } & \multicolumn{4}{|c|}{ Post1980Low-rise_DHW } & \\
\hline \multicolumn{5}{|c|}{ Daylight mesh resolution } & \multicolumn{4}{|c|}{\begin{tabular}{|r|r}
$\mathrm{m}$ \\
\end{tabular}} & \\
\hline \multicolumn{5}{|c|}{ Daylight workplane height } & \multicolumn{4}{|c|}{\begin{tabular}{rr|r}
0.8 & $n$ \\
\end{tabular}} & \\
\hline \multicolumn{5}{|c|}{ Internal mass construction } & \multicolumn{4}{|c|}{ Std Wood 6inch } & \\
\hline \multicolumn{5}{|c|}{ Internal mass exposed per floor area } & \multicolumn{4}{|r|}{1} & \\
\hline \multicolumn{4}{|c|}{ Zones Loads Constructions } & \multicolumn{2}{|c|}{ Conditioning } & Ventilation & \multicolumn{2}{|c|}{ Domestic Hot Water } & Windows \\
\hline \multicolumn{4}{|c|}{ Setting } & \multicolumn{4}{|c|}{ Value } & \multicolumn{2}{|l|}{ Units } \\
\hline Peopl & & & & & & & $\checkmark$ & & \\
\hline Occup & pancy de & ensity & & & & & 0.03125 & $\mathrm{p} / \mathrm{m} 2$ & \\
\hline Occup & Jancy sc & chedule & & B_R & es_Y_Oc & C_post $1980 \mathrm{~L}$ & owrise $"$ & & \\
\hline Equip & ment & & & & & & $\checkmark$ & & \\
\hline Equip & ment po & wer de & nsity & & & & 10 & $\mathrm{~W} / \mathrm{m} 2$ & \\
\hline Equip & ment av & ailabilit & y schedule & \begin{tabular}{l|l}
$e$ & $B_{-} R$
\end{tabular} & es_Y_Plg & g-post1980 L & owrise $\checkmark$ & & \\
\hline Lighti & & & & & & & $\checkmark$ & & \\
\hline Lighti & hg powe & er densi & & & & & 7 & $\mathrm{~W} / \mathrm{m} 2$ & \\
\hline Lighti & ng availa & ability s & chedule & B_R & es_Y_Lg & t_post1980 L & owrise $\checkmark$ & & \\
\hline Dimm & ing type & & & Off & & & $\checkmark$ & & \\
\hline Illumi & hance ta & rget & & & & & 200 & lux & \\
\hline Zones & Loads & Const: & ructions & Condit & ioning & Ventilation & Domestic & Hot Water & Windows \\
\hline Settin & & & Value & & & & Units & & \\
\hline Enable & & & & & & $\checkmark$ & & & \\
\hline Sched & & & B_Res_Y_L & Dhw_p & ost 1980 & Lowrise $\square$ & & & \\
\hline Supply & temper & rature & & & & 60 & $\operatorname{deg} C$ & & \\
\hline Inlet to & emperat & ture & & & & 16 & $\operatorname{deg} C$ & & \\
\hline Flow $\mathrm{r}$ & & & & & & 0.0002 & $\mathrm{~m} 3 / \mathrm{h} / \mathrm{m} 2$ & & \\
\hline
\end{tabular}




\begin{tabular}{||l|l|l|l|l|l|}
\hline Zones Loads Constructions & Conditioning & Ventilation & Domestic Hot Water & Windows \\
\hline Setting & Value & \multicolumn{3}{|c|}{ Units } \\
\hline Facade & Steel Frame Res Ext Wall & $\checkmark$ & & \\
\hline Ground & ext-slab & & & \\
\hline Partition & Int-walls & $\checkmark$ & & \\
\hline Roof & IEAD Res Roof & $\checkmark$ & & \\
\hline Slab & INT-FLOOR-TOPSIDE & $\checkmark$ & & \\
\hline Facade is adiabatic & & $\square$ & & \\
\hline Ground is adiabatic & & $\square$ & & \\
\hline Partition is adiabatic & & $\square$ & & \\
\hline Roof is adiabatic & & $\square$ & & \\
\hline
\end{tabular}

\begin{tabular}{|c|c|c|c|c|c|}
\hline \begin{tabular}{l|l|l|l} 
Zones & Loads & Constructions \\
\end{tabular} & Conditioning & Ventilatior & on Domes & ic Hot Water & Windows \\
\hline Setting & \multicolumn{2}{|l|}{ Value } & \multicolumn{2}{|l|}{ Units } & \\
\hline Heating & & $\checkmark$ & & & \\
\hline Heating setpoint & & 21 & $\operatorname{deg} \mathrm{C}$ & & \\
\hline Heating schedule & B_Res_Y_h & 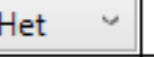 & & & \\
\hline Heating limit type & Nolimit & $\checkmark$ & & & \\
\hline Max heating capacity & & 200 & $\mathrm{~W} / \mathrm{m} 2$ & & \\
\hline Max heat flow & & 100 & $\mathrm{~m} 3 / \mathrm{s} / \mathrm{m} 2$ & & \\
\hline Heating CoP & & 0.84 & & & \\
\hline Cooling & & $\checkmark$ & & & \\
\hline Cooling setpoint & & 21 & $\operatorname{deg} C$ & & \\
\hline Cooling schedule & B_Res_Y_C & $\mathrm{Col} \vee$ & & & \\
\hline Cooling limit type & Nolimit & $\checkmark$ & & & \\
\hline Max cooling capacity & & 150 & $\mathrm{~W} / \mathrm{m} 2$ & & \\
\hline Max cool flow & & 100 & $\mathrm{~m} 3 / \mathrm{s} / \mathrm{m} 2$ & & \\
\hline Cooling CoP & & 3.4 & & & \\
\hline Mechanical ventilation & & $\checkmark$ & & & \\
\hline Mechanical ventilation schedule & AllOn & $\checkmark$ & & & \\
\hline Min fresh air per area & & 0.00045 & $\mathrm{~m} 3 / \mathrm{s} / \mathrm{m} 2$ & & \\
\hline Min fresh air per person & & 0 & $\mathrm{~m} 3 / \mathrm{s} / \mathrm{p}$ & & \\
\hline Economizer type & NoEcono & mizer $\checkmark$ & & & \\
\hline Heat recovery type & None & $\checkmark$ & & & \\
\hline
\end{tabular}




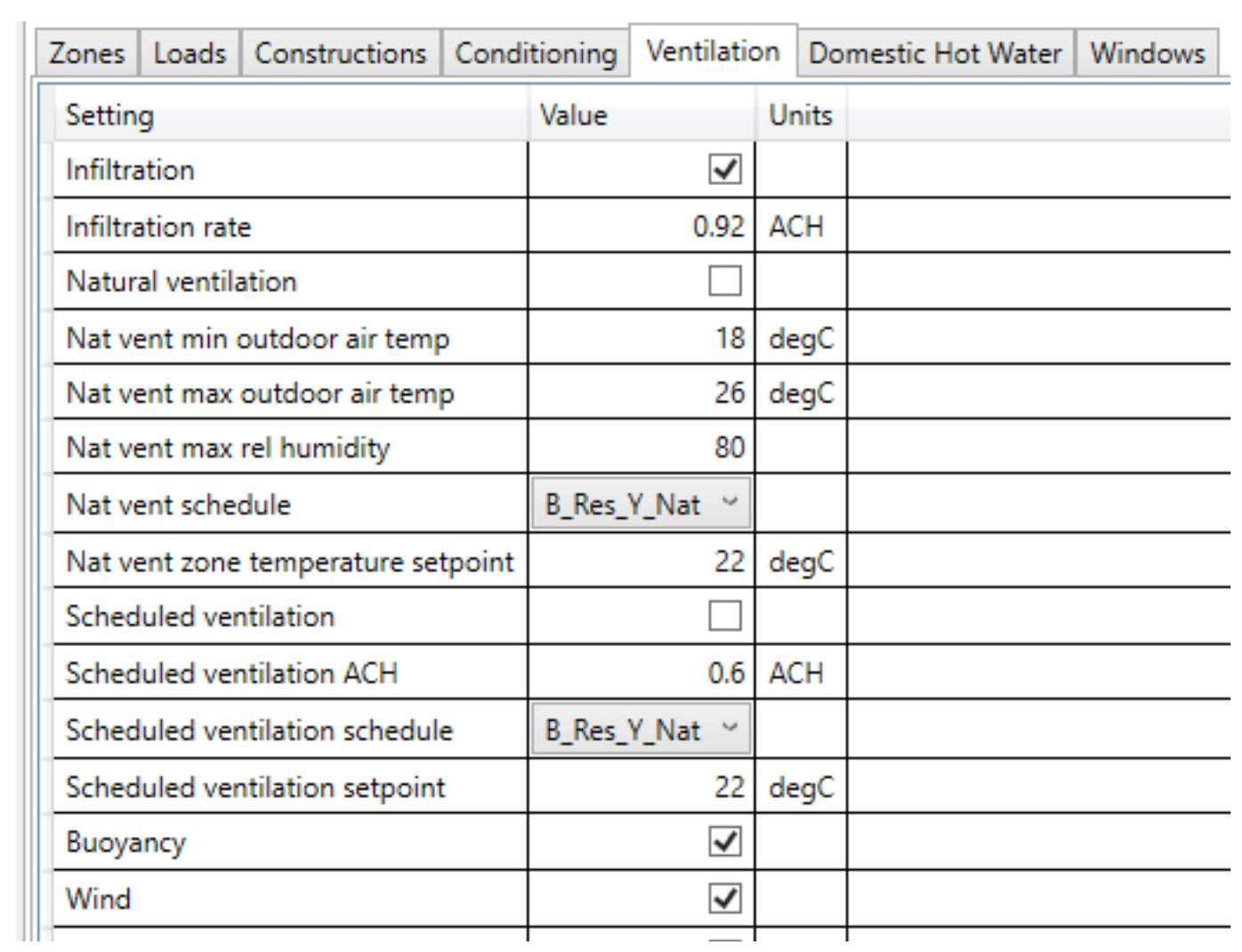

\section{\begin{tabular}{|l|l|l|l|l|l|}
\hline Zones & Loads & Constructions & Conditioning & Ventilation & Domestic Hot Water \\
\hline
\end{tabular}}

\begin{tabular}{|c|c|c|}
\hline Setting & Value & Units \\
\hline Type & External & \\
\hline Construction & Window Res Operable ${ }^{\vee}$ & \\
\hline Operable area & 0 & \\
\hline Shading is used & $\square$ & \\
\hline Shading system availability schedule & B_Res_Y_Occ & \\
\hline Shading system setpoint & 0.5 & $\mathrm{~W} / \mathrm{m} 2$ \\
\hline Shading system transmittance & 0.5 & \\
\hline Shading system type & InteriorShade & \\
\hline Zone mixing & $\checkmark$ & \\
\hline Zone mixing availability schedule & B_Res_Y_Occ & \\
\hline Zone mixing delta temperature & 2 & \\
\hline Zone mixing flow rate & 0.001 & $\mathrm{~m} 3 / 2$ \\
\hline Virtual partition & $\square$ & \\
\hline Airflow network discharge coefficient & 0.65 & \\
\hline Airflow network temperature setpoint & 20 & $\operatorname{deg} C$ \\
\hline
\end{tabular}


Post-1980 Lowrise: Daily Schedules
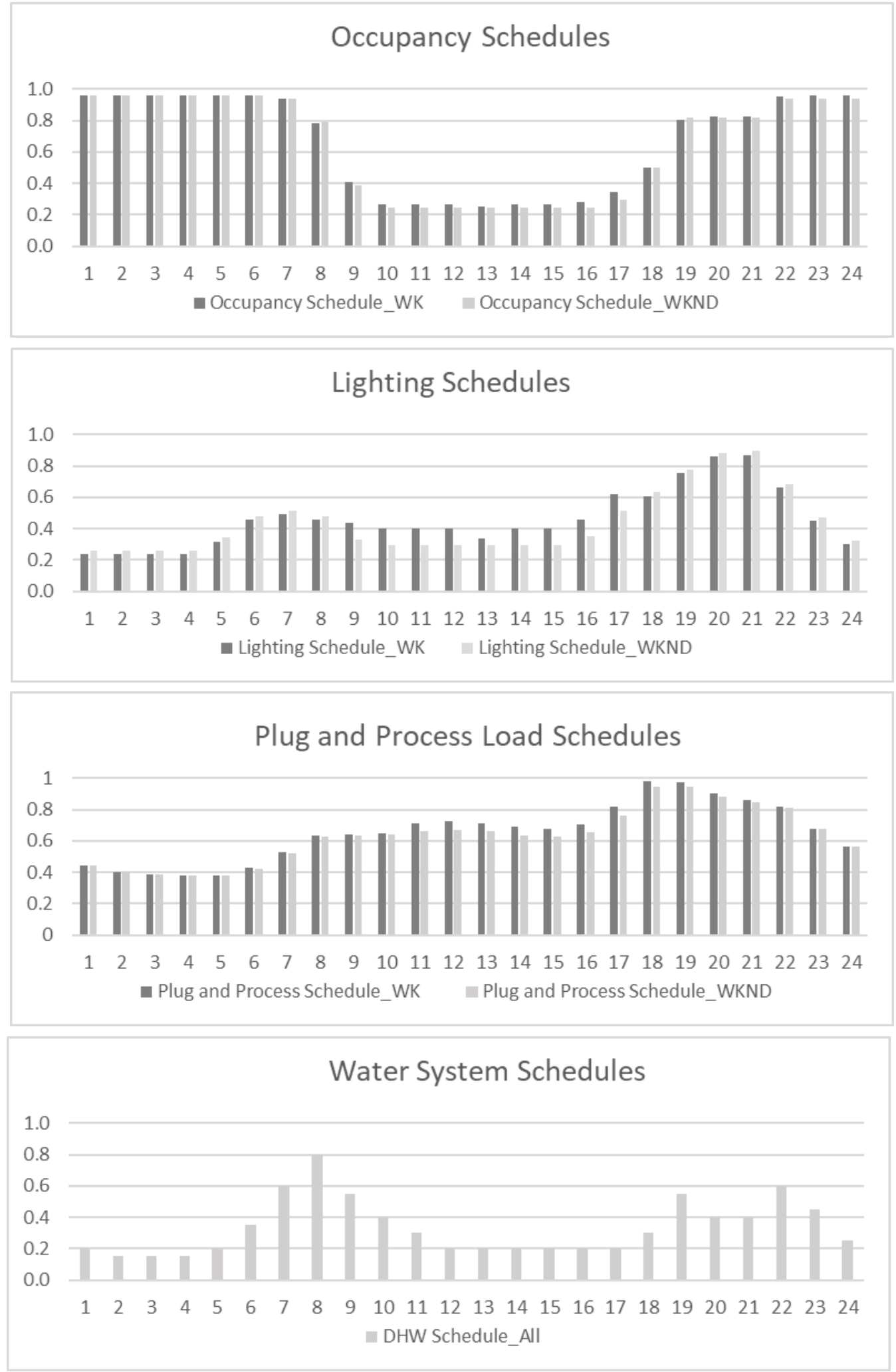
Post-1980 Midrise: Characterization Templates Before Adjusting

\begin{tabular}{|c|c|c|c|c|c|c|c|c|c|}
\hline Zones & Loads & \multicolumn{2}{|c|}{ Constructions } & Condit & tioning & Ventilation & \multicolumn{2}{|c|}{ Domestic Hot Water } & Windows \\
\hline \multicolumn{5}{|c|}{ Setting } & \multicolumn{4}{|l|}{ Value } & Units \\
\hline \multicolumn{5}{|c|}{ Constructions } & \multicolumn{4}{|c|}{ Post1980_Mid-rise Construction $~ \checkmark$} & \\
\hline \multicolumn{5}{|c|}{ Loads } & \multicolumn{3}{|c|}{ B_Res_Post1980-Midrise } & $\checkmark$ & \\
\hline \multicolumn{5}{|c|}{ Conditioning } & \multicolumn{4}{|c|}{ Post1980 Mid-rise_Conditioning $\vee$} & \\
\hline \multicolumn{5}{|c|}{ Ventilation } & \multicolumn{3}{|c|}{ Post1980 Low-rise_Ventilation } & $\checkmark$ & \\
\hline \multicolumn{5}{|c|}{ Domestic hot water } & \multicolumn{3}{|c|}{ Post1980Mid-rise_DHW } & $\checkmark$ & \\
\hline \multicolumn{5}{|c|}{ Daylight mesh resolution } & \multicolumn{3}{|c|}{ 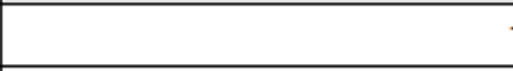 } & \begin{tabular}{l|l}
1 & $\mathrm{~m}$ \\
\end{tabular} & \\
\hline \multicolumn{5}{|c|}{ Daylight workplane height } & \multicolumn{4}{|c|}{$\begin{array}{r} \\
\end{array}$} & \\
\hline \multicolumn{5}{|c|}{ Internal mass construction } & \multicolumn{4}{|c|}{ Std Wood 6inch } & \\
\hline \multicolumn{5}{|c|}{ Internal mass exposed per floor area } & \multicolumn{4}{|c|}{1} & \\
\hline \multicolumn{4}{|c|}{ Zones Loads } & \multicolumn{2}{|c|}{ Conditioning } & Ventilation & \multicolumn{2}{|c|}{ Domestic Hot Water } & Windows \\
\hline \multicolumn{4}{|c|}{ Setting } & \multicolumn{4}{|c|}{ Value } & Units & \\
\hline Peop & & & & & & & $\nabla$ & & \\
\hline Occu & pancy de & ensity & & & & & 0.053 & $\mathrm{p} / \mathrm{m} 2$ & \\
\hline Occu & pancy sc & chedule & & & Res_Y_Oc & ec post $1980 \mathrm{M}$ & lidrise $\vee$ & & \\
\hline Equip & ment & & & & & & $\nabla$ & & \\
\hline Equip & ment po & ower d & lensity & & & & 14.58 & $\mathrm{~W} / \mathrm{m} 2$ & \\
\hline Equip & ment av & railabil & ity schedule & $\begin{array}{lll} & B \_R \\
\end{array}$ & Res_Y_Plo & $g$ post $-1980 \mathrm{~N}$ & Mid-rise $\checkmark$ & & \\
\hline Light: & & & & & & & $\checkmark$ & & \\
\hline Light: & ing powe & er den & sity & & & & 9.43 & $\mathrm{~W} / \mathrm{m} 2$ & \\
\hline Light: & ing availa & ability & schedule & & Res_Y_Lg & post $1980 \mathrm{M}$ & lidrise $\quad \checkmark$ & & \\
\hline Dimn & hing type & & & Off & & & $\checkmark$ & & \\
\hline Illumi & nance ta & arget & & & & & 200 & lux & \\
\hline Zones & Loads & Const & tructions $\mid \mathrm{C}$ & Conditi & ioning & Ventilation & Domestic H & tot Water & Windows \\
\hline Setting & & & Value & & & & Units & & \\
\hline Enable & & & & & & $\checkmark$ & & & \\
\hline Sched & & & B_Res_Y_D & Dhw pc & ost1980 & Mid-rise & & & \\
\hline Supply & temper & rature & & & & 60 & $\operatorname{deg} C$ & & \\
\hline Inlet te & mperatc & & & & & 16 & $\operatorname{deg} C$ & & \\
\hline Flow ra & & & & & & 0.00017 & $|\mathrm{~m} 3 / \mathrm{h} / \mathrm{m} 2|$ & & \\
\hline
\end{tabular}




\begin{tabular}{||l|l|l|l|l|l|l|}
\hline Zones & Loads & Constructions & Conditioning & Ventilation & Domestic Hot Water & Windows \\
\hline Setting & Value & Mass Res Ext Wall & $\checkmark$ & & \\
\hline Facade & ext-slab & $\checkmark$ & & \\
\hline Ground & Int-walls & $\checkmark$ & & \\
\hline Partition & IEAD Res Roof & $\checkmark$ & & \\
\hline Roof & INT-FLOOR-TOPSIDE & $\checkmark$ & & \\
\hline Slab & $\square$ & & \\
\hline Facade is adiabatic & & $\square$ & & \\
\hline Ground is adiabatic & & $\square$ & & \\
\hline Partition is adiabatic & & $\square$ & & \\
\hline Roof is adiabatic & & &
\end{tabular}

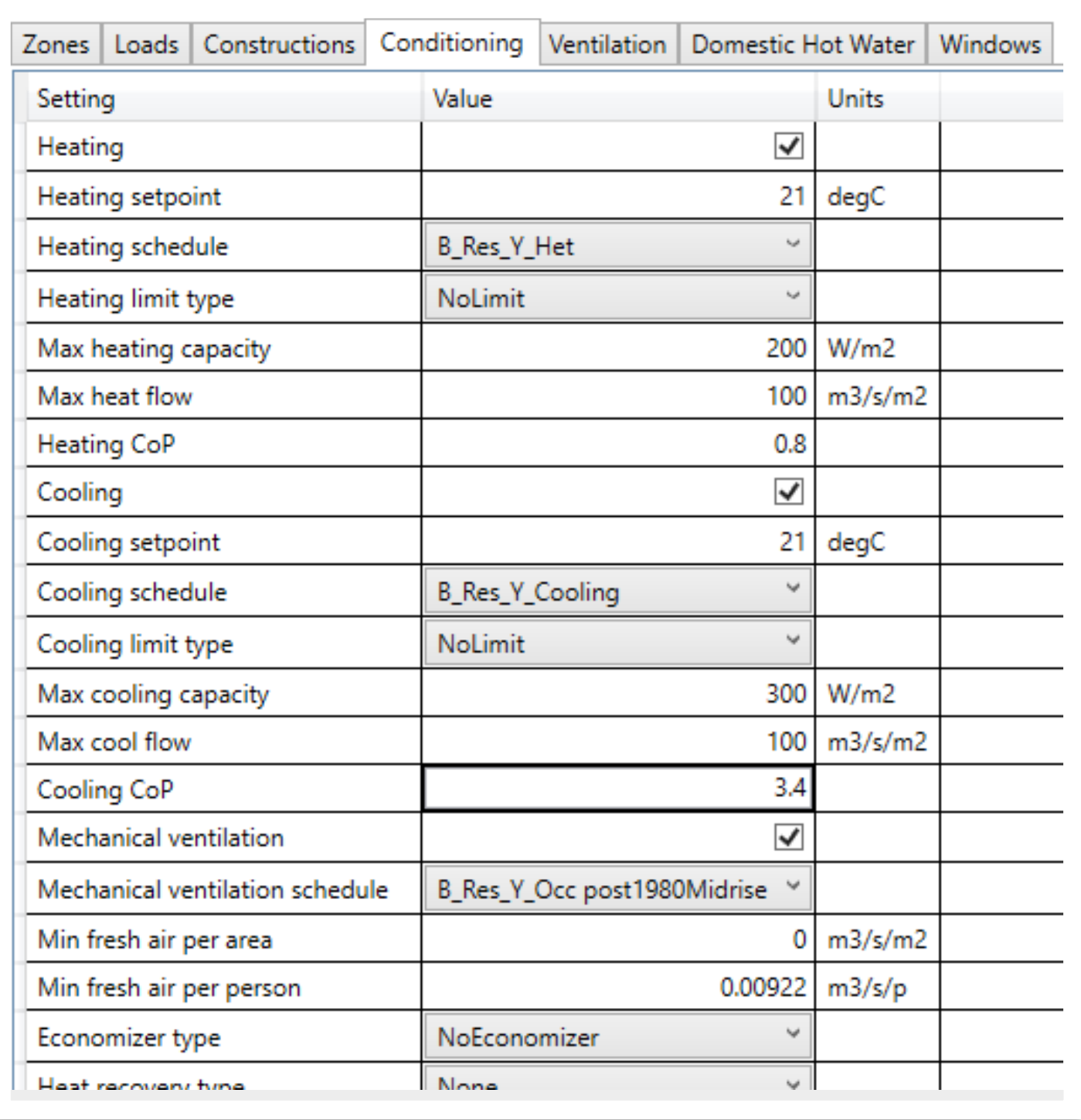




\begin{tabular}{||l|r|r|r|r|}
\hline Zones Loads Constructions & Conditioning & Ventilation & Domestic Hot Water & Windows \\
\hline Setting & \multicolumn{3}{|c|}{ Value } & \multicolumn{3}{|c|}{ Units } \\
\hline Infiltration & 0.6 & ACH & \\
\hline Infiltration rate & $\square$ & & \\
\hline Natural ventilation & 18 & degC & \\
\hline Nat vent min outdoor air temp & 26 & degC & \\
\hline Nat vent max outdoor air temp & 80 & & \\
\hline Nat vent max rel humidity & & 22 & degC & \\
\hline Nat vent schedule & B_Res_Y_Nat & & \\
\hline Nat vent zone temperature setpoint & $\square$ & & \\
\hline Scheduled ventilation & 0.6 & ACH & \\
\hline Scheduled ventilation ACH & & & \\
\hline Scheduled ventilation schedule & B_Res_Y_Nat & & \\
\hline Scheduled ventilation setpoint & 22 & degC & \\
\hline Buoyancy & $\checkmark$ & & \\
\hline Wind & $\checkmark$ & & \\
\hline
\end{tabular}

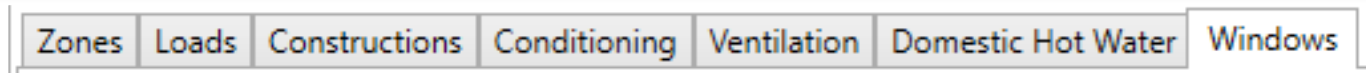

\begin{tabular}{|c|c|c|}
\hline Setting & Value & Units \\
\hline Type & External & \\
\hline Construction & B_Dbl_Air_Cl $(6 \mathrm{~mm}) \quad \checkmark$ & \\
\hline Operable area & 0 & \\
\hline Shading is used & $\square$ & \\
\hline Shading system availability schedule & B_Res_Y_Occ & \\
\hline Shading system setpoint & 0.5 & $\mathrm{~W} / \mathrm{m} 2$ \\
\hline Shading system transmittance & 0.5 & \\
\hline Shading system type & InteriorShade & \\
\hline Zone mixing & $\square$ & \\
\hline Zone mixing availability schedule & B_Res_Y_Occ & \\
\hline Zone mixing delta temperature & 2 & \\
\hline Zone mixing flow rate & 0.001 & $\mathrm{~m} 3 / 2$ \\
\hline Virtual partition & $\square$ & \\
\hline Airflow network discharge coefficient & 0.65 & \\
\hline Airflow network temperature setpoint & 20 & $\operatorname{deg} C$ \\
\hline
\end{tabular}


Post-1980 Midrise: Characterization Templates After Adjusting

\begin{tabular}{|l|l|l|l|l|l|}
\hline Zones Loads & Constructions & Conditioning & Ventilation & Domestic Hot Water & Windows \\
\hline Setting & Value & Post1980_Mid-rise Construction $\checkmark$ & & \\
\hline Constructions & B_Res_Post1980-Midrise & & \\
\hline Loads & Post1980 Mid-rise_Conditioning v & & \\
\hline Conditioning & Post1980 Low-rise_Ventilation v & & \\
\hline Ventilation & Post1980Mid-rise_DHW & & \\
\hline Domestic hot water & & & \\
\hline Daylight mesh resolution & & $\mathrm{m}$ & \\
\hline Daylight workplane height & Std Wood 6inch & $\mathrm{m}$ & \\
\hline Internal mass construction & & & \\
\hline Internal mass exposed per floor area & & & \\
\hline
\end{tabular}

\begin{tabular}{|c|c|c|c|c|c|c|c|}
\hline Zones & Loads & Constructions $\mathrm{C}$ & Conditioning & Ventilation & \multicolumn{2}{|c|}{ Domestic Hot Water } & Windows \\
\hline \multicolumn{3}{|c|}{ Setting } & \multicolumn{3}{|l|}{ Value } & Units & \\
\hline \multicolumn{3}{|c|}{ People } & \multicolumn{4}{|c|}{$\checkmark$} & \\
\hline \multicolumn{3}{|c|}{ Occupancy density } & \multicolumn{3}{|r|}{0.053} & $\mathrm{p} / \mathrm{m} 2$ & \\
\hline \multicolumn{3}{|c|}{ Occupancy schedule } & \multicolumn{3}{|c|}{ B_Res_Y_Occ post 1980 Midrise $\quad \checkmark$} & & \\
\hline \multicolumn{3}{|c|}{ Equipment } & \multicolumn{3}{|r|}{$\checkmark$} & & \\
\hline \multicolumn{3}{|c|}{ Equipment power density } & \multicolumn{3}{|r|}{18} & $\mathrm{~W} / \mathrm{m} 2$ & \\
\hline \multicolumn{3}{|c|}{ Equipment availability schedule } & \multicolumn{3}{|c|}{ B_Res_Y_Plg post-1980 Mid-rise } & & \\
\hline \multicolumn{3}{|c|}{ Lighting } & \multicolumn{3}{|r|}{$\checkmark$} & & \\
\hline \multicolumn{3}{|c|}{ Lighting power density } & \multicolumn{3}{|r|}{13} & $\mathrm{~W} / \mathrm{m} 2$ & \\
\hline \multicolumn{3}{|c|}{ Lighting availability schedule } & \multicolumn{3}{|c|}{ B_Res_Y_Lgt post 1980 Midrise $\quad \checkmark$} & & \\
\hline \multicolumn{3}{|c|}{ Dimming type } & \multicolumn{3}{|l|}{ Off } & & \\
\hline \multicolumn{3}{|c|}{ Illuminance target } & \multicolumn{3}{|r|}{200} & lux & \\
\hline
\end{tabular}

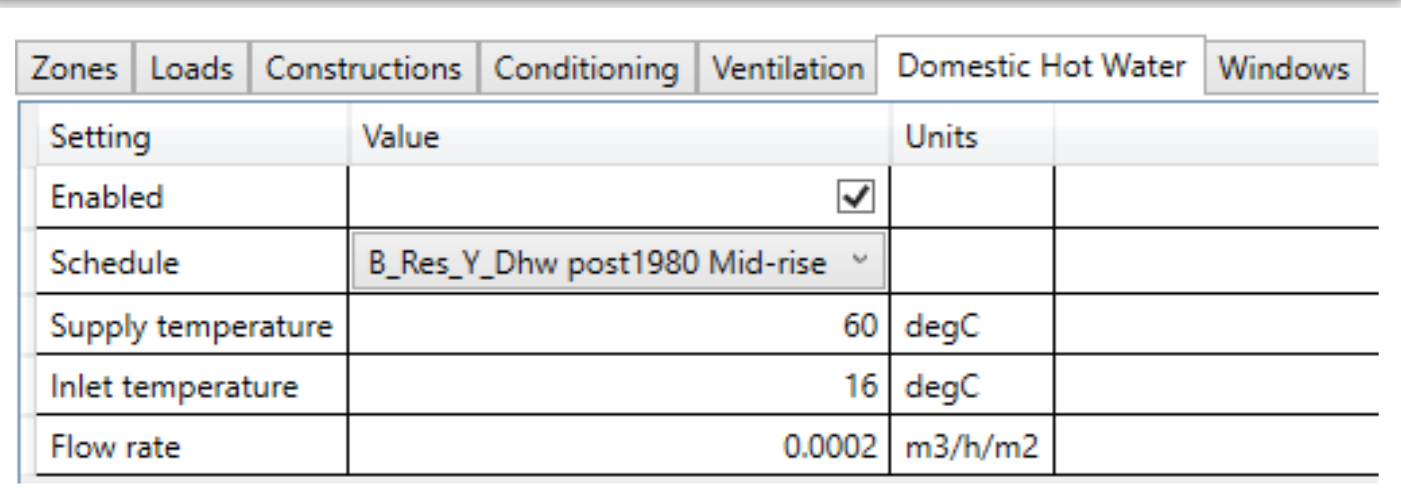




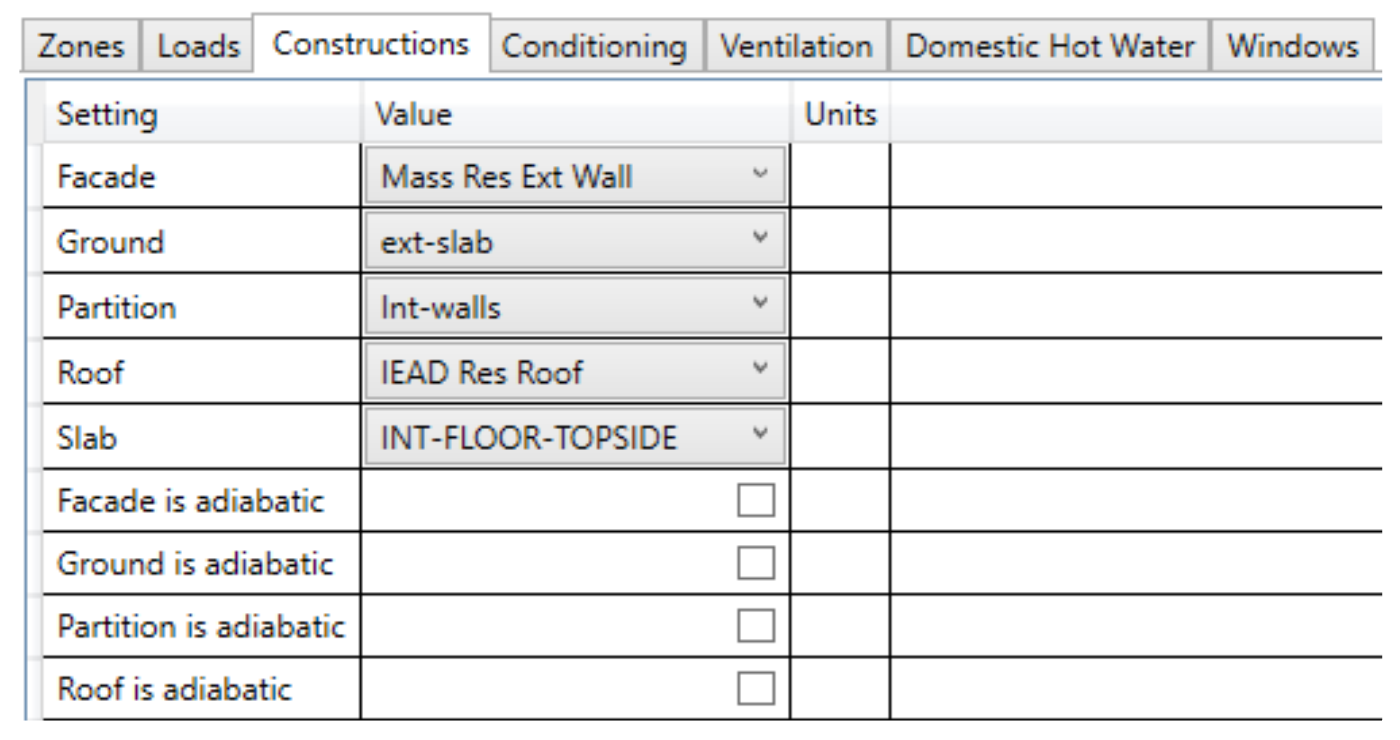

\begin{tabular}{|c|c|c|c|c|c|c|}
\hline \multirow{2}{*}{\begin{tabular}{c|} 
Zones \\
Setting
\end{tabular}} & \multirow{2}{*}{$\begin{array}{ll}\text { Loads } & \text { Constructions } \\
\mathrm{g}\end{array}$} & Conditioning & \multirow[t]{2}{*}{ Ventilation } & \multicolumn{2}{|c|}{ Domestic Hot Water } & \multirow[t]{2}{*}{ Windows } \\
\hline & & \multicolumn{2}{|l|}{ Value } & & Units & \\
\hline \multicolumn{2}{|c|}{ Heating } & & & $\checkmark$ & & \\
\hline \multicolumn{2}{|c|}{ Heating setpoint } & & & 21 & $\operatorname{deg} C$ & \\
\hline \multicolumn{2}{|c|}{ Heating schedule } & \multicolumn{2}{|c|}{ B_Res_Y_Het } & $\checkmark$ & & \\
\hline \multicolumn{2}{|c|}{ Heating limit type } & \multicolumn{2}{|l|}{ NoLimit } & $\checkmark$ & & \\
\hline \multicolumn{2}{|c|}{ Max heating capacity } & & & 200 & $\mathrm{~W} / \mathrm{m} 2$ & \\
\hline \multicolumn{2}{|c|}{ Max heat flow } & & & 100 & $\mathrm{~m} 3 / \mathrm{s} / \mathrm{m} 2$ & \\
\hline \multicolumn{2}{|c|}{ Heating CoP } & & & 0.78 & & \\
\hline \multicolumn{2}{|c|}{ Cooling } & & & $\checkmark$ & & \\
\hline \multicolumn{2}{|c|}{ Cooling setpoint } & & & 21 & $\operatorname{deg} C$ & \\
\hline \multicolumn{2}{|c|}{ Cooling schedule } & B_Res_Y & Cooling & $\checkmark$ & & \\
\hline \multicolumn{2}{|c|}{ Cooling limit type } & NoLimit & & $\checkmark$ & & \\
\hline \multicolumn{2}{|c|}{ Max cooling capacity } & & & 300 & $\mathrm{~W} / \mathrm{m} 2$ & \\
\hline \multicolumn{2}{|c|}{ Max cool flow } & & & 100 & $\mathrm{~m} 3 / \mathrm{s} / \mathrm{m} 2$ & \\
\hline \multicolumn{2}{|c|}{ Cooling CoP } & & & 2.5 & & \\
\hline \multicolumn{2}{|c|}{ Mechanical ventilation } & & & $\checkmark$ & & \\
\hline \multicolumn{2}{|c|}{ Mechanical ventilation schedule } & \multicolumn{3}{|c|}{ B_Res_Y_Occ post1980Midrise $\checkmark$} & & \\
\hline \multicolumn{2}{|c|}{ Min fresh air per area } & & & 0 & $\mathrm{~m} 3 / \mathrm{s} / \mathrm{m} 2$ & \\
\hline \multicolumn{2}{|c|}{ Min fresh air per person } & & & 0.00922 & $\mathrm{~m} 3 / \mathrm{s} / \mathrm{p}$ & \\
\hline \multicolumn{2}{|c|}{ Economizer type } & NoEconc & mizer & $\checkmark$ & & \\
\hline \multicolumn{2}{|c|}{ Heat recovery type } & None & & $\checkmark$ & & \\
\hline
\end{tabular}




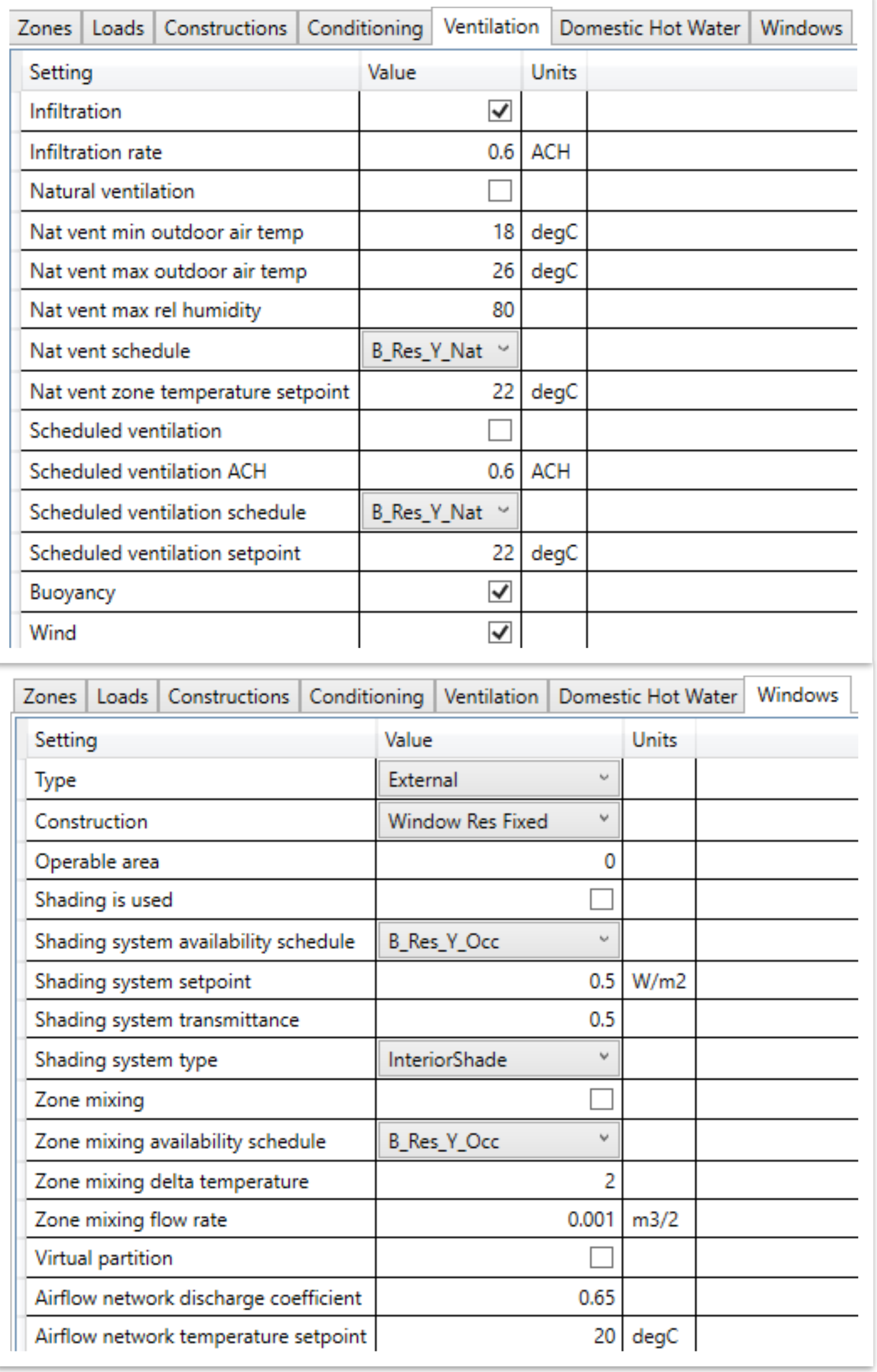


Post-1980 Midrise: Daily Schedules
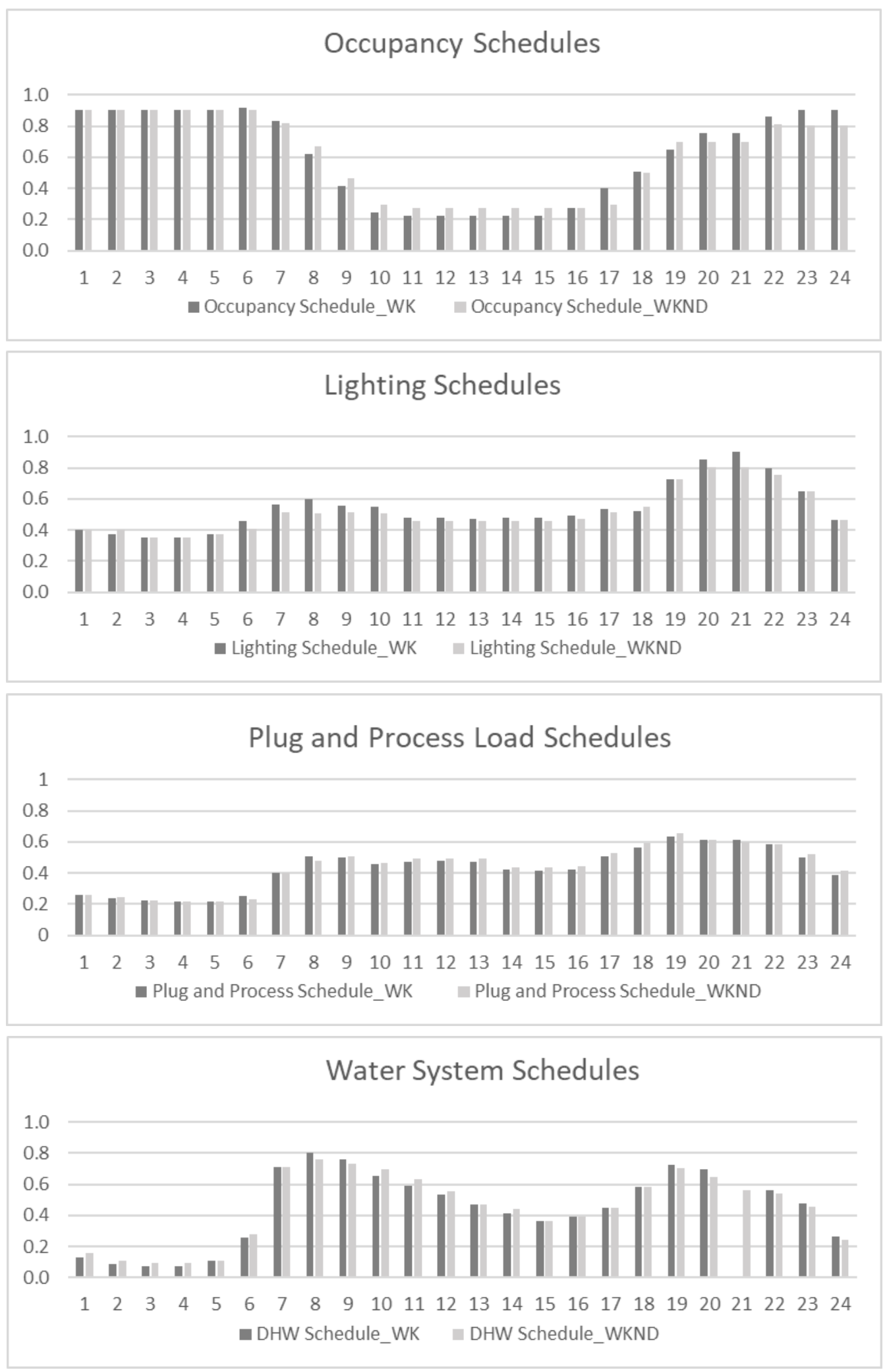


\section{Pre-1980 Highrise: Characterization Templates Before Adjusting}

\begin{tabular}{|c|c|c|c|c|c|c|c|c|c|c|}
\hline Zones & Loads & \multicolumn{2}{|c|}{ Constructions } & Conditio & oning & Ventilation & \multicolumn{3}{|c|}{ Domestic Hot Water } & Windows \\
\hline \multicolumn{5}{|c|}{ Setting } & \multicolumn{4}{|l|}{ Value } & \multicolumn{2}{|l|}{ Units } \\
\hline \multicolumn{5}{|c|}{ Constructions } & \multicolumn{4}{|c|}{ Pre1980_High-rise } & & \\
\hline \multicolumn{5}{|c|}{ Loads } & \multicolumn{4}{|c|}{ B_Res_pre1980 High-rise } & & \\
\hline \multicolumn{5}{|c|}{ Conditioning } & \multicolumn{4}{|c|}{ Pre1980 High-rise_Conditioning $\checkmark$} & & \\
\hline \multicolumn{5}{|c|}{ Ventilation } & \multicolumn{4}{|c|}{ Pre1980 High-rise_Ventilation $\checkmark$} & & \\
\hline \multicolumn{5}{|c|}{ Domestic hot water } & \multicolumn{5}{|c|}{ Pre1980 Highrise_DHW } & \\
\hline \multicolumn{5}{|c|}{ Daylight mesh resolution } & \multicolumn{4}{|c|}{$1 \mathrm{~m}$} & $\mathrm{~m}$ & \\
\hline \multicolumn{5}{|c|}{ Daylight workplane height } & \multicolumn{4}{|c|}{$0.8 \mathrm{r}$} & $m$ & \\
\hline \multicolumn{5}{|c|}{ Internal mass construction } & \multicolumn{4}{|c|}{ Std Wood 6inch } & & \\
\hline \multicolumn{5}{|c|}{ Internal mass exposed per floor area } & \multicolumn{4}{|c|}{ (5) } & & \\
\hline Zones & Loads & \multicolumn{2}{|c|}{\begin{tabular}{|l|l} 
Constructions & \\
\end{tabular}} & \multicolumn{2}{|c|}{ Conditioning } & Ventilation & \multicolumn{3}{|c|}{ Domestic Hot Water } & Windows \\
\hline \multicolumn{4}{|c|}{ Setting } & Value & & & & Units & & \\
\hline People & & & & & & & $\checkmark$ & & & \\
\hline Occup & ancy der & nsity & & & & & 0.052 & $\mathrm{p} / \mathrm{m} 2$ & & \\
\hline Occup & ancy sch & nedule & & B_Res & $\mathrm{S}_{-} \mathrm{Y}_{-} \mathrm{OC}$ & c pre $1980 \mathrm{Hi}$ & ighrise $\vee$ & & & \\
\hline Equipr & nent & & & & & & $\checkmark$ & & & \\
\hline Equipr & nent por & wer der & nsity & & & & 14.63 & $\mathrm{~W} / \mathrm{m} 2$ & & \\
\hline Equipr & nent ava & ailability & ty schedule & B_Res & $\mathrm{S}_{-} \mathrm{Y}_{-} \mathrm{Plg}$ & pre1980 Hig & ghrise $\vee$ & & & \\
\hline Lightir & & & & & & & $\checkmark$ & & & \\
\hline Lightir & g power & idensit & & & & & 12.72 & $\mathrm{~W} / \mathrm{m} 2$ & & \\
\hline Lightir & gavaila & bility sc & schedule & B_Res & $S_{-} Y_{-} L g$ & t pre $1980 \mathrm{Hig}$ & ghrise $\checkmark$ & & & \\
\hline Dimmi & ng type & & & Off & & & $\checkmark$ & & & \\
\hline Illumin & lance tar & rget & & & & & 200 & lux & & \\
\hline Zones & Loads & Constr & tructions $\mathrm{C}$ & Conditior & oning & Ventilation & Domestic & Hot Wat & ter & Windows \\
\hline Setting & & & Value & & Units & & & & & \\
\hline Enable & & & & $\nabla$ & & & & & & \\
\hline Sched & & & B_Res_Y_D & Dhw $\checkmark$ & & & & & & \\
\hline Supply & temper & rature & & 60 & $\operatorname{deg} C$ & & & & & \\
\hline Inlet te & emperat & & & 16 & $\operatorname{deg} C$ & & & & & \\
\hline Flow $r$ & & & & 0.00016 & $\mathrm{~m} 3 / \mathrm{l}$ & $\mathrm{h} / \mathrm{m} 2$ & & & & \\
\hline
\end{tabular}




\begin{tabular}{|c|c|c|c|c|c|c|c|}
\hline Zones & Loads & Constructions & Conditioning & Ventilation & \multicolumn{2}{|c|}{ Domestic Hot Water } & Windows \\
\hline \multicolumn{3}{|c|}{ Setting } & \multicolumn{3}{|c|}{ Value } & \multicolumn{2}{|l|}{ Units } \\
\hline \multicolumn{3}{|c|}{ Facade } & \multicolumn{3}{|c|}{ Typical Insulated Exterior Mass Wall R-6.9 $\checkmark$} & & \\
\hline \multicolumn{2}{|c|}{ Ground } & \multicolumn{4}{|c|}{ ext-slab-mass } & & \\
\hline \multicolumn{2}{|c|}{ Partition } & \multicolumn{4}{|c|}{ Typical interior wall } & & \\
\hline \multicolumn{2}{|l|}{ Roof } & \multicolumn{4}{|c|}{ Typical IEAD Roof R16.67 } & & \\
\hline \multicolumn{2}{|l|}{ Slab } & \multicolumn{4}{|c|}{ Typical interior floor } & & \\
\hline \multicolumn{3}{|c|}{ Facade is adiabatic } & & & $\square$ & & \\
\hline \multicolumn{2}{|c|}{ Ground is adiabatic } & abatic & & & $\square$ & & \\
\hline \multicolumn{3}{|c|}{ Partition is adiabatic } & & & $\square$ & & \\
\hline \multicolumn{3}{|c|}{ Roof is adiabatic } & & & $\square$ & & \\
\hline
\end{tabular}

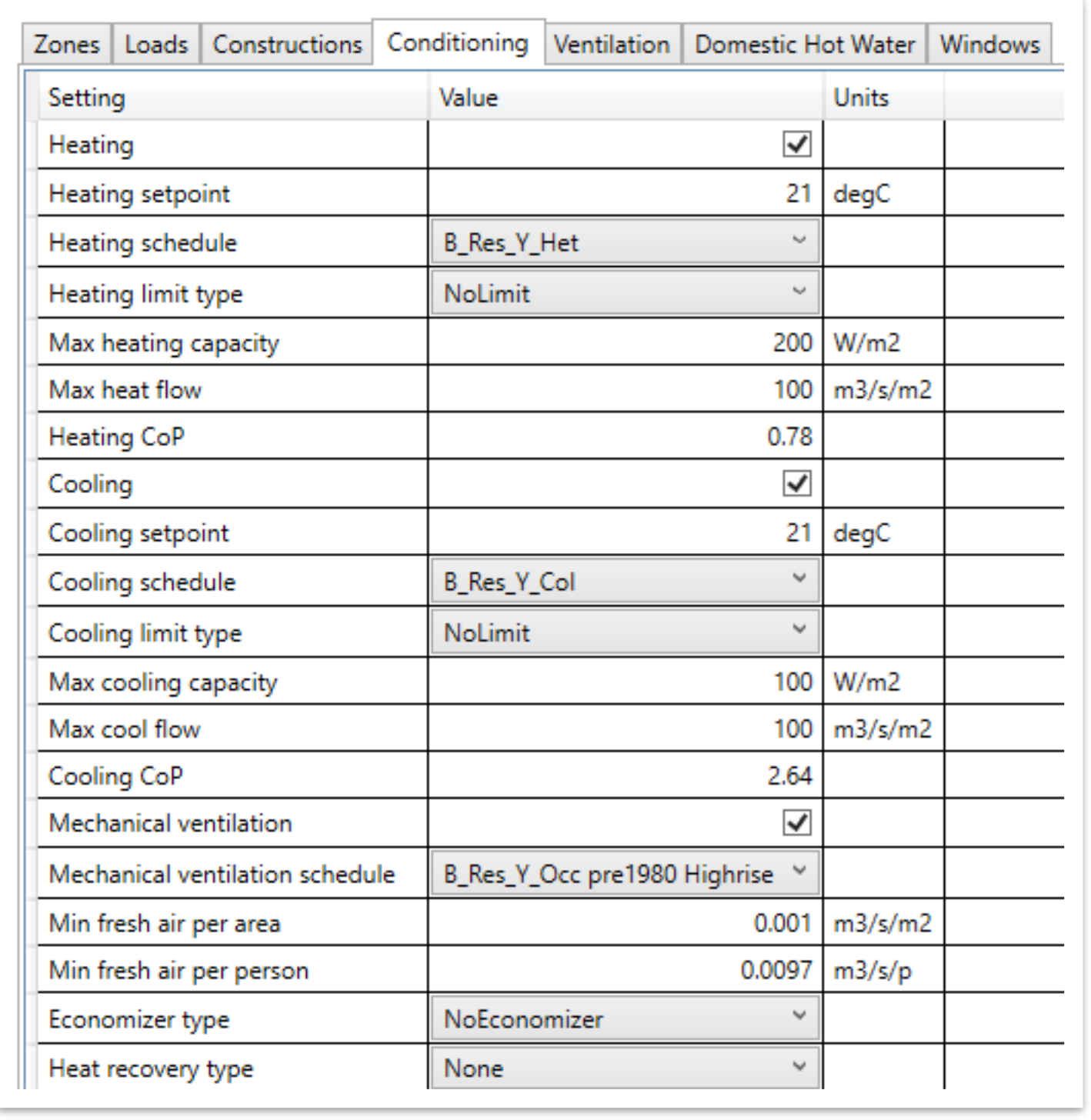




\begin{tabular}{|c|c|c|c|c|c|c|c|}
\hline Zones & Loads & \begin{tabular}{l|l} 
Constructions & Cond
\end{tabular} & itioning & Ventilatio & on $\mathrm{Do}$ & Oomestic Hot Water & Windows \\
\hline \multicolumn{3}{|c|}{ Setting } & \multicolumn{2}{|l|}{ Value } & \multicolumn{3}{|l|}{ Units } \\
\hline \multicolumn{3}{|c|}{ Infiltration } & & $\checkmark$ & & & \\
\hline \multicolumn{3}{|c|}{ Infiltration rate } & & 0.6 & $\mathrm{ACH}$ & & \\
\hline \multicolumn{3}{|c|}{ Natural ventilation } & & $\square$ & & & \\
\hline \multicolumn{3}{|c|}{ Nat vent min outdoor air temp } & & 18 & $\operatorname{deg} \mathrm{C}$ & & \\
\hline \multicolumn{3}{|c|}{ Nat vent max outdoor air temp } & & 26 & $\operatorname{deg} \mathrm{C}$ & & \\
\hline \multicolumn{3}{|c|}{ Nat vent max rel humidity } & & 80 & & & \\
\hline \multicolumn{3}{|c|}{ Nat vent schedule } & B_Res_Y & _Nat $\checkmark$ & & & \\
\hline \multicolumn{3}{|c|}{ Nat vent zone temperature setpoint } & & 22 & $\operatorname{deg} \mathrm{C}$ & & \\
\hline \multicolumn{3}{|c|}{ Scheduled ventilation } & & $\square$ & & & \\
\hline \multicolumn{3}{|c|}{ Scheduled ventilation $\mathrm{ACH}$} & & 0.6 & $\mathrm{ACH}$ & & \\
\hline \multicolumn{3}{|c|}{ Scheduled ventilation schedule } & B_Res_Y & _Nat $\checkmark$ & & & \\
\hline \multicolumn{3}{|c|}{ Scheduled ventilation setpoint } & & 22 & $\operatorname{deg} \mathrm{C}$ & & \\
\hline \multicolumn{3}{|c|}{ Buoyancy } & & $\checkmark$ & & & \\
\hline \multicolumn{3}{|l|}{ Wind } & & $\nabla$ & & & \\
\hline
\end{tabular}

\begin{tabular}{|c|c|c|c|c|c|c|c|c|}
\hline Zones & Loads & Constructions & \multicolumn{2}{|c|}{ Conditioning } & Ventilation & Domestic Hot Wat & \multicolumn{2}{|c|}{ er Windows } \\
\hline \multicolumn{4}{|c|}{ Setting } & \multicolumn{3}{|c|}{ Value } & \multicolumn{2}{|l|}{ Units } \\
\hline \multicolumn{4}{|l|}{ Type } & \multicolumn{3}{|c|}{ External } & & \\
\hline \multicolumn{4}{|c|}{ Construction } & \multicolumn{3}{|c|}{ U 0.62 SHGC 0.41 Simple Glazing $\vee$} & & \\
\hline \multicolumn{4}{|c|}{ Operable area } & \multicolumn{3}{|r|}{0.5} & & \\
\hline \multicolumn{4}{|c|}{ Shading is used } & \multicolumn{3}{|r|}{$\square$} & & \\
\hline \multicolumn{4}{|c|}{ Shading system availability schedule } & \multicolumn{2}{|c|}{ B_Res_Y_Occ } & $\checkmark$ & & \\
\hline \multicolumn{4}{|c|}{ Shading system setpoint } & & & 0.5 & $\mathrm{~W} / \mathrm{m} 2$ & \\
\hline \multicolumn{4}{|c|}{ Shading system transmittance } & & & 0.5 & & \\
\hline \multicolumn{4}{|c|}{ Shading system type } & \multicolumn{3}{|c|}{ InteriorShade } & & \\
\hline \multicolumn{4}{|c|}{ Zone mixing } & \multicolumn{3}{|r|}{$\checkmark$} & & \\
\hline \multicolumn{4}{|c|}{ Zone mixing availability schedule } & \multicolumn{3}{|c|}{ B_Res_Y_Occ } & & \\
\hline \multicolumn{4}{|c|}{ Zone mixing delta temperature } & & & 2 & & \\
\hline \multicolumn{4}{|c|}{ Zone mixing flow rate } & & & 0.001 & $\mathrm{~m} 3 / 2$ & \\
\hline \multicolumn{4}{|c|}{ Virtual partition } & & & $\square$ & & \\
\hline \multicolumn{4}{|c|}{ Airflow network discharge coefficient } & & & 0.65 & & \\
\hline \multicolumn{4}{|c|}{ Airflow network temperature setpoint } & & & 20 & $\operatorname{deg} C$ & \\
\hline
\end{tabular}




\section{Pre-1980 Highrise: Characterization Templates After Adjusting}

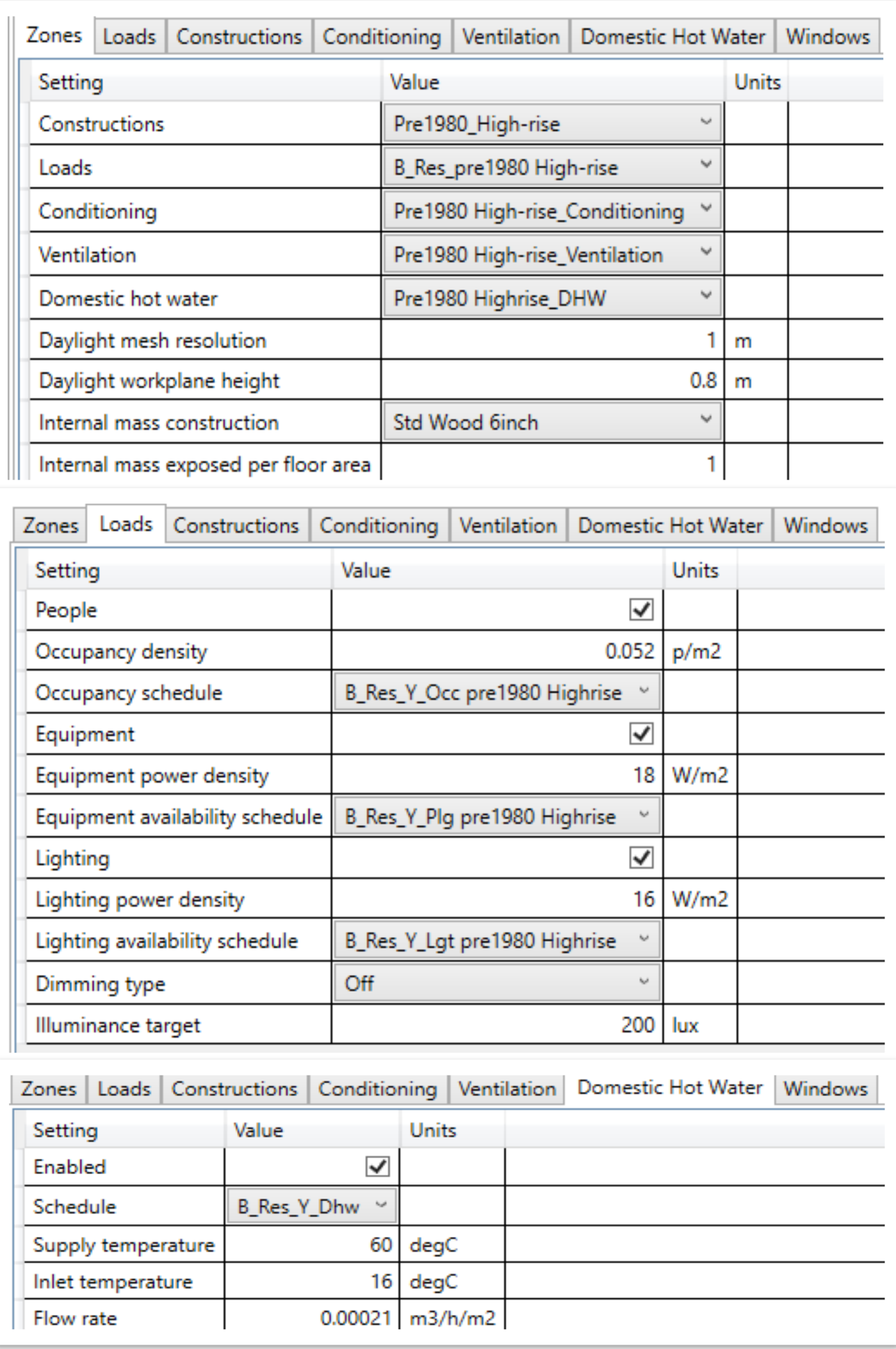




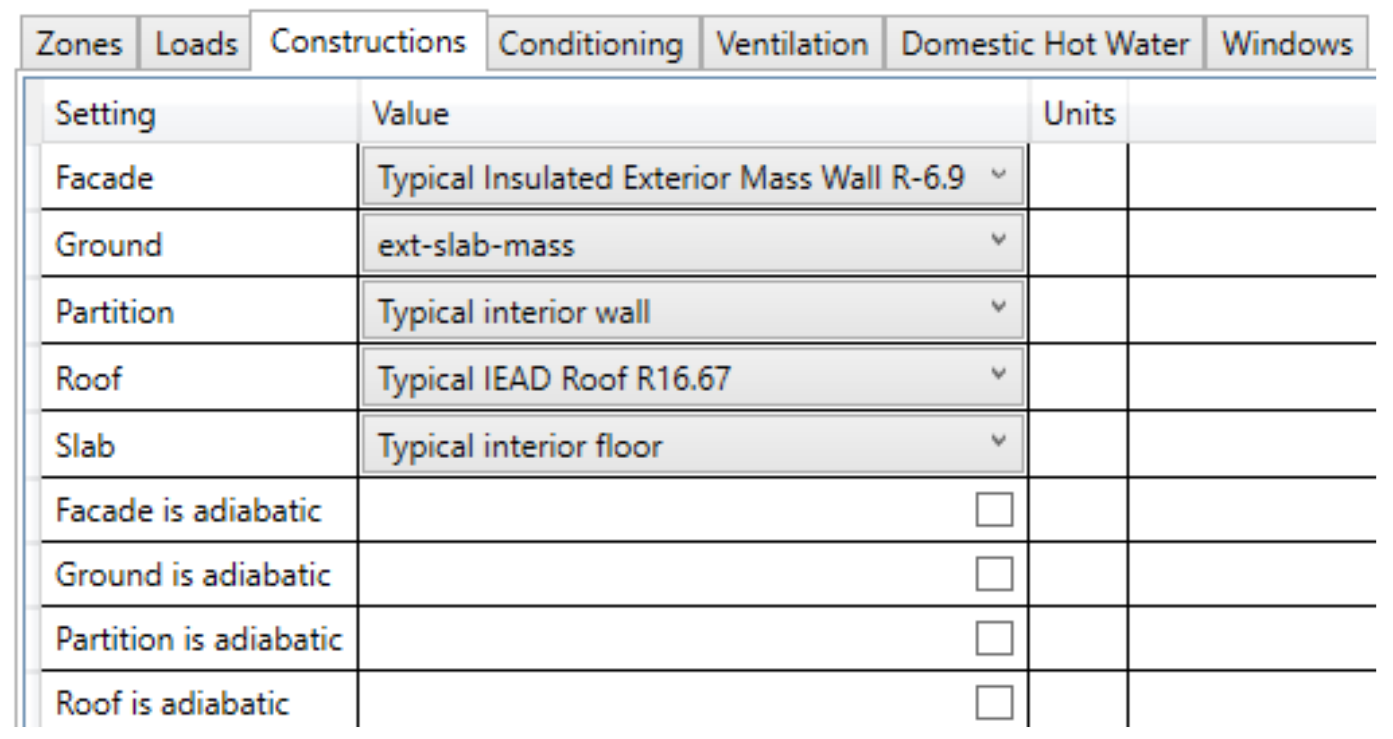

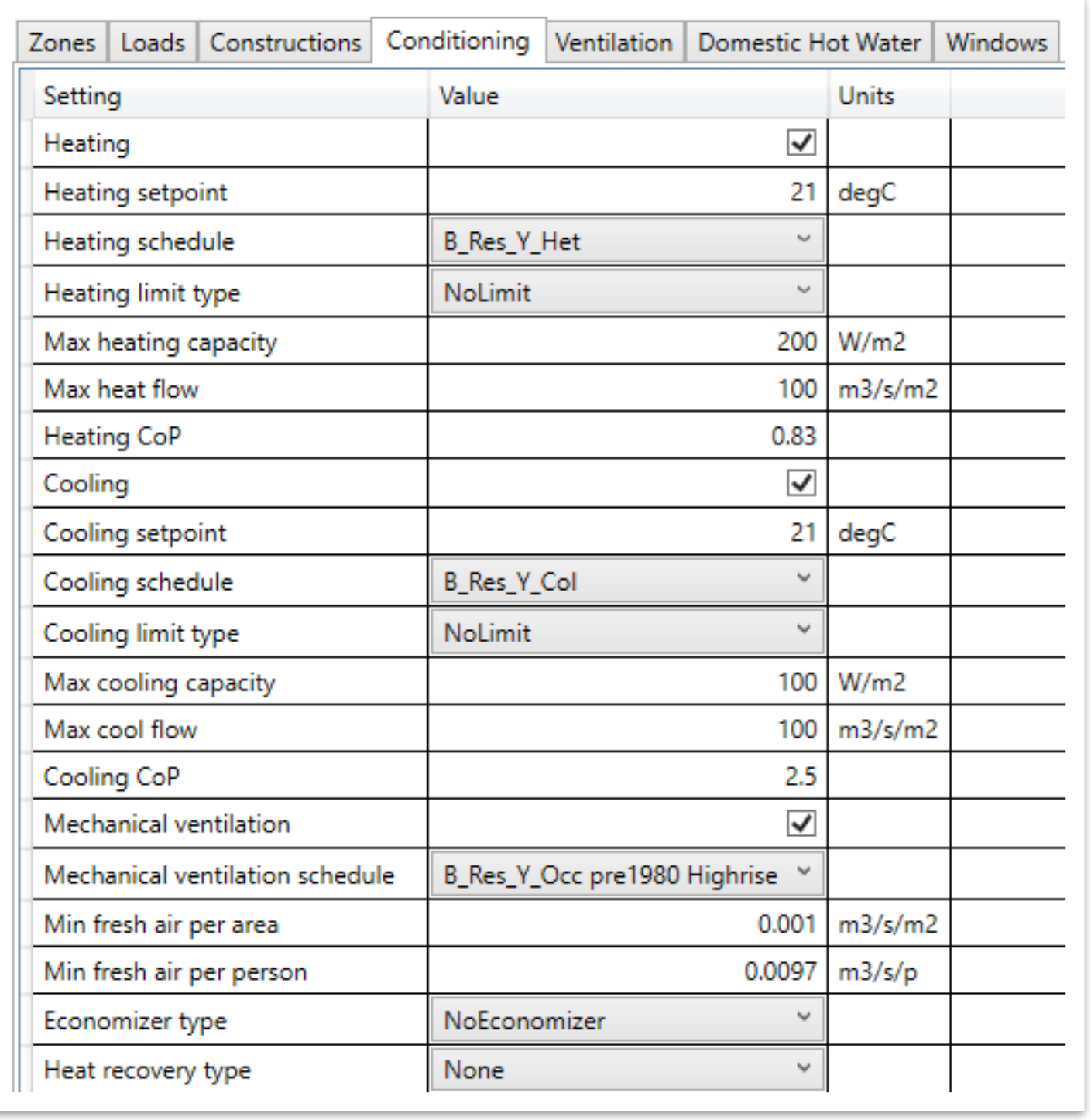




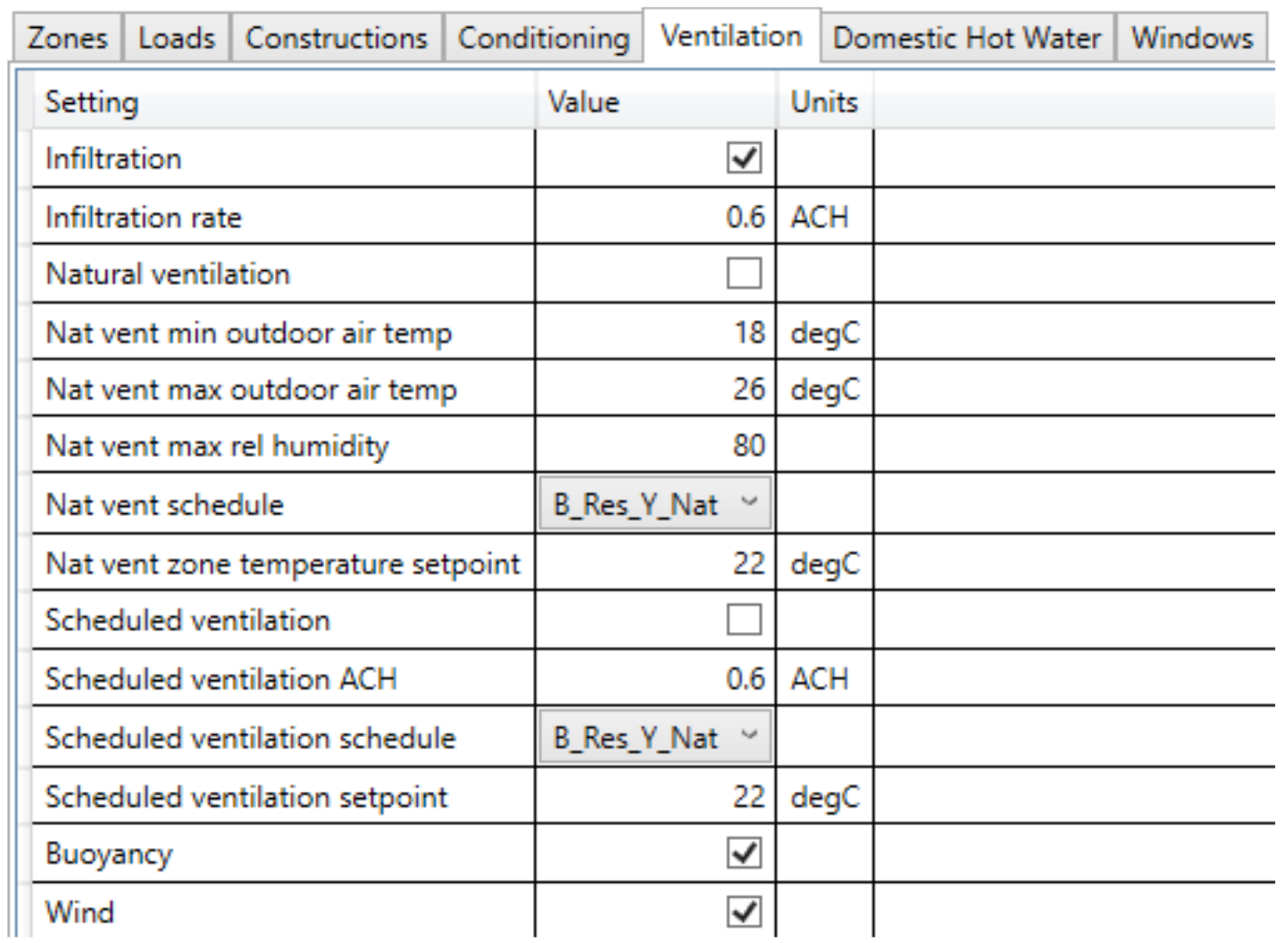

\begin{tabular}{|c|c|c|c|c|c|c|c|}
\hline Zones Loads & Constructions & Conditic & oning & Ventilation & Domestic Hot Wate & ter Wir & indows \\
\hline Setting & & & Value & & & Units & \\
\hline Type & & & Exterr & nal & $\checkmark$ & & \\
\hline Construction & & & U 0.6 & 2 SHGC 0.41 & Simple Glazing & & \\
\hline Operable area & & & & & 0.5 & & \\
\hline Shading is use & & & & & $\square$ & & \\
\hline Shading syste & m availability sc & hedule & B_Res & S_Y_Occ & $\checkmark$ & & \\
\hline Shading syste & m setpoint & & & & 0.5 & $\mathrm{~W} / \mathrm{m} 2$ & \\
\hline Shading syste & $\mathrm{m}$ transmittance & & & & 0.5 & & \\
\hline Shading syste & m type & & Interi & iorShade & $\checkmark$ & & \\
\hline Zone mixing & & & & & $\checkmark$ & & \\
\hline Zone mixing a & availability schec & ule & B_Res & S_Y_Occ & $\checkmark$ & & \\
\hline Zone mixing o & delta temperatu & & & & 2 & & \\
\hline Zone mixing $\mathrm{f}$ & low rate & & & & 0.001 & $\mathrm{~m} 3 / 2$ & \\
\hline Virtual partitic & & & & & $\square$ & & \\
\hline Airflow netwo & rk discharge co & fficient & & & 0.65 & & \\
\hline Airflow netwo & rk temperature & setpoint & & & 20 & $\operatorname{deg} C$ & \\
\hline
\end{tabular}


Pre-1980 Highrise: Daily Schedules
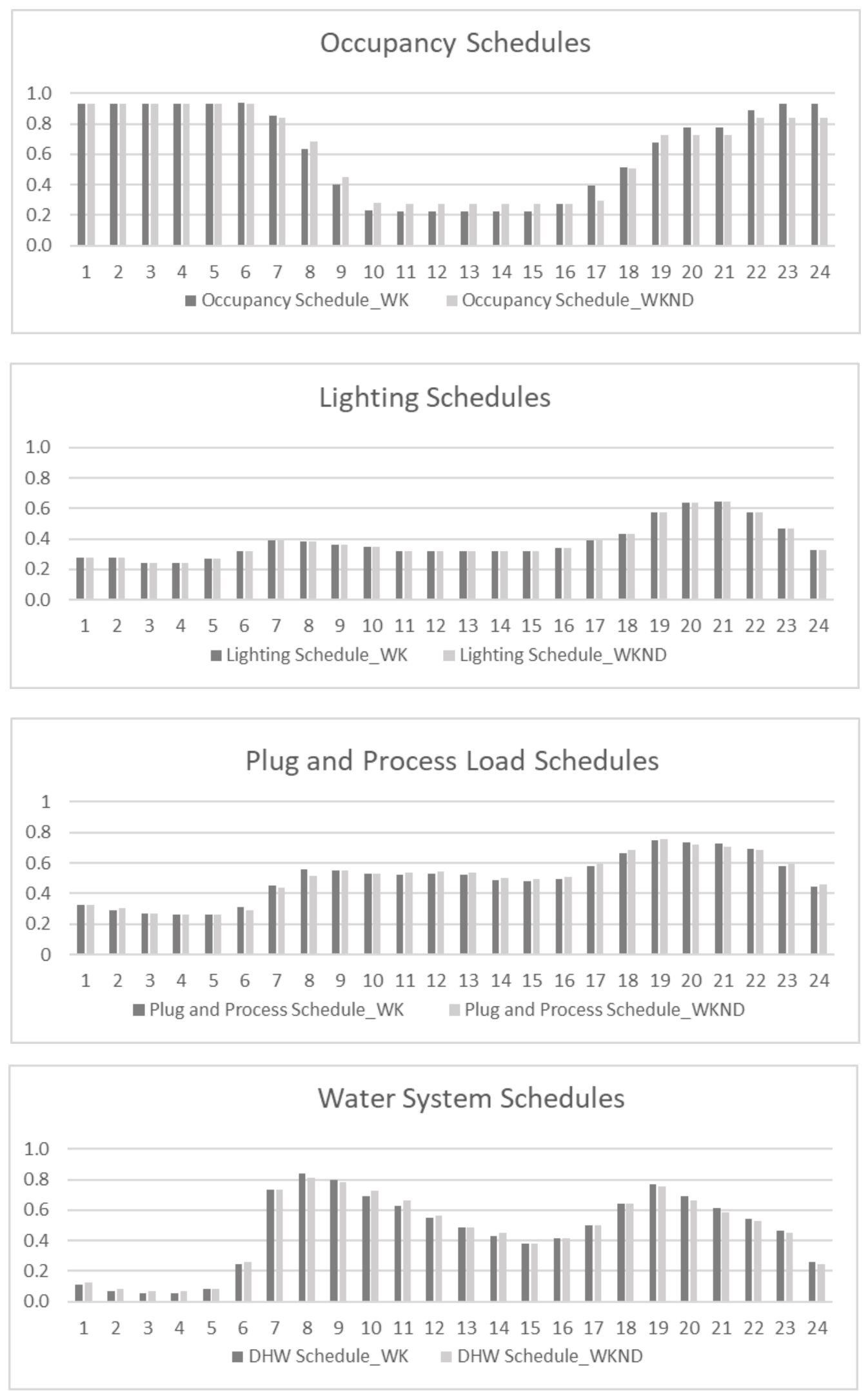
Appendix D: Random Sampling in RStudio 


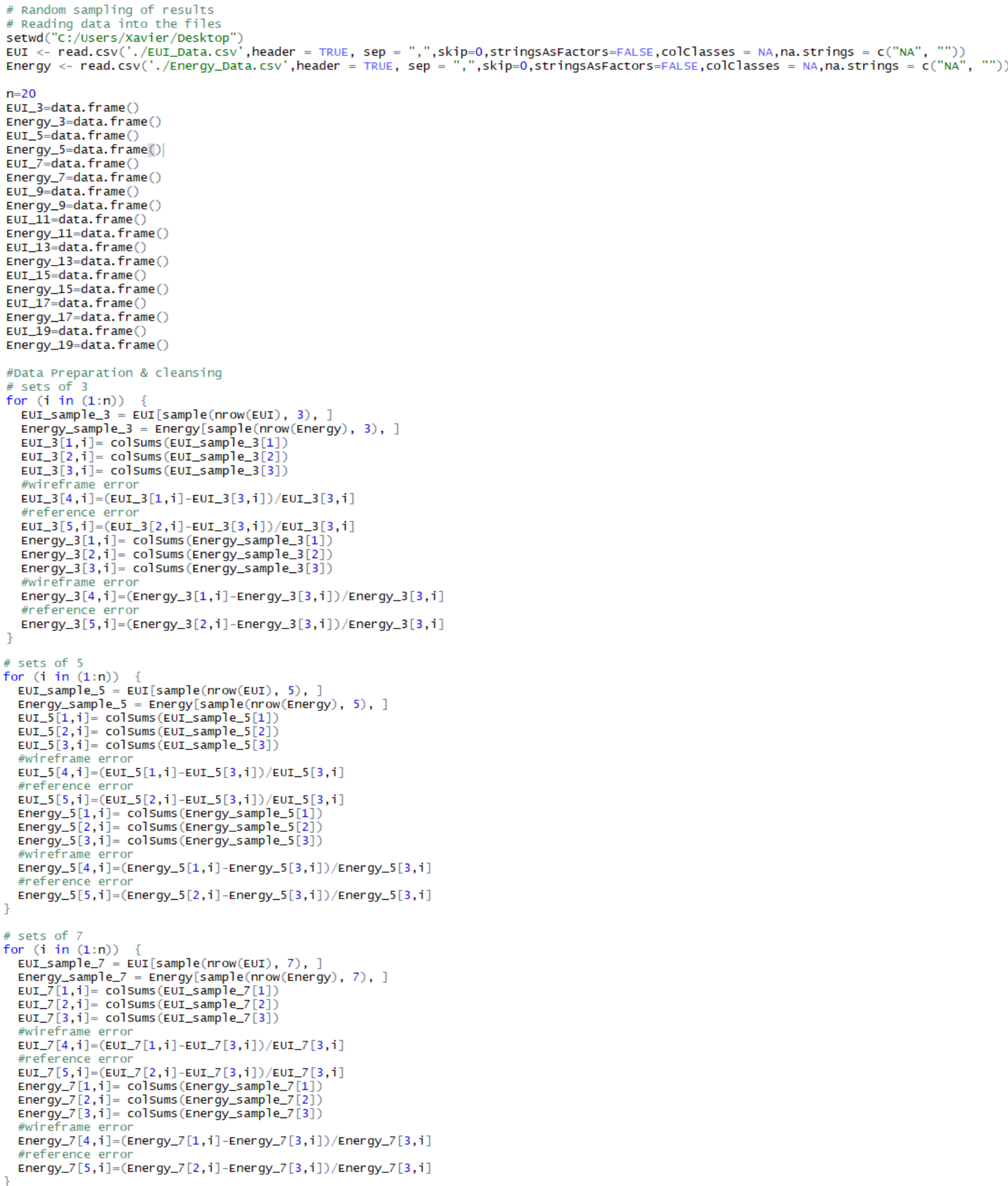




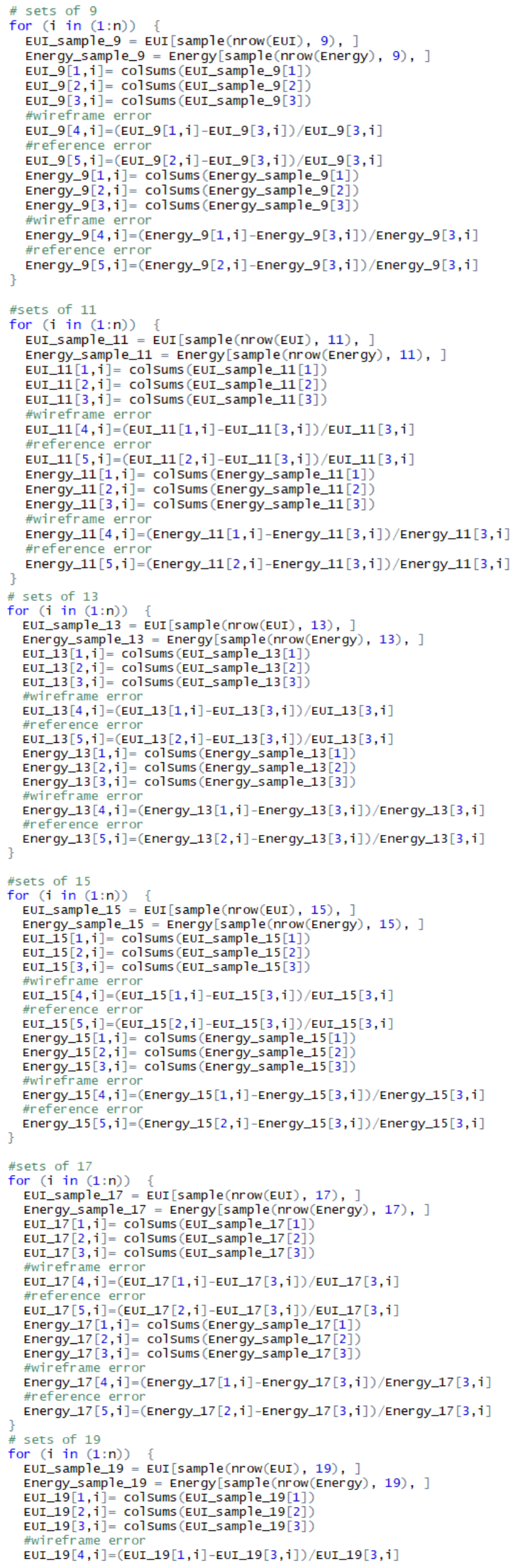




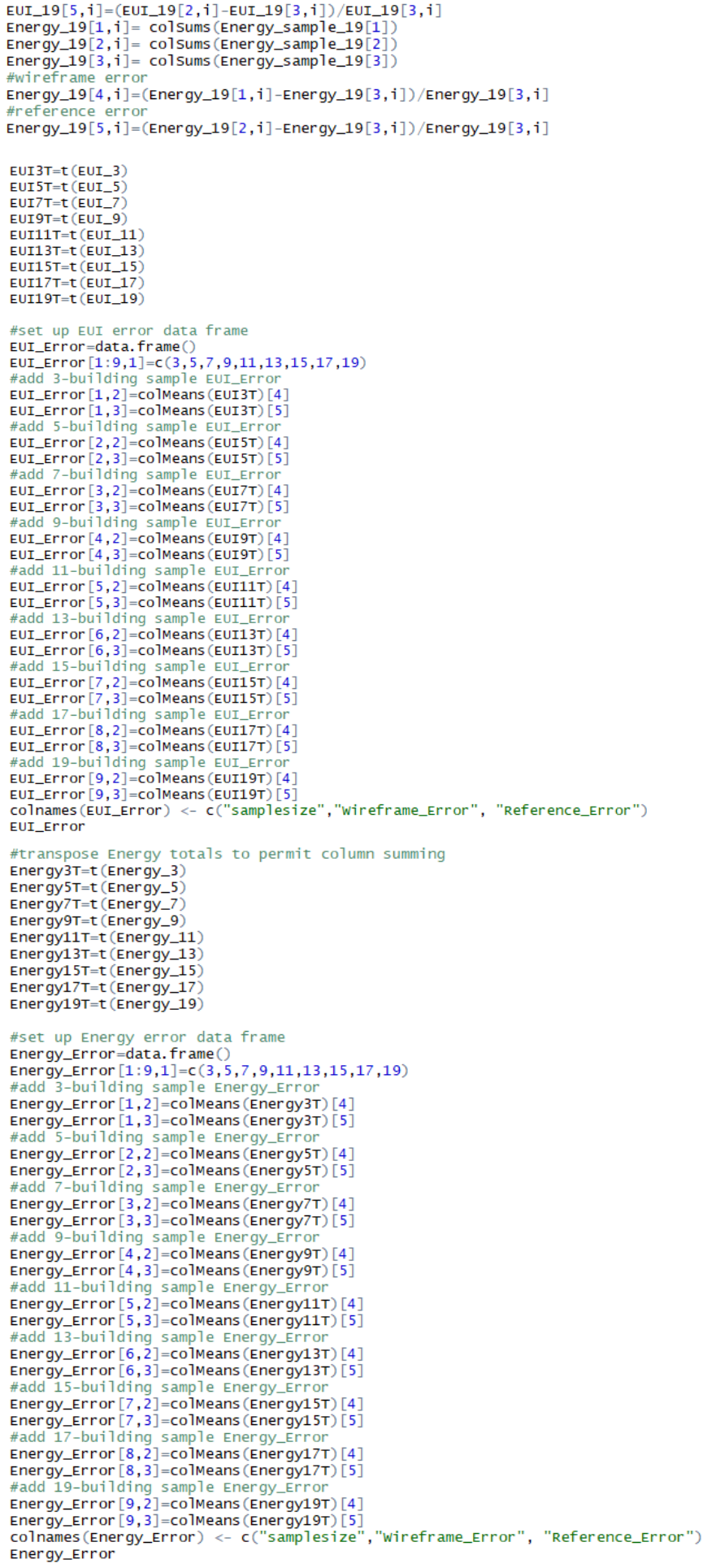

